Jean Carlo Ferreira de Oliveira

Projeto de mecanismo, análise cinemática e dinâmica de um manipulador robótico acionado por junta cardânica ativa com três graus de liberdade

TESE DE DOUTORADO

Tese apresentada como requisito parcial para obtenção do grau de Doutor pelo Programa de Pósgraduação em Engenharia Mecânica, do Departamento de Engenharia Mecânica da PUC-Rio

Orientador: Prof. Hans Ingo Weber

Rio de Janeiro

Junho 2020 


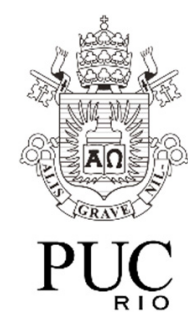

Jean Carlo Ferreira de Oliveira

\section{Projeto de mecanismo, análise cinemática e dinâmica de um manipulador robótico acionado por junta cardânica ativa com três graus de liberdade}

Tese apresentada como requisito parcial para obtenção do grau de Doutor pelo Programa de Pós-graduação em Engenharia Mecânica da PUC-Rio. Aprovada pela Comissão Examinadora abaixo:

Prof. Hans Ingo Weber

Orientador

Departamento de Engenharia Mecânica da PUC-Rio

Prof. Arthur Martins Barbosa Braga

Departamento de Engenharia Mecânica da PUC-Rio

Prof. Cesar Augusto Lampe Linhares da Fonseca Marinha do Brasil | MAR · Centro de Instruções Almirante Wandenkolk

Prof. Maurício Gruzman Instituto Militar de Engenharia, IME.

Prof. Márcio Coelho de Mattos

Centro Tecnológico - Departamento de Engenharia Mecânica - UFES 
Todos os direitos reservados. É proibida a reprodução total ou parcial do trabalho sem autorização da universidade, do autor e do orientador.

\section{Jean Carlo Ferreira de Oliveira}

Possui graduação em Engenharia Mecânica desde 1999 e mestrado em Engenharia Mecânica desde 2001, ambos pela Universidade Federal do Espírito Santo. Empresário com mais de 20 anos de experiência com projetos industriais multidisciplinares e membro professor-fundador da faculdade Unificada do Centro Leste (UCL) no ES, com mais de 20 anos de docência no Ensino Superior, possui ênfase em Mecânica dos Sólidos, Dinâmica e Gerenciamento de Projetos, com certificação PMP pelo PMI, desde 2013.

Ficha Catalográfica

Oliveira, Jean Carlo Ferreira de

Projeto de mecanismo, análise cinemática e dinâmica de um manipulador robótico acionado por junta cardânica ativa com três graus de liberdade / Jean Carlo Ferreira de Oliveira ; orientador: Hans Ingo Weber. - 2020.

134 f. : il. color. ; $30 \mathrm{~cm}$

Tese (doutorado)-Pontifícia Universidade Católica do Rio de Janeiro, Departamento de Engenharia Mecânica, 2020.

Inclui bibliografia

1. Engenharia Mecânica - Teses. 2. Manipulador. 3. Junta cardânica ativa. 4. Junta universal ativa. 5. Cinemática. 6. Dinâmica. I. Weber, Hans Ingo. II. Pontifícia Universidade Católica do Rio de Janeiro. Departamento de Engenharia Mecânica. III. Título. 
Dedico a Deus, minha esposa, Joanalva, e meus filhos Júlia, João e Joaquim! 


\section{Agradecimentos}

Primeiramente, quero agradecer ao meu orientador, Prof. Dr. Hans Ingo Weber, pelo excelente suporte que tive ao longo dos anos de estudo.

Aos professores que participaram da Comissão examinadora.

A todos os professores e funcionários do Departamento, pelos ensinamentos e pela ajuda.

À PUC-Rio, pelos auxílios concedidos, sem os quais este trabalho não poderia ter sido realizado.

A todos os amigos e familiares que de uma forma ou de outra me estimularam ou me ajudaram.

Aos meus colegas da PUC-Rio.

O presente trabalho foi realizado com apoio da Coordenação de Aperfeiçoamento de Pessoal de Nível Superior - Brasil (CAPES) - Código de Financiamento 001. 


\section{Resumo}

Oliveira, Jean Carlo Ferreira; Weber, Hans Ingo. Projeto de mecanismo, análise cinemática e dinâmica de um manipulador robótico acionado por junta cardânica ativa com três graus de liberdade. Rio de Janeiro, 2020, 134p. Tese de Doutorado, Departamento de Engenharia Mecânica, Pontifícia Universidade Católica do Rio de Janeiro.

O uso de juntas cardânicas ativas é restrito pela capacidade de torque de pequenos motorredutores e, atualmente, os dispositivos embarcados são obrigatórios para as aplicações robóticas. O controle dinâmico é essencial para estudar as limitações desse dispositivo, portanto, o objetivo deste estudo foi controlar a junta cardânica ativa de três graus de liberdade usando simulações numéricas e experimento em bancada de testes. O manipulador foi projetado com apenas uma junta cardânica para que a sua cinemática e dinâmica sejam exploradas; por esse motivo, a junta foi construída com sensores de carga na base e sensor de unidade de movimento inercial na parte superior do efetuador do manipulador. Além disso, foram fabricadas três placas de controle: a primeira foi projetada para controlar os três acionamentos dos motores de passo; a segunda, para ler o sensor da unidade de movimento inercial; e a última, para ler os sensores de carga. Quatro problemas foram descritos para testar os limites deste dispositivo, analisando, além da cinemática e dinâmica, o atrito do rolamento, a identificação da folga e o torque do impacto. O primeiro problema mantém a posição do efetuador do manipulador constante enquanto transmite rotação entre os eixos. O segundo problema, o efetuador recebe um caminho planejado, por exemplo, um círculo, mas não transmite rotação entre os eixos. O terceiro problema é a combinação dos movimentos anteriores, em que o efetuador transmite rotação entre os eixos, enquanto segue por um caminho planejado. Para o quarto problema: uma nova abordagem é aplicada para mover o efetuador de um ponto para outro usando rotação cônica.

\section{Palavras-chave}

Manipulador; Junta cardânica ativa; Junta universal ativa; Cinemática; Dinâmica; Atrito dos rolamentos; Identificação de folga; Torque de impacto; Navegação cardânica; Navegação ortodrômica. 


\section{Abstract}

Oliveira, Jean Carlo Ferreira; Weber, Hans Ingo. Mechanism design, kinematic and dynamic analysis of a robotic manipulator driven by an active cardan joint with three degrees of freedom. Rio de Janeiro, 2020, 134p. Tese de Doutorado, Departamento de Engenharia Mecânica, Pontifícia Universidade Católica do Rio de Janeiro.

The use of active cardan joints is restricted by torque capacity of small motors, and currently embedded devices have been mandatory for robotic applications. The dynamic control is essential to learn the limitations of this device, thus the objective of this study is to control active cardan joints of three degrees of freedom using numerical simulations and bench experiment. The manipulator was designed with only one cardan joint to understand its kinematics and dynamics and, for this reason, it was built with load sensors on its base and inertial motion unit sensor at the top of the manipulator end-effector. Furthermore, three control boards were manufactured: the first was designed to control the three stepper motor drives, the second was designed to read the inertial motion unit sensor, and the last was designed to read the load sensors. Four problems were described to test the limits of this device, analysing not only the kinematics and dynamics, but also the bearing friction, the backlash identification, and the impact torque. The first problem keeps the position of the manipulator end-effector constant transmitting rotation between the shafts. The second problem is given a planned path to the manipulator endeffector, such as a circle, but it does not transmit rotation between the shafts. The third problem is the combination of the previous motions, where the manipulator end-effector applies the output spin, while it follows by a planned path. The fourth problem, a new approach is applied to move the manipulator end-effector from one point to another point using a conical rotation.

\section{Keywords:}

Manipulator; Active cardan joint; Active universal joint; Kinematic; Dynamic; Bearings friction; Backlash identification; impact torque; cardan navigation; orthodromic navigation. 


\section{Sumário}

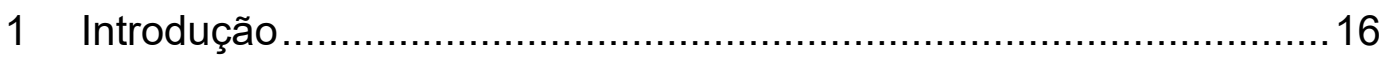

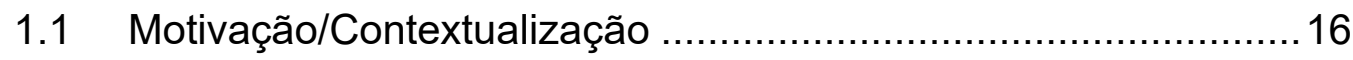

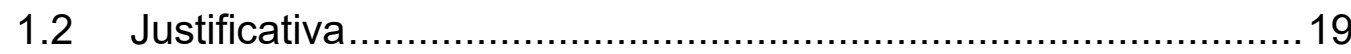

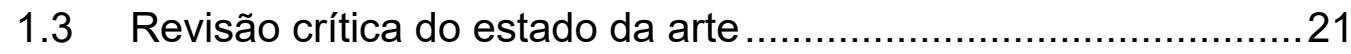

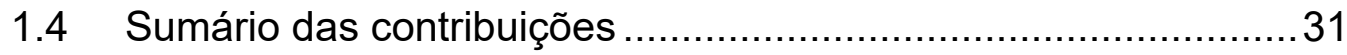

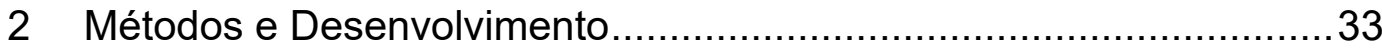

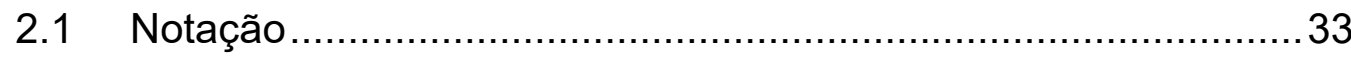

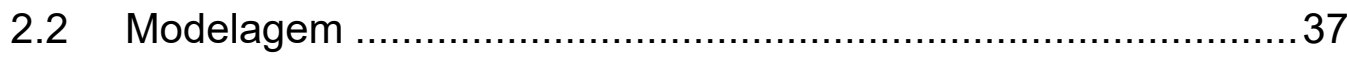

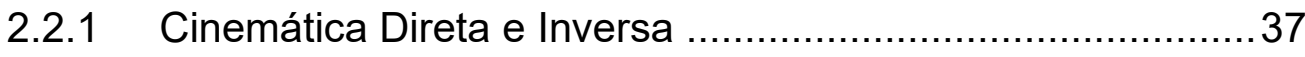

2.2.2 Dinâmica Direta e Inversa .................................................. 40

2.2.3 Torque de atrito dos rolamentos ........................................... 48

2.2.4 Identificação da Folga....................................................... 56

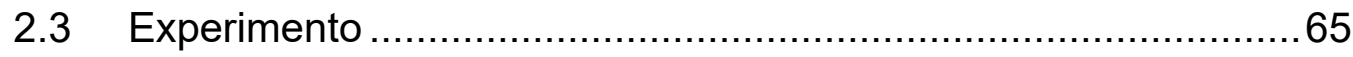

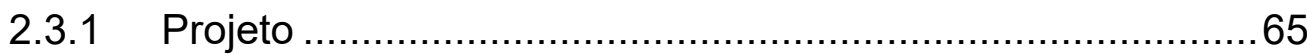

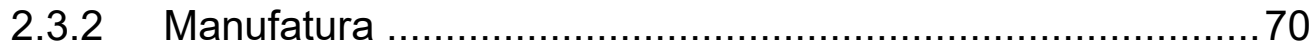

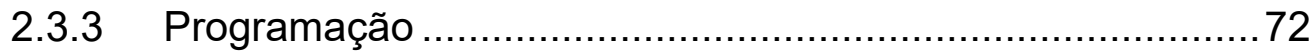

2.4 Proposição dos casos e resolução analítica ................................74

2.4.1 Caso 1 - Cinemática e Dinâmica (problema 1) ....................76

2.4.2 Caso 2 - Cinemática e Dinâmica (problema 2) .....................78

2.4.3 Caso 3 - Cinemática e Dinâmica (problema 3) ..................... 80

2.4.4 Caso 4 - Cinemática e Dinâmica (problema 4) .....................82

3 Contribuições e Análise de Resultados .............................................. 88

3.1 Análise dos limites da área de trabalho....................................... 88

3.2 Análise dos resultados numéricos e experimental ......................92

3.2.1 Caso 1 - Cinemática e Dinâmica..........................................93 
3.2.2 Caso 2 - Cinemática e Dinâmica.........................................99

3.2.3 Caso 3 - Cinemática e Dinâmica.........................................101

3.2.4 Caso 4 - Cinemática e Dinâmica..........................................106

3.3 Análise do redutor planetário ……………………................111

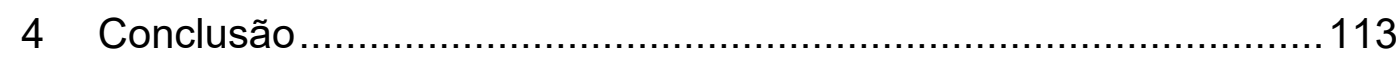

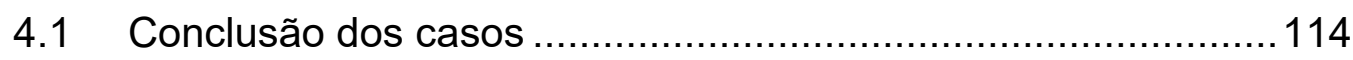

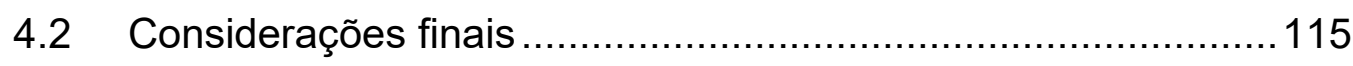

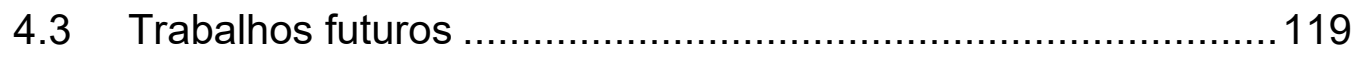

5 Referências Bibliográficas .........................................................120

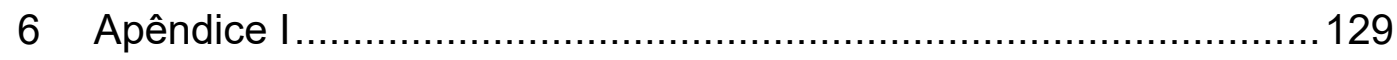

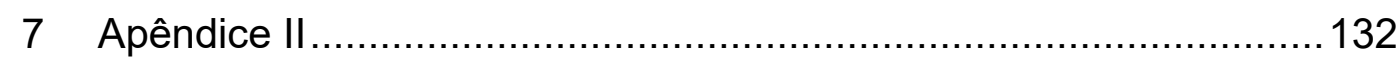




\section{Lista de Figuras}

Figura 1-1 - Tipos comuns de juntas de mais de um grau de liberdade. Junta universal ou cardan (à esquerda), junta homocinética (ao centro) e junta esférica (à direita). [Fonte: Autoria própria] 17

Figura 2-1 - Sistemas de Referência da Junta Universal "Cardan" proposta como Experimento [Fonte: Autoria própria].

Figura 2-2 - DCL do corpo 0 e corpo 1 do manipulador cardânico [Fonte: Autoria própria] 40

Figura 2-3 - DCL do corpo 2 do manipulador cardânico. [Fonte: Autoria própria] 43

Figura 2-4 - DCL do corpo 3 do manipulador cardânico. [Fonte: Autoria própria] 44

Figura 2-5 - Localização dos rolamentos no experimento da junta cardânica ativa [Fonte: Autoria própria] 49

Figura 2-6 - Modelamento das forças radiais dos rolamentos do corpo 1 [Fonte: Autoria própria]. 50

Figura 2-7 - Modelamento simplificado das forças radiais dos rolamentos do corpo 2 [Fonte: Autoria própria]. 52

Figura 2-8 - Modelo de folga de zona morta. [Fonte: Autoria própria] ......59 Figura 2-9 - Uma Cruzeta Cardan B04C625 da ASH (à esquerda) e três motores de passo NEMA 17 modelo $17 \mathrm{HS} 8401$ marca HANPOSE alternando com as seguintes reduções planetárias 1:720, 1:139 e 1:19 (à direita) [Fonte: Autoria própria] 65

Figura 2-10 - Doze Células de Carga 50 Kg + 06 ADC HX711-24 Bits (à esquerda) e um IMU 9DOF Mpu-9250 - Acelerômetro - Giroscópio Magnetômetro (à direita) [Fonte: Autoria própria] 65

Figura 2-11 - Três MicroStep Driver TB6600 40V 4A (à esquerda) e um Anel de deslizamento oco com contato de ouro com doze canais 10A/canal (à direita) [Fonte: Autoria própria]. 66

Figura 2-12 - Três Microcontroladores ESP32 240 MHz Wifi/Bluetooth - o primeiro para a leitura do IMU, o segundo para a leitura das células de 
carga, e terceiro para o controle dos drivers dos motores de passo [Fonte:

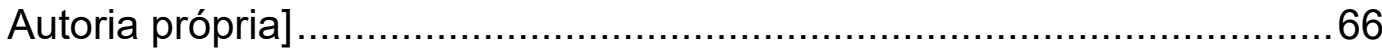

Figura 2-13 - Modelo CAD 3D do Experimento (à esquerda) e o QRCODE para o desenho técnico do experimento (à direita) [Fonte: Autoria própria]

Figura 2-14 - Projeto final da placa do Circuito 1 - Leitura das células de carga e do IMU (à esquerda) e QRCODE para o Diagrama esquemático (à direita) [Fonte: Autoria própria]

Figura 2-15 - Projeto final da placa do Circuito 2 - Comando dos motores de passo e leitura de suas odometrias (à esquerda) e QRCODE para o Diagrama esquemático (à direita) [Fonte: Autoria própria] 69 Figura 2-16 - Foto da bancada experimental completa e o QRCODE para fotografias adicionais do processo de fabricação [Fonte: Autoria própria]70 Figura 2-17 - Receptáculo para acomodação das células de carga nos três eixos e QRCODE para fotografias adicionais [Fonte: Autoria própria] .....71 Figura 2-18 - PCB para leitura das células de carga e IMU (à esquerda), PCB para leitura da odometria e comando dos drivers (no centro) e QRCODE para fotografias dos protoboards, placas de circuitos provisórias e os arquivos no formato Gerber (à direita) [Fonte: Autoria própria] ........71 Figura 2-19 - Código fonte dos microcontroladores em $\mathrm{C} / \mathrm{C}++$ utilizados no experimento [Fonte: Autoria própria]. 74 Figura 2-20 - Sistema de coordenadas cardânicas (à esquerda) e o da junta (à direta) [Fonte: Autoria própria] 75

Figura 2-21 - Representação do movimento do problema 1 simulado no Inventor Dynamic Simulation (à esquerda) e QRCODE na animação do movimento (à direita) [Fonte: Autoria própria] 78

Figura 2-22 - Representação do movimento do problema 2 simulado no Inventor Dynamic Simulation (à esquerda) e QRCODE na animação do movimento (à direita) [Fonte: Autoria própria] 79 Figura 2-23 - Indicação do ângulo $\theta(t)$ visualizando pela vista superior do experimento. [Fonte: Autoria própria] 80

Figura 2-24 - Representação do movimento do problema 3 simulado no Inventor Dynamic Simulation (à esquerda) e QRCODE na animação do movimento (à direita) [Fonte: Autoria própria] 
Figura 2-25 - Representação do SR F para o SR R 1 (à esquerda) e do SR F para o SR R2 (à direita) [Fonte: Autoria própria]

Figura 2-26 - Visualização esquemática do movimento de $R_{1}$ para $R_{2}$ [Fonte: Autoria própria] 85

Figura 2-27 - Representação do movimento do problema 4 simulado no Inventor Dynamic Simulation (à esquerda) e QRCODE da animação do movimento (à direita) [Fonte: Autoria própria] 87

Figura 3-1 - Aceleração $a_{z}, a_{x}$ e o ângulo $\beta$ medidos pelo acelerômetro sem o motorredutor [Fonte: Autoria própria] 89

Figura 3-2 - Aceleração $a_{z}$, $a_{y}$ e o ângulo $\gamma$ medidos pelo acelerômetro sem o motorredutor [Fonte: Autoria própria] 90

Figura 3-3 - Aceleração $a_{z}, a_{x}$ e o ângulo $\beta$ medidos pelo acelerômetro com o motorredutor [Fonte: Autoria própria] 90

Figura 3-4 - Aceleração $a_{z}, a_{y}$ e o ângulo $\gamma$ medidos pelo acelerômetro com o motorredutor [Fonte: Autoria própria] 91

Figura 3-5 - Zona limite de atuação da junta cardânica ativa em função de $\beta$ e $\gamma$ [Fonte: Autoria própria] 91

Figura 3-6 - Limites da área de trabalho workspace da junta cardânica ativa. [Fonte: Autoria própria] 92

Figura 3-7 - QRCODES dos arquivos e das listas de vídeos da realização do experimento [Fonte: Autoria própria] 93 Figura 3-8 - Valores dos vetores de estado: ângulos cardânicos $(\beta, \gamma)$, ângulo da junta $(\phi)$, velocidades angulares $(\dot{\alpha}, \dot{\beta}, \dot{\gamma})$, e acelerações angulares $(\ddot{\alpha}, \ddot{\beta}, \ddot{\gamma})$ para o Caso $1 \mathrm{com} \phi=\pi / 6 \mathrm{rad}$ e $\dot{\alpha}=0,2 \mathrm{rad} / \mathrm{s}$ [Fonte: Autoria própria] 94

Figura 3-9 - Cinemática dos corpos rígidos no SR F para o Caso 1 para $\phi=\pi / 6 \mathrm{rad}$ e $\dot{\alpha}=0,2 \mathrm{rad} / \mathrm{s}$ [Fonte: Autoria própria] 94

Figura 3-10 - Momentos de Reação e Torque dos motorredutores para o Caso 1 para $\phi=\pi / 6 \mathrm{rad}$ e $\dot{\alpha}=0,2 \mathrm{rad} / \mathrm{s}$ [Fonte: Autoria própria]. 95

Figura 3-11 - Torque de atrito dos rolamentos para o Caso 1 para $\phi=\pi / 6 \mathrm{rad}$ e $\dot{\alpha}=0,2 \mathrm{rad} / \mathrm{s}$ [Fonte: Autoria própria] .95 
Figura 3-12 - Cálculo analítico com a identificação da folga e a leitura experimental dos ângulos pelo IMU para o Caso 1 [Fonte: Autoria própria]

Figura 3-13 - Cálculo analítico com a identificação da folga e a leitura experimental da velocidade angular do corpo 3 no SR S do caso 1 [Fonte: Autoria própria]. 98

Figura 3-14 - Cálculo analítico com a identificação da folga e a leitura experimental das forças $F_{3 x}-F_{1 x}$ (Sinal 1) e $F_{2 x}-F_{4 x}$ (Sinal 4$)$ do caso 1 no SR F [Fonte: Autoria própria] 99

Figura 3-15 - Cinemática dos corpos rígidos no SR F para o Caso 2 para $\phi=\pi / 6 \mathrm{rad}$ e $\dot{\theta}=0,2 \mathrm{rad} / \mathrm{s}$ [Fonte: Autoria própria] 100

Figura 3-16 - Cálculo analítico com a identificação da folga e a leitura experimental das forças $F_{3 x}-F_{1 x}$ (Sinal 1) e $F_{2 x}-F_{4 x}$ (Sinal 4$)$ do caso 2 no SR F [Fonte: Autoria própria] 101

Figura 3-17 - Cálculo analítico com a identificação da folga e a leitura experimental da velocidade angular do corpo 3 no SR S do caso 2 [Fonte: Autoria própria]. 101

Figura 3-18 - Comparação entre $\alpha$ e $\theta$ para o Caso 3 para $\phi=\pi / 6 \mathrm{rad}$, $\dot{\theta}=0,2 \mathrm{rad} / \mathrm{s}$ e $\dot{\psi}=1,0 \mathrm{rad} / \mathrm{s}$ [Fonte: Autoria própria] 102 Figura 3-19 - Valores dos vetores de estado: : ângulos cardânicos $(\beta, \gamma)$, ângulo da junta $(\phi)$, velocidades angulares $(\dot{\alpha}, \dot{\beta}, \dot{\gamma})$, e acelerações angulares $(\ddot{\alpha}, \ddot{\beta}, \ddot{\gamma})$ para o Caso $3 \mathrm{com} \phi=\pi / 6 \mathrm{rad}, \dot{\theta}=0,2 \mathrm{rad} / \mathrm{s}$ e $\dot{\psi}=1,0 \mathrm{rad} / \mathrm{s}$ [Fonte: Autoria própria]. 103

Figura 3-20 - Cinemática dos corpos rígidos no SR F para o Caso 3 para $\phi=\pi / 6 \mathrm{rad}, \dot{\theta}=0,2 \mathrm{rad} / \mathrm{s}$ e $\dot{\psi}=1,0 \mathrm{rad} / \mathrm{s}$ [Fonte: Autoria própria] 103

Figura 3-21 - Momentos de Reação e Torque dos motorredutores para o Caso 3 para $\phi=\pi / 6 \mathrm{rad}, \dot{\theta}=0,2 \mathrm{rad} / \mathrm{s}$ e $\dot{\psi}=1,0 \mathrm{rad} / \mathrm{s}$ [Fonte: Autoria própria] 104

Figura 3-22 - Torque de atrito dos rolamentos para o Caso 3 para $\phi=\pi / 6 \mathrm{rad}, \dot{\theta}=0,2 \mathrm{rad} / \mathrm{s}$ e $\dot{\psi}=1,0 \mathrm{rad} / \mathrm{s}$ [Fonte: Autoria própria] ..........104 
Figura 3-23 - Cálculo analítico com a identificação da folga e a leitura experimental dos ângulos pelo IMU para o Caso 3 [Fonte: Autoria própria] 105

Figura 3-24 - Cálculo analítico com a identificação da folga e a leitura experimental da velocidade angular do corpo 3 no SR S do caso 3 [Fonte: Autoria própria]. 106

Figura 3-25 - Cálculo analítico com a identificação da folga e a leitura experimental das forças $F_{3 x}-F_{1 x}$ (Sinal 1) e $F_{2 x}-F_{4 x}$ (Sinal 4$)$ do caso 3 no SR F [Fonte: Autoria própria] 106

Figura 3-26 - Ângulos cardânicos $(\alpha, \beta, \gamma)$ e o ângulo da junta $(\phi)$ em função do ângulo do vetor de Euler $(\Theta)$ para o caso 4 [Fonte: Autoria própria] 107

Figura 3-27 - Valores dos vetores de estado: ângulos cardânicos $(\beta, \gamma)$, ângulo da junta $(\phi)$, velocidades angulares $(\dot{\alpha}, \dot{\beta}, \dot{\gamma})$, e acelerações angulares $(\ddot{\alpha}, \ddot{\beta}, \ddot{\gamma})$ para o caso 4 [Fonte: Autoria própria] 107 Figura 3-28 - Cinemática dos corpos rígidos no SR F para o caso 4 [Fonte:

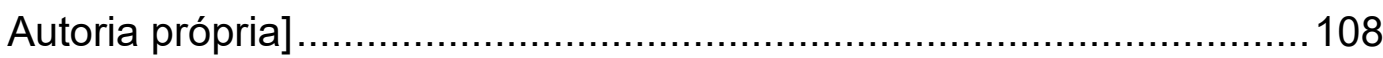
Figura 3-29 - Momentos de Reação e Torque dos motorredutores para o caso 4 [Fonte: Autoria própria] . 109 Figura 3-30 - Cálculo analítico com a identificação da folga e a leitura experimental dos ângulos pelo IMU para o caso 4 [Fonte: Autoria própria] 109

Figura 3-31 - Cálculo analítico com a identificação da folga e a leitura experimental da velocidade angular do corpo 3 no SR S do caso 4 [Fonte: Autoria própria] 110

Figura 3-32 - Cálculo analítico com a identificação da folga e a leitura experimental das forças $F_{3 x}-F_{1 x}$ (Sinal 1) e $F_{2 x}-F_{4 x}$ (Sinal 4 ) do caso 4 no SR F [Fonte: Autoria própria] 110

Figura 3-33 - Modelo BIM 3D do redutor planetário de dois estágios relação 1:139 construído no Autodesk Inventor e Dynamic Simulation e o QRCODE da simulação do redutor planetário de três estágios relação 1:720 [Fonte: Autoria própria]. 
Figura 3-34 - Quebra do dente da engrenagem solar do último estágio do redutor planetário de relação de 1:720 (a esquerda) e simulação do último estágio (à direita) [Fonte: Autoria própria]

Figura 7-1 - Modelo linear unidimensional da rigidez torcional de um grau de liberdade. 132

Figura 7-2 - Deformação máxima do modelo estático linear por elementos finitos das engrenagens do redutor para uma carga de $125 \mathrm{~N}$ na linha de contato do dente [Fonte: Autoria própria] 133 


\section{Introdução}

\subsection{Motivação/Contextualização}

As primeiras informações sobre juntas vieram de Filom de Bizâncio, por volta de 230 a.C., em sua descrição de incensários e tinteiros com suspensão articulada. Em 1245 d.C., o arquiteto francês Villard de Honnecourt esboçou um pequeno forno esférico suspenso em anéis circulares. Em torno de 1500, Leonardo da Vinci desenhou uma bússola posicionada sobre uma roda d'água girando continuamente (FELDHAUS, 1914). "Gimbals" giratórios passaram a ser conhecidos na Europa por meio do relatório do matemático, médico e filósofo Geronimo Cardano. Ele também foi um pioneiro no campo de engenharia e, em 1550, descreveu, em seu livro "De subtilitate libri XXI", uma cadeira do imperador Carlos V "que foi montada em um cardan". Em 1557, ele descreveu anéis articulados em "De armillarum instrumento" (CARDANO, 1663), que são articulados em noventa graus conectados entre si, dando origem a três graus de liberdade. Essa suspensão e a junta formada a partir dela foram denominadas "suspensão cardan" ou a "articulação cardan".

A necessidade de transmitir um movimento rotativo através de eixos unidos em ângulo surgiu no século XIV, na construção de torres de relógio. Um exemplo descrito, em 1664, pelo jesuíta Caspar Schott, foi o relógio da Catedral de Estrasburgo construída em 1354 (SCHOTT, 1664). Ele escreveu que o impulso inclinado poderia ser melhor executado através de uma cruz com quatro pivôs, que conectavam dois eixos com garfos encaixados nas extremidades. A junta universal era, portanto, conhecida muito antes de Schott. Ele tirou sua descrição do manuscrito não publicado "Chronometria Mechanica Nova", de autoria de Amicus, que não estava mais vivo. Foi, então, possível observar a estreita relação entre o conceito de cardan e uma articulação universal. A matemática do movimento da transmissão, entretanto, não era clara para Schott, porque ele acreditava que um garfo deveria girar mais rápido do que o outro.

Em 1663, o físico inglês Robert Hooke construiu um aparelho que incorporava uma transmissão articulada não exatamente na forma da junta de Amicus. Em 1674, ele descreveu, em suas "Animadversions", o helioscópio do astrônomo de Danzig Johannes Hevelius, que compreendia uma junta universal semelhante à de Amicus. Em 1676, ele falou de um "joynt" e um "universal joynt", pois era capaz de muitos tipos de movimentos. Hooke estava totalmente familiarizado com a matemática da época e era hábil em 
cinemática prática. Em contraste com Schott, ele sabia que a junta universal não transmitia o movimento rotativo uniformemente. Embora Hooke não tenha publicado nenhuma teoria sobre isso, assume-se que ele conhecia o princípio da não uniformidade. Cardano e Hooke podem ser considerados como os percussores do caminho para juntas universais e eixos de transmissão modernos (SEHERR-THOSS, SCHMELZ e AUCKTOR, 2006).

As juntas são os componentes básicos dos robôs manipuladores e possuem uma influência decisiva em sua performance. Normalmente, cada grau de liberdade é controlado por um motor, entretanto alguns estudos envolvendo motores esféricos demonstram que é possível controlar uma junta deste tipo apenas com um motor (BAI, XU, et al., 2018) (ZHANG, ZENG, et al., 2016). No entanto este novo motor esférico não é o foco deste estudo, além de ainda não ser utilizado comercialmente (HONEYWELL, 2019).
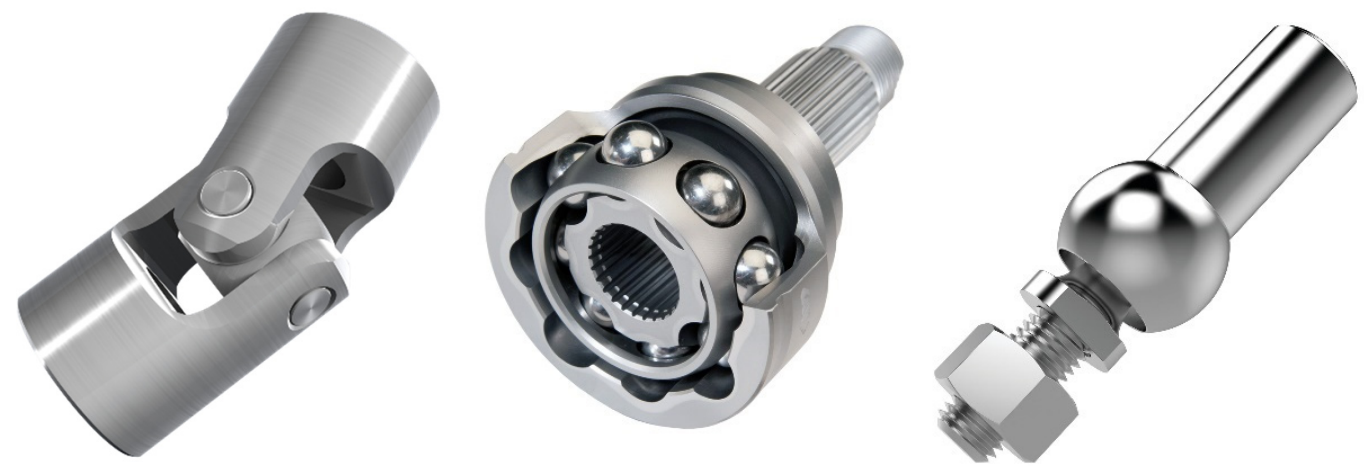

Figura 1-1 - Tipos comuns de juntas de mais de um grau de liberdade. Junta universal ou cardan (à esquerda), junta homocinética (ao centro) e junta esférica (à direita). [Fonte: Autoria própria]

Na Figura 1-1 é possível observar os tipos comuns de juntas de mais de um grau de liberdade, tais como junta universal ou cardan (STAMENIĆ, RISTIVOJEVIĆ, et al., 2012) (KRUDE , 1977), junta cinética de velocidade constante ou junta homocinética (CARDOZO e WEBER, 2017) (KRUDE , 1974), juntas esféricas (GALLARDOALVARADO, RODRIGUEZ-CASTRO, et al., 2018) (HOURAN, YANG e CHEN, 2018) (FROEHLIC e REISER, 2016) (FROEHLIC, REISER, et al., 2018), etc. Apesar da diversidade dos tipos de juntas, o objetivo do projeto inicial das juntas era transmitir o movimento de rotação entre eixos não alinhados. Com a evolução da robótica no último século, as juntas mecânicas começaram a ter um papel diferente da aplicação inicialmente pensada pelos seus criadores. Manipuladores robóticos, muitas vezes, não permitem que a junta realize uma rotação completa em torno de seu eixo, por limitação da própria 
aplicação. Normalmente, as juntas aplicadas em robótica buscam obter a posição do atuador do manipulador numa condição de superfície esférica ou superfície arbitrária (YOSHIKAWA, 1987), e não considera a possibilidade de ser uma ferramenta de transmissão de rotação para eixos oblíquos. Uma das propostas deste estudo é utilizar a junta cardânica controlada com três graus de liberdade para transmitir movimento entre os eixos (links), permitindo o controle de seu posicionamento através de motorredutores acionados diretamente em seus eixos de rotação, sendo assim denominada junta ativa.

Chamar a junta de ativa significa que o acionamento ocorrerá internamente para controlar o comportamento da junta, e existem muitas maneiras de fazer isso. Por exemplo, a junta pode ser acionada por fios ou cabos (YESHMUKHAMETOV, KOGANEZAWA e YAMAMOTO, 2018) (MANFREDI e CUSCHIERI, 2018), ou pode ser acionada diretamente por motores (PALPACELLI, CARBONARI, et al., 2018). Neste estudo, optou-se por embarcar os motorredutores na junta cardânica, buscando a simplicidade na geometria do mecanismo ao utilizar componentes comerciais. Com os motorredutores fixados num sistema de referência não inercial, a sua relação inércia-potência-redução passa a ter influência direta na cinemática e dinâmica do manipulador. Outro ponto a considerar é a necessidade de utilização de anéis deslizantes slip rings para a interligação elétrica e eletrônica dos motores.

O desafio mecânico de utilizar os motores diretamente em seu eixo de rotação é o alto torque necessário em algumas aplicações, tornando a redução mecânica a principal preocupação. Por causa do alto toque e da pequena escala de todos os componentes, a redução mecânica acaba exigindo o uso de materiais avançados, aumentando o custo da junta (HIRZINGER, SPORER, et al., 2004). Uma alternativa a este problema é buscar uma solução que preserve a junta do torque excessivo, evitando colisões não esperadas no manipulador (KIM, PARK e SONG, 2007). A solução para proteção da redução mecânica depende do tipo de motor utilizado na junta; caso seja um motor de corrente contínua, com ou sem escova, é possível correlacionar o torque aplicado ao motor com sua corrente elétrica e, dessa forma, prever um mecanismo de proteção adequado se sua cinemática e dinâmica permitirem, e, às vezes, é necessária a inclusão de freios, mas, caso seja utilizado o motor de passo, a correlação entre o torque e a corrente deixa de ser uma solução, fazendo-se necessário conhecer os limites de atuação da área de trabalho do manipulador workspace para evitar a colisão interna da junta devido à sua geometria. 
Alguns estudos buscam reduzir o número de juntas para melhorar a acurácia do atuador no manipulador (HUANG, DONG, et al., 2017) (SHAMMAS, WOLF e CHOSE, 2006). Quando o manipulador possui várias juntas, possíveis folgas mecânicas são acumuladas, gerando um provável erro de posicionamento. No entanto, ao reduzir a quantidade de juntas de um manipulador mantendo a quantidade de graus de liberdade, incluindo juntas com mais de um grau de liberdade, espera-se que as folgas totais sejam reduzidas, pois, apesar das folgas estarem associadas a cada grau de liberdade, numa junta com mais de um grau de liberdade, elas não ocorrem ao mesmo tempo.

Por essas razões, um dos objetivos deste estudo é propor uma nova geometria de junta cardânica ativa com três graus de liberdade para conhecer os limites de sua área de trabalho workspace, a sua cinemática direta e inversa (OLIVEIRA e WEBER, 2019), a dinâmica direta e inversa, incluindo, na modelagem, atritos, folgas e rendimentos dos componentes. Essa proposição consiste em construir um aparato experimental que permita utilizar os resultados numéricos para validação dos modelos propostos.

\subsection{Justificativa}

O uso de robôs manipuladores tem-se tornado cada vez mais frequente nos dias de hoje, nas mais diversas áreas de aplicação como industrial (ASPRAGATHOS, KOUSTOUMPARDIS e MOULIANITIS, 2018), biomecânica (CARBONE, CECCARELLI e PISLA, 2019), aeroespacial (ZHAO, ZHAO, et al., 2013), serviços (DERBEL , GHOMMAM e ZHU, 2019), entre outras. Os robôs manipuladores são compostos principalmente por conectores links e juntas joints. Alguns trabalhos consistem em desenvolver novas juntas joints de dois ou três graus de liberdade para permitir que o robô manipulador atinja a área de trabalho workspace desejada com o menor número de juntas possível, assemelhando-se, muitas vezes, aos movimentos de juntas existentes na natureza em seres vivos, como, por exemplo: peixes (AKPOLAT, BINGÖL, et al., 2017), cobras (LIU, LIU, et al., 2019) (UM, WANG, et al., 2017), quadrúpedes (BHATTACHARYA, SINGLA, et al., 2019) (MUTLU, HAUSER, et al., 2018) e aves (SREEDHAR, PAVAN, et al., 2019).

Em aplicações industriais, a maioria dos manipuladores utiliza de forma eficiente apenas um grau de liberdade por junta, no entanto novas aplicações comerciais devem surgir após 
uma consolidação dos estudos acadêmicos de juntas de mais de um grau de liberdade. Alguns equipamentos dinâmicos poderiam ser beneficiados com a utilização de uma junta cardânica controlada, como, por exemplo: agitadores para tanques de homogeneização de minério de ferro, onde, por meio da variação do ângulo da junta, vai resultar uma maior área de atuação do agitador dentro do tanque, assim, permitindo tanques com razão largura e altura maior, aumentado a produtividade e a eficiência da mistura. A possibilidade dessa aplicação foi abordada com a empresa VALE ${ }^{1}$ junto com a sua Engenharia de Processos e com a empresa $\mathrm{SEMCO}^{2}$ fornecedora de diversos modelos de agitadores a partir de seu setor de desenvolvimento de novos produtos. Outras aplicações industriais podem ser encontradas no livro "Mechatronics and Robotics Engineering for Advanced and Intelligent Manufacturing" (ZHANG e WEI, 2017), que traz consigo diversos artigos, entre eles uma revisão crítica e o progresso do projeto do controlador adaptativo para manipuladores.

Nas aplicações voltadas à prótese em biomecânica, as juntas buscam atingir a equivalência às juntas do corpo humano com três graus de liberdade, como juntas esféricas, por exemplo (MGHAMES, CATALANO, et al., 2019). Em aplicações cirúrgicas, robôs com múltiplos graus de liberdade são excelentes ferramentas para uma cirurgia invasiva mínima, provendo benefício como redução do tremor da mão, navegação e escalonamento da área de trabalho workspace (PISLA, GHERMAN, et al., 2012) e (MILLER, LIPSCHUTZ, et al., 2008).

Em aplicações aeroespaciais, bocais de foguetes com três graus de liberdade (CARDOZO, 2017) ou o mecanismo cardânico para pouso em asteroides (ZHAO, ZHAO, et al., 2013), já materializam a necessidade da aplicação de juntas de mais de um grau de liberdade. No fim de 2014, o módulo da missão Roseta, da Agência Espacial Europeia, entrou em órbita ao redor do cometa 67P (Churyumov-Gerasimenko) para mapear a sua superfície e aterrissar no cometa, iniciando os experimentos destinados a fornecer informações sobre a composição do corpo celeste. As pernas do módulo são conectadas à parte superior por meio de uma junta de cardânica na qual três motores são integrados: dois para os dois eixos basculantes e um para ajustar a força do freio das embreagens de placas múltiplas (FAULHABER, 2014).

\footnotetext{
${ }^{1}$ Vale S.A. - https://www.vale.com/

${ }^{2}$ SEMCO - https://semcoequipamentos.com.br/
} 
Apesar das inúmeras proposições de juntas ativas de mais de um grau de liberdade nas publicações acadêmicas, elas ainda não são largamente aplicadas comercialmente, portanto, buscar uma solução simples quanto à solução de uma junta existente, como é o caso da junta universal ou junta cardan, pode estimular o uso desse tipo de junta nas mais diversas aplicações robóticas.

\subsection{Revisão crítica do estado da arte}

A pesquisa bibliográfica iniciou-se pelo levantamento das principais fontes acadêmicas relacionadas pelo Qualis da CAPES em ordem crescente de qualidade, buscando referências a trabalhos com foco no estudo de juntas de mais de um grau de liberdade em robôs manipuladores, nas mais diversas áreas de atuação: industrial, biomecânica, aeroespacial, serviços, entre outras. Após o filtro realizado nas publicações desses principais livros, jornais e revistas, foram selecionados alguns trabalhos que contribuíram direta ou indiretamente no presente estudo. A intenção é tecer um resumo da contribuição de cada uma das referências citadas e que levaram ao que será apresentado nesta tese.

As juntas de mais de um grau de liberdade na área de biomecânica possuem características geométricas bem distintas, uma vez que buscam imitar os movimentos humanos, como feito de acordo com a patente de Ikeda et al. (1985), que projetaram um braço robótico com juntas de mais de um grau de liberdade (IKEDA e TAKANASHI, 1985), e conforme Gottlieb et al. (1996), que apresentaram as cargas e as velocidades na movimentação de um braço humano analisando cada uma de suas juntas (GOTTLIEB, SONG, et al., 1996). Para a biomecânica, esse estudo é essencial para o projeto de dispositivos que possam ter a cinemática e dinâmica similares ao braço humano. Por isso, há diversos estudos ainda em desenvolvimento, como é o caso do trabalho de Mghames et al. (2019), que apresentou uma junta ativa acionada por motores embarcados com três graus de liberdade para simular o ombro humano e também para ser usada em aplicações humanoides (MGHAMES, CATALANO, et al., 2019). Essa junta proposta foi explorada em sua área de trabalho workspace, bem como em suas singularidades, cinemática/dinâmica direta e inversa. A conexão desse ombro, a um braço protético similar ao trabalho de Miller et al. (2008) é o próximo passo da pesquisa (MILLER, LIPSCHUTZ, et al., 2008). No entanto Miller et al. (2008) desenvolveram um braço protético de seis graus de liberdade, com aplicação bem comum nos dias de hoje, em que cada junta possui apenas um grau de liberdade. Outros autores (LESSARD, CASTRO, et al., 2016) preferem simular as juntas do braço humano 
como juntas estruturalmente compatíveis e que são movimentadas por cabos/arames, imitando os tendões musculares e garantindo similaridade com o acionamento do movimento humano.

Muitas vezes, o movimento do manipulador pode ser integrado ao movimento humano, no caso de tecnologia assistiva, conforme estudado por Li et al. (2018), que projetaram um mecanismo de assistência humana, que é conectado ao usuário e forma uma cadeia fechada de dois graus de liberdade humano-robô (LI, SHEN, et al., 2018). Outro caso de tecnologia assistiva foi estudado por Bellman et al.(2008), que desenvolveram uma junta passiva protética para o tornozelo com dois graus de liberdade, sendo que um dos graus de liberdade é regenerativo por possuir molas e amortecedores que tendem a manter a posição da junta (BELLMAN, HOLGATE e SUGAR, 2008). Buscando uma interface humano-robô, Ham et al. (2007) desenvolveram o MACCEPA, que trata de um atuador rotacional que pode ser controlado em torno da posição de equilíbrio por meio de uma junta ativa elástica de três graus de liberdade. Isso torna este atuador perfeitamente adequado para caminhadas, interfaces robótico-humanas e dispositivos de reabilitação robótica (HAM, DAMME, et al., 2007). Diversos outros trabalhos inovadores podem ser acompanhados no livro editado por Lenarcic et al. (2018), como, por exemplo, o estudo das singularidades de um robô paralelo utilizando uma junta cardan para reabilitação do cotovelo e punho, ou a análise cinemática de um manipulador robô humanoide paralelo para tornozelo, entre outros trabalhos de cinemática teórica, singularidades, controle e dinâmica, modelagem, projeto e biorrobótica (LENARCIC e PARENTI-CASTELLI, 2018).

Para aplicações humanoides, Bang et al. (2006) desenvolveram um sistema de visão humana para orientar cada olho com três graus de liberdade (3-DOF) nas direções dos eixos horizontal, vertical e torsional. A forma de ligação única e a orientação do link da arquitetura do simulador oculomotor antropomórfico 3-DOF fornecem uma faixa de visão desobstruída do olho robótico. A área de trabalho workspace e a cinemática direta e inversa são desenvolvidas para essa junta, que possui uma aplicação bem específica de imitar o movimento do olho humano (BANG, PAIK, et al., 2006).

A simulação de movimentos de seres vivos, tais como peixes, cobras e quadrúpedes, tem guiado algumas pesquisas sobre juntas de mais de um grau de liberdade. Nos estudos de Yeshmukhametov et al. (2018), foi apresentado uma junta universal não ativa para espinha 
dorsal que pode ser utilizada em diversas aplicações, incluindo biomecânica. O controle da ponta da espinha dorsal foi limitado, visto que não é possível controlar cada uma das juntas de forma independente (YESHMUKHAMETOV, KOGANEZAWA e YAMAMOTO, 2018). Outra aplicação foi feita por Akpolat et al. (2017), que desenvolveram um modelamento energético - Lagrangeano de uma junta ativa para um peixe robótico juntamente com o desenvolvimento do modelo do mecanismo feito pelo pacote SimMechanism/MATLAB (AKPOLAT, BINGÖL, et al., 2017). Nas simulações de cobras: Um et al. (2017) desenvolveram um robô-cobra combinando diversas juntas para obter o movimento, no entanto cada junta está limitada apenas a um grau de liberdade (UM, WANG, et al., 2017), algo que foi melhorado em 2019 por Liu et al., quando projetaram e desenvolveram um robô-cobra snake-robot, propondo uma junta/módulo com dois graus de liberdade controlado por motores de passo (LIU, LIU, et al., 2019). O experimento focou apenas no controle do movimento e não explorou a dinâmica dos corpos rígidos envolvidos. Com uma geometria bem mais robusta, Shammas et al. (2006) apresentaram uma junta ativa de três graus de liberdade para aplicações em robôs-cobras snake-robots. Foi desenvolvida, nesse trabalho, a cinemática direta, inversa e a análise das forças e torques. Uma das desvantagens consiste nas relações de redução da junta, que são diferentes para cada grau de liberdade, algo que é intrínseco da geometria proposta (SHAMMAS, WOLF e CHOSE, 2006). Outra aplicação muita conhecida são os robôs quadrúpedes, como o caso de Bhattacharya et al. (2019), que apresentaram um famoso robô quadrúpede realizando uma análise do custo do transporte baseada na otimização energética para o robô, apesar de usar apenas juntas com um grau de liberdade (BHATTACHARYA, SINGLA, et al., 2019).

Existem alguns estudos recentes com foco no desenvolvimento de novas juntas, como é o caso do trabalho de Houran et al. (2018), em que é feita a proposição de uma junta esférica controlada e direcionou-se para uma abordagem bem inovadora ao utilizar bobinas de indução com transmissão wireless para configurar o posicionamento da junta. Apesar de ter sido realizada a comprovação dos resultados de forma experimental, ainda é um trabalho bem incipiente devido ao baixo rendimento da junta e dos esforços envolvidos, mas é algo que merece ser mencionado devido à crescente utilização da tecnologia de alimentação por indução, como acontece com o carregamento dos celulares nos dias de hoje (HOURAN, YANG e CHEN, 2018). Outra forma de acionamento de uma junta esférica, proposta por Zhang et al. (2016), utiliza levitação magnética e propõe a malha de controle do dispositivo. Todavia o trabalho não foi experimental, apesar de as simulações das forças magnéticas envolvidas terem sido formuladas. Além disso, foi estudada a folga de ar entre os dois 
estatores e rotor para garantir o torque eletromagnético (ZHANG, ZENG, et al., 2016). Zhang et al. (2015) desenvolveram um sistema inverso de rede neural fuzzy para simular os resultados cinemáticos e dinâmicos desse tipo de junta (ZENG e ZHANG, 2015). Essa linha de estudo difere da linha de estudo desta tese por propor outra solução física para resolver o problema.

Uma das abordagens mais inovadoras vale-se do uso de um motor esférico, citado por Bai et al. (2018), que é uma continuação do motor esférico com dois graus de liberdade proposto por Kok-Meng Lee (1999), que, desde 1999, trabalha no desenvolvimento de um motor esférico (BAI, XU, et al., 2018). A proposta desses rotores e estatores posicionados em uma esfera está sendo aplicada para posicionar a mesa de uma impressora 3D a fim de permitir a realização de impressões 3D curvas. Seguindo essa linha de raciocínio, a empresa Honeywell já está propondo comercialmente o primeiro motor esférico comercial com dois graus de liberdade do mundo. No entanto esses motores ainda não possuem uma linha de produção ativa, conforme contato realizado com o gerente de vendas, no início de 2019 (HONEYWELL, 2019). Seguindo a linha das abordagens inovadoras, Manfredi et al. (2018) desenvolveram uma junta de dois graus de liberdade utilizando fios de material com memória de forma para atuar conforme a passagem de corrente elétrica. Com essa corrente elétrica há o objetivo de modificar o comprimento do arame e o comportamento da junta. Esse tipo junta pode ser considerado uma junta ativa, apesar da forma de acionamento não acontecer por acionamentos motorizados e ainda por estar configurada para baixíssimos torques e movimentos, conforme demonstrado em seus resultados (MANFREDI e CUSCHIERI, 2018).

Outras referências que trabalham com juntas com mais de um grau de liberdade utilizam manipuladores paralelos - PKMs - "Parallel Kinematics Machines". Um manipulador paralelo é formado por duas plataformas, uma fixa (base) e uma móvel (plataforma móvel), ligadas por dois ou mais conectores com cinemáticas abertas e independentes, como é o caso da plataforma de Gough-Stewart. De maneira geral, um manipulador em série (antropomórfico) com relação a um manipulador paralelo possui: boa capacidade de posicionamento, elevada capacidade de carga, grande rigidez estrutural, baixa inércia e reduzida área de trabalho workspace. Uma das primeiras patentes sobre um robô manipulador paralelo foi registrada por Rosheim (1999), que patenteou um robô manipulador bem complexo quando comparado com o manipulador de Osuka et al. (2003), que utilizou para manipular peças pesadas na ponta do manipulador (ROSHEIM, 1999) 
(OSUKA e NAKAMURA, 2003). A documentação da patente não traz consigo os estudos cinemáticos e dinâmicos, no entanto estudos acadêmicos anteriores sobre o assunto foram desenvolvidos, como é o caso do estudo de Lee et al. (1988), que propuseram a análise cinemática de um manipulador paralelo de três graus de liberdade, contribuindo para vários outros estudos em robô manipuladores paralelos que foram feitos na sequência (LEE e SHAH, 1988). Neste mesmo ano, Caccavale et al. (2003) realizaram a modelagem cinemática e dinâmica de um robô paralelo Tricept, adotando simplificações no modelo dinâmico que levou a uma forma simbólica das equações de movimento com reduzida complexidade, sendo assim um controle de impedância de seis graus de liberdade geometricamente consistente foi projetado para gerenciar a interação com o ambiente (CACCAVALE, SICILIANO e VILLANI, 2003). No ano seguinte, Grotjahn et al. (2004) abordaram, na análise cinemática, a aplicação do princípio de Jourdain na formulação de parâmetro linear e a determinação da configuração dos parâmetros mínimos. Na sequência foi proposto um modelo de identificação de atrito para uma posterior aplicação ao Hexapod PALIDA. O modelo de atrito proposto consiste em uma função não linear, que é descrita em termos do amortecimento viscoso e do atrito seco, similar ao modelo dinâmico do atrito de manipuladores proposto por Kelly et al. (2005) (GROTJAHN, HEIMANN e ABDELLATIF, 2004) (KELLY, SANTIBÁÑEZ e LORÍA, 2005).

Manipuladores paralelos são comumente utilizados devido ao seu elevado desempenho em operações estáticas ou quase estáticas. Carbone et al. (2005) apresentaram um esquema para avaliação do equilíbrio estático e da matriz de rigidez de um manipulador de cinco graus de liberdade paralelo, chamado CaHyMan (Cassino Hybrid Manipulador), e propuseram formulações com expressões de forma fechada em razão da geometria proposta do CaHyMan (CARBONE e CECCARELLI, 2005). Neste mesmo ano, Denkena et al. (2005) desenvolveram a cinemática inversa e a dinâmica inversa utilizando a equação de Newton-Euler em combinação com os princípios de D'Alembert ou Jourdain, para o manipulador paralelo, que possui juntas passivas de mais de um grau de liberdade (DENKENA, HEIMANN, et al., 2005). Em 2014, Gosh et al. (2014) desenvolveram um manipulador paralelo eletro-hidráulico de dois cilindros para diferentes tipos de sistema de controle: PID, fuzzy híbrido PID, fuzzy auto-ajustado PID e auto-tuning fuzzy PID com controladores de polarização. Os tipos de controle propostos foram utilizados para estudar o desempenho do manipulador (GHOSH, SARKAR e SAHA, 2014). 
Um exemplo de robôs para aplicação cirúrgica foi dado por Plitea et al. (2007), que apresentaram um novo robô paralelo a ser utilizado como módulo de base para o posicionamento de instrumentos cirúrgicos, desenvolvido a partir de demandas customizadas da sala de operação. Nessa publicação não foi apresentada a parte experimental, apenas um modelo computacional (PLITEA, HESSELBACH, et al., 2007). Plitea et al. (2012) desenvolveram um modelo cinemático de um robô paralelo híbrido de cinco graus de liberdade, utilizando juntas ativas em seu funcionamento para a realização de cirurgias invasivas mínimas, neste caso, conhecidas por laparoscopias. As juntas utilizadas possuem apenas um grau de liberdade cada, no entanto, em sua ponta end factor, um mecanismo similar a uma junta universal é montado para atender à área de trabalho que se deseja (PISLA, GHERMAN, et al., 2012).

Uma das inspirações da presente tese foi o trabalho realizado por Cardozo (2017), que desenvolveu um manipulador eletro-hidráulico utilizando uma junta universal "cardan" ou uma junta homocinética "CVJ - Constant Velocity Joint". Inicialmente é estudada uma plataforma cardânica com transdutores de posição angular medindo o deslocamento da cruzeta da junta. Em seguida, uma nova configuração da plataforma é proposta, substituindo o cardan por uma junta homocinética. A modelagem do sistema começa com a cinemática e, na sequência, a modelagem dinâmica utiliza a formulação de Newton-Euler para obter a equação de movimento (CARDOZO, 2017). Em seguida, Cardozo et al. (2017) elaboraram uma abordagem compacta para juntas homocinéticas "CVJ", para tanto, considerando o vetor de Euler para obter, através das variações temporais das matrizes de transformação, a velocidade angular da junta. A junta homocinética, comumente utilizada na indústria automobilística, possui um comportamento similar ao de uma junta esférica, visto que a velocidade angular é transmitida de forma constante, ao contrário da junta universal "cardan", que possui uma variação de fase na transmissão da velocidade angular (CARDOZO e WEBER, 2017). Esses trabalhos realizados por Cardozo (2017) também utilizam a mesma notação que foi usada nesta tese, conhecida como notação de Weber, para formular a cinemática e dinâmica (WEBER, 2019).

Desenvolver novas configurações geométricas para juntas esféricas já acontece há certo tempo, como Gosselin et al. (1999), que patentearam um dispositivo de dois graus de liberdade para orientação esférica. Essa patente é documentação precursora de diversos estudos de juntas ativas de mais de um grau de liberdade criadas posteriormente (GOSSELIN e CARON, 1999). Seguindo essa linha de trabalho, Palpacelli et al. (2018) 
projetaram uma junta ativa e esférica configurável. Esse trabalho focalizou apenas o projeto, não havendo desenvolvimento de experimento/protótipo nem o estudo de sua cinemática, dinâmica e controle. Ao realizar a análise do trabalho, observa-se uma complexidade muito grande na estrutura mecânica de alguns componentes e a resistência dos materiais envolvida necessita ser verificada em detalhe, pois os esforços, no ponto central da junta esférica, são bastante elevados (PALPACELLI, CARBONARI, et al., 2018). Porém o trabalho experimental de Gallardo et al. (2018) utiliza atuadores externos para posicionar um manipulador paralelo à junta esférica, sendo este trabalho similar ao trabalho proposto por Legnani et al. (2018), que consiste em formular a cinemática direta e inversa de uma junta esférica a partir de seus ângulos projetivos (GALLARDOALVARADO, RODRIGUEZ-CASTRO, et al., 2018) (LEGNANI e FASSI, 2018). Relacionar os ângulos projetivos é uma proposta interessante porque os ângulos cardânicos necessitam ser associados com o ângulo da junta, por exemplo. Para aplicações em robôs de serviços, Froehlic et al. (2016) demonstraram a comparação da área de trabalho workspace, bem como estabilidade e torque de uma junta de revolução com uma junta esférica (FROEHLIC e REISER, 2016). No trabalho seguinte, Froehlic et al. (2018) apresentaram o mecanismo de uma junta esférica do tipo cunha. Esse trabalho compara as áreas de trabalho workspace das juntas do tipo cunha, universal "cardan" e esférica (FROEHLIC, REISER, et al., 2018).

Nesta tese, optou-se pelo processo de posicionamento do atuador do manipulador por um sensor inercial "IMU - Inertial Motion Unit", em combinação com as odometrias dos motores. Em alguns trabalhos, utiliza-se a visão computacional para o posicionamento final do robô manipulador, como é o caso do trabalho de Araujo et al. (2018), existindo, inclusive, inúmeras bibliotecas gratuitas, como é o caso da biblioteca opencv, para calibrar e verificar o posicionamento das juntas durante a sua resolução da cinemática direta ou inversa (ARAUJO, ARAUJO, et al., 2018). Wang et al. (2019) propuseram utilizar uma rede neural artificial para melhorar a precisão do posicionamento na ponta do manipulador, através de um modelo de erro de posicionamento, lido por escâner a laser de alta precisão (FARO Laser Tracker) (WANG, CHEN , et al., 2019). Seguindo a linha da utilização de sensores inerciais e suas aplicações em juntas, Mcginnis et al. (2013) utilizaram um IMU sem fio miniaturizado para realizar previsões rápidas e precisas do centro de rotação de juntas esféricas (MCGINNIS e PERKINS, 2013). No entanto, para o conhecimento do posicionamento do atuador, a solução de hardware proposta nesta tese é similar à de Nishida (2017), que utilizou uma forma de transmitir informações do IMU (MPU 6250) por $W i-F i$, através do microcontrolador ESP8266, para captura de movimento humano 
(NISHIDA, 2017). Com o intuito de melhorar a confiabilidade dos resultados medidos pelo IMU (MPU 9250), o estudo de Yuan et al. (2019) apresenta um algoritmo de incerteza para movimentos dinâmicos para acompanhamento da orientação do IMU. Nesse artigo foi proposto um novo método de fusão para garantir a maior confiabilidade do IMU, aplicando o filtro de Kalman estendido. O workflow proposto para a fusão inclui considerar as informações do acelerômetro, do giroscópio e do magnetômetro para que, após a passagem no filtro de Kalman estendido possa fornecer com confiabilidade as informações de posições angulares (YUAN, ASADI, et al., 2019). Neste mesmo ano, Lee et al. (2019) desenvolveram um trabalho bem semelhante ao de Yuan et al. (2019) utilizando o IMU (MPU-6050) e aplicando um o filtro de Kalman, conseguindo obter os principais ângulos (roll and pitch) (LEE e CHOI, 2019). Alguns problemas de modelagem de IMUs podem ser encontrados na publicação editada por Szewczyk et al. (2018), que dedicaram uma seção inteira a técnicas e a sistemas de medição para robótica. Apesar de diversos trabalhos para controlar o atuador do manipulador, é comum o desenvolvimento de trabalhos de otimização em busca de solução ótima sobre as incertezas de seu posicionamento, conforme indicado por Kova et al. (2016) (SZEWCZYK, ZIELIŃSKI e KALICZYŃSKA, 2018) (KOVA, HSU, et al., 2016).

Uma das ações para a redução do torque envolvido no acionamento da junta ativa é a utilização de juntas elásticas, como pode ser visto no trabalho de Kim et al. (2014), no qual foi desenvolvido um mecanismo de contrabalanceamento para diminuir os torques envolvidos no acionamento das juntas do robô manipulador (KIM e SONG, 2014). Seguindo essa linha de estudo, Zollo et al. (2014) também desenvolveram um novo procedimento de identificação de parâmetros dinâmicos para juntas elásticas partindo da formulação de Lagrange do robô manipulador, computando a energia elástica, cinemática e potencial (ZOLLO, LOPEZ, et al., 2014). Posteriormente, Ożóg (2017) desenvolveu uma formulação dinâmica para uma junta universal elástica que pode servir como minimização de energia para manter o braço próximo à posição de interesse dentro da área de trabalho workspace (OżÓG, 2017). Combinando esses trabalhos é possível desenvolver a formulação dinâmica para junta ativa elástica cardan como um trabalho futuro desta tese.

Com respeito às inovações nas juntas esféricas, Kimata et al. (2005) desenvolveram um experimento que registrou as forças de contatos das esferas de uma homocinética "CVJ" (KIMATA, NAGATANI, et al., 2005), e Mekid (2011) patenteou um freio bem engenhoso para as juntas esféricas não ativas (MEKID , 2011). Jin et al. (2015) propuseram um modelo 
de contato para juntas esféricas baseado no modelo de Winkler e com geometria constante, utilizando o ANSYS como programa de elementos finitos para simular a força de contato e a deformação (JIN, HONG-WEI, et al., 2015). Outros estudos sobre contatos em juntas foram desenvolvidos, como de Marques et al (2017), no qual foi realizado um modelo para contato e impacto em juntas esféricas (MARQUES, DOURADO, et al., 2017). Apesar de a proposta nesta tese ser uma junta cardânica, analisar os contatos causados dentro do rolamento de agulha ajudará a entender o torque resistivo que será previsto no modelo, similar ao trabalho de Stamenić et al (2012), no qual foi estudado um modelo de contato em juntas cardânicas através de uma distribuição linear de carregamento e executado um modelo numérico para analisar a correlação entre o estado de tensão nas superfícies de contato das peças de rolamento e a distribuição da carga linear (STAMENIĆ, RISTIVOJEVIĆ, et al., 2012). Estudo similar ao de Tian et al. (2019), onde foi apresentada uma junta esférica com folga, com modelo de contato seco e modelo de contato lubrificado, que pode ser aplicado à junta cardan ativa que é proposta nesta tese (TIAN, ZHANG, et al., 2009).

Diversas literaturas sobre manipuladores robóticos, como, por exemplo, no trabalho de Jazar (2010), utilizam o método de Denavit-Hartenberg para a obtenção da matriz homogeneizada, incluindo a rotação e translação (JAZAR, 2010), como é visto no trabalho de Shah et al. (2012), onde se desenvolveram vários parâmetros de Denavit-Hartenberg para juntas angulares de Euler, montando as matrizes de rotação para diversas configurações de juntas de até três graus de liberdade (SHAH, SAHA e DUTT, 2012). Shah et al. (2009) também desenvolveram uma representação unificada das articulações de um, dois e três graus de liberdade, assim, criando um algoritmo recursivo para resolver as matrizes montadas com os parâmetros de Denavit-Hartenberg (SHAH, SAHA e DUTT, 2009). Nesta tese, como o objetivo era o estudo de uma única junta de três graus de liberdade em um manipulador, foi utilizada uma abordagem de formulação e notação da cinemática e dinâmica proposta por Weber (2019), que culminou nos mesmos resultados de translação e rotação da cinemática direta e inversa.

O estudo do acoplamento de Thompson, feito por Watson et al. (2013), propôs uma nova junta de velocidade constante "CVJ", que opera usando o mecanismo duplo robusto de cardan. A velocidade constante e a cinemática da ligação determinada são mantidas por um pantógrafo esférico que forma um loop extra conectado ao eixo intermediário na dupla conexão cardan e, consequentemente, restringe esse eixo para dividir o eixo de entrada e 
saída. Dessa forma, o duplo cardan consegue manter a velocidade angular de transmissão de seu eixo principal constante, similar ao que acontece com a junta homocinética (WATSON, PRUSTY e OLSEN, 2013). Alguns trabalhos utilizam apenas uma junta cardânica, apesar de sua variação de rotação do eixo de saída, visto que a junta cardânica ativa pode ser controlada. Dessa forma, Zhao et al. (2013) criaram um mecanismo de cardan com funções de amortecimento e ajuste de atitude para o pouso em asteroide. $\mathrm{O}$ ajuste de atitude do mecanismo de cardan é realizado pela utilização de um controlador PD. Os resultados desse trabalho demonstram que o controlador PD possui uma reposta melhor do que um controlador PID para um mecanismo cardan (ZHAO, ZHAO, et al., 2013). De forma similar, Huang et al. (2017) desenvolveram uma junta universal controlada por atuadores no formato de cunha para simular o movimento de uma junta universal cardan (HUANG, DONG, et al., 2017). Com respeito ao manipulador em série (antropomórfico), para o qual, comumente, algumas literaturas utilizam juntas com apenas um grau de liberdade (KELLY, SANTIBÁÑEZ e LORÍA, 2005) (LONG, SHUAI e MIRZA, 2019), diversos tipos de controle são utilizados, como controlador PD com compensação adaptativa, controlador PD com compensação de gravidade desejada, controle adaptativo utilizando redes neurais. Outro exemplo de um manipulador em série, que atua como plataforma de desenvolvimento robótico, é o KUKA-DLR, criado por Bischoff et al. (2010). Ele é um robô manipulador leve que foi o resultado da colaboração de diversos pesquisadores da empresa KUKA e o Instituto de Robótica e Mecatrônica do Centro Aeroespacial Alemão (DLR), com o objetivo de desenvolver um manipulador com as seguintes características: portabilidade, execução de tarefas raramente repetidas, programado on-line podendo operar off-line e com compartilhamento da área de trabalho com seres humanos, entre outras características (BISCHOFF, KURTH, et al., 2010).

No experimento proposto nesta tese, optou-se por utilizar motores de passos nos acionamentos da junta de três graus de liberdade, assim, permitindo resolver numericamente o problema proposto e acionar os motores em malha aberta, apesar de ser comum a utilização de motores de corrente contínua, como Valencia et al. (2017), que implementaram um controle dinâmico em um robô manipulador com quatro juntas, sendo apenas um grau de liberdade por junta e utilizando motores DC com encoders para realizar o controle durante o deslizamento sobre uma superfície da ponta do manipulador (VALENCIA C, AVILÉS e MAULEDOUX, 2017). Muitas vezes, podem ser introduzidos freios nas juntas dos manipuladores para auxiliar no controle de juntas ativas com motores DC com encoders, como é o caso do trabalho de Arai et al. (1991), que também montaram 
o protótipo de um manipulador com uma junta ativa e outra passiva, controlando o freio na junta passiva (ARAI e TACHI, 1991).

Após a revisão bibliográfica foi possível constatar a importância de um estudo sobre juntas universais "cardan" ativas controladas com três graus de liberdade. A proposta do mecanismo de junta ativa cardan em si já é uma inovação, e não foi encontrada, até o término do estudo, proposta nesta linha, apesar da vasta pesquisa bibliográfica realizada. Com a proposta de desenvolver a cinemática direta e inversa, a dinâmica direta e inversa, como pilar essencial do estudo da junta já corrobora o estado da arte dentro da área de pesquisa proposta. De fato, o novo dispositivo proposto permite desenvolver diversas pesquisas em juntas ativas, como, por exemplo, transformar o dispositivo em uma junta ativa elástica cardan de três graus de liberdade, conforme citado em algumas referências.

\subsection{Sumário das contribuições}

O objetivo deste estudo foi o de controlar a dinâmica da junta universal (cardan) a partir do interior da cruzeta, para tanto, usando motores de passo com redutores de alto torque para alcançar dispositivos leves e compactos, chamados de juntas ativas. A junta ativa foi projetada com sensores IMU (Inertial Measurement Unit) e células de carga na base para possibilitar a validação do modelo teórico e flexibilizar a comparação entre estudos experimentais e numéricos do dispositivo. Conhecer os componentes críticos de uma junta cardan ativa de 3DOF também fez parte do objetivo deste trabalho. Conforme salientado, esse tipo de junta ainda não se encontra amplamente utilizado no mercado, exatamente pelas suas limitações de torque em seu centro de atuação.

Após esta introdução, no capítulo 2 são abordados os métodos e desenvolvimentos utilizados neste trabalho, apresentando a notação de Weber, a modelagem cinemática, a dinâmica, os atritos nos rolamentos e as folgas na junta. Em seguida, é apresentado o projeto, a manufatura e a programação do experimento, fornecendo adendos através de QRCODES inseridos no texto. E, por fim, nesse capítulo, propõe-se quatro casos para o estudo do movimento da junta cardânica ativa utilizando a modelagem proposta. 
Já no capítulo 3, são descritas as contribuições para a área de juntas ativas cardânicas, incluindo a análise da área de trabalho (workspace), além dos resultados numéricos e experimentais dos quatro casos propostos, contendo toda a sua cinemática e dinâmica. Ao final desde capítulo, analisam-se os componentes críticos, como é o caso do redutor planetário, que passa ser a chave para ampliar a aplicação desse tipo de junta. Portanto, conhecer os limites de torque nos eixos principais da junta é essencial para a segurança do dispositivo.

A conclusão, no capítulo 4, sumariza a contribuição do comportamento de cada tipo de caso proposto, permitindo realizar as considerações finais do trabalho e apontar melhorias para trabalhos futuros. 


\section{Métodos e Desenvolvimento}

\subsection{Notação}

A notação de Weber (WEBER, 2019) permite inúmeras vantagens e simplificações por ser uma notação diferenciada, pela qual, muitas vezes, um vetor é tratado como uma matriz antissimétrica, enquanto, na maioria dos textos, os vetores ainda são identificados como $\vec{r}$. A notação de Weber explora todas as possibilidades de expoentes e índices para um vetor no espaço tridimensional. Sendo ${ }_{\mathrm{O}}^{\mathrm{S}} \mathbf{r}_{\mathrm{P}}$ o vetor que parte do ponto $\mathrm{O}$ para o ponto $\mathrm{P}$ e suas coordenadas estarão escritas no Sistema de Referência - "SR" (ou Base) (S) e seu módulo equivale a $r$. As coordenadas deste vetor podem ser explicitadas pela matriz [3x1], conforme eq. (2.1).

$$
{ }_{\mathrm{O}}^{\mathrm{S}} \mathbf{r}_{\mathrm{P}}=\left[\begin{array}{c}
x \\
y \\
z
\end{array}\right]
$$

Para as operações de soma de vetores as regras são elementares, somando-se as coordenadas desde que possuam o mesmo "SR". No entanto, para o produto de dois vetores $\mathbf{r}, \mathbf{s}$ há algumas variantes: a primeira delas é transpor o primeiro $\mathbf{r}^{\mathrm{T}} \mathbf{S}$ e o resultado será um escalar [1x3]x[3x1], a segunda é transpor o segundo $\mathbf{r} \mathbf{s}^{\mathrm{T}}$ e o resultado será uma matriz

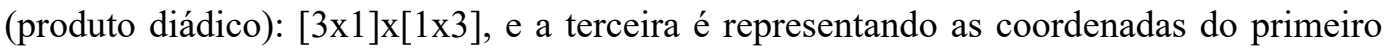
vetor em uma matriz antissimétrica e multiplicando pelo segundo e o resultado será outro vetor, pois ela tem exatamente três termos distintos: [3x3]x[3x1]. Como exemplo, conforme eq. (2.2), pode-se comprovar os critérios do produto vetorial em sistemas de coordenadas dextrogiros, isto é, na notação tradicional:

$$
\vec{i} \times \vec{j}=\vec{k}, \quad \vec{j} \times \vec{k}=\vec{i}, \quad \vec{k} \times \vec{i}=\vec{j}
$$

No produto vetorial, quando os vetores são paralelos, o resultado é nulo: $\vec{i} x \vec{i}=\overrightarrow{0}$. Na equivalência da notação para vetores unitários:

$$
\vec{i} \Rightarrow \mathbf{e}_{x}=\left[\begin{array}{l}
1 \\
0 \\
0
\end{array}\right], \quad \vec{j} \Rightarrow \mathbf{e}_{y}=\left[\begin{array}{l}
0 \\
1 \\
0
\end{array}\right], \quad \vec{k} \Rightarrow \mathbf{e}_{z}=\left[\begin{array}{l}
0 \\
0 \\
1
\end{array}\right]
$$

Para procurar a matriz antissimétrica do primeiro vetor com componentes $a, b$ e $c$ que atenda às regras do produto vetorial na eq. (2.2), pode-se escrever usando os vetores unitários na eq. (2.3): 
$\vec{i} \times \vec{j}=\vec{k}=\left[\begin{array}{ccc}0 & a & b \\ -a & 0 & c \\ -b & -c & 0\end{array}\right]\left[\begin{array}{l}0 \\ 1 \\ 0\end{array}\right]=\left[\begin{array}{l}0 \\ 0 \\ 1\end{array}\right] \Rightarrow a=0,-c=1, b \in \mathbb{R}$

A componente $b$ da eq. (2.4) pode ser qualquer, por ser a parcela do vetor paralela ao outro vetor e que não contribui para o resultado. Pode-se tomar $b=0$ e a representação de $\vec{i}$, e das outras direções usando o mesmo raciocínio, na forma de matrizes antissimétricas será dada por:

$$
\vec{i} \Rightarrow \tilde{\mathbf{e}}_{x}=\left[\begin{array}{ccc}
0 & 0 & 0 \\
0 & 0 & -1 \\
0 & 1 & 0
\end{array}\right], \quad \vec{j} \Rightarrow \tilde{\mathbf{e}}_{y}=\left[\begin{array}{ccc}
0 & 0 & 1 \\
0 & 0 & 0 \\
-1 & 0 & 0
\end{array}\right], \quad \vec{k} \Rightarrow \tilde{\mathbf{e}}_{z}=\left[\begin{array}{ccc}
0 & -1 & 0 \\
1 & 0 & 0 \\
0 & 0 & 0
\end{array}\right]
$$

Por inferência conforme eq. (2.5), a representação geral do um vetor ${ }_{\mathrm{O}}^{\mathrm{S}} \mathbf{r}_{\mathrm{P}}$ acima na forma de matriz antissimétrica, ou conhecida também como matriz "til", é dito como: "r til de O para P no SR S”.

$$
{ }_{\mathrm{O}}^{\mathrm{S}} \tilde{\mathbf{r}}_{\mathrm{P}}=\left[\begin{array}{ccc}
0 & -z & y \\
z & 0 & -x \\
-y & x & 0
\end{array}\right]
$$

Algumas vantagens e algumas propriedades desta notação, exibida na eq. (2.6), podem ser aplicadas na cinemática, como, por exemplo: $\vec{\omega} x(\vec{\omega} x \vec{r}) \Rightarrow \tilde{\boldsymbol{\omega}} \tilde{\boldsymbol{\omega}} \mathbf{r}=\tilde{\boldsymbol{\omega}}^{2} \mathbf{r}$. Ou até mesmo em dinâmica na definição do tensor de inércia em relação a um ponto $\mathrm{O}$, sendo $\mathrm{P}$ um ponto genérico de massa $d m$ em um corpo que ocupa um volume $\mathrm{V}$, onde passa a ser:

$$
\mathbf{I}_{\mathrm{O}}=-\int_{\mathrm{V}} \tilde{\mathrm{r}}_{\mathrm{P}}^{2} d m \text {, onde, } \tilde{\mathbf{r}}^{2}=\left[\begin{array}{ccc}
-y^{2}-z^{2} & x y & x z \\
x y & -x^{2}-z^{2} & y z \\
x z & y z & -x^{2}-y^{2}
\end{array}\right]
$$

Outra aplicação ocorre ao definir a velocidade angular de um corpo no espaço usando a representação antissimétrica do vetor. As propriedades rotativas estão presentes na variação temporal da matriz de orientação de um corpo (também chamada de matriz dos cossenos diretores, matriz de transformação de coordenadas e matriz de rotação). Dessa forma, como esta matriz é ortogonal com determinante unitário e sendo o produto da derivada temporal de uma matriz ortogonal pela sua transposta antissimétrico, permite definir a velocidade angular como:

$$
{ }_{\mathrm{F}}^{\mathrm{F}} \tilde{\boldsymbol{\omega}}_{\mathrm{S}}={ }^{\mathrm{F}} \dot{\mathbf{T}}^{\mathrm{S}} \mathrm{S} \mathbf{T}^{\mathrm{F}} .
$$

$\mathrm{Na}$ leitura desta notação, tem-se: a velocidade angular de $\mathrm{S}$ em relação a $\mathrm{F}$ escrita em componentes em F é igual à variação temporal da matriz de orientação multiplicada pela transposta desta mesma matriz. Pode-se dizer também que ${ }^{\mathrm{F}} \mathbf{T}^{\mathrm{s}}$ na eq. (2.8) é a matriz de 
transformação de coordenadas do "SR" F para o "SR" S. Diversas propriedades são observadas, como, por exemplo, na inversão de ordem do produto vetorial, onde $\tilde{\boldsymbol{\omega}} \mathbf{r}=-\tilde{\mathbf{r}} \boldsymbol{\omega}$, ou na potência de uma matriz antissimétrica, pois se $\|\mathbf{r}\|=1$ então $\tilde{\mathbf{r}}^{3}=-\tilde{\mathbf{r}}$, $\tilde{\mathbf{r}}^{4}=-\tilde{\mathbf{r}}^{2}, \tilde{\mathbf{r}}^{5}=+\tilde{\mathbf{r}}, \ldots$ e também $\tilde{\mathbf{r}}^{2}=\mathbf{r} \mathbf{r}^{\mathrm{T}}-\mathbf{E}$, sendo $\mathbf{E}$ é a matriz identidade [3x3].

A análise vetorial do movimento de rotação começa com o vetor posição, cujas derivadas vão dar o movimento. A análise vetorial da rotação inicia na definição da velocidade angular, já que ângulos finitos não podem ser representados por vetores. Assim, na rotação, a matriz de orientação cumpre o papel que, na translação, é do vetor posição. A despeito dos nove termos desta matriz, apenas três são independentes, correspondentes aos graus de liberdade possíveis.

Há duas formas totalmente distintas de olhar para essas matrizes: como sua posição vai alternando-se no espaço, uma maneira prática de visualizar o movimento é recorrer a rotações sequenciais elementares (em torno dos eixos coordenados). Nascem assim os ângulos de Euler ou sua variante Cardânica (ou Tate-Bryan). Pode-se definir um vetor do corpo rotativo e comparar as coordenadas deste corpo no SR fixo ao corpo com as coordenadas do mesmo vetor o SR fixo. A matriz de orientação faz o papel da matriz de transformação de coordenadas. Ela vai variando por incrementos nos ângulos definidos de um instante a outro e pode ser escrita em termos dos três ângulos cardânicos.

A segunda variante parte da observação de que existe um eixo (dado pelo vetor de Euler) em torno do qual a rotação por certo ângulo desloca um vetor do corpo de sua posição inicial para uma posição final. Neste caso, a posição do SR, em um dado instante, é sempre referenciada à posição inicial. Ela é conhecida por Matriz de Rotação, mas pode-se mostrar que é a própria matriz de orientação. Ela pode ser escrita em termos de vetor de Euler (que é unitário) e seu ângulo de giro $(\mathbf{p}, \theta)$. Seu uso implica algumas singularidades, que podem ser eliminadas utilizando os parâmetros de Euler-Rodrigues. Atualmente, viu-se que também os quatérnios podem ser usados para contornar essas singularidades.

Quatérnios são vetores [4x1] que podem ser imaginados como oriundos de dois vetores $\mathbf{r}$ e s, [3x1], conforme eq. (2.9). Particularmente, os vetores que interessam são aqueles de módulo unitário e que possuem entre si um ângulo $\theta$, por exemplo. Na sua utilização, no 
estudo da rotação, é feita uma associação do quatérnio formado por um vetor e um escalar com o vetor de Euler e seu ângulo de giro $(\mathbf{p}, \theta)$ na forma descrita na eq. (2.9).

$\mathbf{q}=\left[\begin{array}{c}\tilde{\mathbf{r}} \mathbf{s} \\ \mathbf{r}^{\mathrm{T}} \mathbf{s}\end{array}\right], \quad \mathbf{q}=\left[\begin{array}{l}\mathbf{v} \\ l\end{array}\right]=\left[\begin{array}{c}\mathbf{p} \sin (\theta / 2) \\ \cos (\theta / 2)\end{array}\right]$

Voltam a existir as diversas operações com quatérnios, sendo novamente necessário definir as regras para o equivalente ao produto vetorial anterior. No caso, como definir propriedades para que o produto de dois vetores [4x1] resulte em um vetor [4x1].

Sem entrar em detalhes que estão no texto "Raciocinando Dinâmica de Rotação" (WEBER, 2019), associa-se a este vetor q uma matriz bem específica $\hat{\mathbf{q}}$. Representando o quatérnio por um vetor $\mathbf{v}$ e um escalar $l$ :

$\mathbf{q}_{1}=\left[\begin{array}{c}\mathbf{v}_{1} \\ l_{1}\end{array}\right] \Rightarrow \hat{\mathbf{q}}_{1}=\left[\begin{array}{ccc}l_{1} \mathbf{E}+\tilde{\mathbf{v}}_{1} & \mathbf{v}_{1} \\ -\mathbf{v}_{1}^{\mathrm{T}} & l_{1}\end{array}\right]$

o produto $\mathbf{q}_{1} \cdot \mathbf{q}_{2}$ é dado por:

$\hat{\mathbf{q}}_{1} \mathbf{q}_{2}=\left[\begin{array}{cc}l_{1} \mathbf{E}+\tilde{\mathbf{v}}_{\mathbf{1}} & \mathbf{v}_{\mathbf{1}} \\ -\mathbf{v}_{1}^{\mathrm{T}} & l_{1}\end{array}\right]\left[\begin{array}{c}\mathbf{v}_{\mathbf{2}} \\ l_{2}\end{array}\right]=\left[\begin{array}{c}\left(l_{1} \mathbf{E}+\tilde{\mathbf{v}}_{\mathbf{1}}\right) \mathbf{v}_{\mathbf{2}}+l_{2} \mathbf{v}_{\mathbf{1}} \\ -\mathbf{v}_{1}^{\mathrm{T}} \mathbf{v}_{\mathbf{2}}+l_{1} l_{2}\end{array}\right]=\left[\begin{array}{c}l_{1} \mathbf{v}_{2}+l_{2} \mathbf{v}_{1}+\tilde{\mathbf{v}}_{1} \mathbf{v}_{2} \\ -\mathbf{v}_{1}^{\mathrm{T}} \mathbf{v}_{2}+l_{1} l_{2}\end{array}\right]$

A matriz associada ao vetor na eq. (2.10) ou eq. (2.11), neste caso, não é antissimétrica, mas ela é ortogonal, isto é sua inversa, que é igual à transposta.

Diversas outras vantagens podem ser observadas no uso da notação de Weber, que foi utilizado para modelar o experimento proposto. Para maiores detalhes sobre aplicações e exemplos da notação, aconselha-se a leitura do livro (WEBER, 2019). 


\subsection{Modelagem}

\subsubsection{Cinemática Direta e Inversa}

O primeiro passo é modelar a cinemática dos corpos rígidos do experimento proposto na Figura 2-1 aplicando a notação de Weber. Os Sistemas de Referência (SRs) F (fixo), Q (fixo no corpo 1), R (fixo na cruzeta), S (fixo ao eixo de saída) e os ângulos entre eles devem ser definidos para cada um dos quatro corpos rígidos envolvidos, conforme mostrado na Figura 2-1. Embarcados na junta, tem-se o movimento produzido por dois motores de passo controlando as rotações $\beta$ e $\gamma$, enquanto no ponto A inferior, na base, tem-se o movimento gerado por um motor de passo controlando a rotação $\alpha$.

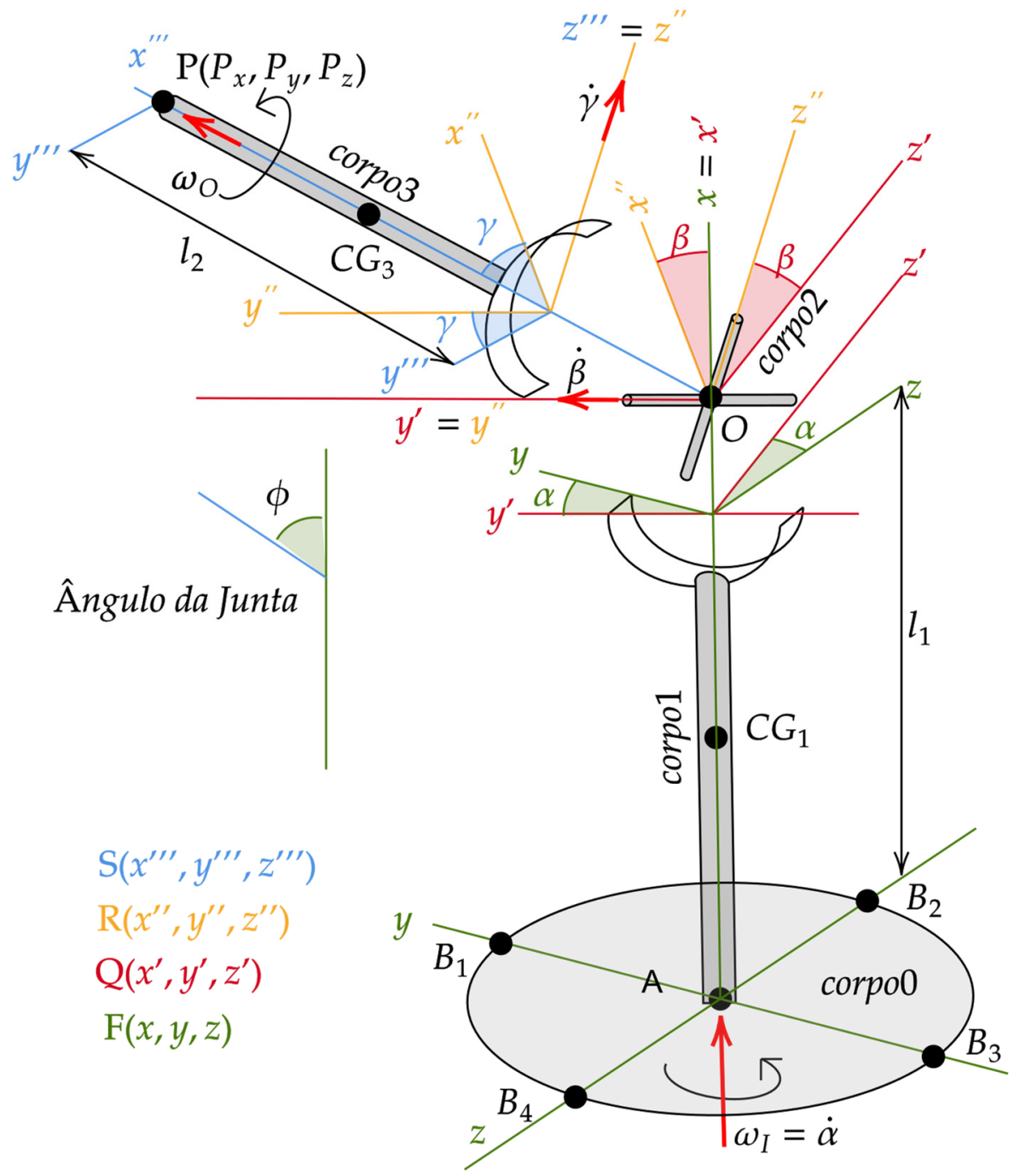

Figura 2-1 - Sistemas de Referência da Junta Universal “Cardan” proposta como Experimento [Fonte: Autoria própria] 
A matriz de transformação, de acordo com Weber (2019), pode ser escrita conforme a eq. (2.12), onde foi utilizada uma notação simplificada para as funções trigonométricas, como indicado: $\cos (\alpha)=c_{\alpha} ; \sin (\alpha)=s_{\alpha} ; \tan (\alpha)=t_{\alpha}$, de forma similar para os ângulos $\beta$ e $\gamma$.

$$
\begin{aligned}
& \underset{(x, y, z)}{\mathrm{F}} \stackrel{\alpha(x)}{\longrightarrow} \underset{\left(x, y^{\prime}, z^{\prime}\right)}{\mathrm{Q}} \stackrel{\beta\left(\mathrm{y}^{\prime}\right)}{\longrightarrow} \underset{\left(x^{\prime \prime}, y^{\prime}, z^{\prime \prime}\right)}{\mathrm{R}} \stackrel{\gamma\left(\mathrm{z}^{\prime \prime}\right)}{\longrightarrow} \underset{\left(x^{\prime \prime}, y^{\prime \prime}, z^{\prime \prime}\right)}{\mathrm{S}} \\
& \cdot{ }^{\mathrm{F} \mathbf{T}^{\mathrm{s}}{ }_{\text {Cardan }}=\mathrm{F}^{\mathrm{F}} \mathbf{T} \mathrm{Q}} \mathbf{T}^{\mathrm{R}}{ }^{\mathrm{R}} \mathbf{T}^{\mathrm{S}}=\left[\begin{array}{ccc}
c_{\beta} c_{\gamma} & -c_{\beta} s_{\gamma} & s_{\beta} \\
s_{\alpha} s_{\beta} c_{\gamma}+c_{\alpha} s_{\gamma} & -s_{\alpha} s_{\beta} s_{\gamma}+c_{\alpha} c_{\gamma} & -s_{\alpha} c_{\beta} \\
-c_{\alpha} s_{\beta} c_{\gamma}+s_{\alpha} s_{\gamma} & c_{\alpha} s_{\beta} s_{\gamma}+s_{\alpha} c_{\gamma} & c_{\alpha} c_{\beta}
\end{array}\right] .
\end{aligned}
$$

A velocidade angular pode ser escrita como uma matriz antissimétrica usando a derivada temporal da matriz de orientação na forma da eq. (2.12), multiplicada pela própria, conforme eq. (2.8). De volta à Figura 2-1, o "corpo 1" possui velocidade angular igual a ${ }_{\mathrm{F}} \boldsymbol{\omega}_{\mathrm{Q}}$, enquanto o "corpo 2" tem velocidade angular igual a ${ }_{\mathrm{F}} \boldsymbol{\omega}_{\mathrm{Q}}+{ }_{\mathrm{Q}} \boldsymbol{\omega}_{\mathrm{R}}$ e, por fim, o "corpo 3 " tem velocidade angular ${ }_{\mathrm{F}} \boldsymbol{\omega}_{\mathrm{Q}}+{ }_{\mathrm{Q}} \boldsymbol{\omega}_{\mathrm{R}}+{ }_{\mathrm{R}} \boldsymbol{\omega}_{\mathrm{S}}$. Escrevendo as velocidades angulares em seus respectivos SRs, resulta:

$$
{ }_{\mathrm{F}}^{\mathrm{F}} \boldsymbol{\omega}_{\mathrm{Q}}=\left[\begin{array}{c}
\dot{\alpha} \\
0 \\
0
\end{array}\right]={ }_{\mathrm{F}}^{\mathrm{Q}} \boldsymbol{\omega}_{\mathrm{Q}} ;{ }_{\mathrm{Q}}^{\mathrm{Q}} \boldsymbol{\omega}_{\mathrm{R}}=\left[\begin{array}{c}
0 \\
\dot{\beta} \\
0
\end{array}\right]={ }_{\mathrm{Q}}^{\mathrm{R}} \boldsymbol{\omega}_{\mathrm{R}} ;{ }_{\mathrm{R}}^{\mathrm{R}} \boldsymbol{\omega}_{\mathrm{S}}=\left[\begin{array}{c}
0 \\
0 \\
\dot{\gamma}
\end{array}\right]={ }_{\mathrm{R}}^{\mathrm{S}} \boldsymbol{\omega}_{\mathrm{S}} ;
$$

Escolher em qual SR deve ser resolvido o problema é um desafio interessante, uma vez que, ao escolher um SR embarcado, como, por exemplo, o SR "R", pode-se reduzir a complexidade das equações envolvidas. No entanto, como há o intuito de comparar a cinemática do corpo com os valores do sistema fixo, é importante conhecer os valores das velocidades angulares no SR "F". Dessa forma, pode-se escrever as equações (2.14), (2.15) e (2.16) para cada corpo a partir das transformações da eq. (2.13) para o "SR" desejado, resultando nas seguintes velocidades angulares:

“corpo 3":

$$
\begin{aligned}
& { }_{\mathrm{F}} \boldsymbol{\omega}_{\mathrm{S}}={ }_{\mathrm{F}} \boldsymbol{\omega}_{\mathrm{Q}}+{ }_{\mathrm{Q}} \boldsymbol{\omega}_{\mathrm{R}}+{ }_{\mathrm{R}} \boldsymbol{\omega}_{\mathrm{S}} \\
& { }_{\mathrm{F}}^{\mathrm{F}} \tilde{\boldsymbol{\omega}}_{\mathrm{S}}={ }_{\mathrm{F}} \dot{\mathbf{T}}^{\mathrm{S}} \mathrm{S} \mathbf{T}^{\mathrm{F}}=\left[\begin{array}{ccc}
0 & -\omega_{3 z} & \omega_{3 y} \\
\omega_{3 z} & 0 & -\omega_{3 x} \\
-\omega_{3 y} & \omega_{3 x} & 0
\end{array}\right] \Rightarrow\left\{\begin{array}{c}
\omega_{3 x}=\dot{\alpha}+\dot{\gamma} s_{\beta} \\
\omega_{3 y}=c_{\alpha} \dot{\beta}-c_{\beta} s_{\alpha} \dot{\gamma} \\
\omega_{3 z}=s_{\alpha} \dot{\beta}+c_{\beta} c_{\alpha} \dot{\gamma}
\end{array}\right.
\end{aligned}
$$

“corpo 2":

$$
{ }_{\mathrm{F}} \boldsymbol{\omega}_{\mathrm{R}}={ }_{\mathrm{F}} \boldsymbol{\omega}_{\mathrm{Q}}+{ }_{\mathrm{Q}} \boldsymbol{\omega}_{\mathrm{R}} \Rightarrow{ }_{\mathrm{F}}^{\mathrm{F}} \tilde{\boldsymbol{\omega}}_{\mathrm{R}}={ }_{\mathrm{F}} \dot{\mathbf{T}}^{\mathrm{R} R} \mathbf{T}^{\mathrm{F}} \Rightarrow\left\{\begin{array}{c}
\omega_{2 x}=\dot{\alpha} \\
\omega_{2 y}=c_{\alpha} \dot{\beta} \\
\omega_{2 z}=s_{\alpha} \dot{\beta}
\end{array}\right.
$$


“corpo 1":

${ }_{\mathrm{F}} \boldsymbol{\omega}_{\mathrm{Q}}={ }_{\mathrm{F}} \boldsymbol{\omega}_{\mathrm{Q}} \Rightarrow{ }_{\mathrm{F}} \tilde{\boldsymbol{\omega}}_{\mathrm{Q}}=\mathrm{F} \dot{\mathbf{T}} \mathrm{Q} \mathrm{Q} \mathbf{T}^{\mathrm{F}} \Rightarrow\left\{\begin{array}{l}\omega_{1 x}=\dot{\alpha} \\ \omega_{1 y}=0 \\ \omega_{1 z}=0\end{array}\right.$

Conforme Weber (2019), existe um ângulo de fase na junta cardânica entre as velocidades angulares dos eixos que depende do ângulo de junta $\phi$ entre os frames, que pode ser calculado como $\phi=\arccos \left(c_{\beta} c_{\gamma}\right)$, fazendo com que a velocidade angular do eixo de saída possa ser escrita em função de $\phi$ e $\alpha$, de acordo com a eq. (2.17)

$\omega_{O}=\frac{\omega_{I}}{c_{\phi}+s_{\alpha}^{2} s_{\phi} t_{\phi}}$

Para desenvolver a cinemática direta e inversa, a posição do ponto P no SR "F" pode ser escrita conforme eq. (2.18).

$$
\begin{aligned}
& { }_{\mathrm{A}}^{\mathrm{F}} \mathbf{r}_{\mathrm{P}}={ }_{\mathrm{A}}^{\mathrm{F}} \mathbf{r}_{\mathrm{O}}+{ }_{\mathrm{F}}^{\mathrm{F}} \mathbf{T}_{\mathrm{O}}^{\mathrm{S}} \mathbf{r}_{\mathrm{P}} \\
& \cdot{ }_{\mathrm{A}}^{\mathrm{F}} \mathbf{r}_{\mathrm{P}}=\left[\begin{array}{l}
l_{1} \\
0 \\
0
\end{array}\right]+\left[\begin{array}{ccc}
c_{\beta} c_{\gamma} & -c_{\beta} s_{\gamma} & s_{\beta} \\
s_{\alpha} s_{\beta} c_{\gamma}+c_{\alpha} s_{\gamma} & -s_{\alpha} s_{\beta} s_{\gamma}+c_{\alpha} c_{\gamma} & -s_{\alpha} c_{\beta} \\
-c_{\alpha} s_{\beta} c_{\gamma}+s_{\alpha} s_{\gamma} & c_{\alpha} s_{\beta} s_{\gamma}+s_{\alpha} c_{\gamma} & c_{\alpha} c_{\beta}
\end{array}\right]\left[\begin{array}{c}
l_{2} \\
0 \\
0
\end{array}\right]=\left[\begin{array}{c}
P_{x} \\
P_{y} \\
P_{z}
\end{array}\right] .
\end{aligned}
$$

Resultando nas equações que relacionam a posição do atuador do ponto $\mathrm{P}$, com os ângulos $\alpha, \beta$ e $\gamma$ da junta cardânica. Define-se como cinemática direta a obtenção das coordenadas do ponto $\mathrm{P}$ do atuador conhecido os ângulos cardânicos, e, como cinemática inversa, a obtenção dos ângulos cardânicos dado um determinado ponto P do atuador.

$$
\left[\begin{array}{c}
P_{x} \\
P_{y} \\
P_{z}
\end{array}\right]=\left[\begin{array}{c}
l_{1}+l_{2} c_{\beta} c_{\gamma} \\
l_{2}\left(c_{\alpha} s_{\gamma}+s_{\alpha} s_{\beta} c_{\gamma}\right) \\
l_{2}\left(s_{\alpha} s_{\gamma}-c_{\alpha} s_{\beta} c_{\gamma}\right)
\end{array}\right]
$$

A solução da cinemática inversa das equações em (2.19) não é desenvolvida analiticamente. Entretanto, para resolver os problemas propostos nesta tese, o ângulo $\alpha(t)$ é supostamente conhecido. Dessa forma, é possível resolver analiticamente os ângulos $\beta$ e $\gamma$ conforme as equações em (2.20).

$$
\gamma=\operatorname{asin}\left(\frac{P_{y}}{l_{2}} c_{\alpha}+\frac{P_{z}}{l_{2}} S_{\alpha}\right) ; \beta=\operatorname{acos}\left(\frac{P_{x}-l_{1}}{l_{2} c_{\gamma}}\right)
$$

Portanto, todos os movimentos dos três corpos são agora conhecidos, usando a cinemática direta e inversa para resolver os problemas propostos nesta tese. 


\subsubsection{Dinâmica Direta e Inversa}

Para o equacionamento da dinâmica dos corpos rígidos do manipulador, optou-se em utilizar o método direto fundamentado nos princípios de Newton e Euler por entender que os métodos energéticos variacionais são mais úteis para uma sistematização de problemas com um número elevado de graus de liberdade e servem como uma proposição alternativa da mecânica clássica (WANG e PAO, 2002). Além disso, métodos como o princípio variacional de D'Alambert - Lagrange, que opera com deslocamentos virtuais ou trabalhos virtuais, ou o princípio variacional de Jourdain, que trabalha com velocidades virtuais ou potências virtuais, e, até mesmo, o princípio variacional de Gauss-Gibs, que utiliza acelerações virtuais, não levam a uma representação gráfica eficiente para o estudo e entendimento das forças envolvidas no corpo, como é o caso dos Diagramas de Corpo Livre (DCL) que são definidos para os corpos rígidos a seguir.

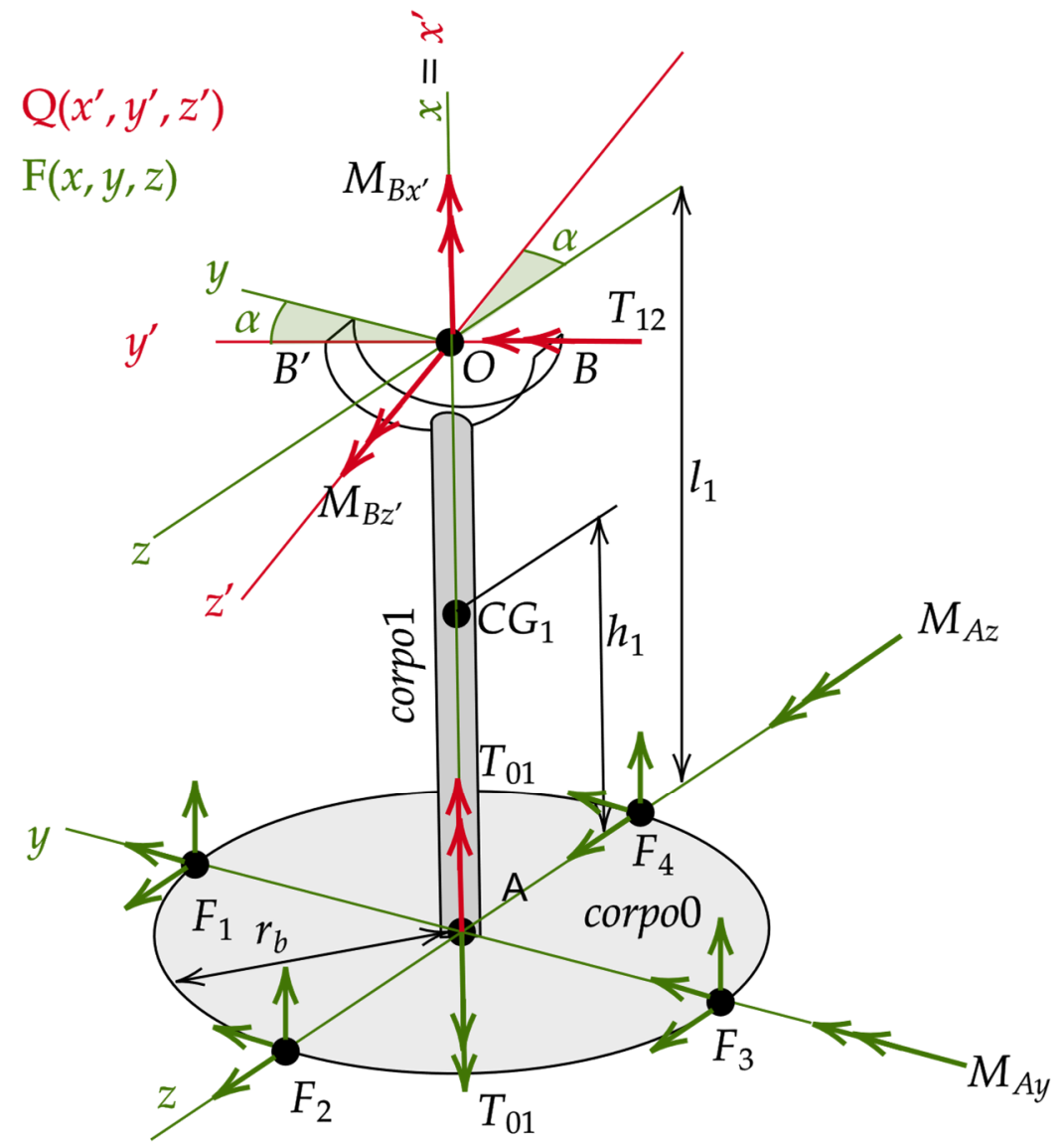

Figura 2-2 - DCL do corpo 0 e corpo 1 do manipulador cardânico [Fonte: Autoria própria]

As forças e os momentos representados em verde na Figura 2-2 estão no SR F, sendo que as forças $F_{1}, F_{2}, F_{3}$ e $F_{4}$ correspondem às reações nos apoios do corpo 0 sobre as células 
de carga, e o momento $T_{01}$ em torno do ponto A, corresponde ao torque gerado pelo motorredutor que está com a carcaça fixada no corpo 0 e seu eixo acoplado no corpo 1 . Dessa forma, as forças dinâmicas $F_{2}$ e $F_{4}$ na base se equilibram em $x$, onde $F_{2 x}=-F_{4 x}$ e criam o momento $M_{A y}$ que equivale ao binário puro. Este princípio repete-se com as forças dinâmicas $F_{1}$ e $F_{3}$, onde $F_{1 x}=-F_{3 x}$, criando o momento $M_{A z}$ que também equivale ao binário puro. Um ponto importante a observar trata-se do sistema das células de carga que é zerado na inicialização do experimento, fazendo com que as forças do peso próprio dos corpos rígidos não influenciem na leitura do componente $x$ das forças. Os momentos de reação $M_{A y^{\prime}}, M_{A z^{\prime}}, M_{B x^{\prime}}, M_{B z^{\prime}}$ e torque $T_{12}$ do motorredutor acoplado no corpo 1 representados em vermelho na Figura 2-2 - estão no SR Q e são descritos em detalhes a seguir.

Conforme indicado na Figura 2-2, a base corpo 0 está parada, portanto, apenas o equilíbrio estático será necessário para o equacionamento das forças e dos momentos envolvidos. Como as forças $F_{1}, F_{2}, F_{3}$ e $F_{4}$ serão conhecidas a partir das células de cargas instaladas na base, será possível comparar os valores dos momentos de reação em A no SR fixo (F), pela equação (2.21).

$r_{b}\left[\begin{array}{c}F_{1 z}-F_{2 y}-F_{3 z}+F_{4 y} \\ F_{2 x}-F_{4 x} \\ -F_{1 x}+F_{3 x}\end{array}\right]=\left[\begin{array}{c}T_{01} \\ -M_{A y} \\ -M_{A z}\end{array}\right]$

A análise dos resultados numéricos e experimentais das forças nas células de carga é a ferramenta para a validação da modelagem dinâmica posta a seguir. Portanto, qualquer premissa adotada na modelagem que tenda a simplificar o problema, poderia ser responsável por divergências nos resultados. Como, por exemplo, na simplificação dos tensores de inércia dos corpos rígidos, que são definidos contendo apenas os momentos principais de inércias, ou seja, sem os produtos de inércia em seus SRs embarcados, conforme equação (2.22), onde o índice sobrescrito (1), $\mathbf{Q}_{C G 1}^{(1)}$, representa a indicação do corpo rígido.

$$
\mathrm{Q} \mathbf{I}_{C G 1}^{(1)}=\left[\begin{array}{ccc}
I_{1 x} & 0 & 0 \\
0 & I_{1 y} & 0 \\
0 & 0 & I_{1 z}
\end{array}\right] ;{ }^{\mathrm{R}} \mathbf{I}_{O}^{(2)}=\left[\begin{array}{ccc}
I_{2 x} & 0 & 0 \\
0 & I_{2 y} & 0 \\
0 & 0 & I_{2 z}
\end{array}\right] ; \mathrm{S} \mathbf{I}_{C G 3}^{(3)}=\left[\begin{array}{ccc}
I_{3 x} & 0 & 0 \\
0 & I_{3 y} & 0 \\
0 & 0 & I_{3 z}
\end{array}\right]
$$

O centro de massa do corpo 1 é fixo, logo, aplicar a Lei de Newton/Euler resume-se no estudo da rotação. Para o corpo 1 no SR Q no ponto $\mathrm{O}$, o momento total que atua sobre este 
corpo pode ser igualado à derivada temporal do vetor da quantidade de movimento angular de acordo com a equação (2.23).

$\left[\begin{array}{c}T_{01}+M_{B x^{\prime}} \\ T_{12}-M_{A y^{\prime}} \\ M_{B z^{\prime}}-M_{A z^{\prime}}\end{array}\right]=\mathbf{M}_{O}^{(1)}=\frac{d \mathbf{H}_{O}^{(1)}}{d t}=\mathrm{Q} \dot{\mathbf{H}}_{O}^{(1)}+\mathrm{Q} \tilde{\boldsymbol{\omega}}_{\mathrm{Q}}^{(1)} \mathrm{Q} \mathbf{H}_{O}^{(1)}$

A derivada local de um vetor será sempre indicada por um ponto sobre o símbolo do vetor.

De acordo com o teorema de Steiner ou teorema dos eixos paralelos, pode-se escrever a matriz de inércia do corpo 1 em relação ao ponto $\mathrm{O}$ da seguinte maneira: $\mathbf{I}_{O}^{(1)}=\mathbf{I}_{C G 1}^{(1)}-m_{1 C G 1} \tilde{\mathbf{r}}_{O}^{2} \mathrm{e}$, portanto, a quantidade de movimento angular pode ser escrita $\mathbf{H}_{O}^{(1)}=\mathbf{I}_{O}^{(1)} \boldsymbol{\omega}_{Q}^{(1)}=\left(\mathbf{I}_{C G 1}^{(1)}-m_{1 C G 1} \tilde{\mathbf{r}}_{O}^{2}\right) \boldsymbol{\omega}_{Q}^{(1)}$. Desenvolvendo o vetor de quantidade de movimento angular para o corpo 1 e utilizando a equação (2.16) e (2.22), obtém-se:

$$
\begin{aligned}
\mathbf{H}_{O}^{(1)} & =\left(\left[\begin{array}{ccc}
I_{1 x} & 0 & 0 \\
0 & I_{1 y} & 0 \\
0 & 0 & I_{1 z}
\end{array}\right]-m_{1}\left[\begin{array}{ccc}
0 & 0 & 0 \\
0 & 0 & -l_{1}+h_{1} \\
0 & l_{1}-h_{1} & 0
\end{array}\right]^{2}\right)\left[\begin{array}{l}
\dot{\alpha} \\
0 \\
0
\end{array}\right] \\
\mathbf{H}_{O}^{(1)} & =\left[\begin{array}{ccc}
I_{1 x} & 0 & 0 \\
0 & I_{1 y}+m_{1}\left(l_{1}-h_{1}\right)^{2} & 0 \\
0 & 0 & I_{1 z}+m_{1}\left(l_{1}-h_{1}\right)^{2}
\end{array}\right]\left[\begin{array}{l}
\dot{\alpha} \\
0 \\
0
\end{array}\right]=\left[\begin{array}{c}
I_{1 x} \dot{\alpha} \\
0 \\
0
\end{array}\right]
\end{aligned}
$$

A quantidade de movimento angular do corpo 1, mostrada na equação (2.24), possui apenas a coordenada em $x$, e, ao usar a equação (2.23), é possível obter $\left.\mathbf{M}_{O}^{(1)}\right|_{x}=I_{1 x} \ddot{\alpha}$. Realizando o somatório dos momentos no SR Q, identificados na Figura 2-2, tem-se os seguintes momentos: $T_{01}$ - Torque do Motor Alpha; $T_{12}$ - Torque do Motor Beta; $M_{B x^{\prime}}$ - Momento de reação do corpo 2 no corpo 1 em x'; $M_{B z^{\prime}}$ - Momento de reação do corpo 2 no corpo 1 em z'; $M_{A y}$ - Momento de Reação da Base em y; $M_{A z}$ - Momento de Reação da Base em z. No entanto é importante transformar $M_{A y}$ e $M_{A z}$ do SR F para Q, resultando em $M_{A y^{\prime}}$ Momento de Reação da Base em y'; $M_{A z^{\prime}}$ - Momento de Reação da Base em z', conforme a equação (2.25).

$$
\mathrm{Q} \mathbf{M}_{A}=\left[\begin{array}{c}
0 \\
M_{A y^{\prime}} \\
M_{A z^{\prime}}
\end{array}\right]=\mathrm{Q} \mathbf{T}^{\mathrm{F} \mathrm{F}} \mathbf{M}_{A}=\left[\begin{array}{ccc}
1 & 0 & 0 \\
0 & c_{\alpha} & -s_{\alpha} \\
0 & s_{\alpha} & c_{\alpha}
\end{array}\right]\left[\begin{array}{c}
0 \\
M_{A y} \\
M_{A z}
\end{array}\right]
$$

Logo, a dinâmica do corpo 1 é obtida conforme eq. (2.26):

$$
\left[\begin{array}{c}
T_{01}+M_{B x^{\prime}} \\
T_{12}-M_{A y^{\prime}} \\
M_{B z^{\prime}}-M_{A z^{\prime}}
\end{array}\right]=\left[\begin{array}{c}
I_{1 x} \ddot{\alpha} \\
0 \\
0
\end{array}\right]
$$


Aplicando a Lei de Newton/Euler para o corpo 2 no ponto O e embarcando no SR R resulta na equação (2.27), e conforme Figura 2-3, relaciona-se os momentos ainda não descritos: $T_{23}$ - Torque do Motor Gama; $M_{C x^{\prime \prime}}$ - Momento de Reação do corpo 3 no corpo 2 em x"; $M_{C y^{\prime \prime}}$ - Momento de Reação do corpo 3 no corpo 2 em y'.

$$
\left[\begin{array}{c}
M_{C x^{\prime \prime}} \\
M_{C y^{\prime \prime}} \\
-T_{23}
\end{array}\right]+{ }^{\mathrm{R}} \mathbf{T} \mathrm{Q}\left[\begin{array}{c}
-M_{B x^{\prime}} \\
-T_{12} \\
-M_{B z^{\prime}}
\end{array}\right]=\mathbf{M}_{O}^{(2)}={ }^{\mathrm{R}} \dot{\mathbf{H}}_{O}^{(2)}+{ }^{\mathrm{R}} \tilde{\boldsymbol{\omega}}_{\mathrm{R}}^{(2)} \mathrm{R} \mathbf{H}_{O}^{(2)}
$$

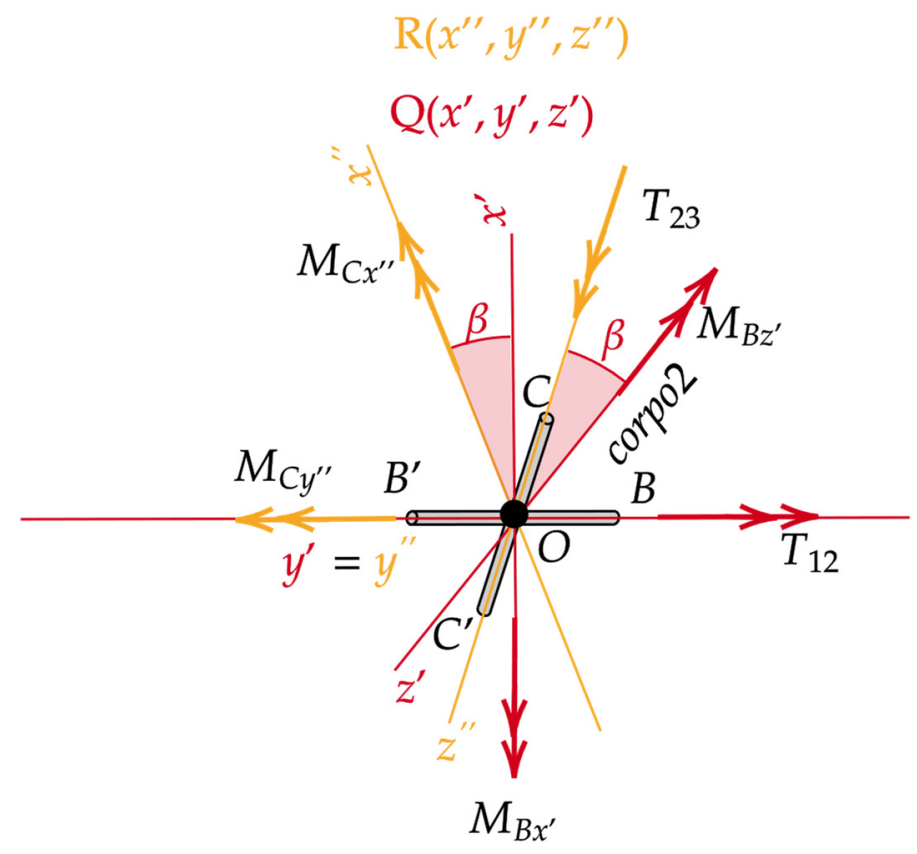

Figura 2-3 - DCL do corpo 2 do manipulador cardânico. [Fonte: Autoria própria]

O segundo termo do lado esquerdo da equação (2.27) contém momentos no SR Q, sendo necessário transformá-los para o SR R, resultando na equação (2.28).

$\mathrm{R} \mathbf{T} \mathrm{Q}\left[\begin{array}{c}-M_{B x^{\prime}} \\ -T_{12} \\ -M_{B z^{\prime}}\end{array}\right]=\left[\begin{array}{ccc}c_{\beta} & 0 & -s_{\beta} \\ 0 & 1 & 0 \\ s_{\beta} & 0 & c_{\beta}\end{array}\right]\left[\begin{array}{c}-M_{B x^{\prime}} \\ -T_{12} \\ -M_{B z^{\prime}}^{2}\end{array}\right]=\left[\begin{array}{c}-M_{B x^{\prime}} c_{\beta}+M_{B z^{\prime}} s_{\beta} \\ -T_{12} \\ -M_{B x^{\prime}} s_{\beta}-M_{B z^{\prime}} c_{\beta}\end{array}\right]$

Para a resolução do segundo termo do lado direito da equação (2.27) se faz necessário multiplicar a matriz "til" da velocidade angular do corpo 2 no SR R pelo vetor da quantidade de movimento angular do corpo 2 no ponto $\mathrm{O}$ e escrito no SR R, dado pela equação (2.29). Resulta a equação (2.30). 


$$
\begin{gathered}
{ }_{\mathrm{R}} \mathbf{H}_{O}^{(2)}=\mathrm{R} \mathbf{I}_{O}^{(2)}{ }_{\mathrm{R}} \boldsymbol{\omega}_{\mathrm{R}}^{(2)}=\left[\begin{array}{ccc}
I_{2 x} & 0 & 0 \\
0 & I_{2 y} & 0 \\
0 & 0 & I_{2 z}
\end{array}\right]\left[\begin{array}{c}
\dot{\alpha} c_{\beta} \\
\dot{\beta} \\
\dot{\alpha} s_{\beta}
\end{array}\right]=\left[\begin{array}{c}
I_{2 x} \dot{\alpha} c_{\beta} \\
I_{2 y} \dot{\beta} \\
I_{2 z} \dot{\alpha} s_{\beta}
\end{array}\right] \\
{ }^{\mathrm{R}} \tilde{\boldsymbol{\omega}}_{\mathrm{R}}^{(2)} \mathrm{R} \mathbf{H}_{O}^{(2)}=\left[\begin{array}{ccc}
0 & -\dot{\alpha} s_{\beta} & \dot{\beta} \\
\dot{\alpha} s_{\beta} & 0 & -\dot{\alpha} c_{\beta} \\
-\dot{\beta} & \dot{\alpha} c_{\beta} & 0
\end{array}\right]\left[\begin{array}{c}
I_{2 x} \dot{\alpha} c_{\beta} \\
I_{2 y} \dot{\beta} \\
I_{2 z} \dot{\alpha} s_{\beta}
\end{array}\right]=\left[\begin{array}{c}
\left(I_{2 z}-I_{2 y}\right) \dot{\alpha} \dot{\beta} s_{\beta} \\
\left(I_{2 x}-I_{2 z}\right) \dot{\alpha} s_{\beta} c_{\beta} \\
\left(I_{2 y}-I_{2 x}\right) \dot{\alpha} \dot{\beta} c_{\beta}
\end{array}\right]
\end{gathered}
$$

Resolvendo o primeiro termo do lado direito da equação (2.27) derivando a equação (2.29) é possível obter a equação (2.31).

$$
{ }^{\mathrm{R}} \dot{\mathbf{H}}_{O}^{(2)}=\left[\begin{array}{c}
I_{2 x}\left(\ddot{\alpha} c_{\beta}-\dot{\alpha} \dot{\beta} s_{\beta}\right) \\
I_{2 y} \ddot{\beta} \\
I_{2 z}\left(\ddot{\alpha} s_{\beta}+\dot{\alpha} \dot{\beta} c_{\beta}\right)
\end{array}\right]
$$

Portanto para o corpo 2 é possível obter as seguintes equações de movimento:

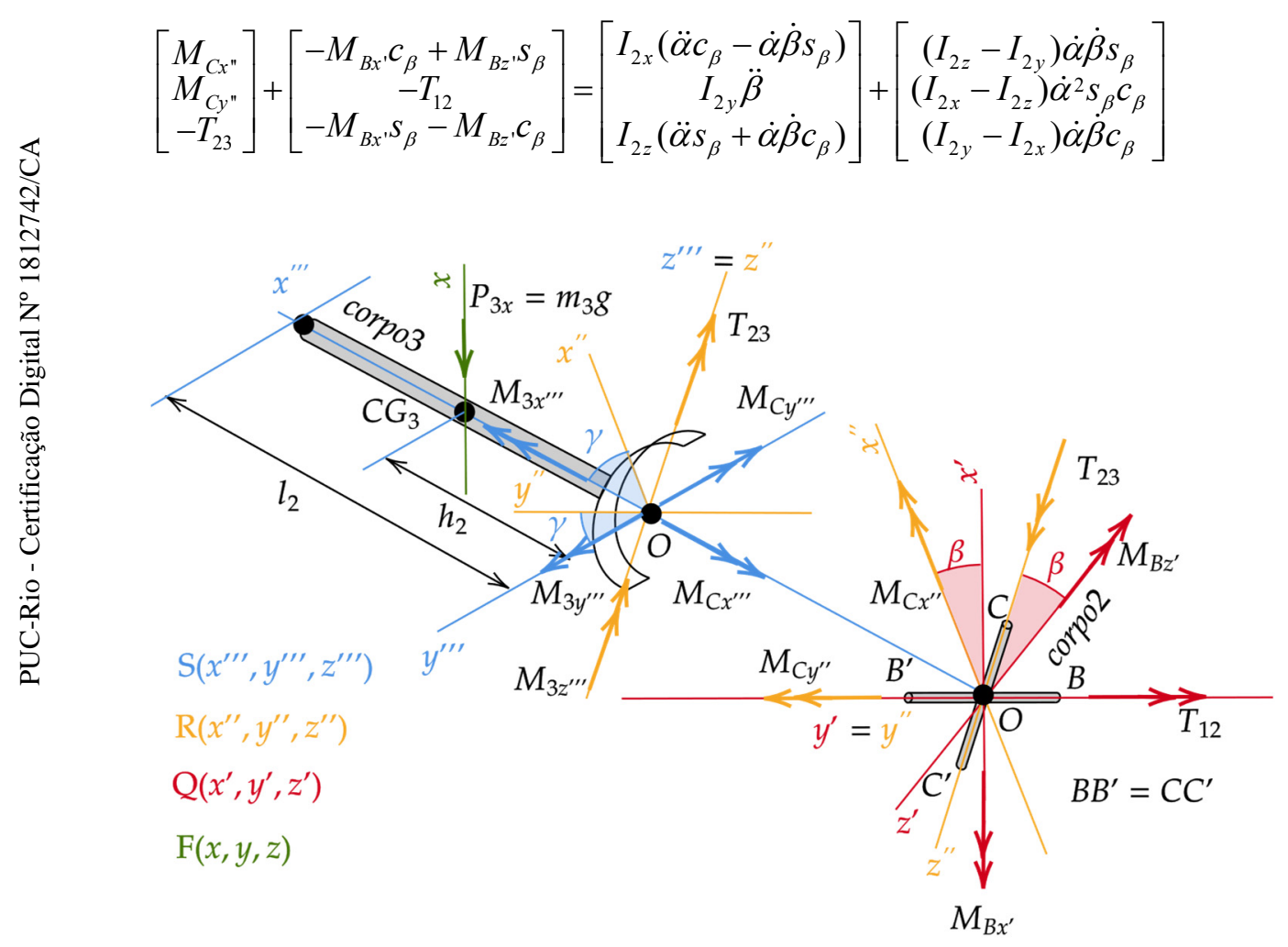

Figura 2-4 - DCL do corpo 3 do manipulador cardânico. [Fonte: Autoria própria]

Aplicando a Lei de Newton/Euler para o corpo 3 no SR R no ponto fixo O, conforme Figura 2-4, e descrevendo os carregamentos ainda não descritos para o corpo 3 em R no ponto $\mathrm{O}$, tem-se: $M_{C x^{m}}$ - Momento de Reação do corpo 2 no corpo 3 em x"”; $M_{C y^{\prime \prime}}$ - Momento de Reação do corpo 2 no corpo 3 em y",'; s $\mathbf{M}_{3}=\left[\begin{array}{lll}M_{3 x^{\prime \prime \prime}} & M_{3 y " \prime} & M_{3 z^{\prime \prime \prime}}\end{array}\right]^{T}-$ Momento no SR S 
devido à força peso ${ }^{\mathrm{F}} \mathbf{P}_{3}=\left[\begin{array}{lll}P_{3 x} & 0 & 0\end{array}\right]^{T}$. A equação de movimento (2.33) para o corpo 3 será:

$\left[\begin{array}{c}-M_{C x^{\prime \prime}} \\ -M_{C y^{\prime \prime}} \\ T_{23}\end{array}\right]+{ }^{\mathrm{R}} \mathbf{T}^{\mathrm{S} \mathrm{S}} \mathbf{M}_{3}={ }^{\mathrm{R}} \dot{\mathbf{H}}_{O}^{(3)}+{ }^{\mathrm{R}} \tilde{\boldsymbol{\omega}}_{\mathrm{S}}^{(3)}{ }^{\mathrm{R}} \mathbf{H}_{O}^{(3)}$

Para desenvolver o segundo termo do lado esquerdo da equação (2.33) é importante perceber que o momento ${ }^{\mathrm{S}} \mathbf{M}_{3}$, proveniente do peso próprio do corpo $3{ }^{\mathrm{F}} \mathbf{P}_{3}$ representado em seu centro de gravidade $C G_{3}$, encontra-se no $\mathrm{SR} F$, sendo necessária sua transformação para o SR S, resultando na equação (2.34).

${ }^{\mathrm{S}} \mathbf{M}_{3}={ }_{C G 3}^{\mathrm{S}} \tilde{\mathbf{r}}_{O}\left({ }^{\mathrm{S}} \mathbf{T}^{\mathrm{F} F} \mathbf{P}_{3}\right)$

O momento de reação ${ }^{\mathrm{S}} \mathbf{M}_{C}$ no corpo 3 mostrado na Figura 2-4 encontra-se do SR S e necessita ser transformado para o SR R, portanto ${ }^{\mathrm{R}} \mathbf{M}_{C}={ }^{\mathrm{R}} \mathbf{T}^{\mathrm{S} \mathrm{S}} \mathbf{M}_{C}$. A velocidade angular do corpo 3 em SR R, ${ }_{\mathrm{F}}^{\mathrm{R}} \boldsymbol{\omega}_{\mathrm{S}}^{(3)}$ do lado direito da equação (2.33) pode ser escrita conforme a equação (2.35)

$$
{ }_{\mathrm{F}}^{\mathrm{R}} \boldsymbol{\omega}_{\mathrm{S}}^{(3)}={ }_{\mathrm{F}}^{\mathrm{R}} \boldsymbol{\omega}_{\mathrm{Q}}^{(3)}+{ }_{\mathrm{Q}}^{\mathrm{R}} \boldsymbol{\omega}_{\mathrm{R}}^{(3)}+{ }_{\mathrm{R}}^{\mathrm{R}} \boldsymbol{\omega}_{\mathrm{S}}^{(3)}=\left[\begin{array}{c}
\dot{\alpha} c_{\beta} \\
\dot{\beta} \\
\dot{\alpha} s_{\beta}+\dot{\gamma}
\end{array}\right]
$$

Dessa forma, a quantidade de movimento angular do corpo 3, representada no lado direito da equação (2.33), pode ser escrita usando a equação (2.36), realizando o produto entre o tensor de inércia do corpo 3 com a sua velocidade angular. No entanto é necessário transladar o tensor de inércia no SR R do ponto $C G 3$ para o ponto $O$, usando o teorema de Steiner ou teorema dos eixos paralelos.

$$
{ }^{\mathrm{R}} \mathbf{H}_{O}^{(3)}={ }^{\mathrm{R}} \mathbf{I}_{O}^{(3)}{ }_{\mathrm{F}}^{\mathrm{R}} \boldsymbol{\omega}_{\mathrm{R}}^{(3)}=\left({ }^{\mathrm{R}} \mathbf{I}_{C G 3}^{(3)}-m_{3 \rightarrow G 3}{ }_{C G 3}^{\mathrm{R}} \tilde{\mathbf{r}}_{O}^{2}\right){ }_{\mathrm{F}}^{\mathrm{R}} \boldsymbol{\omega}_{\mathrm{R}}^{(3)}
$$

A transformação, mostrada na equação (2.37), do SR S para o SR R, dos momentos principais de inércia do corpo 3 , permite escrever o tensor de inércia no mesmo SR da equação (2.36).

$$
{ }^{\mathrm{R}} \mathbf{I}_{C G 3}^{(3)}={ }^{\mathrm{R}} \mathbf{T}^{\mathrm{S} \mathrm{S}} \mathbf{I}_{C G 3}^{(3)} \mathrm{s} \mathbf{T}^{\mathrm{R}}=\left[\begin{array}{ccc}
I_{3 x} c_{\gamma}^{2}+I_{3 y} s_{\gamma}^{2} & \left(I_{3 x}-I_{3 y}\right) c_{\gamma} s_{\gamma} & 0 \\
\left(I_{3 x}-I_{3 y}\right) c_{\gamma} s_{\gamma} & I_{3 x} s_{\gamma}^{2}+I_{3 y} c_{\gamma}^{2} & 0 \\
0 & 0 & I_{3 z}
\end{array}\right]
$$

De forma semelhante à transformação do vetor ${ }_{C G 3}^{\mathrm{S}} \mathbf{r}_{O}$ para $\underset{C G 3}{\mathrm{R}} \mathbf{r}_{O}$ pode ser escrita conforme equação (2.38). 


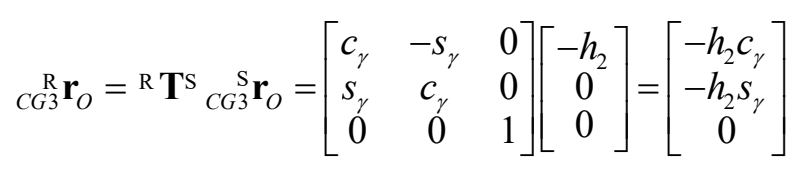

Escrevendo a quantidade de movimento angular em função dos ângulos cardânicos e das inércias do corpo 3 é possível obter a equação (2.39).

$$
{ }^{\mathrm{R}} \mathbf{H}_{O}^{(3)}=\left[\begin{array}{c}
I_{3 x} \dot{\alpha} c_{\gamma}^{2} c_{\beta}+\left(I_{3 y}+m_{3} h_{2}^{2}\right) \dot{\alpha} s_{\gamma}^{2} c_{\beta}+\left(I_{3 x}-I_{3 y}-m_{3} h_{2}^{2}\right) \dot{\beta} s_{\gamma} c_{\gamma} \\
\left(I_{3 x}-I_{3 y}-m_{3} h_{2}^{2}\right) \dot{\alpha} c_{\beta} s_{\gamma} c_{\gamma}+I_{3 x} \dot{\beta} s_{\gamma}^{2}+\left(I_{3 y}+m_{3} h_{2}^{2}\right) \dot{\beta} c_{\gamma}^{2} \\
\left(I_{3 z}+m_{3} h_{2}^{2}\right)\left(\dot{\alpha} s_{\beta}+\dot{\gamma}\right)
\end{array}\right]
$$

Voltando à equação (2.33), o desenvolvimento do segundo termo do lado direito também pode ser escrito em função das variáveis de entrada do problema conforme a equação (2.40) $a_{1}=\mid \begin{aligned} & -\left\{\left(I_{3 x}-I_{3 y}-m_{3} h_{2}^{2}\right) \dot{\alpha} c_{\beta} s_{\gamma} c_{\gamma}+I_{3 x} \dot{\beta} s_{\gamma}^{2}+\left(I_{3 y}+m_{3} h_{2}^{2}\right) \dot{\beta} c_{\gamma}^{2}\right\}\left(\dot{\alpha} s_{\beta}+\dot{\gamma}\right)+ \\ & +\left\{\left(I_{3 z}+m_{3} h_{2}^{2}\right) \dot{\alpha} s_{\beta}+\left(I_{3 z}+m_{3} h_{2}^{2}\right) \dot{\gamma}\right\} \dot{\beta}\end{aligned}$
$a_{2}=\mid \begin{aligned} & \left\{I_{3 x} \dot{\alpha} c_{\gamma}^{2} c_{\beta}+\left(I_{3 y}+m_{3} h_{2}^{2}\right) \dot{\alpha} s_{\gamma}^{2} c_{\beta}+\left(I_{3 x}-I_{3 y}-m_{3} h_{2}^{2}\right) \dot{\beta} s_{\gamma} c_{\gamma}\right\}\left(\dot{\alpha} s_{\beta}+\dot{\gamma}\right)+ \\ & -\left\{\left(I_{3 z}+m_{3} h_{2}^{2}\right) \dot{\alpha} s_{\beta}+\left(I_{3 z}+m_{3} h_{2}^{2}\right) \dot{\gamma}\right\} \dot{\alpha} c_{\beta}\end{aligned}$

$a_{3}=\mid \begin{aligned} & -\left\{I_{3 x} \dot{\alpha} c_{\gamma}^{2} c_{\beta}+\left(I_{3 y}+m_{3} h_{2}^{2}\right) \dot{\alpha} s_{\gamma}^{2} c_{\beta}+\left(I_{3 x}-I_{3 y}-m_{3} h_{2}^{2}\right) \dot{\beta} s_{\gamma} c_{\gamma}\right\} \dot{\beta}+ \\ & +\left\{\left(I_{3 x}-I_{3 y}-m_{3} h_{2}^{2}\right) \dot{\alpha} c_{\beta} s_{\gamma} c_{\gamma}+I_{3 x} \dot{\beta} s_{\gamma}^{2}+\left(I_{3 y}+m_{3} h_{2}^{2}\right) \dot{\beta} c_{\gamma}^{2}\right\} \dot{\alpha} c_{\beta}\end{aligned}$

${ }^{\mathrm{R}} \tilde{\boldsymbol{\omega}}_{\mathrm{R}}^{(3) \mathrm{R}} \mathbf{H}_{O}^{(3)}=\left[\begin{array}{l}a_{1} \\ a_{2} \\ a_{3}\end{array}\right]$

Realizando a derivada da quantidade de movimento angular da equação (2.39) é possível obter a equação (2.41).

$$
\begin{aligned}
& b_{1}=\mid \begin{array}{l}
I_{3 x}\left(\ddot{\alpha} c_{\gamma}^{2} c_{\beta}-2 \dot{\alpha} \dot{\gamma} s_{\gamma} c_{\gamma} c_{\beta}-\dot{\alpha} \dot{\beta} c_{\gamma}^{2} s_{\beta}\right)+ \\
+\left(I_{3 y}+m_{3} h_{2}^{2}\right)\left(\ddot{\alpha} s_{\gamma}^{2} c_{\beta}+2 \dot{\alpha} \dot{\gamma} s_{\gamma} c_{\gamma} c_{\beta}-\dot{\alpha} \dot{\beta} s_{\gamma}^{2} s_{\beta}\right)+ \\
+\left(I_{3 x}-I_{3 y}-m_{3} h_{2}^{2}\right)\left(\ddot{\beta} s_{\gamma} c_{\gamma}+\dot{\beta} \dot{\gamma} c_{\gamma} c_{\gamma}-\dot{\beta} \dot{\gamma} s_{\gamma} s_{\gamma}\right)
\end{array} \\
& b_{2}=\left\{\begin{array}{l}
\left(I_{3 x}-I_{3 y}-m_{3} h_{2}^{2}\right)\left(\ddot{\alpha} c_{\beta} s_{\gamma} c_{\gamma}-\dot{\alpha} \dot{\beta} s_{\beta} s_{\gamma} c_{\gamma}+\dot{\alpha} \dot{\gamma} c_{\beta} c_{\gamma} c_{\gamma}-\dot{\alpha} \dot{\gamma} c_{\beta} s_{\gamma} s_{\gamma}\right)+ \\
+I_{3 x}\left(\ddot{\beta} s_{\gamma}^{2}+2 \dot{\beta} \dot{\gamma} s_{\gamma} c_{\gamma}\right)+\left(I_{3 y}+m_{3} h_{2}^{2}\right)\left(\ddot{\beta} c_{\gamma}^{2}-2 \dot{\beta} \dot{\gamma} c_{\gamma} s_{\gamma}\right)
\end{array}\right. \\
& b_{3}=\mid\left(I_{3 z}+m_{3} h_{2}^{2}\right)\left(\ddot{\alpha} s_{\beta}+\dot{\alpha} \dot{\beta} c_{\beta}+\ddot{\gamma}\right) \\
& { }^{\mathrm{R}} \dot{\mathbf{H}}_{O}^{(3)}=\left[\begin{array}{l}
b_{1} \\
b_{2} \\
b_{3}
\end{array}\right]
\end{aligned}
$$

Voltando à equação (2.34), é possível agora resolver o segundo termo do lado esquerdo da equação (2.33) obtendo a equação (2.42). 
${ }^{\mathrm{R}} \mathbf{T}^{\mathrm{S}}\left({ }_{C G 3}^{\mathrm{S}} \tilde{\mathbf{r}}_{O}\left({ }^{\mathrm{S}} \mathbf{T}^{\mathrm{F} F} \mathbf{P}_{3}\right)\right)=m_{3} g h_{2}\left[\begin{array}{c}-s_{\beta} s_{\gamma} \\ s_{\beta} c_{\gamma} \\ c_{\beta} s_{\gamma}\end{array}\right]$

Portanto, para o corpo 3, obtêm-se as seguintes equações de movimento:

$$
\left[\begin{array}{c}
-M_{C x^{\prime \prime}} \\
-M_{C y "} \\
T_{23}
\end{array}\right]=-m_{3} g h_{2}\left[\begin{array}{c}
-s_{\beta} s_{\gamma} \\
s_{\beta} c_{\gamma} \\
c_{\beta} s_{\gamma}
\end{array}\right]+\left[\begin{array}{l}
b_{1} \\
b_{2} \\
b_{3}
\end{array}\right]+\left[\begin{array}{l}
a_{1} \\
a_{2} \\
a_{3}
\end{array}\right]
$$

Condensando as equações (2.26), (2.32) e (2.43) através de funções das variáveis de entrada, $\Phi_{1 x}, \Phi_{2 x}, \Phi_{2 y}, \Phi_{2 z}, \Phi_{3 x}, \Phi_{3 y}$ e $\Phi_{3 z}$ é possível simplificar as equações de movimento conforme as equações:

Corpo 1 em Q:

$\left[\begin{array}{c}T_{01}+M_{B x^{\prime}} \\ T_{12}-M_{A y^{\prime}} \\ M_{B z^{\prime}}-M_{A z^{\prime}}\end{array}\right]=\left[\begin{array}{c}\Phi_{1 x}\left(I_{1}, \alpha, \dot{\alpha}, \ddot{\alpha}\right) \\ 0 \\ 0\end{array}\right]$

Corpo 2 em R:

$\left[\begin{array}{c}M_{C x^{\prime \prime}} \\ M_{C y^{\prime \prime}} \\ -T_{23}\end{array}\right]+\left[\begin{array}{c}-M_{B x^{\prime}} c_{\beta}+M_{B z} s_{\beta} \\ -T_{12} \\ -M_{B x^{\prime}} S_{\beta}-M_{B z} c_{\beta}\end{array}\right]=\left[\begin{array}{c}\Phi_{2 x}\left(I_{2}, \alpha, \beta, \dot{\alpha}, \dot{\beta}, \ddot{\alpha}, \ddot{\beta}\right) \\ \Phi_{2 y}\left(I_{2}, \alpha, \beta, \dot{\alpha}, \dot{\beta}, \ddot{\alpha}, \ddot{\beta}\right) \\ \Phi_{2 z}\left(I_{2}, \alpha, \beta, \dot{\alpha}, \dot{\beta}, \ddot{\alpha}, \ddot{\beta}\right)\end{array}\right]$

Corpo 3 em R:

$\left[\begin{array}{c}-M_{C x^{\prime \prime}} \\ -M_{C y^{\prime \prime}} \\ T_{23}\end{array}\right]=\left[\begin{array}{c}\Phi_{3 x}\left(I_{3}, m_{3}, h_{2}, \alpha, \beta, \gamma, \dot{\alpha}, \dot{\beta}, \dot{\gamma}, \ddot{\alpha}, \ddot{\beta}, \ddot{\gamma}\right) \\ \Phi_{3 y}\left(I_{3}, m_{3}, h_{2}, \alpha, \beta, \gamma, \dot{\alpha}, \dot{\beta}, \dot{\gamma}, \ddot{\alpha}, \ddot{\beta}, \ddot{\gamma}\right) \\ \Phi_{3 z}\left(I_{3}, m_{3}, h_{2}, \alpha, \beta, \gamma, \dot{\alpha}, \dot{\beta}, \dot{\gamma}, \ddot{\alpha}, \ddot{\beta}, \ddot{\gamma}\right)\end{array}\right]$

Analisando as equações (2.44), (2.45) e (2.46), observam-se nove equações com três torques $T_{01}, T_{12}$ e $T_{23}$, e seis momentos de reação $M_{A y^{\prime}}, M_{A z^{\prime}}, M_{B x^{\prime}}, M_{B z^{\prime}}, M_{C x^{\prime \prime}}$ e $M_{C y^{\prime \prime}}$

. Como os ângulos cardânicos $(\alpha, \beta$ e $\gamma)$ são obtidos através da cinemática inversa do movimento desejado, após as operações das equações, é possível encontrar as equações dos momentos de reação e dos torques em função das variáveis de entrada, conforme a equação (2.47). 


$$
\left[\begin{array}{c}
M_{A y^{\prime}} \\
M_{A z^{\prime}} \\
M_{B x^{\prime}} \\
M_{B z^{\prime}} \\
M_{C x^{\prime \prime}} \\
M_{C y^{\prime \prime}} \\
T_{23} \\
T_{12} \\
T_{01}
\end{array}\right]=\left[\begin{array}{c}
-\left(\Phi_{2 y}+\Phi_{3 y}\right) \\
\frac{\left(\Phi_{2 x}+\Phi_{3 x}\right)\left(1-c_{\beta}\right)}{s_{\beta}}-\left(\Phi_{2 z}+\Phi_{3 z}\right) \\
-\left[\left(\Phi_{2 x}+\Phi_{3 x}\right) c_{\beta}+\left(\Phi_{2 z}+\Phi_{3 z}\right) s_{\beta}\right] \\
\frac{\left(\Phi_{2 x}+\Phi_{3 x}\right)\left(1-c_{\beta}\right)}{s_{\beta}}-\left(\Phi_{2 z}+\Phi_{3 z}\right) \\
-\Phi_{3 x} \\
-\Phi_{3 y} \\
\Phi_{3 z} \\
-\left(\Phi_{3 y}+\Phi_{2 y}\right) \\
\Phi_{1 x}+\left(\Phi_{2 x}+\Phi_{3 x}\right) c_{\beta}+\left(\Phi_{2 z}+\Phi_{3 z}\right) s_{\beta}
\end{array}\right]
$$

Portanto, as dinâmicas direta e inversa estão interligadas, uma vez que, para o caso da dinâmica direta, o momento gerado pelo peso próprio do corpo 3 passa a ser um carregamento que permite conhecer a cinemática do manipulador de acordo com o segundo termo do lado esquerdo da equação (2.33). Outra situação a explorar na dinâmica direta seria considerar a ausência de torque dos motores, por exemplo, $T_{01}=0$ e/ou $T_{12}=0$ e/ou $T_{23}=0$, e dessa forma também seria possível obter as variáveis de estado $(\alpha, \beta, \gamma, \dot{\alpha}, \dot{\beta}, \dot{\gamma}, \ddot{\alpha}, \ddot{\beta}, \ddot{\gamma})$ do problema resolvendo numericamente o sistema de equações diferenciais não lineares. No entanto o objetivo deste trabalho foi o de resolver a dinâmica inversa para conhecer os momentos das reações e os torques necessários através da cinemática proposta, isto é, conhecer os esforços dinâmicos envolvidos a partir das variáveis de estado da junta cardânica.

\subsubsection{Torque de atrito dos rolamentos}

Com o intuito de criar um modelo mais assertivo da junta cardânica foram considerados os torques resistivos gerados pelos atritos presentes nos rolamentos de esfera e de agulha do experimento proposto, conforme Figura 2-5. O item 1 indicado corresponde aos rolamentos dos motores modelo SKF $625-2 Z$, que possuem $5 \mathrm{~mm}$ de diâmetro interno, $16 \mathrm{~mm}$ de diâmetro externo, $5 \mathrm{~mm}$ de largura, classificação básica para carga dinâmica $C=1,14 \mathrm{kN}$ e a classificação básica para carga estática $C_{0}=0,38 \mathrm{kN}$. O item 2 indicado corresponde aos rolamentos dos redutores modelo SKF W619/8-2Z ou similar com $8 \mathrm{~mm}$ de diâmetro interno, $19 \mathrm{~mm}$ de diâmetro externo, $6 \mathrm{~mm}$ de largura, classificação básica para carga dinâmica $C=1,25 \mathrm{kN}$ e a classificação básica para carga estática $C_{0}=0,45 \mathrm{kN}$. O item 3 corresponde aos apoios para garantir a estabilidade do corpo 1, composto por dois rolamentos no eixo $x$ do SR F modelo SFK 6205-2Z com 25 mm de diâmetro interno, 52 
mm de diâmetro externo, 15 mm de largura, classificação básica para carga dinâmica $C=14,8 \mathrm{kN}$ e a classificação básica para carga estática $C_{0}=7,8 \mathrm{kN}$. O item 4 é o rolamento da junta universal ASH B04C625 utilizado na área automobilística e, para critérios de cálculos, foi utilizado, por similaridade, o rolamento de rolos de agulha com anéis usinados sem o uso de um anel interno da SKF modelo RNA 4901, com $16 \mathrm{~mm}$ de diâmetro interno, $24 \mathrm{~mm}$ de diâmetro externo, $13 \mathrm{~mm}$ de largura, classificação básica para carga dinâmica $C=9,9 \mathrm{kN}$ e a classificação básica para carga estática $C_{0}=12,2 \mathrm{kN}$. O atrito de rolamento não é constante e depende de certos fenômenos tribológicos que ocorrem no filme lubrificante entre os corpos rolantes, as pistas e as gaiolas. A força radial do rolamento $F_{r}$ necessária para o cálculo do atrito é obtida mediante o equilíbrio hiperestático dos momentos de reações de cada corpo rígido, e a força axial $F_{a 1}$ do esquema de rolamento do corpo 1 apenas dependerá do vetor peso dos corpos rígidos envolvidos.

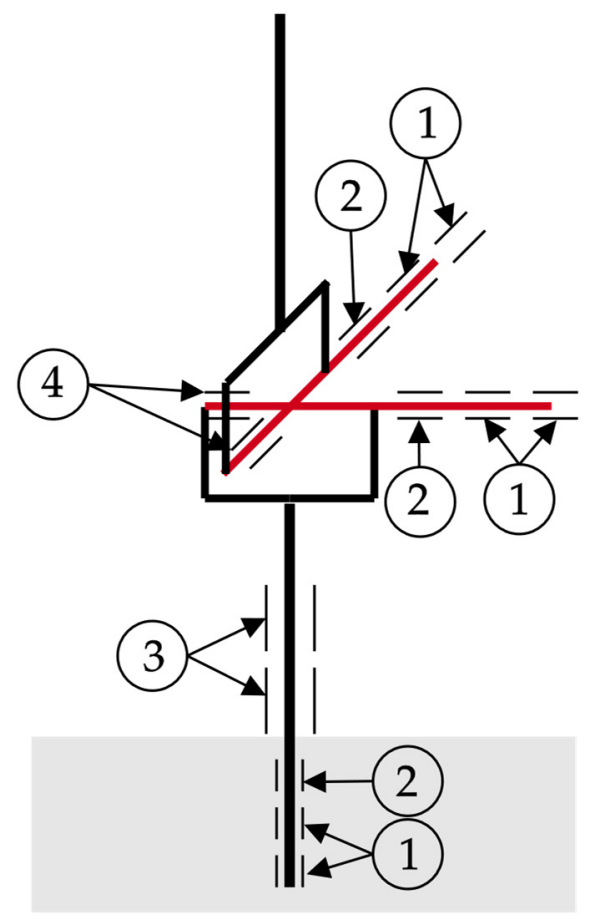

Figura 2-5 - Localização dos rolamentos no experimento da junta cardânica ativa [Fonte: Autoria própria]

No entanto é importante visualizar que o centro de gravidade do corpo 3 encontra-se em movimento conforme a equação (2.48). Devido à característica construtiva, apenas um dos rolamentos SKF 6205-Z (item3) suporta o peso da estrutura através de um anel de travamento. 
$F_{a 1}=P_{1}+P_{2}+P_{3}=m_{1} g+m_{2} g+m_{3}\left(g+\ddot{x}_{C G 3}\right)$, onde $x_{C G 3}={ }_{o} r_{C G 3}\left(c_{\beta} c_{\gamma}\right)$.

Consequentemente, a velocidade e a aceleração do centro de gravidade do corpo $3 \mathrm{em}$ relação ao SR F podem ser escritas conforme eq. (2.49) e eq. (2.50).

$$
\begin{aligned}
& \dot{x}_{C G 3}=-{ }_{o} r_{C G 3}\left(s_{\beta} c_{\gamma} \dot{\beta}+c_{\beta} s_{\gamma} \dot{\gamma}\right) \\
& \ddot{x}_{C G 3}=-{ }_{O} r_{C G 3}\left(c_{\beta} c_{\gamma} \dot{\beta}^{2}+c_{\beta} c_{\gamma} \dot{\gamma}^{2}+s_{\beta} c_{\gamma} \ddot{\beta}+c_{\beta} s_{\gamma} \ddot{\gamma}-2 s_{\beta} s_{\gamma} \dot{\beta} \dot{\gamma}\right)
\end{aligned}
$$

Para o cálculo das forças radiais dos rolamentos do corpo 1 utilizando o SR Q, conforme Figura 2-2, é possível demonstrar que os momentos de reação em $z^{\prime}$ e $y^{\prime}$ são $M_{R l z^{\prime}}=M_{A z^{\prime}}$ e $M_{R 1 y^{\prime}}=M_{A y^{\prime}}$. Assim o momento de reação resultante pode ser escrito como $M_{R 1^{\prime}}=\sqrt{M_{R 1 z^{\prime}}^{2}+M_{R 1 y^{\prime}}^{2}}$ e, de acordo com a Figura 2-6, as equações de equilíbrio estático podem ser escritas conforme eq. (2.51).

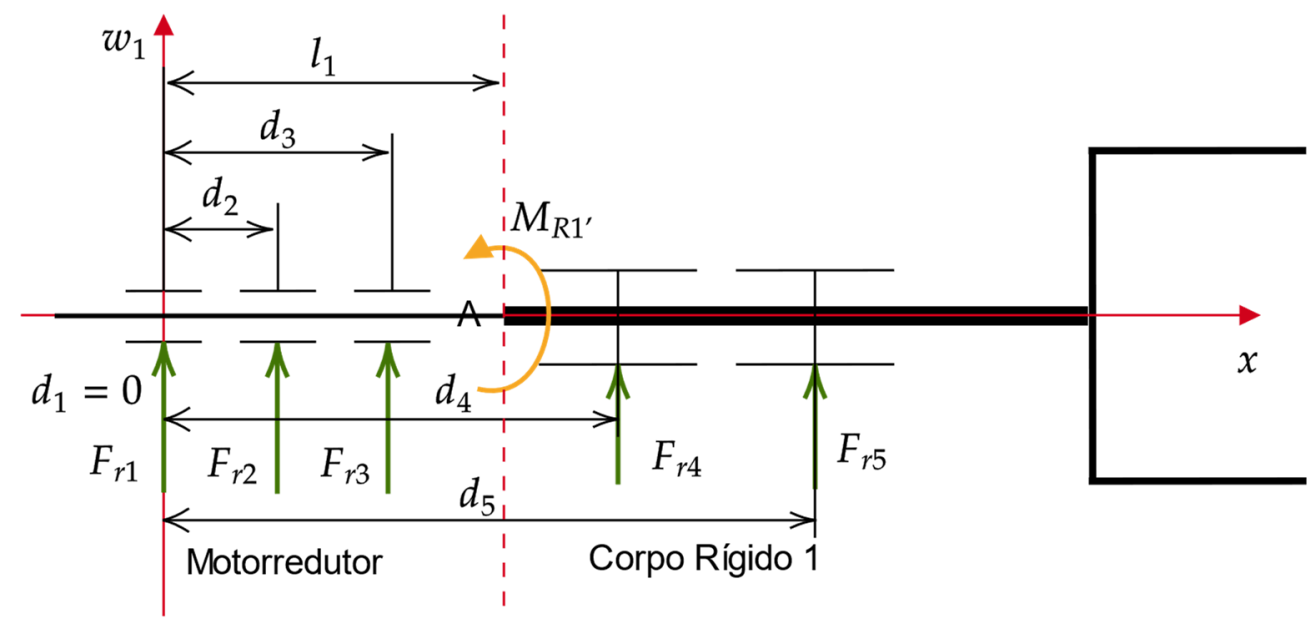

Figura 2-6 - Modelamento das forças radiais dos rolamentos do corpo 1 [Fonte: Autoria própria]

$$
\begin{aligned}
& 0=\sum_{i=1}^{5} F_{r i} \\
& M_{R 1^{\prime}}=\sum_{i=1}^{5} F_{r i} d_{i}
\end{aligned}
$$

Por ser um problema hiperestático, uma das soluções possíveis é desenvolver a equação do raio de curvatura de uma função, simplificada para pequenos deslocamentos usando as funções de Macaulay. Assim, o problema pode ser escrito conforme eq. (2.52).

$$
E I w_{1}(x)=-M_{R 1} \frac{\left\langle x-l_{1}\right\rangle^{2}}{2}+\sum_{i=1}^{2} \frac{F_{r i}}{6}\left\langle x-d_{i}\right\rangle^{3}+C_{1} x+C_{2} \text {, onde: } E I \text { constante. }
$$


É interessante observar que a constante $E I$ equivale ao produto do módulo de elasticidade pela inércia da seção transversal, no entanto o seu valor indefere ao considerar apoios ideais, ou seja, sem deformação. Assim, aplicando as condições de contorno identificadas na Figura 2-6 e considerando que os rolamentos são apoios ideais, obtém-se:

$$
E I w_{1}\left(d_{j}\right)=0=-M_{R 1^{\prime}} \frac{\left\langle d_{j}-l_{1}\right\rangle^{2}}{2}+\sum_{i=1}^{5} \frac{F_{r i}}{6}\left\langle d_{j}-d_{i}\right\rangle^{3}+C_{1} d_{j}+C_{2}, \quad j=1 . .5
$$

Desenvolvendo a equação em (2.53) é possível montar um sistema de equações para que as cinco forças radiais $F_{r i}$ e as duas constantes de integração $C_{1}$ e $C_{2}$ possam ser encontradas pelo sistema linear [7x7] na eq. (2.54).

$$
\left[\begin{array}{ccccccc}
1 & 1 & 1 & 1 & 1 & 0 & 0 \\
0 & d_{2} & d_{3} & d_{4} & d_{5} & 0 & 0 \\
0 & 0 & 0 & 0 & 0 & 0 & 1 \\
\frac{d_{2}^{3}}{6} & 0 & 0 & 0 & 0 & d_{2} & 1 \\
\frac{d_{3}^{3}}{6} & \frac{\left(d_{3}-d_{2}\right)^{3}}{6} & 0 & 0 & 0 & d_{3} & 1 \\
\frac{d_{4}^{3}}{6} & \frac{\left(d_{4}-d_{2}\right)^{3}}{6} & \frac{\left(d_{4}-d_{3}\right)^{3}}{6} & 0 & 0 & d_{4} & 1 \\
\frac{d_{5}^{3}}{6} & \frac{\left(d_{5}-d_{2}\right)^{3}}{6} & \frac{\left(d_{5}-d_{3}\right)^{3}}{6} & \frac{\left(d_{5}-d_{4}\right)^{3}}{6} & 0 & d_{5} & 1
\end{array}\right]\left[\begin{array}{c}
F_{r 1} \\
F_{r 2} \\
F_{r 3} \\
F_{r 4} \\
F_{r_{5}} \\
C_{1} \\
C_{2}
\end{array}\right]=\left[\begin{array}{c}
0 \\
-M_{R 1^{\prime}} \\
0 \\
0 \\
M_{R 1^{\prime}} \frac{\left(d_{4}-l_{1}\right)^{2}}{2} \\
M_{R 1^{\prime}} \frac{\left(d_{5}-l_{1}\right)^{2}}{2}
\end{array}\right]
$$

Analisando as forças radiais para o corpo 2 é importante observar, na Figura 2-3 e na Figura 2-7, que o eixo $y^{\prime}=y^{\prime \prime}$ possui o mesmo conjunto de rolamentos que o eixo $z$ "' $=z$ ",". Analisando, primeiramente, o conjunto de rolamentos do eixo $y^{\prime}=y^{\prime \prime}$ é possível visualizar que no SR Q existem duas componentes, $M_{B z^{\prime}}$ e $M_{B x^{\prime}}$ onde a sua resultante $M_{B x z^{\prime}}=\sqrt{M_{B x^{\prime}}^{2}+M_{B z^{\prime}}^{2}}$ contribui para as forças radiais por estar no plano $x^{\prime} z^{\prime}$, e no SR R existem outras duas componentes, $M_{C x^{\prime \prime}}$ e $T_{23}$ onde a sua resultante $M_{C z^{\prime \prime}}=\sqrt{M_{C x^{n}}^{2}+T_{23}^{2}}$ também contribui para as forças radiais. No entanto essa última necessita ser transformada para o SR Q, Q $\mathbf{M}_{C^{\prime}}=\mathrm{Q}^{\mathrm{R} R} \mathrm{R}_{C^{\prime \prime}}$, onde as coordenadas $x$ ' e $z$ ' serão as novas componentes radiais. Assim, o momento resultante ${ }^{\mathrm{Q}} \mathbf{M}_{R 2}$, que contribui para as forças radiais do conjunto de rolamentos do eixo $y^{\prime}=y^{\prime \prime}$ pode ser escrito conforme equação (2.55), sendo o módulo $M_{R 2^{\prime}}$ e $\theta_{R 2}$ o ângulo entre o momento ${ }^{\mathrm{Q}} \mathbf{M}_{R 2^{\prime}}$ e o eixo $z$ '.

$$
\begin{aligned}
& \mathrm{Q} \mathbf{M}_{R 2^{\prime}}=\mathrm{Q} \mathbf{T}^{\mathrm{R} \mathrm{R}} \mathbf{M}_{C^{\prime \prime}}+\mathrm{Q} \mathbf{M}_{B^{\prime}}=\left[\begin{array}{c}
M_{C x^{\prime \prime}} c_{\beta}+T_{23} s_{\beta}+M_{B x^{\prime}} \\
0 \\
-M_{C x^{\prime \prime}} s_{\beta}+T_{23} c_{\beta}+M_{B z^{\prime}}
\end{array}\right] \\
& M_{R 2^{\prime}}=\sqrt{\left(M_{C x^{\prime \prime}} c_{\beta}+T_{23} s_{\beta}+M_{B x^{\prime}}\right)^{2}+\left(-M_{C x^{\prime \prime}} s_{\beta}+T_{23} c_{\beta}+M_{B z^{\prime}}\right)^{2}} \\
& \theta_{R 2^{\prime}}=\operatorname{atan}\left(\left(M_{C x^{\prime \prime}} c_{\beta}+T_{23^{\prime}} s_{\beta}+M_{B x^{\prime}}\right) /\left(-M_{C x^{\prime \prime}} s_{\beta}+T_{23} c_{\beta}+M_{B z^{\prime}}\right)\right)
\end{aligned}
$$


Analisando a Figura 2-3 e a Figura 2-7, no segundo conjunto de rolamentos $z$ "'=z', é possível observar que no SR R existem duas componentes, $M_{C x^{\prime \prime}}$ e $M_{C y^{\prime \prime}}-T_{12}$ onde a sua resultante $M_{C x y^{\prime \prime}}=\sqrt{M_{C x^{\prime \prime}}^{2}+\left(M_{C y^{\prime \prime}}-T_{12}\right)^{2}}$ contribui para as forças radiais por estar no plano x' $y^{\prime \prime}$, e no SR Q existem outras duas componentes, $M_{B z^{\prime}}$ e $M_{B x^{\prime}}$ onde a sua resultante $M_{B x z^{\prime}}=\sqrt{M_{B x^{\prime}}^{2}+M_{B z^{\prime}}^{2}}$ contribui para as forças radiais por estar no plano $x^{\prime} z^{\prime}$. No entanto é necessário realizar a transformação para o SR R, ${ }^{\mathrm{R}} \mathbf{M}_{B^{\prime \prime}}={ }^{\mathrm{R}} \mathbf{T} \mathrm{Q}$ Q $\mathbf{M}_{B^{\prime}}$, onde as coordenadas $x$ ' e $y$ "' serão as novas componentes radiais. Assim, o momento resultante que contribui para as forças radiais do segundo conjunto de rolamentos pode ser escrito conforme equação (2.56), sendo o $M_{R 3^{\prime \prime}}$ a resultante das componentes $x$ '” e $y$ ', de ${ }^{\mathrm{R}} \mathbf{M}_{R 3^{\prime \prime}}$, e $\theta_{R 3^{\prime \prime}} \mathrm{o}$ ângulo entre o momento resultante $M_{R 3^{\prime \prime}}$ e o eixo $y^{\prime \prime}$.

$$
\begin{aligned}
& { }^{\mathrm{R}} \mathbf{M}_{R 3^{\prime \prime}}={ }^{\mathrm{R}} \mathbf{T}^{\mathrm{Q}} \mathrm{Q} \mathbf{M}_{B^{\prime}}+\mathbf{M}_{C^{\prime \prime}}=\left[\begin{array}{c}
M_{B x^{\prime}} c_{\beta}-M_{B z^{\prime}} s_{\beta}+M_{C x^{\prime \prime}} \\
M_{C y^{\prime \prime}}-T_{12} \\
M_{B x^{\prime}} s_{\beta}+M_{B z} c_{\beta}
\end{array}\right] \\
& M_{R 3^{\prime \prime}}=\sqrt{\left(M_{B x^{\prime}} c_{\beta}-M_{B z} s_{\beta}+M_{C x^{\prime \prime}}\right)^{2}+\left(M_{C y^{\prime \prime}}-T_{12}\right)^{2}} \\
& \theta_{R 3^{\prime \prime}}=\operatorname{atan}\left(\left(M_{B x^{\prime}} c_{\beta}-M_{B z^{\prime}} s_{\beta}+M_{C x^{\prime \prime}}\right) /\left(M_{C y^{\prime \prime}}-T_{12}\right)\right)
\end{aligned}
$$

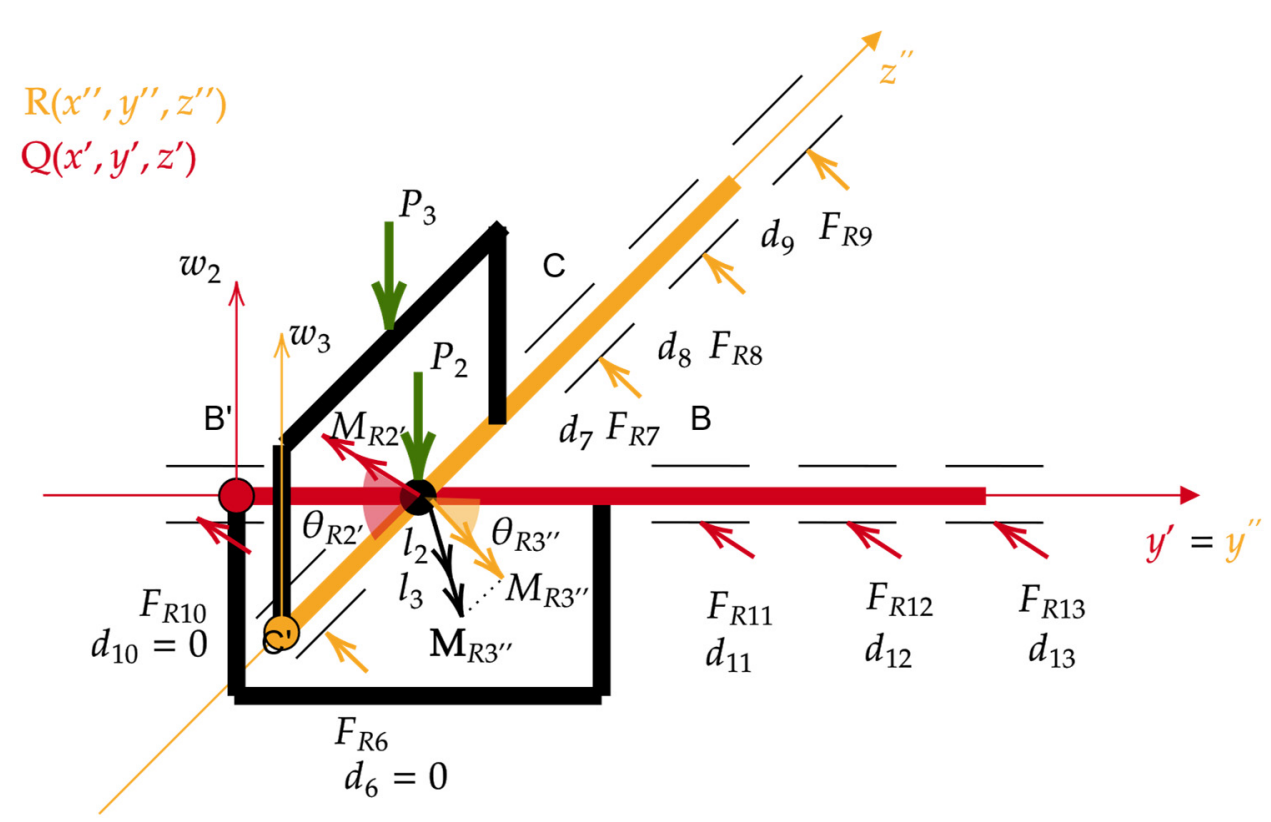

Figura 2-7 - Modelamento simplificado das forças radiais dos rolamentos do corpo 2 [Fonte: Autoria própria]

De acordo com a Figura 2-7, as equações de equilíbrio estático podem ser escritas conforme a equação (2.57), apenas, atentando-se ao fato que os momentos resultantes $M_{R 2^{\prime}}$ e $M_{R 3^{\prime \prime}}$ 
podem não estar perpendiculares com as forças estáticas $P_{2}$ e $P_{3}$, dessa forma, recomendase a utilização dos ângulos $\theta_{R 2^{\prime}}$ e $\theta_{R 3^{\prime \prime}}$. Outra premissa a ser utilizada é considerar que a força radial máxima $F_{r i}$ ocorrerá exatamente onde os momentos resultantes $\mathbf{M}_{R 2}, \mathbf{M}_{R 3^{\prime \prime}}$ serão máximos nos planos $x$ 'z' e $x$ '” $y$ ' respectivamente.

$$
\begin{aligned}
& P_{2} c_{\theta_{R 2}}+P_{3} c_{\theta_{R 3^{*}}}=\sum_{i=6}^{13} F_{r i} \\
& -M_{R 3^{\prime \prime}}=\sum_{i=6}^{9} F_{r i} d_{i}-\frac{P_{3} c_{\theta_{R 3^{\prime \prime}}}}{2}\left(d_{6}+d_{7}\right)-P_{2} c_{\theta_{R 3^{\prime \prime}}} l_{3} \\
& -M_{R 2^{\prime}}=\sum_{i=10}^{13} F_{r i} d_{i}-P_{2} c_{\theta_{R 2^{\prime}}} l_{2}
\end{aligned}
$$

Similar ao problema anterior, este é um problema hiperestático e pode ser escrito conforme a equação (2.58) para o primeiro conjunto de rolamentos no SR Q no eixo $y^{\prime}$.

$$
E I w_{2}\left(y^{\prime}\right)=-M_{R 2^{\prime}} \frac{\left\langle y^{\prime}-l_{2}\right\rangle^{2}}{2}-\frac{\left(P_{2}+P_{3}\right) c_{\theta R 2^{\prime}}}{6}\left\langle y^{\prime}-l_{2}\right\rangle^{3}+\sum_{i=10}^{13} \frac{F_{r i}}{6}\left\langle y^{\prime}-d_{i}\right\rangle^{3}+C_{1} y^{\prime}+C_{2}
$$

Aplicando as condições de contorno identificadas na Figura 2-7 e considerando que os rolamentos são apoios ideais, resultando em:

$$
\begin{aligned}
& \operatorname{EIw}_{2}\left(d_{j}\right)=0=-M_{R 2^{\prime}} \frac{\left\langle d_{j}-l_{2}\right\rangle^{2}}{2}-\frac{\left(P_{2}+P_{3}\right) c_{\theta R 2^{\prime}}}{6}\left\langle d_{j}-l_{2}\right\rangle^{3}+ \\
& +\sum_{i=10}^{13} \frac{F_{r i}}{6}\left\langle d_{j}-d_{i}\right\rangle^{3}+C_{1} d_{j}+C_{2}, \quad j=10 . .13
\end{aligned}
$$

Escreve-se a equação (2.60) para o segundo esquema de rolamento no SR R no eixo $z$ '” observando os pontos de apoio da carga $P_{3}$ e $P_{2}$.

$$
\begin{aligned}
& \operatorname{EIw}_{3}\left(z^{\prime \prime}\right)=-M_{R 3^{\prime \prime}} \frac{\left\langle z^{\prime \prime}-l_{3}\right\rangle^{2}}{2}-\frac{P_{3} c_{\theta R 3^{\prime \prime}}}{12}\left(\left\langle z^{\prime \prime}-d_{6}\right\rangle^{3}+\left\langle z^{\prime \prime}-d_{7}\right\rangle^{3}\right)-\frac{P_{2} c_{\theta R 3^{\prime \prime}}}{6}\left\langle z^{\prime \prime}-l_{3}\right\rangle^{3}+ \\
& +\sum_{i=6}^{9} \frac{F_{r i}}{6}\left\langle z^{\prime \prime}-d_{i}\right\rangle^{3}+C_{3} z^{\prime \prime}+C_{4}
\end{aligned}
$$

Aplicando as condições de contorno identificadas na Figura 2-7 e considerando que os rolamentos são apoios ideais, resultando em:

$$
\begin{aligned}
& E I w_{3}\left(d_{j}\right)=0=-M_{R 3^{\prime \prime}} \frac{\left\langle d_{j}-l_{3}\right\rangle^{2}}{2}-\frac{P_{3} c_{\theta R 3^{\prime \prime}}}{12}\left(\left\langle d_{j}-d_{6}\right\rangle^{3}+\left\langle d_{j}-d_{7}\right\rangle^{3}\right) \\
& -\frac{P_{2} c_{\theta R 3^{\prime \prime}}}{6}\left\langle d_{j}-l_{3}\right\rangle^{3}+\sum_{i=6}^{9} \frac{F_{r i}}{6}\left\langle d_{j}-d_{i}\right\rangle^{3}+C_{3} d_{j}+C_{4}, \quad j=6 . .9
\end{aligned}
$$


Fazendo a compatibilidade no ponto $\mathrm{O}$ da cruzeta é possível representar a equação conforme eq. (2.62).

$$
\begin{aligned}
& E \operatorname{Iw}_{2}\left(l_{2}\right)=\operatorname{EIw}_{3}\left(l_{3}\right) \\
& \frac{F_{r 10}}{6} l_{2}{ }^{3}+C_{1} l_{2}+C_{2}=-\frac{P_{3} c_{\theta R 3^{3}} l_{3}^{3}}{12}+\frac{F_{r 6}}{6} l_{3}{ }^{3}+C_{3} l_{3}+C_{4}
\end{aligned}
$$

Desenvolvendo as equações (2.57), (2.59), (2.61) e (2.62), pode-se montar um sistema de equações tal que as oito forças radiais $F_{r i}$ e as quatro constantes de integração $C_{1}, C_{2}, C_{3}$ e $C_{4}$ possam ser resolvidas pelo sistema linear na eq. (2.63).

Ao analisar as forças axiais da cruzeta, observa-se que, no primeiro conjunto de rolamento no SR Q, a componente em $y$ ' será zero, $F_{a 2}=0$. No entanto, ao verificar o segundo esquema de rolamento no SR R, a força axial pode ser escrita como $F_{a 3}=\left(P_{2}+P_{3}\right) \mathrm{s}_{\gamma}$.

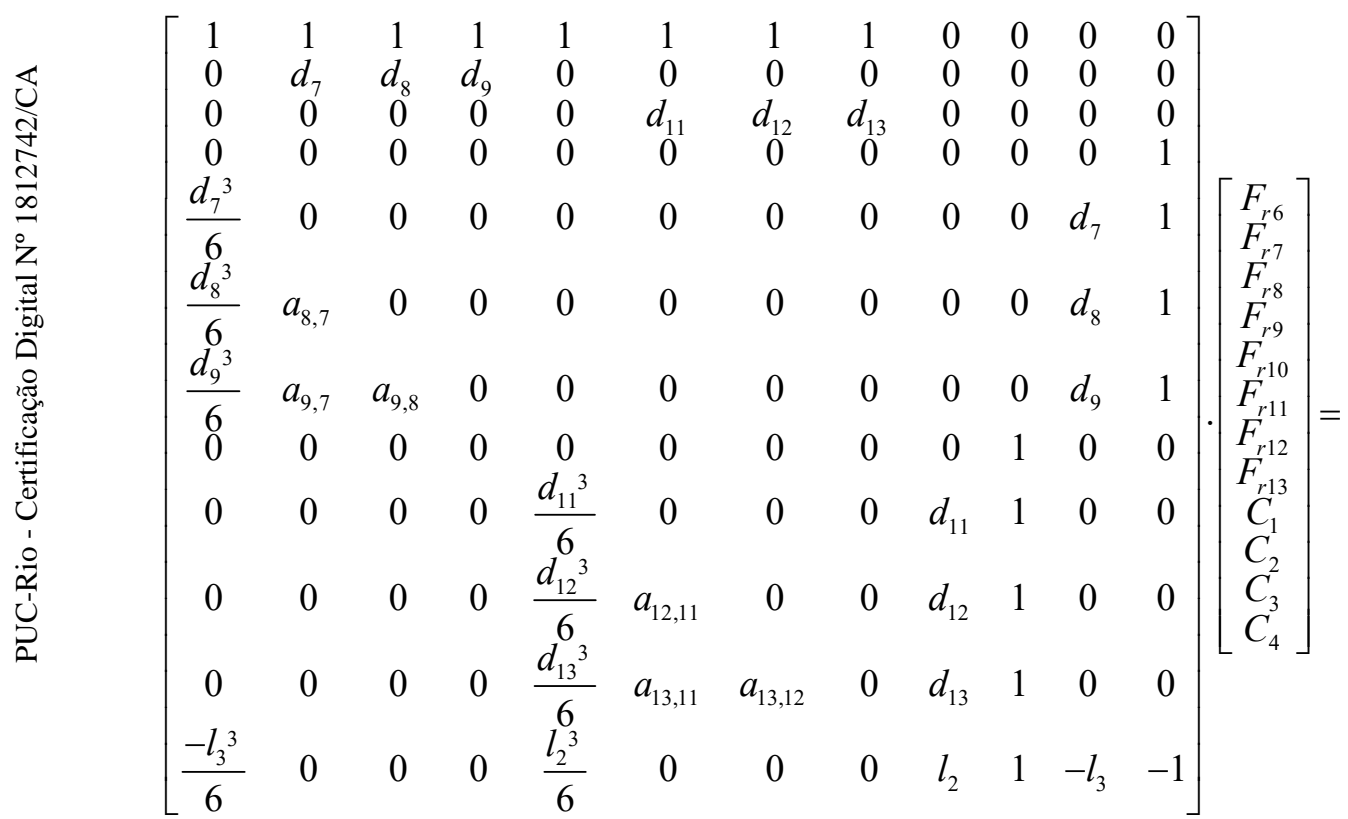

Sendo $a_{r, s}=\frac{\left(d_{r}-d_{s}\right)^{3}}{6}$ 


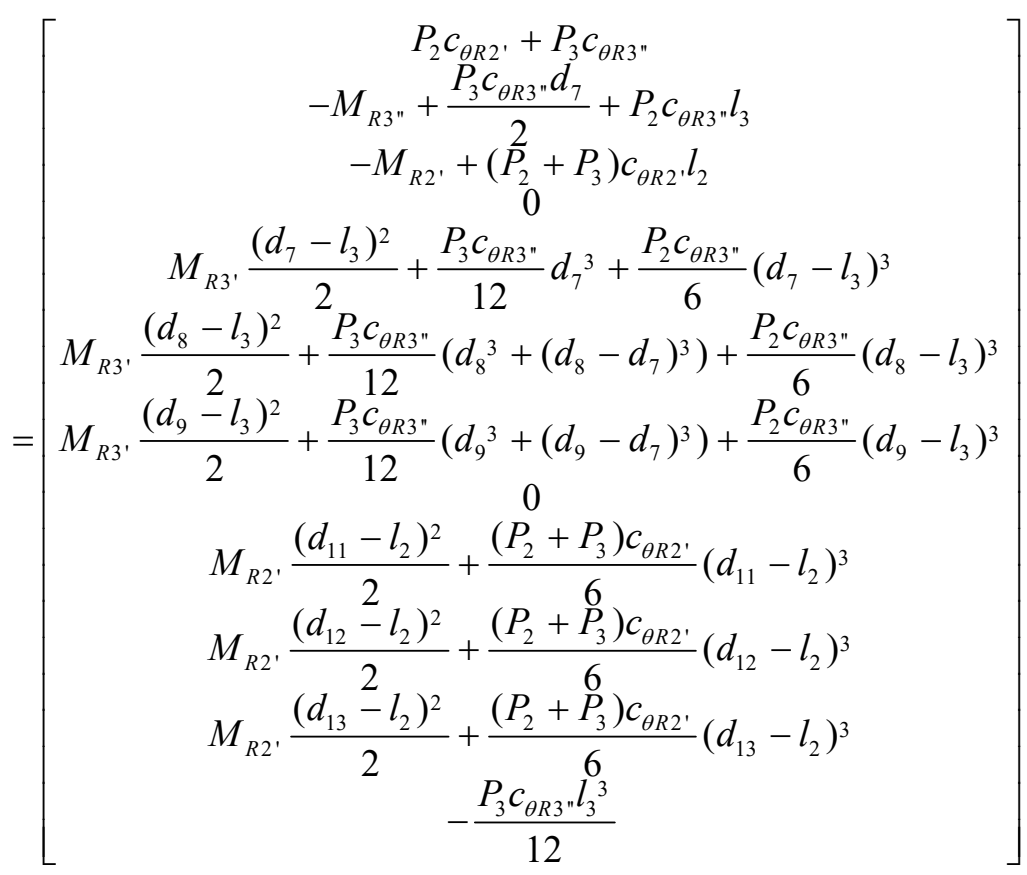

O atrito no rolamento muda em função da velocidade e em função do lubrificante utilizado, desse modo, criando quatro zonas distinguíveis: Zona 1 - Condição de lubrificação da camada limite, em que apenas as asperezas carregam a carga e, assim, o atrito devido ao movimento relativo das superfícies é alto. Zona 2 - Condição mista de lubrificação, em que um filme de óleo de separação transporta parte da carga, com menos asperezas em contato e, assim, o atrito diminui. Zona 3 - Condição de lubrificação total do filme, na qual o filme lubrificante carrega a carga, aumentando as perdas viscosas e, portanto, o atrito aumenta. E, Zona 4 - Lubrificação total do filme entre as superfícies com efeitos térmicos dissipativos, onde o aumento da temperatura devido ao cisalhamento gera os fatores de redução, que compensam parcialmente as perdas viscosas e, assim, o atrito diminui. Dessa forma, conforme (SKF, 2019), para calcular o momento de atrito total em um rolamento, pode-se escrever:

$$
M=M_{r r}+M_{s l}+M_{\text {seal }}+M_{\text {drag }}
$$

Sendo: $M$ - momento de atrito total; $M_{r r}$ - momento de atrito rolante; $M_{s l}$ - momento de atrito deslizante; $M_{\text {seal }}$ - momento de atrito das vedações; $M_{\text {drag }}$ - momento de atrito de perdas por arrasto, agitação, salpicos, etc.

O momento do atrito rolante pode ser calculado como:

$M_{r r}=\phi_{i s h} \phi_{r s} G_{r r}(v n)^{0,6}$ 
O momento de atrito deslizante pode ser calculado como:

$$
M_{s l}=G_{s l} \mu_{s l}
$$

O momento de atrito das vedações existe apenas nos rolamentos rígidos de esferas SKF 625-2Z, SKF W619/8-2Z e SFK 6205-2Z, podendo ser calculado como:

$$
M_{\text {seal }}=K_{S 1} d_{S}^{\beta}+K_{S 2}
$$

O momento de atrito de perdas pode ser calculado para o rolamento rígido de esferas como:

$$
M_{\text {drag }}=0,4 V_{M} K_{\text {ball }} d_{m}^{5} n^{2}+1,093 \cdot 10^{-7} R_{S} d_{m}^{3} n^{2}\left(\frac{n d_{m}^{2} f_{t}}{v}\right)^{-1,379}
$$

E para o rolamento de rolos rígidos:

$$
M_{\text {drag }}=4 V_{M} K_{\text {roll }} C_{W} B d_{m}^{4} n^{2}+1,093.10^{-7} R_{S} d_{m}^{3} n^{2}\left(\frac{n d_{m}^{2} f_{t}}{v}\right)^{-1,379}
$$

Os termos das equações (2.65), (2.66), (2.70), (2.68) e (2.69) foram obtidos a partir de estudos experimentais fornecidos pelo fabricante. A explicação detalhada de cada variável encontra-se no Apêndice I. Portanto, as formulações sobre o atrito dos rolamentos usando o modelo SKF, conforme equação (2.64), consideram diversas fórmulas empíricas que são confiáveis e consolidadas para o entendimento deste fenômeno. E, apesar das diversas constantes presentes, é possível observar que a velocidade angular e a viscosidade do lubrificante são os fatores essenciais para os momentos de atritos rolante $\left(M_{r r}\right)$, deslizante $\left(M_{s l}\right)$ e de perdas $\left(M_{\text {drag }}\right)$, comportando-se fisicamente estes com sendo atritos viscosos. Apenas o momento de atrito por vedação $\left(M_{\text {seal }}\right)$ é formulado como atrito seco. Dessa forma, a resolução analítica para os casos propostos na operação da junta ativa construída no escopo desta tese considerará apenas o torque de atrito dos rolamentos envolvidos que estarão em sentidos opostos aos torques dos motores principais $T_{01}, T_{12}$ e $T_{23}$.

\subsubsection{Identificação da Folga}

Em geral, as folgas existentes em um sistema de motorredutores com juntas robóticas são indesejáveis devido ao acréscimo da incerteza para o atuador; e, na busca por uma solução para a sua eliminação, algumas empresas têm trabalhado com motorredutores com alta precisão (MAXON, 1961), que conseguem reduzir parcialmente a folga no sistema, mas 
não eliminar. No entanto há uma solução bem engenhosa que tende a eliminar as folgas: são os redutores de engrenagens por onda de deformação, também conhecidos como engrenagens harmônicas ("Harmonic Drive"). Foi inventada por Musser (1955) e possui diversas vantagens que incluem: ausência de folga, compactação e peso leve, altas relações de transmissão, relações reconfiguráveis dentro de uma carcaça padrão, boa resolução e excelente repetibilidade ao reposicionar cargas inerciais, alta capacidade de torque e eixos de entrada e saída coaxiais (MUSSER, 1955). Outra solução que tende a eliminar a folga foi patenteada por Vranish (2003), com a criação de redutor planetário de rolamentos de engrenagens ("Gear Bearings"). Ao incorporar formas de dentes de engrenagem helicoidais aos rolamentos, obtém-se também uma redução de alta e baixa velocidade através da incorporação de ajuste nos estágios. O ajuste de um estágio permite a diferenciação no número de dentes que devem ser engatados entre os estágios de entrada e saída em um conjunto de engrenagens planetárias, permitindo taxas de redução bem-sucedidas de 1:2 a 1:2000. Devido a essa proposta, fornecem um controle suave e preciso sem folga entre os dentes, mesmo sob carga, pois o estágio de uma redução planetária possui duas seções defasadas, de modo que os dentes de uma seção e os dentes de outra seção façam contato em lados opostos da folga. A parte interna de uma engrenagem gira (como um projétil no cano de um rifle), enquanto se move axialmente através da ação de uma mola até que a folga seja removida. Isso resulta em uma transmissão planetária com folga zero (VRANISH, 2003). Portanto, para uma aplicação robótica de alta precisão, a utilização da engrenagem harmônica ou de um redutor planetário de rolamentos de engrenagens é extremamente recomendável, apesar de seus custos de aquisição e manutenção serem muito superiores ao uso do motorredutor de engrenagens planetárias comum, por exemplo. Nas demais aplicações, como as aplicações industriais, a utilização de motorredutor de engrenagens consegue ser suficiente, desde que a folga fique gerenciável dentro do projeto do equipamento, e, para tal, portanto, é necessário modelá-la.

A folga é o efeito do desengajamento repentino entre o eixo do motor e a carga, e vários modelos dinâmicos foram desenvolvidos com base nesse torque de interconexão (NORDIN, GALIC e GUTMAN, 1997) (GERDES e KUMAR, 1995) (NORDIN e GUTMAN, 2002). Alguns trabalhos que necessitaram estudar a folga em um sistema de mais de um grau de liberdade (GRUZMAN, 2011) (BAEK, 2006), também, utilizaram a formulação da zona morta elaborada por Nordin (1997). No entanto algumas premissas adotadas simplificam demasiadamente o problema aqui proposto, uma vez que, os impactos são restaurados e amortecidos apenas pela rigidez e amortecimento do eixo do motor (NORDIN, GALIC e GUTMAN, 1997), além disso, a junta cardânica ativa proposta possui 
uma dinâmica própria que deve obedecer ao sistema de equações em (2.47), quando o eixo do motor estiver com o torque passando por zero, isto é, no intervalo de tempo em que a folga irá ocorrer, excluindo os impactos.

Alguns autores, preferiram modelar o redutor de velocidade levando em consideração cada uma de suas engrenagens com a inércia, a rigidez, o amortecimento e as folgas angulares (BAEK, KWAK e KIM, 2003) (XU, CUI, et al., 2017). No entanto a complexidade deste estudo para um redutor planetário, cujas folgas são distribuídas pelas diversas engrenagens planetárias e solares dentro de cada estágio, acoplado a um motor de passo, que possui sua própria rigidez e amortecimento eletromagnético, além da folga dos acoplamentos entre os eixos e cubos, bem como a rigidez e o amortecimento da própria estrutura, tudo isso dificultaria conhecer as variáveis necessárias para utilizar os modelos propostos de folgas e contatos existentes na literatura (FLORES e LANKARANI, 2016) (ZAFER, 2013). Portanto, foi adotada uma abordagem mais simplista e direta, tanto para a dinâmica da folga quanto para o impacto presente após o final do fenômeno da folga.

A cinemática inversa modelada no subcapítulo 2.2.1 permite conhecer os ângulos do movimento desejado $\alpha, \beta$ e $\gamma$ com antecedência, e a dinâmica no subcapítulo 2.2.2 permite conhecer os momentos de reação e os torques necessários nos motores para os movimentos dos múltiplos corpos rígidos. Para os casos específicos investigados nesta tese, o motorredutor alpha, responsável pelo grau de liberdade do ângulo $\alpha$, não passará pelo fenômeno da folga, visto que o seu torque não passará por zero devido à sua força de atrito ser superior a variação de seu torque. No entanto os motorredutores beta e gama, responsáveis pelos graus de liberdade dos ângulos $\beta$ e $\gamma$, respectivamente, sofrerão com o fenômeno da folga. Apesar da alta precisão do motor de passo, quando o fenômeno da folga ocorrer, a desacoplagem entre o eixo e a carga irá acontecer, e o motor de passo continuará seguindo o seu ângulo preestabelecido na cinemática inversa e os corpos rígidos deverão obedecer às equações que levam em conta a dinâmica alterada do sistema. Estas equações acoplam os ângulos, os momentos de reação e os torques necessários nos motores e que não estarão naquele instante passando pelo fenômeno da folga. Portanto, a condição para o início do fenômeno da folga será $T_{23}=0$, para folga em $\gamma$ e/ou $T_{12}=0$, para a folga em $\beta$ e para os problemas propostos nesta tese essas folgas não ocorrerão simultaneamente. 


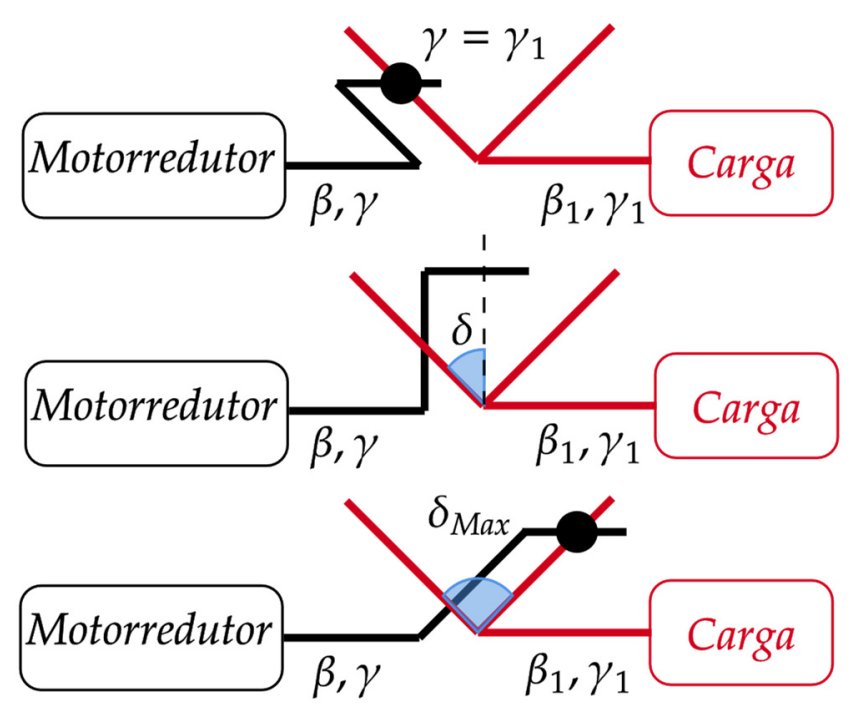

(a)

(b)

(c)

Figura 2-8 - Modelo de folga de zona morta. [Fonte: Autoria própria]

Realizando a formulação para a folga no ângulo $\gamma$, é possível observar o surgimento de um novo $\mathrm{SR}_{1}$ na eq. (2.71), que está solidário ao corpo rígido corpo 3, e após o término processo da folga é importante observar que $\left|\gamma-\gamma_{1}\right|=\delta_{\text {Max }}$.

$$
\underset{(x, y, z)}{\mathrm{F}} \stackrel{\alpha(x)}{\longrightarrow} \underset{\left(x, y^{\prime}, z^{\prime}\right)}{\mathrm{Q}} \stackrel{\beta\left(\mathrm{y}^{\prime}\right)}{\longrightarrow} \underset{\left(x^{\prime \prime}, y^{\prime}, z^{\prime \prime}\right)}{\mathrm{R}} \stackrel{\gamma\left(\mathrm{z}^{\prime \prime}\right)}{\longrightarrow} \underset{\left(x^{\prime \prime}, y^{\prime \prime}, z^{\prime \prime}\right)}{\mathrm{S}} \stackrel{\delta_{3}=\gamma_{1}-\gamma\left(\mathrm{z}^{\prime \prime}\right)}{\longrightarrow} \underset{\left(x^{\prime \prime *}, y^{\prime \prime *}, z^{\prime \prime}\right)}{\mathrm{S}_{1}}
$$

Na Figura 2-8, em (a), inicia-se o fenômeno da folga, em que, até aquele instante $\gamma=\gamma_{1}$, durante este instante de desacoplamento, não há impacto. Em seguida, durante o movimento relativo da folga, representado na Figura 2-8, em (b), o ângulo $\gamma$ segue a trajetória planejada; e o ângulo $\gamma_{1}$ passa a ser uma incógnita que tenderá a obedecer ao sistema de equações dinâmicas (2.47), logo, para conhecer o ângulo $\gamma_{1}$, no intervalo de folga, é necessário resolver a equação (2.72). Após a resolução, este novo ângulo $\gamma_{1}$ deverá ser aplicado no lugar do ângulo $\gamma$, nas funções de entrada $\Phi_{3 x}\left(I_{3}, m_{3}, h_{2}, \alpha, \beta, \gamma_{1}, \dot{\alpha}, \dot{\beta}, \dot{\gamma}_{1}, \ddot{\alpha}, \ddot{\beta}, \ddot{\gamma}_{1}\right) \quad$ e $\quad \Phi_{3 y}\left(I_{3}, m_{3}, h_{2}, \alpha, \beta, \gamma_{1}, \dot{\alpha}, \dot{\beta}, \dot{\gamma}_{1}, \ddot{\alpha}, \ddot{\beta}, \ddot{\gamma}_{1}\right)$, que consequentemente influenciará os torques $T_{01}$ e $T_{12}$, além dos seis momentos de reação $M_{A y^{\prime}}, M_{A z^{\prime}}, M_{B x^{\prime}}, M_{B z^{\prime}}, M_{C x^{\prime \prime}}$ e $M_{C y^{\prime \prime}}$. 


$$
\begin{aligned}
& T_{23}=\Phi_{3 z}\left(I_{3}, m_{3}, h_{2}, \alpha, \beta, \gamma_{1}, \dot{\alpha}, \dot{\beta}, \dot{\gamma}_{1}, \ddot{\alpha}, \ddot{\beta}, \ddot{\gamma_{1}}\right)=0 \\
& T_{23}=\Phi_{3 z}=\left\{\begin{array}{l}
-m_{3} g h_{2} c_{\beta} s_{\gamma_{1}}+\left(I_{3 z}+m_{3} h_{2}^{2}\right)\left(\ddot{\alpha} s_{\beta}+\dot{\alpha} \dot{\beta} c_{\beta}+\ddot{\gamma}_{1}\right)+ \\
-\left[I_{3 x} \dot{\alpha} c_{\gamma_{1}}^{2} c_{\beta}+\left(I_{3 y}+m_{3} h_{2}^{2}\right) \dot{\alpha} s_{\gamma_{1}}^{2} c_{\beta}+\left(I_{3 x}-I_{3 y}-m_{3} h_{2}^{2}\right) \dot{\beta} s_{\gamma_{1}} c_{\gamma_{1}}\right] \dot{\beta}+=0 \\
+\left[\left(I_{3 x}-I_{3 y}-m_{3} h_{2}^{2}\right) \dot{\alpha} c_{\beta} s_{\gamma_{1}} c_{\gamma_{1}}+I_{3 x} \dot{\beta} s_{\gamma_{1}}^{2}+\left(I_{3 y}+m_{3} h_{2}^{2}\right) \dot{\beta} c_{\gamma_{1}}^{2}\right] \dot{\alpha} c_{\beta}
\end{array}\right.
\end{aligned}
$$

A E.D.O não linear conforme eq. (2.72) pode ser resolvida por diferenças finitas, uma vez que as variáveis $\alpha, \beta, \gamma$ e suas derivadas no tempo de primeira e segunda ordem são conhecidas nos instantes anteriores. Assim, o novo valor de $\gamma_{1}$, no novo instante $i+1$, é conhecido conforme eq. (2.73) e, em seguida, as suas derivadas no tempo de primeira e segunda ordem são calculadas também por diferenças finitas, onde $h$ equivale à discretização no tempo.

$$
\gamma_{1(i+1)}=\left\{\begin{array}{l}
\left\{m_{3} g h_{2} c_{\beta(i)} s_{\gamma 1(i)}-\left(I_{3 z}+m_{3} h_{2}^{2}\right)\left(\ddot{\alpha}_{(i)} s_{\beta(i)}+\dot{\alpha}_{(i)} \dot{\beta}_{(i)} c_{\beta(i)}\right)+\right. \\
+\left[I_{3 x} \dot{\alpha}_{(i)} c_{\gamma 1(i)}^{2} c_{\beta(i)}+\left(I_{3 y}+m_{3} h_{2}^{2}\right) \dot{\alpha}_{(i)} s_{\gamma 1(i)}^{2} c_{\beta(i)}+\left(I_{3 x}-I_{3 y}-m_{3} h_{2}^{2}\right) \dot{\beta}_{(i)} s_{\gamma 1(i)} c_{\gamma 1(i)}\right] \dot{\beta}_{(i)}+ \\
\left.-\left[\left(I_{3 x}-I_{3 y}-m_{3} h_{2}^{2}\right) \dot{\alpha}_{(i)} c_{\beta(i)} s_{\gamma 1(i)} c_{\gamma 1(i)}+I_{3 x} \dot{\beta}_{(i)} s_{\gamma 1(i)}^{2}+\left(I_{3 y}+m_{3} h_{2}^{2}\right) \dot{\beta}_{(i)} c_{\gamma 1(i)}^{2}\right] \dot{\alpha}_{(i)} c_{\beta(i)}\right\} \\
h^{2}\left(I_{3 z}+m_{3} h_{2}^{2}\right)^{-1}+2 \gamma_{1(i)}-\gamma_{1(i-1)}
\end{array}\right.
$$

$\dot{\gamma}_{1(i)}=\frac{\gamma_{1(i+1)}-\gamma_{1(i-1)}}{2 h}$

$\ddot{\gamma}_{1(i)}=\frac{\gamma_{1(i+1)}-2 \gamma_{1(i)}+\gamma_{1(i-1)}}{h^{2}}$

Para completar o entendimento do processo de folga, chega-se na condição da Figura 2-8, em (c), em que ocorrerá o impacto para que volte a existir o acoplamento. Optou-se por utilizar uma abordagem energética do impacto, visto que as velocidades da carga e do eixo do motorredutor são conhecidas e a fenomenologia detalhada do impacto é bastante complexa. Neste ponto do processo de folga, o ângulo $\gamma$ voltará a ser único, mas defasado de $\delta_{\text {Max }}$. Assim, escrevendo a energia cinética do corpo 3 no momento do impacto é possível afirmar que será equivalente ao torque de impacto $T_{I}$ multiplicado pela deformação angular $\Delta \delta$, no instante do impacto que será inserido no eixo $z$ '” da Figura 2-4. Além disso, o torque também pode ser escrito pela lei de Hooke como $T_{I}=K_{G} \Delta \delta$ resultando na eq. (2.74).

$$
\Delta E^{(3)}=\frac{\left(T_{\mathrm{I}}^{(3)}\right)^{2}}{K_{G}}=\frac{1}{2}\left[{ }_{\mathrm{F} 1}^{\mathrm{S} 1} \boldsymbol{\omega}_{\mathrm{S} 1}^{T}{ }_{\mathrm{S} 1} \mathbf{I}_{O}^{(3)} \underset{\mathrm{F} 1}{\mathrm{~S}} \boldsymbol{\omega}_{\mathrm{S} 1}\right]
$$


Onde: ${ }_{\mathrm{F}}^{\mathrm{S} 1} \boldsymbol{\omega}_{\mathrm{S} 1}=\left[\begin{array}{l}\dot{\beta} s_{\gamma 1}+\dot{\alpha} c_{\beta} c_{\gamma 1} \\ \dot{\beta} c_{\gamma 1}-\dot{\alpha} c_{\beta} s_{\gamma 1} \\ \dot{\alpha} s_{\beta}+\dot{\gamma}{ }_{1}-\dot{\gamma}\end{array}\right]$ e ${ }^{\mathrm{S} 1} \mathbf{I}_{O}^{(3)}={ }^{\mathrm{s} 1} \mathbf{I}_{C G 3}^{(3)}-m_{3} \underset{C G 3}{\mathrm{~S} 1} \tilde{\mathbf{r}}_{O}^{2}$

A rigidez global do grau de liberdade $K_{G}$ será modelada de forma linear conforme o Apêndice II e assim o torque de impacto do corpo 3 no sistema do motorredutor do grau de liberdade $\gamma$ pode ser escrito conforme eq. (2.75).

$$
T_{\mathrm{I}}^{(3)}=\sqrt{\frac{K_{G}\left[I_{3 x}\left(\dot{\beta} s_{\gamma 1}+\dot{\alpha} c_{\beta} c_{\gamma 1}\right)^{2}+\left(I_{3 y}+m_{3} h_{2}^{2}\right)\left(\dot{\beta} c_{\gamma 1}-\dot{\alpha} c_{\beta} s_{\gamma 1}\right)^{2}+\left(I_{3 z}+m_{3} h_{2}^{2}\right)\left(\dot{\delta}_{3}+\dot{\alpha} s_{\beta}\right)^{2}\right]}{2}}
$$

De forma similar ao anterior, a folga do ângulo $\beta$ acontecerá quando o $T_{12}=-\Phi_{3 y}-\Phi_{2 y}=0$ gerar um novo SR $\mathrm{R}_{1}$, e analisando as equações (2.32) e (2.47), precisa-se conhecer a dinâmica deste grau de liberdade ao encontrar-se no processo de folga, resultando na eq. (2.76).

$$
\begin{aligned}
& \underset{(x, y, z)}{\mathrm{F}} \stackrel{\alpha(x)}{\longrightarrow} \underset{\left(x, y^{\prime}, z^{\prime}\right)}{\mathrm{Q}} \stackrel{\beta\left(\mathrm{y}^{\prime}\right)}{\longrightarrow} \underset{\left(x^{\prime \prime}, y^{\prime}, z^{\prime \prime}\right)}{\mathrm{R}} \stackrel{\delta_{2}=\beta_{1}-\beta\left(\mathrm{y}^{\prime}\right)}{\longrightarrow} \underset{\left(x^{\prime \prime *}, y^{\prime}, z^{\prime \prime *}\right)}{\mathrm{R}} \stackrel{\gamma\left(\mathrm{z}^{\prime \prime}\right)}{\longrightarrow} \underset{\left(x^{\prime \prime \prime}, y^{\prime \prime}, z^{\prime \prime}\right)}{\mathrm{S}} \\
& T_{12}=\mid \begin{array}{l}
m_{3} g h_{2} s_{\beta 1} c_{\gamma}+ \\
-\left(I_{3 x}-I_{3 y}-m_{3} h_{2}^{2}\right)\left(\ddot{\alpha} c_{\beta 1} s_{\gamma} c_{\gamma}-\dot{\alpha} \dot{\beta}_{1} s_{\beta 1} s_{\gamma} c_{\gamma}+\dot{\alpha} \dot{\gamma} c_{\beta 1} c_{\gamma}^{2}-\dot{\alpha} \dot{\gamma} c_{\beta 1} s_{\gamma}^{2}\right)+ \\
-I_{3 x}\left(\ddot{\beta_{1}} s_{\gamma}^{2}+2 \dot{\beta} \dot{\gamma} s_{\gamma} c_{\gamma}\right)-\left(I_{3 y}+m_{3} h_{2}^{2}\right)\left(\ddot{\beta} c_{\gamma}^{2}-2 \dot{\beta} \dot{\gamma} c_{\gamma} s_{\gamma}\right)+ \\
-\left\{I_{3 x} \dot{\alpha} c_{\gamma}^{2} c_{\beta 1}+\left(I_{3 y}+m_{3} h_{2}^{2}\right) \dot{\alpha} s_{\gamma}^{2} c_{\beta 1}+\left(I_{3 x}-I_{3 y}-m_{3} h_{2}^{2}\right) \dot{\beta} s_{\gamma} c_{\gamma}\right\}\left(\dot{\alpha} s_{\beta 1}+\dot{\gamma}\right)+ \\
+\left\{\left(I_{3 z}+m_{3} h_{2}^{2}\right)\left(\dot{\alpha} s_{\beta 1}+\dot{\gamma}\right)\right\} \dot{\alpha} c_{\beta 1}-I_{2 y} \ddot{\beta}-\left(I_{2 x}-I_{2 z}\right) \dot{\alpha}^{2} s_{\beta 1} c_{\beta 1}
\end{array}=0
\end{aligned}
$$

Resolvendo a E.D.O também por diferenças finitas para achar o comportamento do ângulo $\beta$ em função das variáveis de entrada definidas na eq. (2.47), obtém-se: 


$$
\begin{aligned}
& t n=\mid \begin{array}{l}
m_{3} g h_{2} s_{\beta 1(i)} c_{\gamma(i)}+ \\
-\left(I_{3 x}-I_{3 y}-m_{3} h_{2}^{2}\right)\left[\ddot{\alpha}_{(i)} c_{\beta 1(i)} s_{\gamma(i)} c_{\gamma(i)}+\dot{\alpha}\left(\frac{\beta_{(i-1)}}{2 h}\right) s_{\beta 1(i)} s_{\gamma(i)} c_{\gamma(i)}+\right. \\
\left.+\dot{\alpha}_{(i)} \dot{\gamma}_{(i)} c_{\beta 1(i)} c_{\gamma(i)}^{2}-\dot{\alpha}_{(i)} \dot{\gamma}_{(i)} c_{\beta 1(i)} s_{\gamma(i)}^{2}\right]+ \\
-I_{3 x}\left[\left(\frac{2 \beta_{(i)}-\beta_{(i-1)}}{h^{2}}\right) s_{\gamma(i)}^{2}-\left(\left(\frac{\beta_{(i-1)}}{h}\right) \dot{\gamma}_{(i)} s_{\gamma(i)} c_{\gamma(i)}\right)\right]+ \\
+\left(I_{3 y}+m_{3} h_{2}^{2}\right)\left[\left(\frac{2 \beta_{(i)}-\beta_{(i-1)}}{h^{2}}\right) c_{\gamma(i)}^{2}-\left(\frac{\beta_{(i-1)}}{h}\right) \dot{\gamma}_{(i)} c_{\gamma(i)} s_{\gamma(i)}\right]+ \\
-\left[I_{3 x} \dot{\alpha}_{(i)} c_{\gamma(i)}^{2} c_{\beta 1(i)}+\left(I_{3 y}+m_{3} h_{2}^{2}\right) \dot{\alpha}_{(i)} s_{\gamma(i)}^{2} c_{\beta 1(i)}+\right. \\
\left.-\left(I_{3 x}-I_{3 y}-m_{3} h_{2}^{2}\right)\left(\frac{\beta_{(i-1)}}{2 h}\right) s_{\gamma(i)} c_{\gamma(i)}\right]\left(\dot{\alpha}_{(i)} s_{\beta 1(i)}+\dot{\gamma}_{(i)}\right)+ \\
+\left[\left(I_{3 z}+m_{3} h_{2}^{2}\right)\left(\dot{\alpha}_{(i)} s_{\beta 1(i)}+\dot{\gamma}_{(i)}\right)\right] \dot{\alpha}_{(i)} c_{\beta 1(i)}-\left(I_{2 x}-I_{2 z}\right) \dot{\alpha}_{(i)} s_{\beta 1(i)} c_{\beta 1(i)}+ \\
+I_{2 y}\left(\frac{2 \beta_{(i)}-\beta_{(i-1)}}{h^{2}}\right)
\end{array} \\
& t d=\left\{\begin{array}{l}
\left(I_{3 x}-I_{3 y}-m_{3} h_{2}^{2}\right) \dot{\alpha}\left(\frac{1}{2 h}\right) s_{\beta 1(i)} s_{\gamma(i)} c_{\gamma(i)}+I_{3 x}\left[\left(\frac{1}{h^{2}}\right) s_{\gamma(i)}^{2}+\left(\frac{1}{h}\right) \dot{\gamma}_{(i)} s_{\gamma(i)} c_{\gamma(i)}\right]+ \\
+\left(I_{3 y}+m_{3} h_{2}^{2}\right)\left[\left(\frac{1}{h^{2}}\right) c_{\gamma(i)}^{2}-\left(\frac{1}{h}\right) \dot{\gamma}_{(i)} c_{\gamma(i)} s_{\gamma(i)}\right]+ \\
-\left(I_{3 x}-I_{3 y}-m_{3} h_{2}^{2}\right)\left(\dot{\alpha}_{(i)} s_{\beta 1(i)}+\dot{\gamma}_{(i)}\right)\left(\frac{1}{2 h}\right) s_{\gamma(i)} c_{\gamma(i)}+I_{2 y}\left(\frac{1}{h^{2}}\right)
\end{array}\right. \\
& \beta_{i+1}=\frac{t n}{t d} \\
& \dot{\beta}_{(i)}=\frac{\beta_{i+1}-\beta_{(i-1)}}{2 h} \\
& \ddot{\beta}_{(i)}=\frac{\beta_{i+1}-2 \beta_{(i)}+\beta_{(i-1)}}{h^{2}}
\end{aligned}
$$

Analisando o impacto de forma similar, a energia cinética dos corpos 2 e 3 no momento do impacto é possível afirmar que será equivalente ao torque de impacto multiplicado pela deformação angular $\Delta \delta$, no instante do impacto que será inserido no eixo $y$ '” da Figura 2-3. Assim, o torque também pode ser escrito pela lei de Hooke como $T_{I}=K_{G} \Delta \delta$ resultando na eq. (2.78).

$$
\Delta E^{(2)}=\frac{\left(T_{\mathrm{I}}^{(2)}\right)^{2}}{K_{G}}=\frac{1}{2}\left[{ }_{\mathrm{F}}^{\mathrm{R} 1} \boldsymbol{\omega}_{\mathrm{R} 1}^{T}{ }_{\mathrm{R} 1} \mathbf{I}_{O}^{(2)}{ }_{\mathrm{F} 1}^{\mathrm{R}} \boldsymbol{\omega}_{\mathrm{R} 1}\right]+\frac{1}{2}\left[{ }_{\mathrm{F}}^{\mathrm{S}} \boldsymbol{\omega}_{\mathrm{S}}^{T} \mathrm{~S} \mathbf{I}_{O}^{(3)}{ }_{\mathrm{F}}^{\mathrm{S}} \boldsymbol{\omega}_{\mathrm{S}}\right]
$$

Onde: ${ }_{\mathrm{F}}^{\mathrm{R} 1} \boldsymbol{\omega}_{\mathrm{R} 1}=\left[\begin{array}{c}\dot{\alpha} c_{\beta 1} \\ \dot{\beta}_{1} \\ \dot{\alpha} s_{\beta 1}\end{array}\right],{ }^{\mathrm{R} 1} \mathbf{I}_{O}^{(2)}={ }^{\mathrm{R}} \mathbf{I}_{O}^{(2)},{ }_{\mathrm{F}}^{\mathrm{S}} \boldsymbol{\omega}_{\mathrm{S}}=\left[\begin{array}{c}\dot{\beta} s_{\gamma}+\dot{\alpha} c_{\beta 1} c_{\gamma} \\ \dot{\beta_{1}} c_{\gamma}-\dot{\alpha} c_{\beta 1} s_{\gamma} \\ \dot{\alpha} s_{\beta 1}+\dot{\gamma}\end{array}\right], \mathrm{e}{ }^{\mathrm{S}} \mathbf{I}_{O}^{(3)}={ }^{\mathrm{S}} \mathbf{I}_{C G 3}^{(3)}-m_{3 C G 3}{ }_{\mathrm{S}} \tilde{\mathbf{r}}_{O}^{2}$.

Portanto, o torque de impacto dos corpos 2 e 3 no sistema do motorredutor do grau de liberdade $\beta$ pode ser escrito como: 
$T_{\mathrm{I}}^{(2)}=\sqrt{K_{G}\left\{\begin{array}{l}\frac{\left[I_{2 x} \dot{\alpha}^{2} c_{\beta 1}^{2}+I_{2 z} \dot{\alpha}^{2} s_{\beta 1}^{2}+I_{2 y} \dot{\delta}_{2}^{2}\right]}{2}+ \\ \left.+\frac{\left[I_{3 x}\left(\dot{\delta}_{2} s_{\gamma}+\dot{\alpha} c_{\beta 1} c_{\gamma}\right)^{2}+\left(I_{3 y}+m_{3} h_{2}^{2}\right)\left(\dot{\delta}_{2} c_{\gamma}-\dot{\alpha} c_{\beta 1} s_{\gamma}\right)^{2}+\left(I_{3 z}+m_{3} h_{2}^{2}\right)\left(\dot{\gamma}+\dot{\alpha} s_{\beta 1}\right)^{2}\right]}{2}\right\}\end{array}\right.}$

Conforme Zhao te al. (2017), que realizou uma revisão bibliográfica dos cinco modelos de impacto mais comuns, a deformação após o contato $\delta_{1}=\delta-\delta_{\text {Max }}$ poderia ser solucionada por meio das equações a seguir, de acordo com o modelo escolhido (ZHAO, LIU e LI, 2017).

- Modelo elástico linear, que é o tipo mais simples de modelo de análise de colisão, onde a expressão do torque de impacto pode ser escrita como:

$$
\text { ○ } T_{c}=\left\{\begin{array}{cc}
k_{l} \delta_{1} & \delta_{1}>0 \\
0 & \delta_{1} \leq 0
\end{array}\right.
$$

- onde $k_{l}=$ rigidez do impacto.

- Modelo de Kelvin é o mais usado e utiliza o modelo elástico linear acrescentado de um amortecimento viscoso linear que representa a perda de energia, sendo:

$$
\text { ○ } T_{c}=\left\{\begin{array}{cc}
k_{k} \delta_{1}+c_{k} \dot{\delta}_{1} & \delta_{1}>0 \\
0 & \delta_{1} \leq 0
\end{array},\right.
$$

- onde $k_{k}=$ rigidez do impacto,

- $c_{k}=2 \xi \sqrt{k_{k} \frac{I_{1} I_{2}}{I_{1}+I_{2}}}=$ amortecimento do impacto,

- $I_{1}$ e $I_{2}$ representam momentos de inércia dos corpos que sofrerão o impacto,

- $\quad \xi=-\frac{\ln e_{r}}{\sqrt{\pi^{2}+\left(\ln e_{r}\right)^{2}}}=$ constante de amortecimento.

- Modelo Hertz é um modelo não linear, onde muitos pesquisadores utilizaram a força de impacto baseado na teoria de Hertz para resultar na equação:

$$
\text { - } T_{c}=\left\{\begin{array}{cc}
k_{h} \delta_{1}^{3 / 2} & \delta_{1}>0 \\
0 & \delta_{1} \leq 0
\end{array},\right.
$$

- onde $k_{h}=$ rigidez do impacto.

- Modelo Hertz-Amortecido corrige o modelo anterior de Hertz ao acrescentar a parcela dissipativa de amortecimento não linear conforme:

$$
\text { ○ } \quad T_{c}=\left\{\begin{array}{cc}
k_{h} \delta_{1}^{3 / 2}+c_{h} \dot{\delta}_{1} & \delta_{1}>0 \\
0 & \delta_{1} \leq 0
\end{array},\right.
$$

- onde $k_{k}=$ rigidez do impacto,

- $c_{k}=\xi \delta_{1}^{3 / 2}=$ amortecimento do impacto,

- $\xi=\frac{3 k_{h}\left(1-e_{r}^{2}\right)}{4 \dot{\delta}_{1}}=$ constante de amortecimento.

- Modelo viscoelástico não linear, o processo de colisão foi dividido entre o período de aproximação e o período de restituição. Este processo foi proposto dessa forma por considerar que as trincas, os esmagamentos e as deformações plásticas 
ocorreram principalmente no período de aproximação, portanto, a perda da energia dissipativa ocorreu sobretudo nesta etapa. Assim, pode-se escrever:

$$
\text { ○ } T_{c}=\left\{\begin{array}{cc}
k_{h} \delta_{1}^{3 / 2}+c_{h} \dot{\delta}_{1} & \dot{\delta}_{1}>0 \\
k_{h} \delta_{1}^{3 / 2} & \dot{\delta}_{1} \leq 0
\end{array},\right.
$$

- onde $k_{h}=$ rigidez do impacto,

- $c_{k}=2 \xi \sqrt{k_{h} \sqrt{\delta_{1}} \frac{I_{1} I_{2}}{I_{1}+I_{2}}}=$ amortecimento do impacto,

- $I_{1}$ e $I_{2}$ representam momentos de inércia dos corpos que sofrerão o impacto,

- $\xi=\frac{9 \sqrt{5}\left(1-e_{r}^{2}\right)}{2 e_{r}\left(e_{r}(9 \pi-16)+16\right)}=$ constante de amortecimento.

Geralmente, o processo de folga ocorre num intervalo de tempo muito pequeno, às vezes, insuficiente para ser perceptível pelos sensores propostos pelo experimento desta tese, que possui uma taxa de amostragem de $50 \mathrm{~ms}$ para o IMU e até $200 \mathrm{~ms}$ para a célula de carga. E num intervalo de tempo menor ainda, aproximadamente entre $1 \mathrm{~ms}$ a $10 \mathrm{~ms}$, ocorre o torque do impacto indicado nas equações (2.75) e (2.79). O torque de impacto $T_{c}$ proveniente dos modelos supradescritos pode ser associado ao impulso angular dado pelos torques de impacto $T_{\mathrm{I}}^{(2)}$ e $T_{\mathrm{I}}^{(3)}$, resultando na eq. (2.80).

$$
\text { Impulso }=T_{I} \Delta t=\int_{-\infty}^{\infty} T_{c}(t) d t
$$

Portanto, a importância da verificação do torque de impacto é garantir que não seja alcançado o torque máximo do motor de passo, acarretando o pulo do passo, perdendo então o seu posicionamento de referência apontado pela sua odometria. 


\subsection{Experimento}

\subsubsection{Projeto}

O projeto consiste em produzir um aparato experimental para permitir o estudo da dinâmica de juntas cardânicas ativas utilizando componentes mecânicos e eletrônicos comerciais, viabilizando um orçamento limitado disponível para este estudo. O projeto apresentado, a seguir, já é o resultado da comparação de diversos modelos de geometrias e que foram estudados e comparados com as soluções existentes, citados no subcapítulo 1.3, buscando sempre a solução mais simples possível e que atenda às necessidades experimentais. Os componentes mecânicos comerciais utilizados estão indicados na Figura 2-9, e os componentes eletrônicos comerciais são: a célula de carga e o IMU na Figura 2-10, e o driver do motor de passo e o anel de deslizamento na Figura 2-11, e, por fim, o microcontrolador na Figura 2-12.
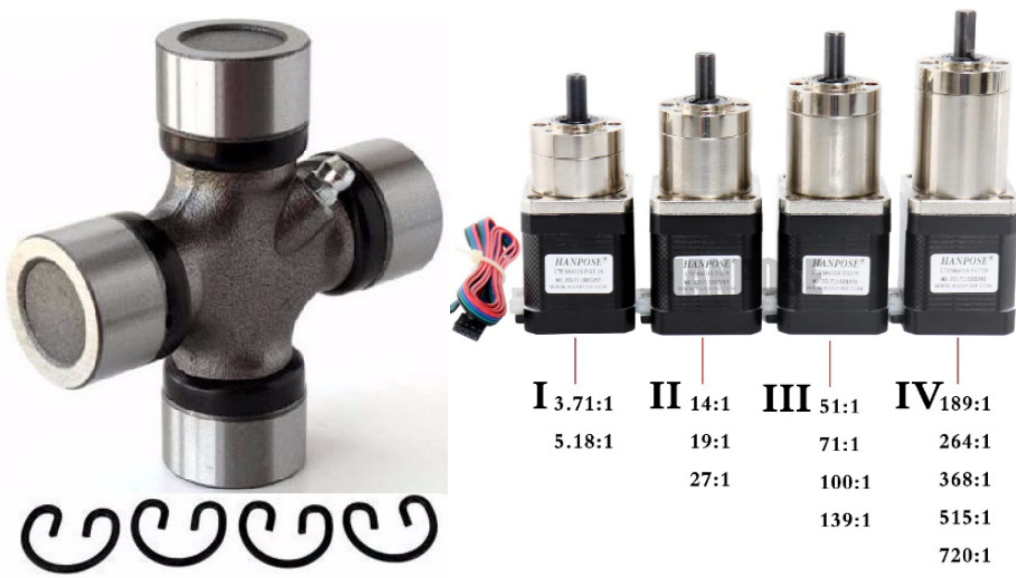

Figura 2-9 - Uma Cruzeta Cardan B04C625 da ASH (à esquerda) e três motores de passo NEMA 17 modelo 17HS8401 marca HANPOSE alternando com as seguintes reduções planetárias 1:720, 1:139 e 1:19 (à direita) [Fonte: Autoria própria]
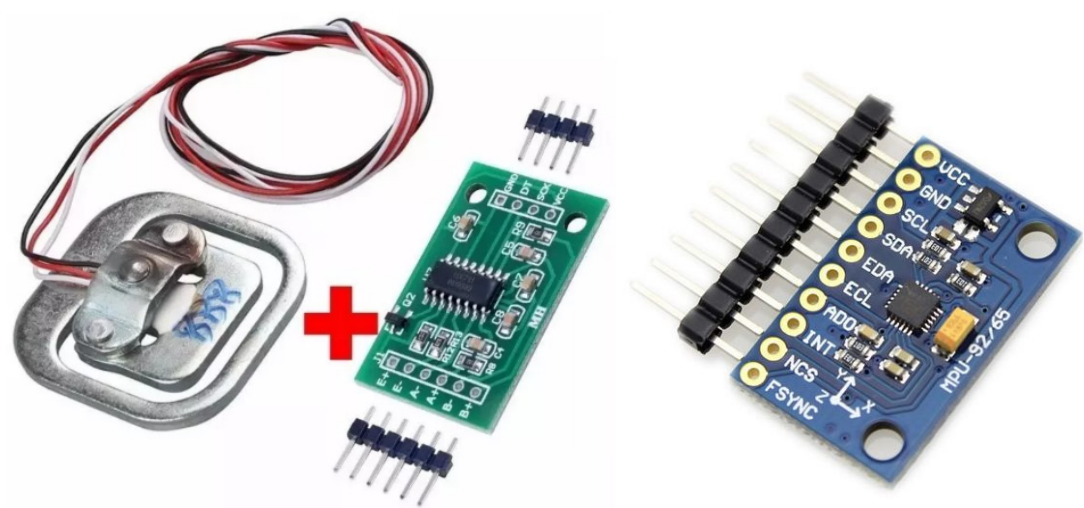

Figura 2-10 - Doze Células de Carga 50 Kg + 06 ADC HX711-24 Bits (à esquerda) e um IMU 9DOF Mpu-9250 - Acelerômetro - Giroscópio - Magnetômetro (à direita) [Fonte: Autoria própria] 

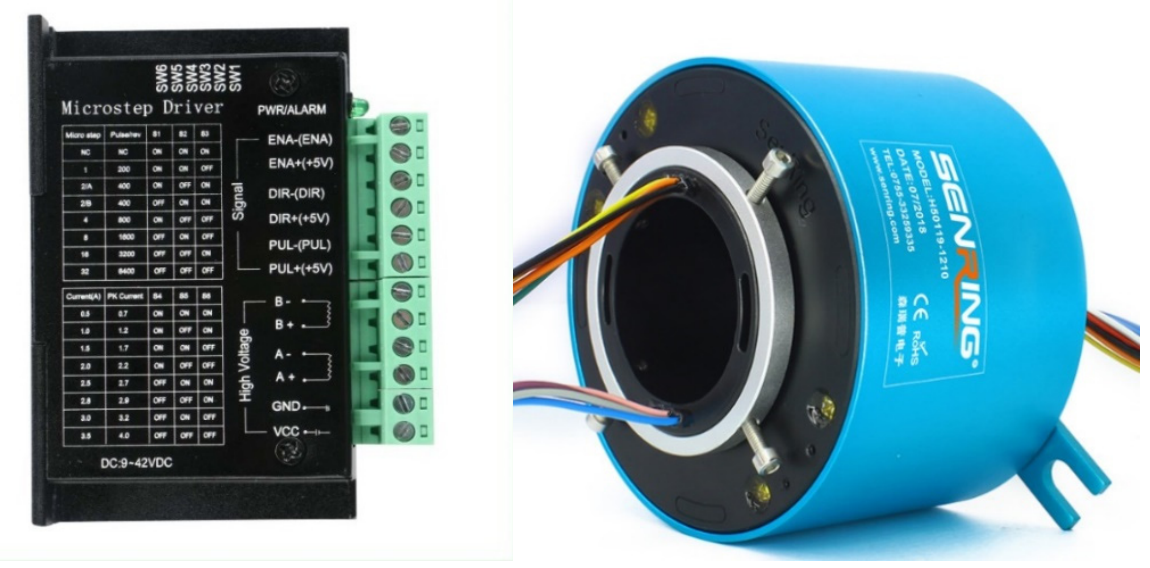

Figura 2-11 - Três MicroStep Driver TB6600 40V 4A (à esquerda) e um Anel de deslizamento oco com contato de ouro com doze canais 10A/canal (à direita) [Fonte: Autoria própria]

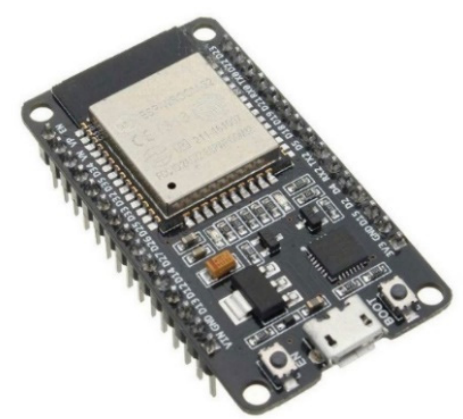

Figura 2-12 - Três Microcontroladores ESP32 240 MHz Wifi/Bluetooth - o primeiro para a leitura do IMU, o segundo para a leitura das células de carga, e terceiro para o controle dos drivers dos motores de passo [Fonte: Autoria própria]

O mecanismo ilustrado na Figura 2-13 foi projetado usando a metodologia Building Information Model (BIM) com o software Autodesk Inventor, ainda, utilizando o Dynamic Simulation e o Nastran para uma análise por elementos finitos integrados à simulação dinâmica, principalmente nas partes críticas, como é o caso da redução planetária escolhida. O desafio de uma junta ativa, sobretudo, aquela de mais de um grau de liberdade, é aplicar, de forma embarcada, uma solução de motores e redutores com relação ao tamanho, ao peso e à potência suficientes para conseguir atender aos critérios de projeto. Dos diversos componentes apontados no modelo em CAD, o redutor planetário, por já ser uma solução compacta de redução, merece uma atenção especial por conter em seu interior as maiores velocidades, torques e tensões envolvidas durante a dinâmica do movimento. É possível também observar os contrapesos variáveis utilizados para balancear os motorredutores, dessa forma, buscando garantir a simetria da matriz de inércia dos corpos rígidos, conforme proposto na equação (2.22). 


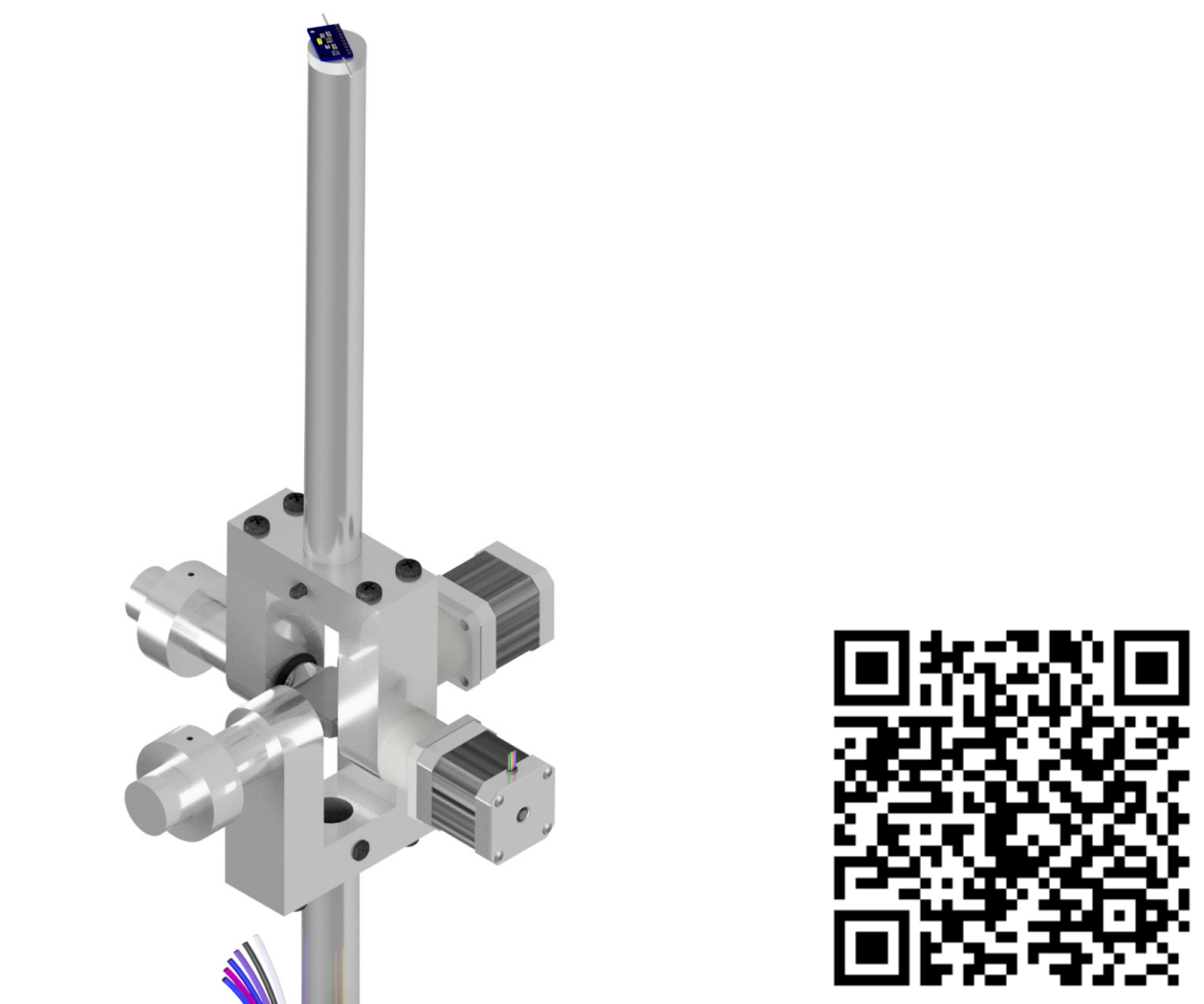

Figura 2-13 - Modelo CAD 3D do Experimento (à esquerda) e o QRCODE para o desenho técnico do experimento (à direita) [Fonte: Autoria própria]

Após o projeto mecânico, a realização do projeto eletrônico utilizou o software EAGLE para criar os diagramas de ligações e o projeto final das placas, ulteriormente às validações dos testes unitários de cada um dos componentes por protoboard e placas de circuitos provisórias. Apenas um microcontrolador ESP32, indicado na Figura 2-12, não possuía portas suficientes para atender à demanda do experimento. Por conseguinte, foram idealizados dois circuitos separados, o primeiro, conforme a Figura 2-14, para realizar as medições dos sensores, neste caso, as doze células de carga e o IMU MPU 9250, indicados 
na Figura 2-10, e o outro circuito, conforme a Figura 2-15, para comandar os drivers dos motores, indicado na Figura 2-11 e também para ler sua odometria.

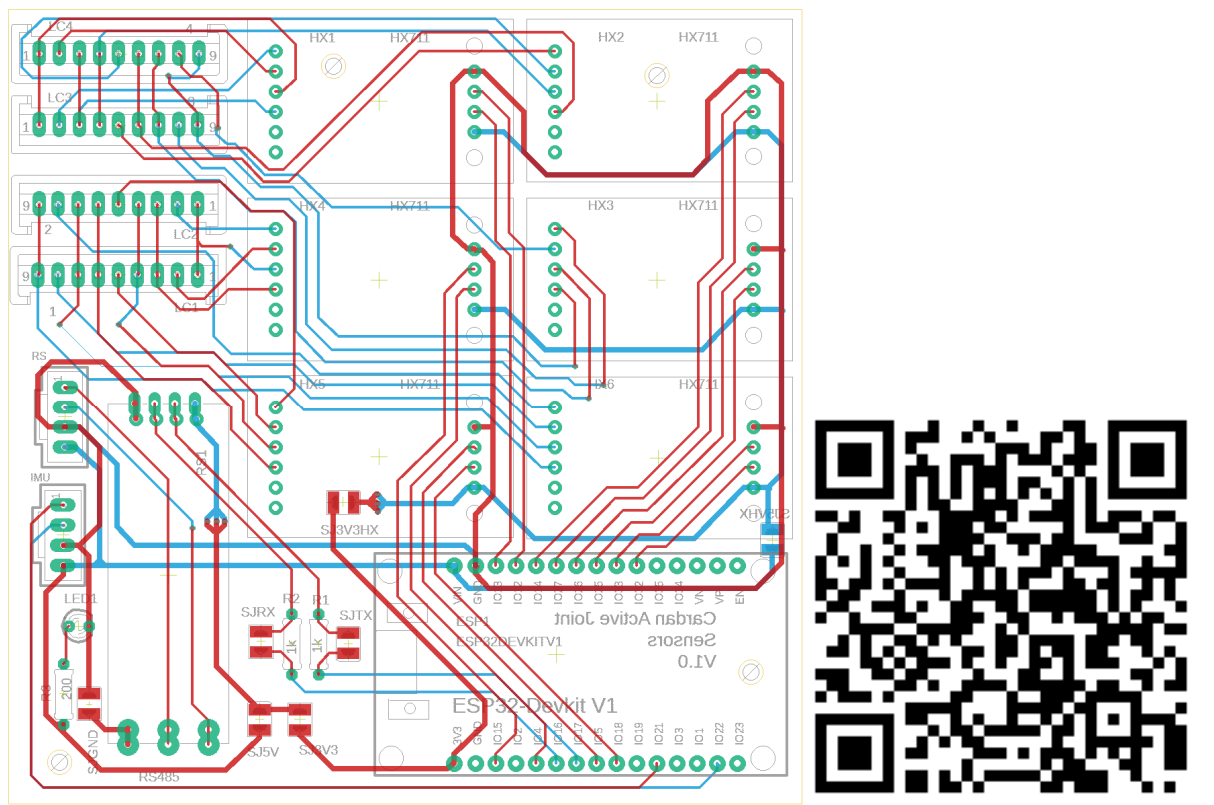

Figura 2-14 - Projeto final da placa do Circuito 1 - Leitura das células de carga e do IMU (à esquerda) e QRCODE para o Diagrama esquemático (à direita) [Fonte: Autoria própria]

Na Figura 2-14, o modelo da célula de carga utilizado representa apenas a metade da ponte de Wheatstone necessária ao equilíbrio dos sinais dos strain-gauges. Comumente, a outra metade da ponte pode ser completada por um resistor de $1 \mathrm{KO} \mathrm{hms}$, no entanto optou-se, por questão de qualidade do sinal, por utilizar outra célula de carga para completar a ponte, assim, garantindo um equilíbrio melhor das resistências envolvidas. Portanto, cada conversor digital ADC HX 711 de 24 bits ilustrado na Figura 2-10 corresponde à leitura de uma ponte de Wheatstone, ou seja, duas células. A relação de cada leitura feita pelo conversor digital com as forças modeladas no subcapítulo 2.2.2 pode ser vista na Tabela 1 . Ainda, no diagrama da Figura 2-14, o circuito permite a leitura do sensor IMU MPU 9250 através do protocolo $\mathrm{I} 2 \mathrm{C}$, viabilizando ao microcontrolador ESP32 realizar as seis leituras dos conversores digitais provenientes das células de carga e os noves valores do IMU (três para aceleração, três para velocidade angular e três para o magnetômetro). Com este primeiro circuito, a proposta foi de conectá-lo por $W i-F i$ diretamente ao MATLAB, permitindo então a leitura de seus sensores. Por fim, pensando na possibilidade da interligação direta dos dois circuitos com maior taxa de amostragem, caso no futuro fosse necessário, foi utilizado um módulo conversor RS485 para TTL, com isso, permitindo a comunicação entre os dois controladores. 


\begin{tabular}{|c|l|}
\hline Sinal do ADC HX 711 & Forças - Figura 2-2 \\
\hline Sinal 1 & $F_{3 x}-F_{1 x}$ \\
\hline Sinal 2 & $F_{3 z}-F_{1 z}$ \\
\hline Sinal 3 & $F_{3 y}-F_{1 y}$ \\
\hline Sinal 4 & $F_{2 x}-F_{4 x}$ \\
\hline Sinal 5 & $F_{2 y}-F_{4 y}$ \\
\hline Sinal 6 & $F_{2 z}-F_{4 z}$ \\
\hline
\end{tabular}

Tabela 1 - Relação de leituras das células de carga [Fonte: Autoria própria]

Durante a fase experimental, observou-se um ruído significativo nos sinais e travamentos no sensor IMU. Após meticulosa análise, constatou-se que esse problema ocorria devido aos seguintes motivos: comprimento excessivo do cabo de comunicação (cerca de um metro); sensibilidade do protocolo I2C e resistência adicional variável devido ao anel de deslizamento oco. Para resolver o problema, optou-se por embarcar um terceiro microcontrolador próximo ao IMU, para processar o seu sinal e enviando por $W i$ - Fi, não havendo necessidade da confecção de nenhuma outra placa, uma vez que foram utilizados quatro cabos curtos relativos aos sinais do IMU indicados na Figura 2-14. Para alimentar este terceiro microcontrolador embarcado, foi utilizada a energia proveniente do circuito 1.

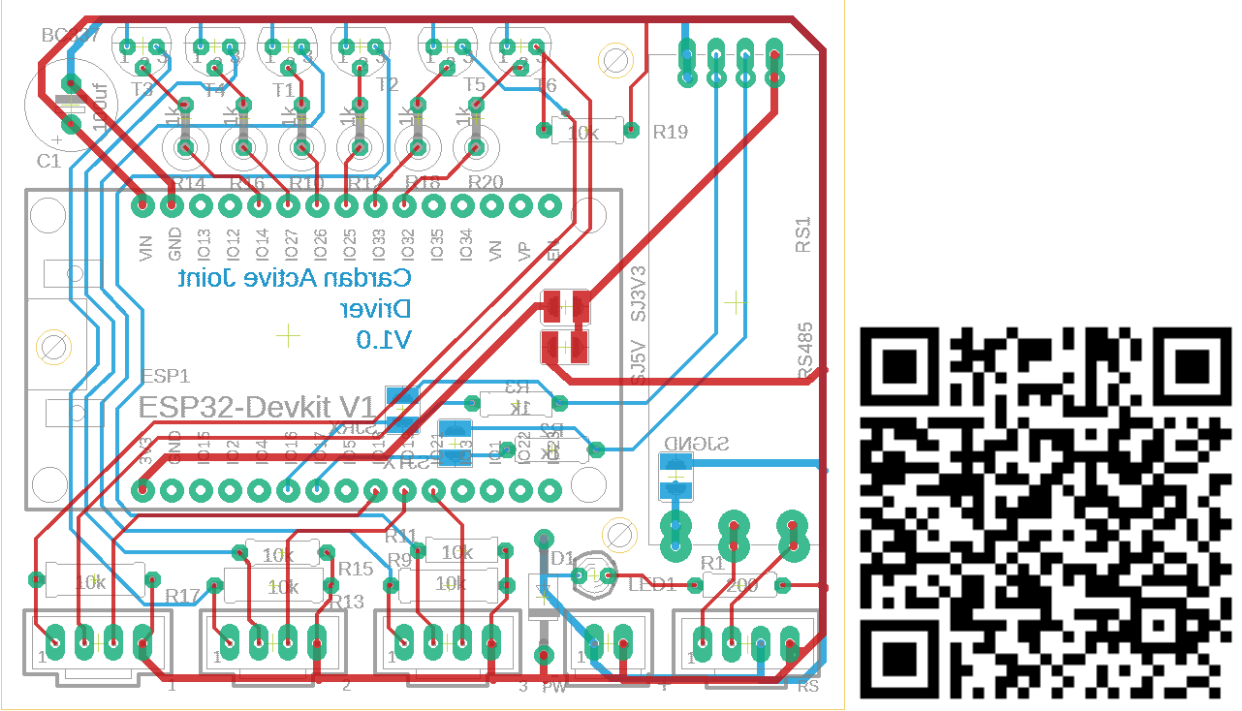

Figura 2-15 - Projeto final da placa do Circuito 2 - Comando dos motores de passo e leitura de suas odometrias (à esquerda) e QRCODE para o Diagrama esquemático (à direita)

[Fonte: Autoria própria] 
No circuito 2, indicado na Figura 2-15, além do protocolo de comunicação utilizando o módulo conversor RS485 para TTL, existem as saídas de comando dos pulsos para cada driver TB6600 que alimenta e controla cada motor de passo.

\subsubsection{Manufatura}

O processo de manufatura foi realizado conforme o projeto indicado no subcapítulo 2.3.1 seguindo as boas práticas da engenharia, principalmente das partes não comerciais, conforme indicado na Figura 2-16.

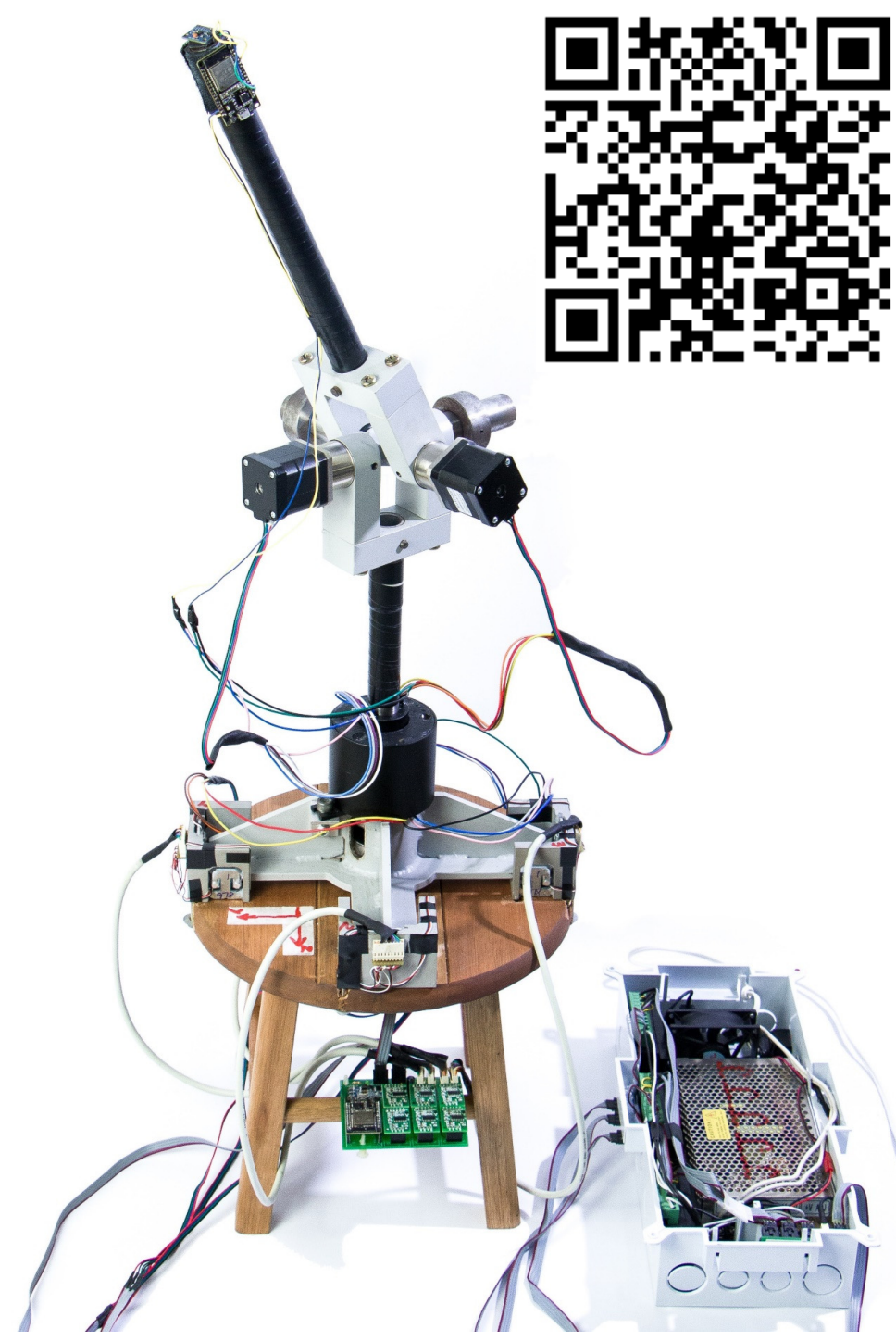

Figura 2-16 - Foto da bancada experimental completa e o QRCODE para fotografias adicionais do processo de fabricação [Fonte: Autoria própria] 
Conforme projeto, na Figura 2-16 é possível observar no ponto P, indicado na Figura 2-1, o posicionamento do IMU na ponta do atuador para a medição da aceleração, velocidade angular e do magnetômetro. E, para a realização das medições dos momentos de reações em SR F no ponto A, foi elaborado em alumínio, conforme Figura 2-17, um receptáculo para acomodação das três células de carga indicadas na Figura 2-10 e fixado por parafusos no banco em madeira, como se observa na Figura 2-16.

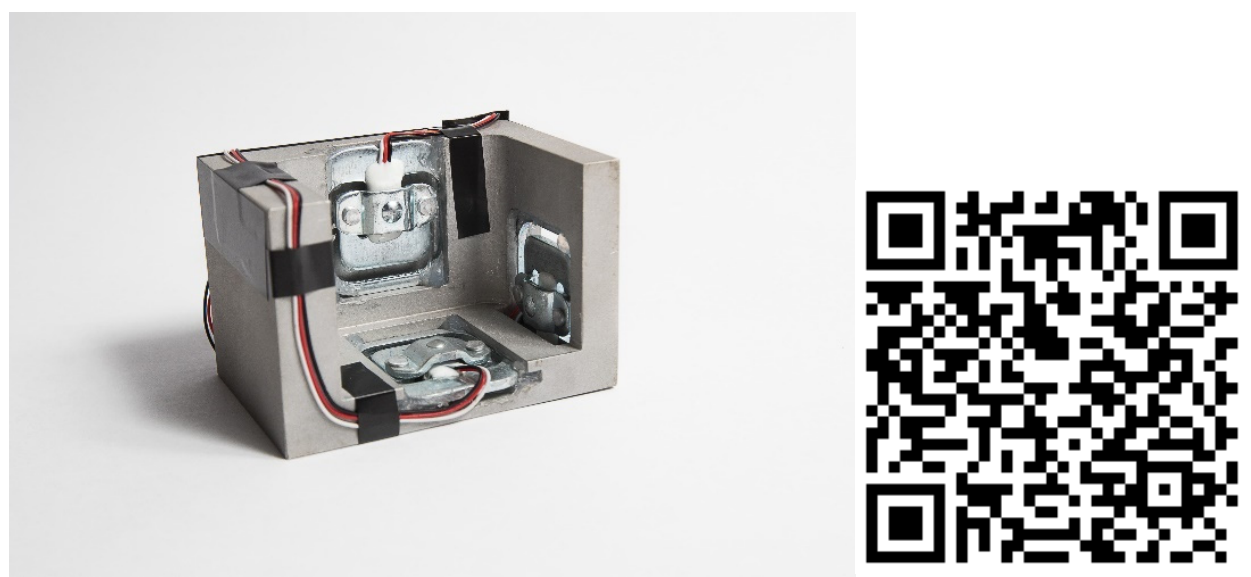

Figura 2-17 - Receptáculo para acomodação das células de carga nos três eixos e QRCODE para fotografias adicionais [Fonte: Autoria própria]

$\mathrm{Na}$ manufatura eletrônica, os primeiros testes foram realizados utilizando os componentes em protoboards, em seguida, em placas de circuitos provisórias até a confirmação do circuito final, que foi impresso profissionalmente por JLCPCB, enviando os arquivos no formato Gerber, pelo site <https://jlcpcb.com/>. Na Figura 2-18 é possível observar as Printed Circuit Board (PCB) finais com os componentes montados.
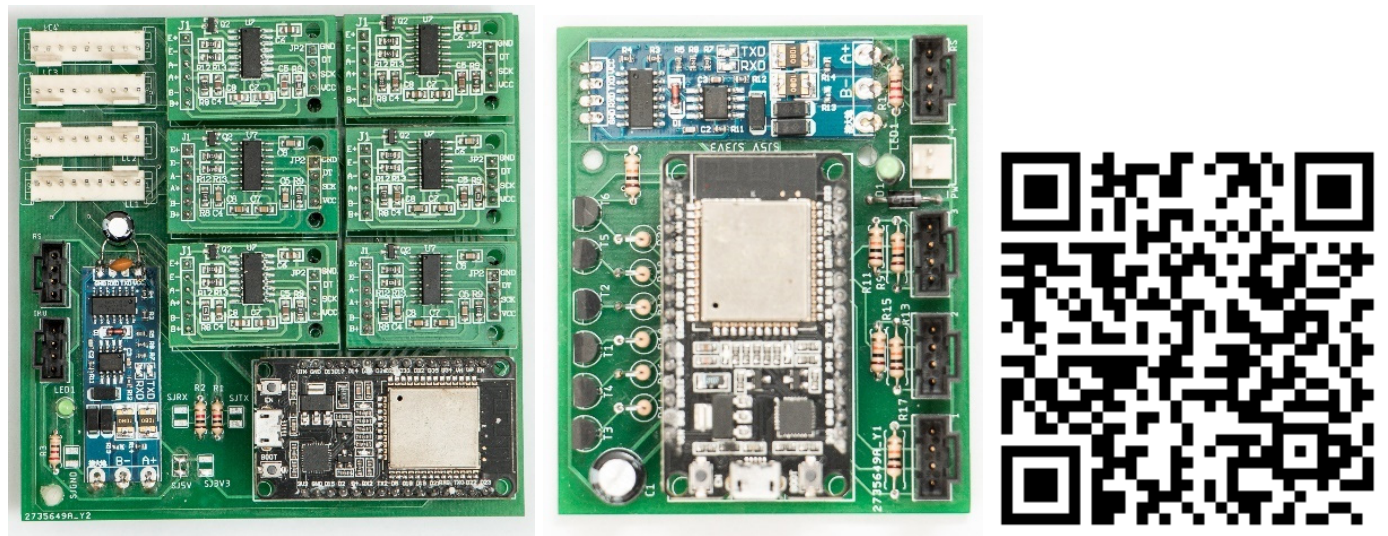

Figura 2-18 - PCB para leitura das células de carga e IMU (à esquerda), PCB para leitura da odometria e comando dos drivers (no centro) e QRCODE para fotografias dos protoboards, placas de circuitos provisórias e os arquivos no formato Gerber (à direita)

[Fonte: Autoria própria] 


\subsubsection{Programação}

A programação dos microcontroladores foi desenvolvida em linguagem $\mathrm{C} / \mathrm{C}++$, na interface de desenvolvimento do Arduino, instalando bibliotecas adicionais para trabalhar com a placa "ESP 32 Dev Module".

No primeiro microcontrolador, controlador dos drivers e a sua odometria, foram utilizadas tarefas em sua programação, com uso da biblioteca FreeRTOS para comandar os pulsos dos motores de passo: alpha (taskStepperMa $-100 \mathrm{~ms}$ ), beta (taskStepperMb $-100 \mathrm{~ms}$ ) e gama (taskStepperMc - 100ms), além das tarefas para a comunicação serial (taskSerialCom - 50ms) e por $W i-F i$ (taskWifi - 50ms). As tarefas para comunicação permitem receber diversos comandos por texto que serão interpretados dentro do código, por exemplo: ao enviar por $\mathrm{Wi}-\mathrm{Fi}$ ou serial, o comando em texto “A0.5B1.0C00" será interpretado como sendo velocidade angular do motor-redutor alpha igual a $0,5 \mathrm{rad} / \mathrm{s}$, do motor-redutor beta $1,0 \mathrm{rad} / \mathrm{s}$ e do motor-redutor gama $0 \mathrm{rad} / \mathrm{s}$, já considerando a redução mecânica aplicada ao experimento. Caso o comando em texto fosse com letras minúsculas "a0.5b1.0c00", essas seriam a velocidade angular no eixo do motor, desconsiderando a redução mecânica utilizada. De uma maneira geral, os textos programados que comandam o microcontrolador são:

- $\mathrm{t}$ - Ativa a tarefa alive (led que indica o funcionamento)

- 1 - Ativa a tarefa do motor alpha

- ! - Suspende a tarefa do motor alpha

- 2 - Ativa a tarefa do motor beta

- @ - Suspende a tarefa do motor beta

- 3 - Ativa a tarefa do motor gama

- \# - Suspende a tarefa do motor gama

- p10 - Incremento da rampa do pulso do motor de 10

- P10 - Incremento da rampa do pulso do motorredutor de 10

- a00 - Velocidade angular do motor alpha

- b00 - Velocidade angular do motor beta

- c00 - Velocidade angular do motor gama

- A00 - Velocidade angular do motorredutor alpha

- B00 - Velocidade angular do motorredutor beta

- C00 - Velocidade angular do motorredutor gama

- $\mathrm{s}$ - Início do envio dos dados

- $\mathrm{S}$ - Término do envio dos dados

- d - Desconecta a serial

- $\mathrm{z}$ - Zera as odometrias

- $r$ - Reinicia a serial em 500000

- R - Reinicia a serial em 921600

- i - Início do envio dos dados pela serial

- o - Término do envio dos dados pela serial 
No segundo microcontrolador para as células de carga, similar ao primeiro, foi utilizada a programação por tarefas, então, usando FreeRTOS para criar as tarefas de comunicação (taskWifi - 20ms e taskSerialCom - 20ms) e outras tarefas para a preparação (InitializationLoadCell) e leitura (taskReadLoadCell - 150ms) das células de carga, onde também foi possível interagir com o controlador via serial e Wi-Fi com os seguintes comandos em texto:

- $\mathrm{t}$ - Ativa a tarefa alive (led que indica o funcionamento)

- $\mathrm{z}$ - Ativa a tarefa xtaskZerarTara

- $\mathrm{s}$ - Início do envio dos dados

- S - Término do envio dos dados

- d - Desconecta a serial

- i - Início do envio dos dados pela serial

- o - Término do envio dos dados pela serial

No terceiro microcontrolador embarcado na ponta do atuado para a leitura do IMU, de forma similar aos anteriores, foi utilizada programação por tarefas, para tanto, usando FreeRTOS para criar as tarefas de comunicação (taskWifi - 50 ms e taskSerialCom - 50 $\mathrm{ms}$ ) e outras tarefas de leitura do IMU (taskReadIMU - $50 \mathrm{~ms}$ ), além de utilizar os seguintes textos para comando:

- $\mathrm{t}$ - Ativa a tarefa alive (led que indica o funcionamento)

- s - Início do envio dos dados

- S - Término do envio dos dados

- d - Desconecta a serial

- i - Início do envio dos dados pela serial

- o - Término do envio dos dados pela serial

Nas tarefas de comunicação, comuns a todos os microcontroladores, os dados enviados possuem a seguinte formatação:

- Microcontrolador dos drivers

○ $\quad 0.000000,0.000000,0.000000,0.000000$;

- Timer, auxodometryMa, auxodometryMb, auxodometryMc;

- Microcontrolador das células de carga (conforme Tabela 1)

○ $0.000,0.000,0.000,0.000,0.000,0.000,0.000$;

- Timer, load1Val, load2 Val, load3Val, load4Val, load5Val, load6Val;

- Microcontrolador da IMU

○ $\quad 0.000,0.000,0.000,0.000,0.000,0.000,0.000,0.000,0.000,0.000$;

○ Timer, getAccelX_mss, getAccelY_mss, getAccelZ_mss, getGyroX_rads, getGyroY_rads, getGyroZ_rads, getMagX_uT, getMagY_uT, getMagZ_uT.

Dessa forma, a programação realizada no microcontrolador consiste apenas numa sequência de leituras e comandos, conforme pode ser verificado no código no link do QRCODE na Figura 2-19, que irá interagir com o MATLAB por meio das tarefas de 
comunicação para a resolução dos problemas que exigem uma capacidade de processamento superior.

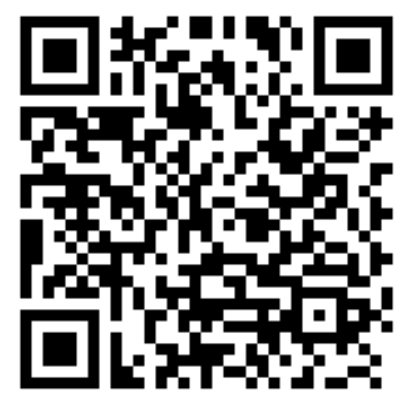

Figura 2-19 - Código fonte dos microcontroladores em C/C++ utilizados no experimento [Fonte: Autoria própria]

\subsection{Proposição dos casos e resolução analítica}

A ideia principal desta tese consistiu em estudar uma junta cardânica ativa com aspectos originais tanto na parte construtiva como na aplicação dos conceitos de cinemática direta e inversa e na formulação das equações de movimento. Para tanto foi projetado um dispositivo de baixo custo e totalmente instrumentado para permitir a validação do estudo analítico. O projeto foi executado a partir de um modelo que facilitasse a compreensão da cinemática, dinâmica e adaptado à medida que os componentes fossem sendo comprados, construídos e montados. Para o estudo teórico/experimental foram concebidos quatro problemas específicos. Eles não somente serviram para encontrar os limites que definem a atuação de uma junta cardânica ativa como mostravam as particularidades operacionais de um sistema desse tipo.

Para a resolução dos três primeiros problemas, a abordagem tradicional consiste em conhecer o vetor de estado das coordenadas cardânicas $(\alpha, \beta, \gamma, \dot{\alpha}, \dot{\beta}, \dot{\gamma})$ para resolver a cinemática proposta dentro da área de trabalho contida na superfície esférica (bidimensional), conforme indicado na Figura 2-20. No entanto a conjunção dos três graus de liberdade cardânicos abre espaço para uma discussão sobre o movimento de rotação em torno de um eixo que passa pelo centro do corpo conhecido por spin. Enquanto o spin de entrada, caracterizado por $\dot{\alpha}=\omega_{I}(t)$, é a rotação do corpo 1 em torno de seu eixo, sendo ao mesmo tempo uma das componentes do vetor estado, o spin de saída, caracterizado por $\omega_{O}(t)$, é a rotação do corpo $3 \mathrm{em}$ torno de seu eixo, não sendo parte do vetor de estado. A relação entre o spin de entrada e o spin de saída é mostrada na equação (2.17). 
O quarto problema propõe uma abordagem inovadora ao definir o vetor de estado da junta $(\theta, \phi, \psi, \dot{\theta}, \dot{\phi}, \dot{\psi})$, que é baseado no conceito do ângulo do plano de junta ( $\theta)$, ângulo de junta $(\phi)$, e o ângulo do spin de saída ( $\psi$ ), como ilustrado na Figura 2-20. Como os eixos dos corpos 1 e 3 formam um plano quando não estão colineares, o ângulo entre estes eixos é o ângulo de junta, e a posição deste plano em referência a outro plano ortogonal ao eixo do corpo 1 define o ângulo do plano de junta. Esse novo sistema de coordenadas proposto, denominado sistema de coordenadas da junta, retrata, de uma maneira mais direta e clara, a posição do atuador do manipulador, além de permitir a utilização da rotação cônica em torno de um só vetor de Euler, para movimentar através do menor caminho de um ponto ao outro na área de trabalho da junta, conforme será demonstrado a seguir. A inovação nesta abordagem é que, como mecanicamente a operação da junta é por parâmetros cardânicos, a trajetória otimizada via coordenadas de estado da junta deve ser transformada a cada instante em coordenadas cardânicas.
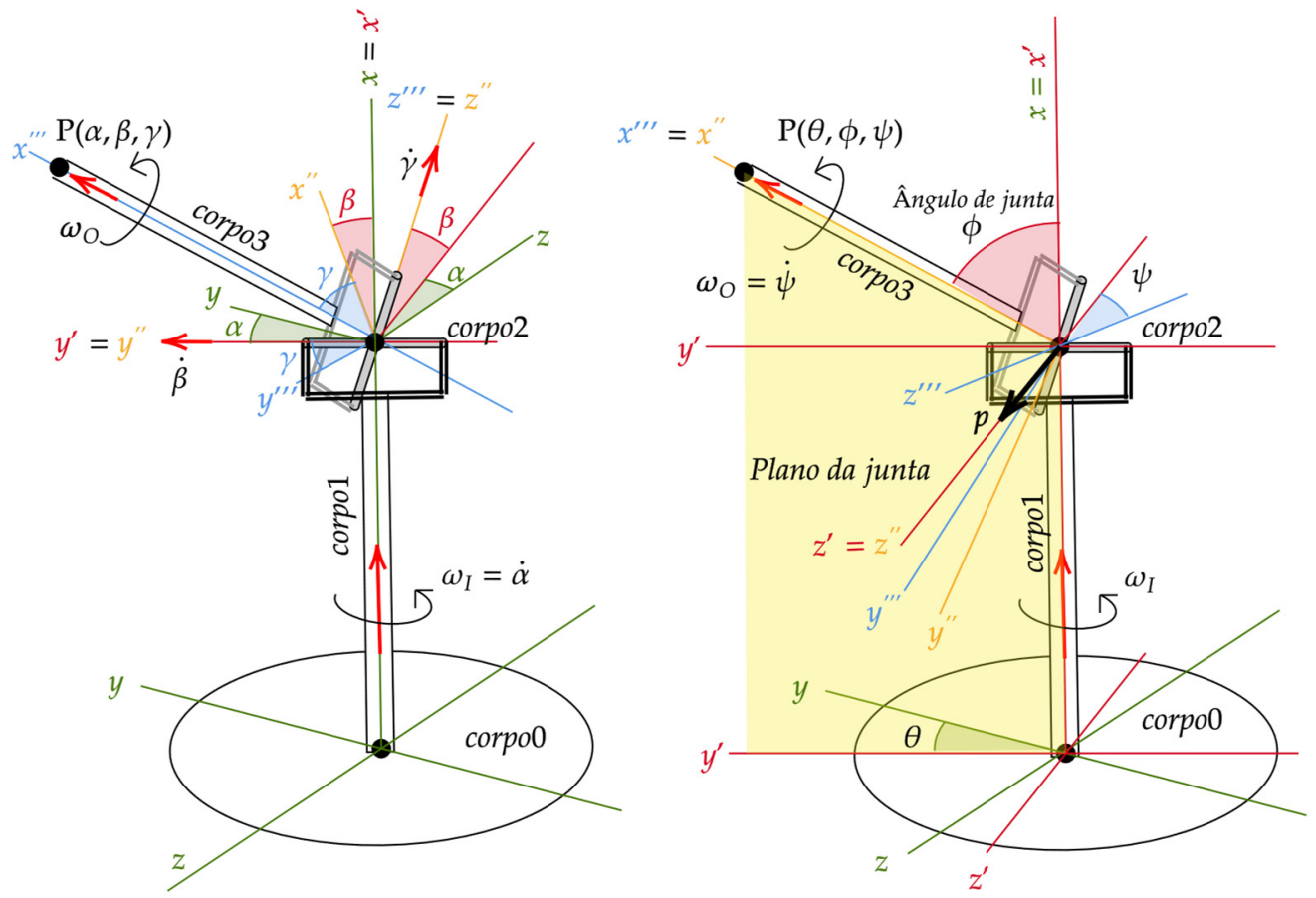

Figura 2-20 - Sistema de coordenadas cardânicas (à esquerda) e o da junta (à direta) [Fonte: Autoria própria]

No livro de Weber (2019) é introduzido o conceito de rotação cônica: neste caso, tem-se o vetor de Euler girando em torno do corpo 1 sempre ortogonal ao plano de junta, e o ângulo de rotação em torno do vetor representa o ângulo de junta. Discute-se nesse texto que essas 
duas rotações levam a um movimento em que o corpo 3 não possui spin. Assim, segue-se uma rotação sequencial em torno do eixo de saída que descreve o spin. Na obtenção da Matriz de Orientação, esta técnica usa a metodologia de obter a matriz de rotação (com p e $\phi$ ) com uma Matriz de Transformação de coordenadas a partir da rotação elementar sequencial elementar em torno do eixo de saída.

\subsubsection{Caso 1 - Cinemática e Dinâmica (problema 1)}

Neste primeiro caso, as variáveis de entrada são as coordenadas da posição do atuador em um ponto $P(x, y, z)$ fixo e a rotação $\dot{\alpha}$ constante do motor alpha. E, como saída, deve-se ter $\beta(t)$ e $\gamma(t)$ para encontrar uma solução do problema que consista em manter a posição do atuador apesar do giro em $\alpha$. Na condição inicial para este problema, foi escolhido um ponto $P(x, y, z)$ de tal forma que o ângulo de junta fosse representado pelo acionamento do ângulo $\gamma$, ou seja, como $c_{\phi}=c_{\beta} c_{\gamma}$ pode-se inferir que $\gamma(t=0)=\phi$, e os outros ângulos iguais a zero. $\alpha(t=0)=\beta(t=0)=0$. E, para esta condição inicial, usando a equação (2.19) , o ponto $P(x, y, z)$ pode ser dado por:

$$
\left[\begin{array}{c}
P_{x} \\
P_{y} \\
P_{z}
\end{array}\right]=\left[\begin{array}{c}
l_{1}+l_{2} c_{\phi} \\
l_{2} s_{\phi} \\
0
\end{array}\right]
$$

Este problema é similar ao fixar a segunda haste para conhecer os ângulos da junta cardânica (WEBER, 2019). Assim a posição angular de cada ângulo pode ser dada como:

$$
\begin{aligned}
& \alpha(t)=\dot{\alpha} t \\
& \beta(t)=\operatorname{atan}\left(t_{\phi} s_{\alpha(t)}\right) \\
& \gamma(t)=\operatorname{atan}\left(s_{\beta(t)} / t_{\alpha(t)}\right)
\end{aligned}
$$

Um forma alternativa da equação (2.82) para posicionamento do atuador do problema pode ser obtida ao conjugar a equação (2.20) da cinemática inversa com a equação (2.81), resultando em:

$$
\begin{aligned}
& \alpha(t)=\dot{\alpha} t \\
& \gamma(t)=\operatorname{asin}\left(s_{\phi} c_{\alpha(t)}\right) \\
& \beta(t)=-\operatorname{sign}(\dot{\gamma}) \operatorname{acos}\left(c_{\phi} / c_{\gamma(t)}\right)
\end{aligned}
$$

As equações (2.82) e (2.83) devem ser trabalhadas numericamente para evitar as descontinuidades provenientes das funções trigonométricas inversas mantendo a 
continuidade das funções. Uma vez conhecidas as funções, optou-se por obter as derivadas de primeira e segunda ordem no tempo, por diferenciação numérica, sendo possível determinar todo o estado do problema $\alpha, \dot{\alpha}, \ddot{\alpha}, \beta, \dot{\beta}, \ddot{\beta}$ e $\gamma, \dot{\gamma}, \ddot{\gamma}$ com antecedência. Ao conhecer as variáveis de estado do problema, foi possível, portanto, resolver a eq. (2.47) para obter todos os torques e momentos de reação do problema. Em seguida, para calcular o torque de atrito dos rolamentos, foi necessário calcular as forças radiais nos rolamentos através do sistema de equações (2.54) e (2.84), tornando assim possível a obtenção dos momentos resistivos de cada rolamento de acordo com a equação (2.64). E, por fim, incorporou-se ao problema a identificação da folga, uma vez que a folga é localizada, a dinâmica do problema modifica-se para obedecer à equação (2.73) para o grau de liberdade $\gamma$ e à equação (2.77) para o grau de liberdade $\beta$. Resolvido o problema da folga, calculase o torque de impacto referente ao novo acoplamento do eixo do motor com a carga por questões de dimensionamento do motor de passo.

A solução analítica e numérica foi desenvolvida em MATHCAD e confirmada no MATLAB para diversos valores de condições iniciais do ângulo de junta $\phi=[\pi / 12, \pi / 6] \mathrm{rad}$ e velocidades angulares $\dot{\alpha}=[0,1 ; 0,2 ; 0,4 ; 0,8 ; 1,6] \mathrm{rad} / \mathrm{s}$ que foram validados tanto pela simulação no Inventor Dynamic Simulation quanto na parte experimental apresentada no subcapítulo 3.2.1. Para conseguir visualizar o spin do corpo 3, foi desenhada uma pequena haste no disco superior, conforme indicado na Figura 2-21.

Durante a fase da simulação analítica e experimental, observou-se que qualquer pequena variação na montagem dos corpos rígidos que altere a localização do ponto $\mathrm{O}$, indicado na Figura 2-1, compromete o modelo proposto. E a trajetória circular devido ao spin do atuador, mostrado na Figura 2-21, torna-se um traçado curvilíneo genérico, acarretando uma variação no ponto $P(x, y, z)$. Este ponto de atenção foi levado como critério de projeto na confecção do experimento. 

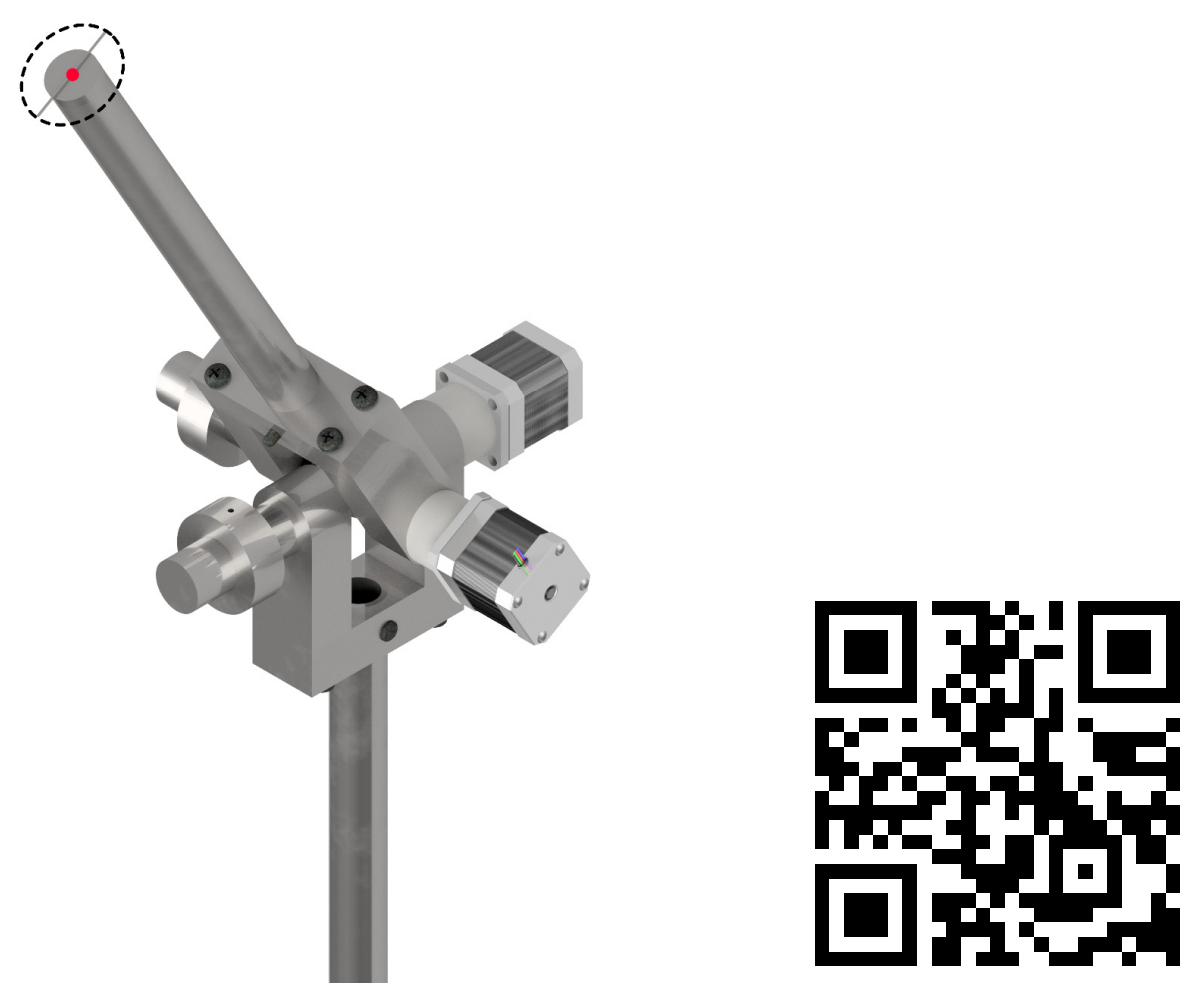

Figura 2-21 - Representação do movimento do problema 1 simulado no Inventor Dynamic Simulation (à esquerda) e QRCODE na animação do movimento (à direita) [Fonte: Autoria própria]

\subsubsection{Caso 2 - Cinemática e Dinâmica (problema 2)}

Neste segundo problema, optou-se por fazer o efetuador percorrer uma trajetória circular paralela ao plano $y z$ no SR F. E, para tal, foram definidas as seguintes condições iniciais $\gamma(t=0)=\phi$ e $\alpha(t=0)=\beta(t=0)=0$. No entanto, desta vez, o ângulo $\alpha$ deveria permanecer nulo durante todo o trajeto $\alpha(t)=0$, e, para resolver os valores do ângulos $\beta$ e $\gamma$, escreveu-se as coordenadas do ponto $P(x, y, z)$ em função do círculo desejado, logo:

$$
\left[\begin{array}{c}
P_{x} \\
P_{y} \\
P_{z}
\end{array}\right]=\left[\begin{array}{c}
l_{1}+l_{2} c_{\phi} \\
l_{2} s_{\phi} c_{\theta} \\
l_{2} s_{\phi} s_{\theta}
\end{array}\right]
$$

Onde $\theta(t)$ é o ângulo formado no plano do círculo conforme Figura 2-23, sendo também o ângulo do plano de junta definido na Figura 2-20 à direita. Pressupondo o ângulo de junta 
$\phi$ constante, obtém-se $P_{x}$ conforme equação (2.85) também constante. Desta forma, pela cinemática inversa na eq. (2.20) é possível calcular os ângulos $\beta$ e $\gamma$.

$$
\begin{aligned}
& \gamma(t)=\operatorname{asin}\left(s_{\phi} c_{\theta(t)}\right) \\
& \beta(t)=-\operatorname{sign}(\dot{\gamma}) \operatorname{acos}\left(c_{\phi} / c_{\gamma(t)}\right)
\end{aligned}
$$

A solução analítica e numérica foi desenvolvida em MATHCAD e confirmada pelo MATLAB para diversos valores de condições iniciais do ângulo de junta $\phi=[\pi / 12, \pi / 6] \mathrm{rad}$ e velocidades angulares $\dot{\theta}=[0,1 ; 0,2 ; 0,4 ; 0,8 ; 1,6] \mathrm{rad} / \mathrm{s}$ que foram validados tanto pela simulação no Inventor Dynamic Simulation quanto na parte experimental no subcapítulo 3.2.2. Para conseguir visualizar o spin do corpo 3, foi desenhada uma pequena haste no disco superior, conforme a Figura 2-22.

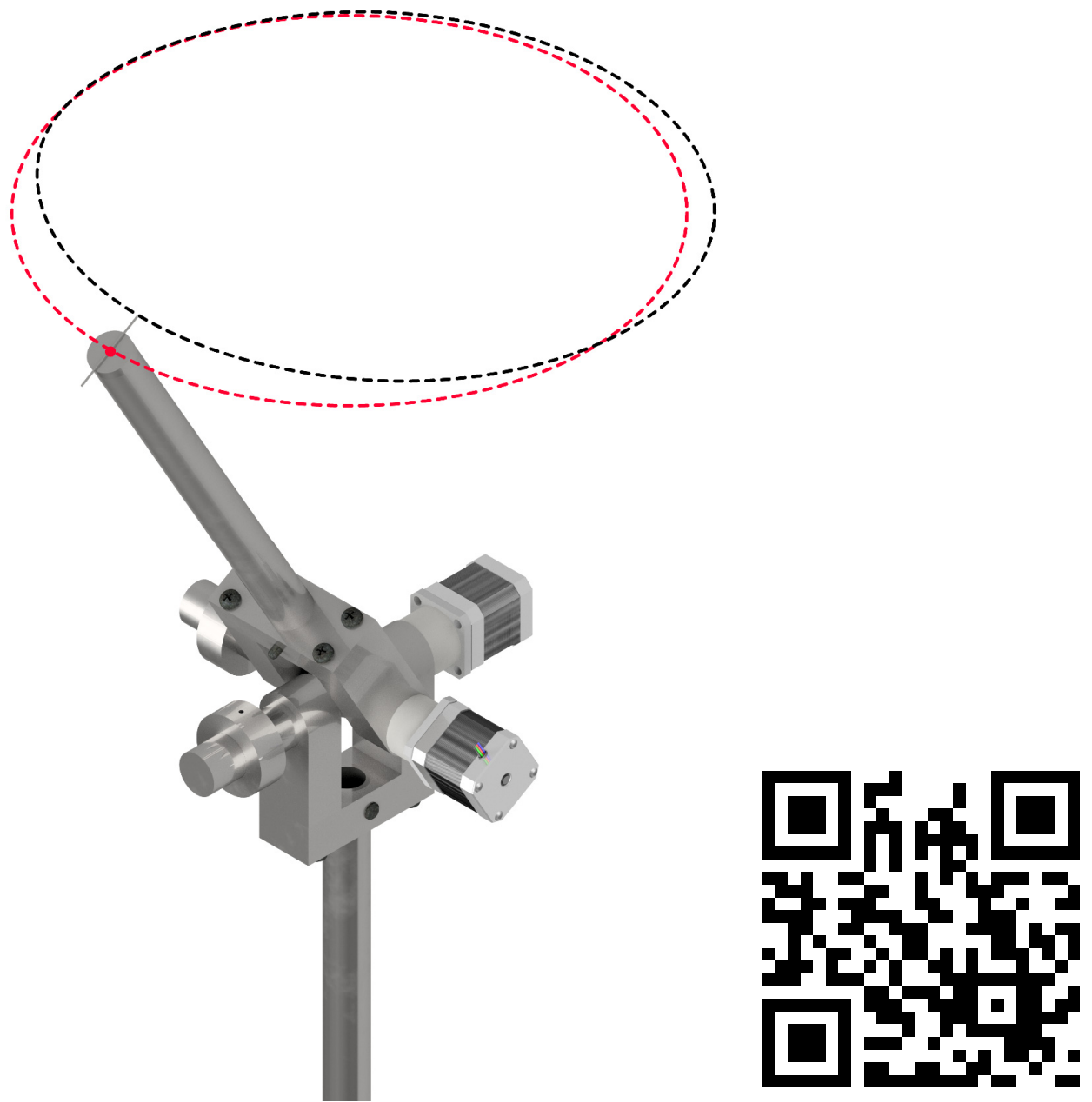

Figura 2-22 - Representação do movimento do problema 2 simulado no Inventor Dynamic Simulation (à esquerda) e QRCODE na animação do movimento (à direita) [Fonte: Autoria própria] 
A equação (2.86) é similar à equação (2.83), apenas substituindo $\theta(t)$ no lugar do $\alpha(t)$, uma vez que $\alpha(t)=0$, mas $\theta(t)$ é o ângulo em torno do eixo $x$ do SR F que se desejava estudar um movimento circular. Uma vez conhecidas as variáveis de estado de posição, velocidade e aceleração dos ângulos, similar ao caso 1, os torques, momentos de reação, o torque de atritos dos rolamentos e as folgas puderam ser calculadas. Uma desvantagem deste problema ao considerar $\alpha(t)=0$, aparece pela dificuldade da análise da folga neste grau de liberdade, nesta posição, o que poderá atrapalhar os resultados dos movimentos estudados, esperando-se, assim, algumas instabilidades nos procedimentos experimentais apresentados no subcapítulo 3.2.2.

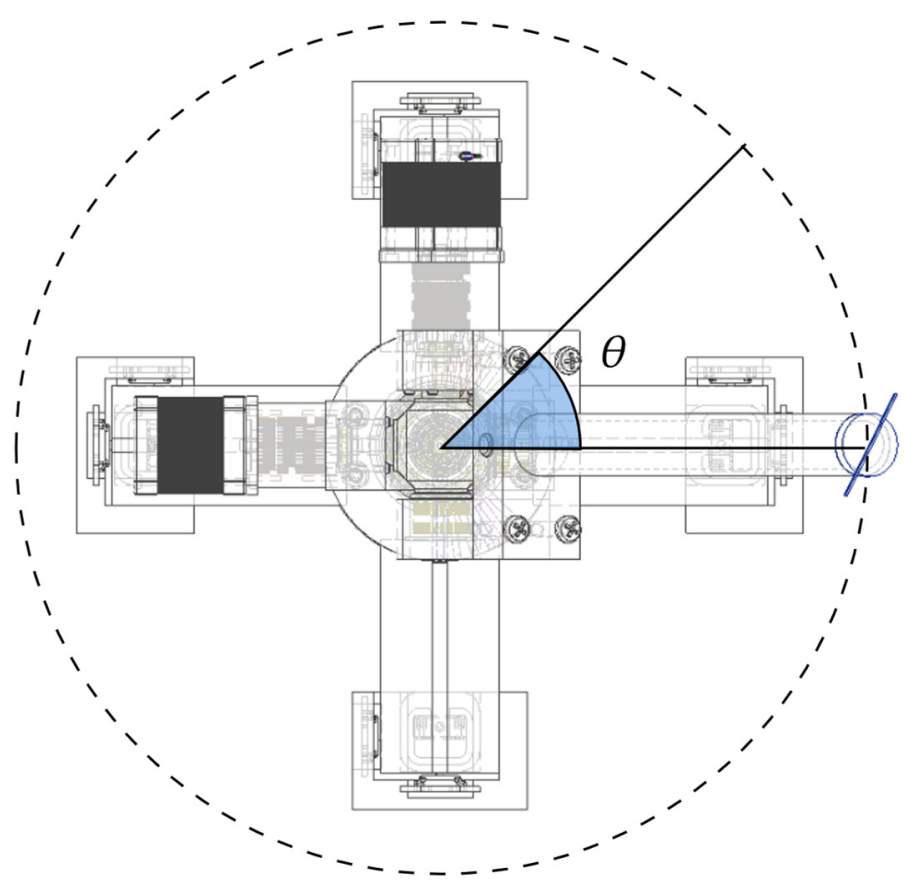

Figura 2-23 - Indicação do ângulo $\theta(t)$ visualizando pela vista superior do experimento. [Fonte: Autoria própria]

\subsubsection{Caso 3 - Cinemática e Dinâmica (problema 3)}

No terceiro problema, o objetivo foi a composição dos movimentos dos problemas anteriores, mas, para tanto, algumas premissas precisam ser colocadas com respeito aos dados de entrada, como sejam: o spin de saída do corpo $3 \omega_{O}(t)=\dot{\psi}$, o ângulo de junta $\phi$ e a trajetória circular dada pelo ângulo de plano de junta $\theta(t)$. Portanto, o primeiro passo foi achar a relação entre o spin de entrada e o spin de saída da junta ativa, conforme eq. 
(2.17). Para tanto, o ângulo de entrada $\alpha$ pôde ser relacionado em função do ângulo de saída $\psi$, e de acordo com Weber (2019), a equação pode ser reescrita como:

$\alpha=\operatorname{atan}\left(t_{\psi} c_{\phi}\right)+n \pi$

Onde n é um número inteiro que permite dar continuidade ao valor de $\alpha$.

O ponto $P(x, y, z)$ em função do círculo desejado é similar à equação (2.85) e, ao usar a cinemática inversa na equação (2.20), é possível obter os ângulos $\beta$ e $\gamma$.

$$
\begin{aligned}
& \gamma(t)=\operatorname{asin}\left(s_{\phi}\left(c_{\theta(t)} c_{\alpha(t)}+s_{\theta(t)} s_{\alpha(t)}\right)\right) \\
& \beta(t)=-\operatorname{sign}(\dot{\gamma}) \operatorname{acos}\left(c_{\phi} / c_{\gamma(t)}\right)
\end{aligned}
$$

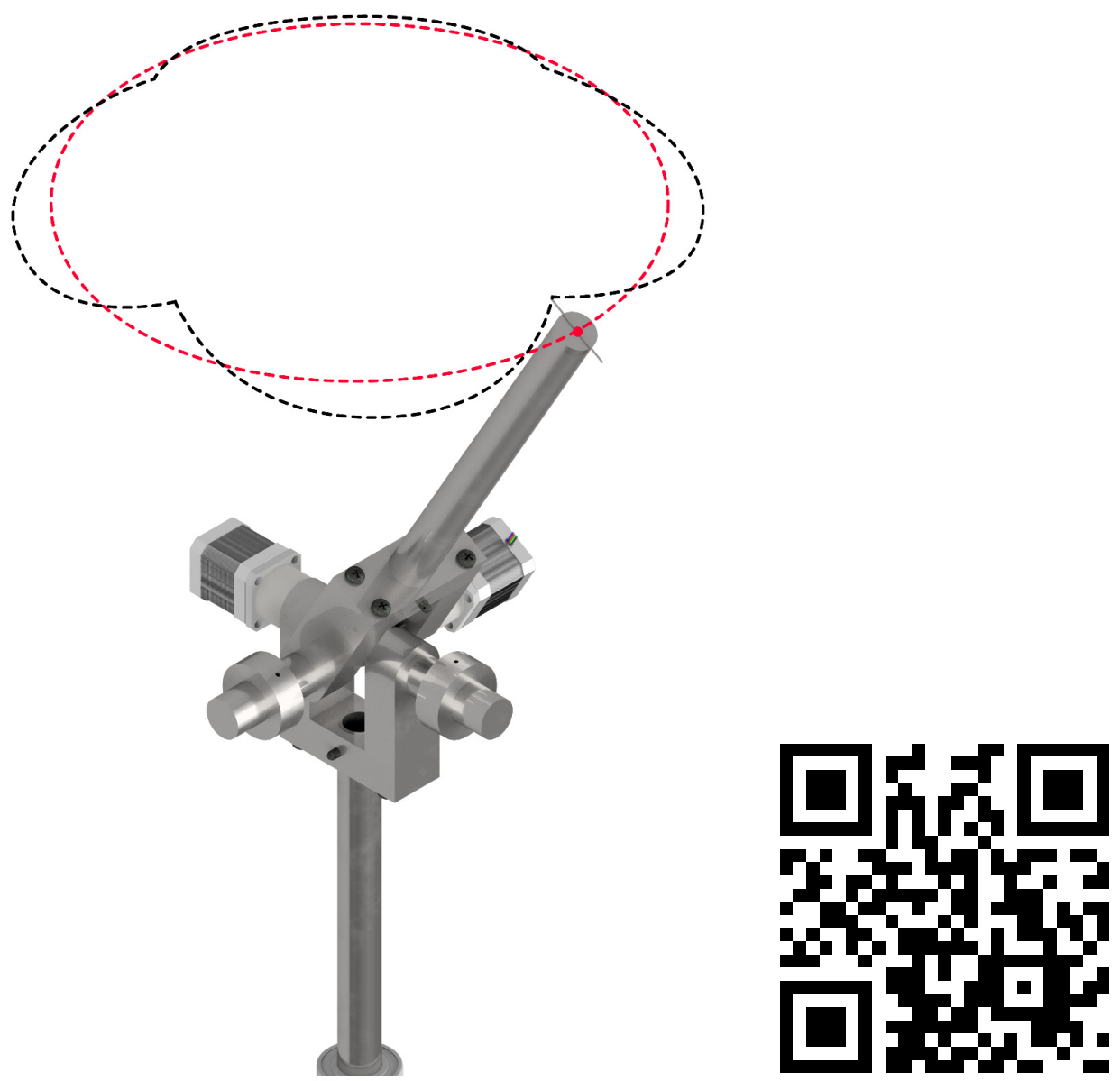

Figura 2-24 - Representação do movimento do problema 3 simulado no Inventor Dynamic Simulation (à esquerda) e QRCODE na animação do movimento (à direita) [Fonte: Autoria própria]

A solução analítica e numérica foi desenvolvida em MATHCAD e confirmada no MATLAB para diversos valores de condições iniciais do ângulo de junta 
$\phi=[\pi / 12, \pi / 6] \mathrm{rad}$ e velocidades angulares $\dot{\theta}=[0.1,0.2,0.4] \mathrm{rad} / \mathrm{s} \quad \mathrm{e}$ $\dot{\psi}=[0.5,1.0,2.0] \mathrm{rad} / \mathrm{s}$, onde $\dot{\psi}=5 \dot{\theta}$, validados tanto pela simulação no Inventor Dynamic Simulation quanto na parte experimental no subcapítulo 3.2.3. Para conseguir visualizar o spin do corpo 3, foi desenhada uma pequena haste no disco superior, conforme indicado na Figura 2-24. Conhecendo as variáveis de estado de posição, velocidade e aceleração dos ângulos, similar aos problemas anteriores, os torques, momentos de reação, o torque de atritos dos rolamentos e as folgas puderam ser calculados.

\subsubsection{Caso 4 - Cinemática e Dinâmica (problema 4)}

O objetivo do quarto problema foi aplicar a rotação cônica utilizando apenas um vetor de Euler movendo-se do $P_{1}(x(t), y(t), z(t))$ para o ponto $P_{2}(x(t), y(t), z(t))$, incluindo um spin de rotação no eixo da saída. Para tanto foi importante utilizar o conceito de plano de junta, introduzido na Figura 2-20 e detalhado na Figura 2-25.

Para obter o movimento entre duas posições quaisquer, trabalhou-se com a composição de dois movimentos, um levando a posição neutra (corpos 1 e 3 alinhados) à posição inicial; e outro da posição neutra à posição final:

- Primeiro movimento de $P_{0}(0,0,0)$ para $P_{1}\left(x_{1}, y{ }_{1}, z{ }_{1}\right)$

- Segundo movimento de $P_{0}(0,0,0)$ para $P_{2}\left(x{ }_{2}, y{ }_{2}, z{ }_{2}\right)$

Em cada um desses movimentos foi definido um vetor de Euler: $\mathbf{p}_{1}$ sendo ortogonal ao plano de junta inicial enquanto $\mathbf{p}_{2}$, ortogonal ao plano de junta da posição final. Para identificar o primeiro movimento, utilizou-se o ângulo do plano de junta $\theta_{1}$ para obter vetor de Euler $\mathbf{p}_{1}$ no plano $y z$ do SR F $(x, y, z)$ e a rotação $\phi_{1}$ em torno de $\mathbf{p}_{1}$ levou ao SR $\mathrm{R}_{1}\left(x_{1}, y_{1}, z_{1}\right)$, conforme equação (2.89).

$$
\underset{(x, y, z)}{\mathrm{F}} \stackrel{\phi_{1}, \mathbf{p}_{1}\left(\theta_{1}\right)}{\longrightarrow} \underset{\left(x_{1}^{\prime \prime}, y_{1}^{\prime \prime}, z_{1}^{\prime \prime}\right)}{\mathrm{R}_{1}}
$$

$\mathrm{O}$ movimento é realizado de $\mathrm{OP}_{0}$ para $\mathrm{OP}_{1}$, sendo o ponto fixo $\mathrm{O}$, centro da junta, e a projeção de $\mathrm{P}_{1}$ sobre $(x, y)$ leva a um ponto que interligado ao ponto $\mathrm{O}$ define um eixo $\mathrm{y}$ '. Assim o plano $x y$ ' é denominado "plano de junta”, cuja posição é determinada no plano $x y$ 
pelo ângulo $\theta_{1}$. A abertura do cone $\phi_{1}$ é chamada de ângulo de junta. Conforme Figura 2-25, pode-se escrever o vetor de Euler de acordo com a eq. (2.90):

${ }^{\mathrm{F}} \mathbf{p}_{1}=\left[\begin{array}{c}0 \\ c_{\Psi_{1}} \\ S_{\Psi_{1}}\end{array}\right]$, sendo $\Psi_{1}=\theta_{1}+\frac{\pi}{2},{ }^{\mathrm{F}} \mathbf{p}_{1}=\left[\begin{array}{c}0 \\ -s_{\theta_{1}} \\ c_{\theta_{1}}\end{array}\right]$

De acordo com Weber (2019), a matriz de rotação de $\mathrm{F}$ para $\mathrm{R}_{1}$, utilizando o vetor de Euler $\mathbf{p}_{1}$ e o seu ângulo $\phi_{1}$, pode ser escrita como:

$$
\mathrm{F} \mathbf{T}^{\mathrm{R}_{1}}=\mathbf{E}+s_{\phi_{1}} \tilde{\mathbf{p}}_{1}+\left(1-c_{\phi_{1}}\right) \tilde{\mathbf{p}}_{1}^{2}=\left[\begin{array}{ccc}
c_{\phi_{1}} & -s_{\phi_{1}} c_{\theta_{1}} & -s_{\theta_{1}} s_{\phi_{\phi_{1}}} \\
s_{\phi_{1}} c_{\theta_{1}} & c_{\theta_{1}}^{2}\left(c_{\phi_{1}}-1\right)+1 & s_{\theta_{1}} c_{\theta_{1}}\left(c_{\phi_{1}}-1\right) \\
s_{\phi_{1}} s_{\theta_{1}} & s_{\theta_{1}} c_{\theta_{1}}\left(c_{\phi_{1}}-1\right) & s_{\theta_{1}}^{2}\left(c_{\phi_{1}}-1\right)+1
\end{array}\right]
$$

De forma similar à eq. (2.91) a matriz de rotação de $\mathrm{F}$ para $\mathrm{R}_{2}\left({ }^{\mathrm{F}} \mathbf{T}^{\mathrm{R} 2}\right)$ pode ser obtida utilizando os ângulos $\theta_{2}$ e $\phi_{2}$ conforme eq. (2.92).

$$
{ }^{\mathrm{F}} \mathbf{T}^{\mathrm{R}}{ }_{2}=\mathbf{E}+s_{\phi_{2}} \tilde{\mathbf{p}}_{2}+\left(1-c_{\phi_{2}}\right) \tilde{\mathbf{p}}_{2}^{2}
$$

Sabendo que ${ }^{\mathrm{R} 1} \mathbf{T}^{\mathrm{F}}=\left({ }^{\mathrm{F}} \mathbf{T}^{\mathrm{R} 1}\right)^{\mathrm{T}}$, é possível escrever a matriz de rotação de $\mathrm{R}_{1}$ para $\mathrm{R}_{2}$ como sendo:

$\mathrm{R}_{1} \mathbf{T}_{2}^{\mathrm{R}_{2}}=\mathrm{R}_{1} \mathbf{T}^{\mathrm{F} F} \mathbf{T}^{\mathrm{R}_{2}}$
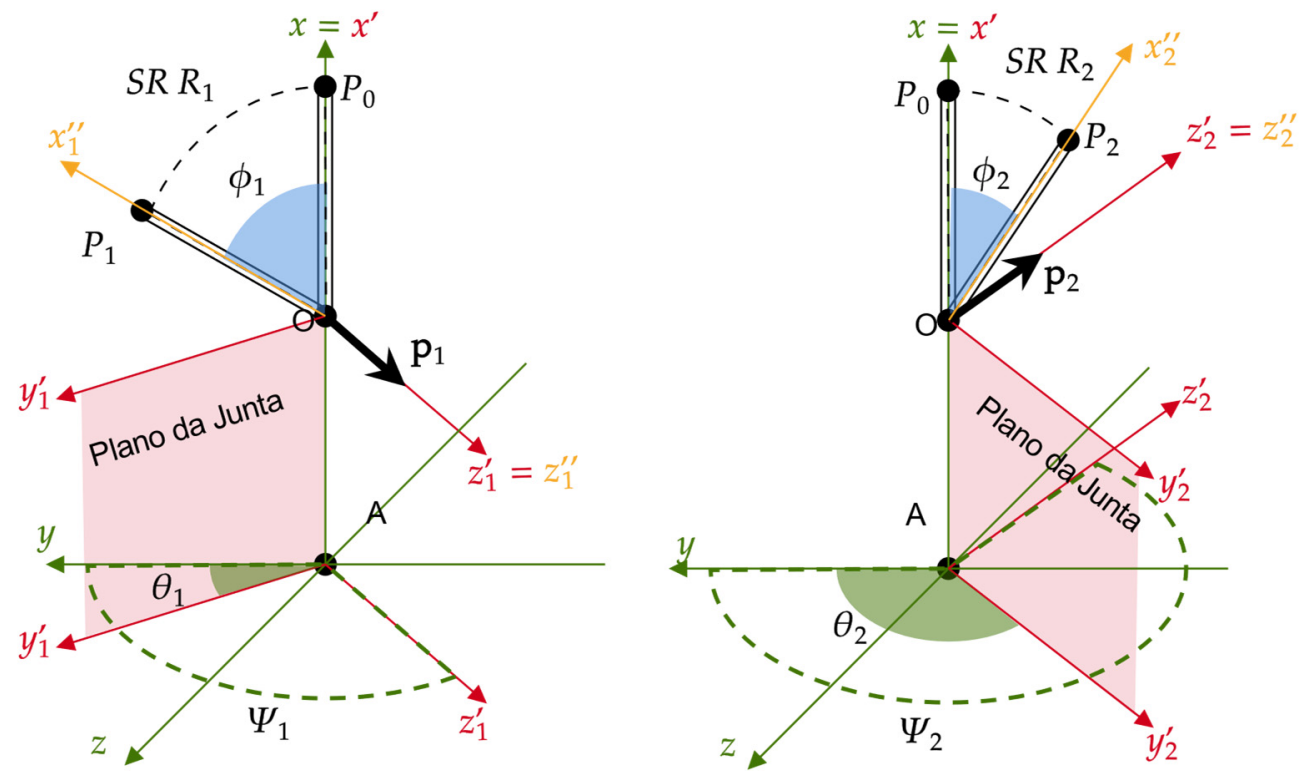

Figura 2-25 - Representação do SR F para o SR R (à esquerda) e do SR F para o SR R (à direita) [Fonte: Autoria própria] 
A matriz de rotação de $R_{1}$ para $R_{2}$ também pode ser escrita como:

$\mathrm{R}_{1} \mathbf{T}^{\mathrm{R}_{2}}=\mathbf{E}+s_{\Theta} \tilde{\mathbf{p}}+\left(1-c_{\Theta}\right) \tilde{\mathbf{p}}^{2}$

onde $\mathbf{p}$ é o vetor de Euler para passar diretamente da posição 1 para 2 e $\Theta$ o ângulo correspondente. Resolvendo o problema inverso usando a eq. (2.94). Esta expressão pode ser separada em parte antissimétrica e simétrica, conforme equação (2.95):

$\mathrm{R}_{1} \mathbf{T}^{\mathrm{R}_{2}}=\left[s_{\Theta} \tilde{\mathbf{p}}\right]+\left[\mathbf{E}+\left(1-c_{\Theta}\right) \tilde{\mathbf{p}}^{2}\right]=\mathbf{T}_{a}+\mathbf{T}_{s}$

Como a eq. (2.93) fornece um resultado numérico, pode-se decompor a matriz em sua parte antissimétrica para a obtenção do vetor de Euler $\mathbf{p}$. Seja $\mathbf{T}_{a}=\left[t_{i, j}\right]$, então $\mathbf{p}$, que tem modulo unitário, é obtido de $\tilde{\mathbf{p}}$, conforme equação (2.96):

$\mathbf{p}=\frac{1}{p}\left[\begin{array}{c}-t_{2,3} \\ t_{1,3} \\ -t_{1,2}\end{array}\right], \quad p=\sqrt{t_{2,3}^{2}+t_{1,3}^{2}+t_{1,2}^{2}}=s_{\Theta}$

Conhecido o seno, há duas soluções para o ângulo de rotação $\Theta$. A maneira mais simples de determinar qual solução parte de uma propriedade bem conhecida do traço da matriz de rotação e que pode ser escrita como:

$$
\operatorname{tr}\left(\mathrm{R}_{1} \mathbf{T}^{\mathrm{R}_{2}}\right)=1+2 \mathrm{c}_{\Theta}
$$

De uma forma geral as transformações podem ser escritas conforme eq. (2.98).

$$
\underset{(x, y, z)}{\mathrm{F}} \stackrel{\phi_{1}, \mathbf{p}_{1}\left(\theta_{1}\right)}{\longrightarrow} \underset{\left(x_{1}^{\prime \prime}, y_{1}^{\prime \prime}, z_{1}^{\prime \prime}\right)}{\mathrm{R}_{1}} \stackrel{\Theta, \mathbf{p}}{\longrightarrow} \underset{\left(x_{2}^{\prime \prime}, y_{2}, z^{\prime \prime}\right)}{\mathrm{R}_{2}} \stackrel{\phi_{2},-\mathbf{p}_{2}\left(\theta_{2}\right)}{\longrightarrow} \underset{(x, y, z)}{\mathrm{F}}
$$

$\mathrm{O}$ que se pretendia na formulação deste Problema 4 era passar de $\mathrm{R}_{1}$ para $\mathrm{R}_{2}$ a partir de um vetor de Euler constante. Essa rotação é mais simples para o caso real e, possivelmente, mais econômica. Assim, a parte variável vem a ser apenas a rotação em torno do vetor de Euler $\Theta$.

Na Figura 2-26, é possível observar o plano de junta formado ao passar da posição neutra à posição $1, \mathrm{OP}_{0} \mathrm{P}_{1}$, e o plano de junta ao passar da posição neutra à posição $2, \mathrm{OP}_{0} \mathrm{P}_{2}$. Todavia o plano para passar de $\mathrm{P}_{1}$ a $\mathrm{P}_{2}$ será ortogonal ao vetor de Euler $\mathbf{p}$ e pertencente aos pontos $\mathrm{P}_{1}$ e $\mathrm{P}_{2}$. Ao longo deste movimento, o efetuador sempre permanecerá neste 
plano. Como se quer passar de $\mathrm{R}_{1}$ para $\mathrm{R}_{2}$ em certo intervalo de tempo, será introduzido um SR ( $(\mathrm{t})$ ) que na posição inicial coincide com $\mathrm{R}_{1}$ e na posição final com $\mathrm{R}_{2}$. Este $\mathrm{SR}$ manterá o vetor de Euler $\mathbf{p}$ desta rotação constante e o ângulo de Euler $\Theta(t)$ que varia entre zero e o valor final $\Theta$, calculado a partir da eq. (2.99).

$\mathrm{R}_{1} \mathbf{T}^{\mathrm{R}(\mathrm{t})}=\mathbf{E}+s_{\Theta(t)} \tilde{\mathbf{p}}+\left(1-c_{\Theta(t)}\right) \tilde{\mathbf{p}}^{2}$

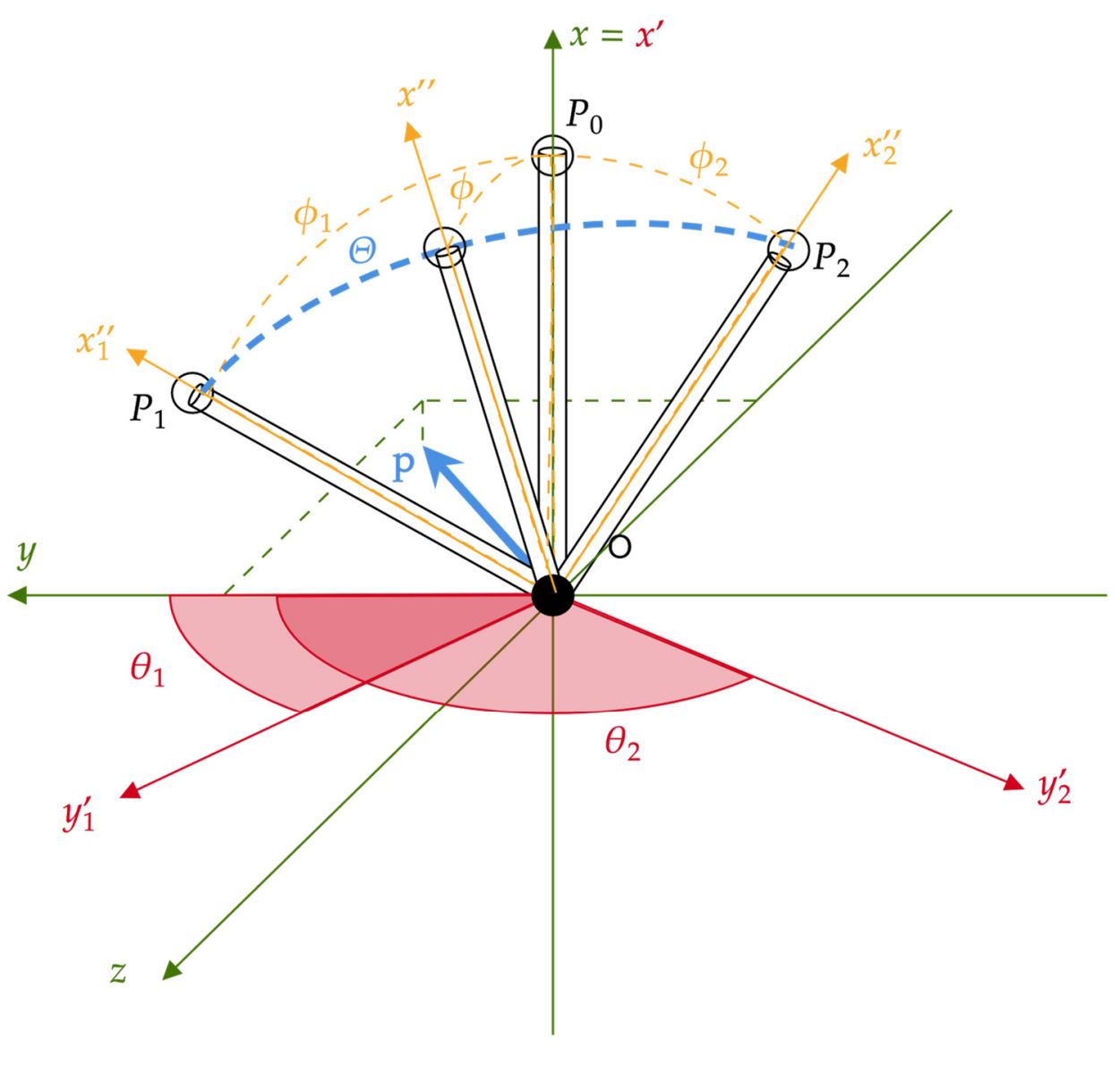

Figura 2-26 - Visualização esquemática do movimento de $\mathrm{R}_{1}$ para $\mathrm{R}_{2}$ [Fonte: Autoria própria]

No estudo da trajetória correspondente a este movimento, precisa-se conhecer a posição de $\mathrm{R}(\mathrm{t})$ em relação ao SR fixo F conforme eq. (2.100).

$\mathrm{F}^{\mathrm{R}(\mathrm{t})}={ }^{\mathrm{F}} \mathbf{T}^{\mathrm{R}_{1}} \mathrm{R}_{1} \mathbf{T}^{\mathrm{R}(\mathrm{t})}$

Com o intuito de incluir um spin a este movimento, a rotação ao redor do eixo $x$ "' " pode ser considerada conforme eq. (2.101). 


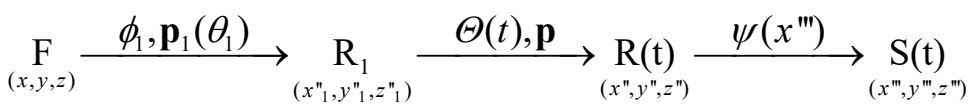

$$
\begin{aligned}
& { }^{\mathrm{R}(\mathrm{t})} \mathbf{T}^{\mathrm{S}(\mathrm{t})}=\left[\begin{array}{ccc}
1 & 0 & 0 \\
0 & c_{\psi} & -S_{\psi} \\
0 & S_{\psi} & c_{\psi}
\end{array}\right]
\end{aligned}
$$

A matriz de transformação do movimento cônico entre dois pontos quaisquer dentro da área de trabalho do manipulador é dada pela eq. (2.102).

$\mathrm{F}^{\mathrm{T}} \mathrm{S}(\mathrm{t})=\mathrm{F}^{\mathrm{T}} \mathbf{T}^{\mathrm{R}_{1}} \mathrm{R}_{1} \mathbf{T}^{\mathrm{R}(\mathrm{t})} \mathrm{R}^{\mathrm{t}(\mathrm{t})} \mathbf{T}^{\mathrm{S}(\mathrm{t})}$

É importante ressaltar a necessidade de obter os valores dos ângulos cardânicos através da matriz de transformação ${ }^{\mathrm{F}} \mathbf{T}^{\mathrm{S}(t)}$, uma vez que o manipulador é comandado pelas variáveis de estados de $\alpha, \beta$ e $\gamma$. Na equação (2.103) foram calculados os ângulos cardânicos analisando os diversos termos da matriz de transformação ${ }^{\mathrm{F}} \mathbf{T}^{\mathrm{S}(\mathrm{t})}$. Durante a utilização da equação é importante observar a continuidade do movimento para que as singularidades trigonométricas possam ser resolvidas.

$\beta=\operatorname{asin}\left(T_{13}\right)$

$\gamma=\left\{\begin{array}{cc}\operatorname{atan}\left(\frac{-T_{12}}{T_{11}}\right) & \forall T_{11}>0 \\ \operatorname{atan}\left(\frac{1-\left(T_{22}\right)^{2}-\left(T_{32}\right)^{2}}{T_{22} T_{21}+T_{32} T_{31}}\right) & \forall T_{11} \leq 0\end{array}\right.$

$\alpha=\left\{\begin{array}{cc}\operatorname{atan}\left(\frac{-T_{23}}{T_{33}}\right) & \forall T_{33}>0 \\ \operatorname{atan}\left(\frac{1-\left(T_{21}\right)^{2}-\left(T_{22}\right)^{2}}{T_{21} T_{31}+T_{32} T_{32}}\right) & \forall T_{33} \leq 0\end{array}\right.$

A solução analítica e numérica foi desenvolvida em MATHCAD e confirmada no MATLAB para os seguintes valores de condições iniciais do ângulo de junta $\phi_{1}=\pi / 6 \mathrm{e}$ $\phi_{2}=\pi / 12$, e do ângulo do plano de junta $\theta_{1}=0$ e $\theta_{2}=\pi / 2$, incluindo cinco voltas (spin) $\dot{\psi}=2 \dot{\phi}_{e}$, durante o movimento validado tanto pela simulação no Inventor Dynamic Simulation quanto na parte experimental no subcapítulo 3.2.4. Para conseguir visualizar o spin do corpo 3, foi desenhada uma pequena haste no disco superior, conforme indicado na Figura 2-27. 

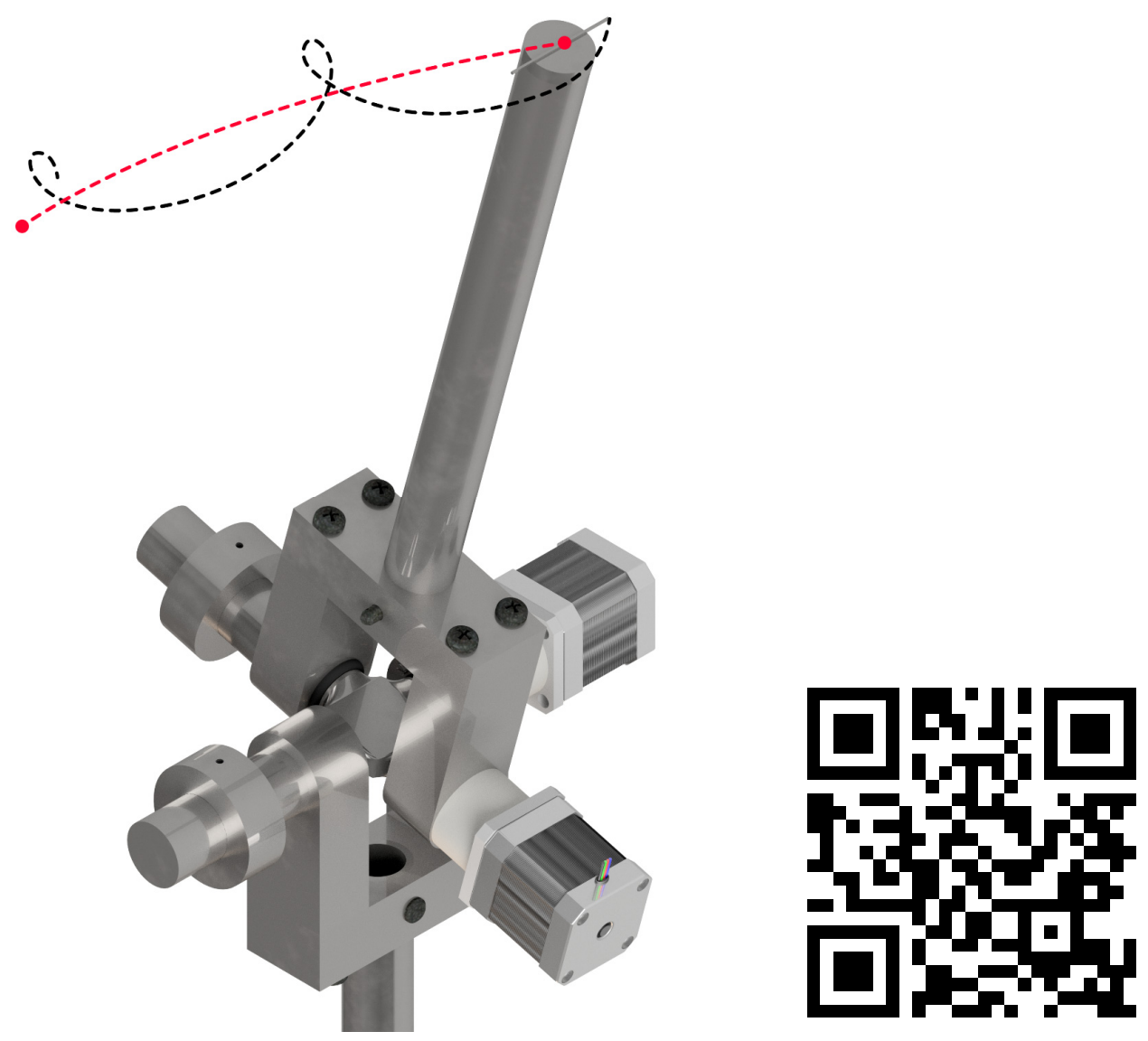

Figura 2-27 - Representação do movimento do problema 4 simulado no Inventor Dynamic Simulation (à esquerda) e QRCODE da animação do movimento (à direita) [Fonte: Autoria própria] 


\section{Contribuições e Análise de Resultados}

O objetivo deste capítulo foi desenvolver e analisar os resultados numéricos e experimentais obtidos através das deduções realizadas no capítulo anterior. Inicialmente, uma análise dos limites da área de trabalho da junta é exibida para que, em seguida, os casos sejam numericamente apresentados e discutidos. Para tais simulações, foi utilizado o MATHCAD para o desenvolvimento numérico das soluções e, ulteriormente, utilizado o MATLAB conectado aos controladores por Wi-Fi para comandar os motores e para a leitura dos sensores. Com o intuito de analisar os resultados dos sensores, principalmente, durante o processo de folga e impacto, foi executada a comparação gráfica entre os resultados numéricos e experimentais. No resultado experimental, optou-se por utilizar o filtro de Kalman no IMU para remover os sinais oriundos de outros fenômenos de alta frequência, como, por exemplo, o pulso dos motores que pode chegar a $1200 \mathrm{~Hz}$, além das leituras das células de carga.

\subsection{Análise dos limites da área de trabalho}

A parte experimental consistiu, inicialmente, em conhecer os limites de atuação da junta cardânica ativa, uma vez que os seus limites são obtidos em função da geometria proposta. Conhecer o limite da junta significa saber em quais valores de $\beta$ e $\gamma$ ela poderá operar sem que haja o contato em suas partes móveis. De acordo com alguns trabalhos (YUAN, ASADI, et al., 2019) (NISHIDA, 2017) (PATRÃO, 2015), o cálculo dos ângulos de rotação $\beta$ e $\gamma$ pode ser feito utilizando as componentes do acelerômetro $a_{x}, a_{y}$ e $a_{z}$, conforme a equação $\beta$ e $\gamma$ (3.1). Entretanto o acelerômetro é insensível ao ângulo $\alpha$, e, apesar de ser possível calcular este ângulo utilizando a medição do magnetômetro e da velocidade angular do IMU, optou-se por utilizar a medida da odometria do motor instalado no grau de liberdade $\alpha$, por ser uma medida mais confiável.

$\mathrm{F} \mathbf{T} \mathrm{S}\left[\begin{array}{l}0 \\ 0 \\ g\end{array}\right]=g\left[\begin{array}{c}s_{\beta} \\ -c_{\beta} s_{\alpha} \\ c_{\beta} c_{\alpha}\end{array}\right]=\left[\begin{array}{l}a_{x} \\ a_{y} \\ a_{z}\end{array}\right] ; \quad \beta=-\operatorname{atan}\left(\frac{a_{x}}{\sqrt{a_{y}^{2}+a_{z}^{2}}}\right) ; \quad \gamma=\operatorname{atan}\left(\frac{a_{y}}{\sqrt{a_{x}^{2}+a_{z}^{2}}}\right)$.

A técnica utilizada para a obtenção desses valores consistiu inicialmente em remover os motorredutores e movimentar a junta manual e lentamente (quase estático) em torno de seus limites, registrando esses movimentos através da leitura do IMU posicionado no 
atuador. As leituras das acelerações e dos ângulos podem ser observadas na Figura 3-1 e Figura 3-2.

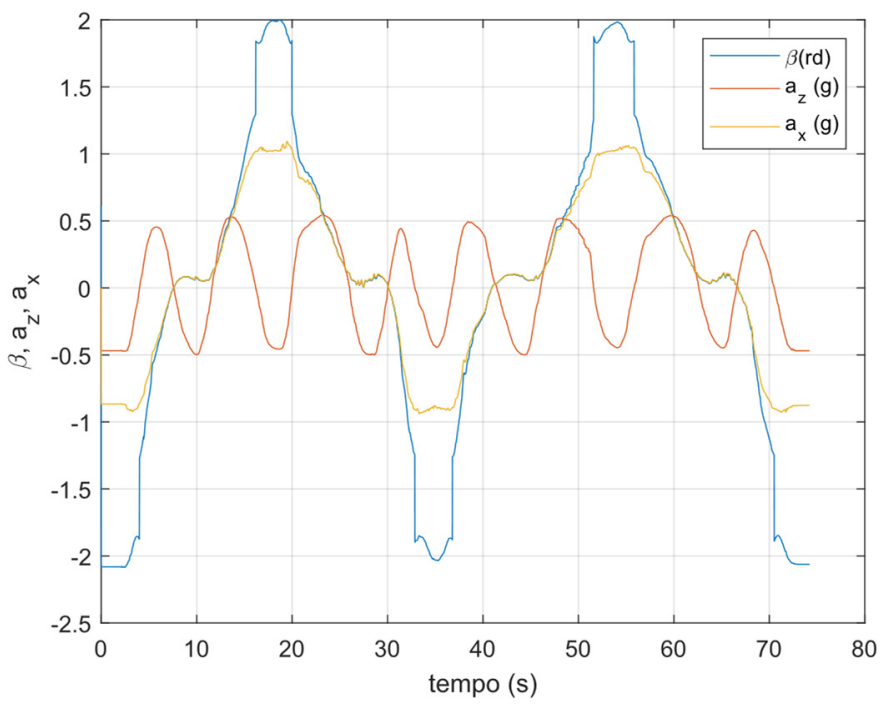

Figura 3-1 - Aceleração $a_{z}, a_{x}$ e o ângulo $\beta$ medidos pelo acelerômetro sem o motorredutor [Fonte: Autoria própria]

Ao analisar os cálculos dos ângulos é possível constatar a singularidade que ocorre nos ângulos $\beta$ e $\gamma$ ao ultrapassar o valor de $\pi / 2$, algo intrínseco à função trigonométrica usada na eq. (3.1). Conhecer os limites da junta sem a presença do motorredutor é importante para conhecer os limites geométricos dos garfos da junta, no entanto é necessário conhecer os limites da junta com a presença dos motorredutores, que limita o ângulo alcançado por um dos lados dos garfos. Sendo assim, a técnica utilizada para a leitura do IMU foi a mesma que a anterior, mas com a presença do motorredutor.

Na Figura 3-3 e Figura 3-4 é possível observar que a presença do motorredutor não permite que os ângulos $\beta$ e $\gamma$ ultrapassem o valor de 1 radiano. Como se espera a utilização de contrapeso no lado oposto ao motor para garantir a simetria da matriz de inércia, o limite de 1 radiano também foi imposto ao lado oposto ao motorredutor. Esta limitação acaba garantindo que os valores dos ângulos $\beta$ e $\gamma$ atuem fora dos valores que causariam as singularidades apontadas na eq. (3.1). 


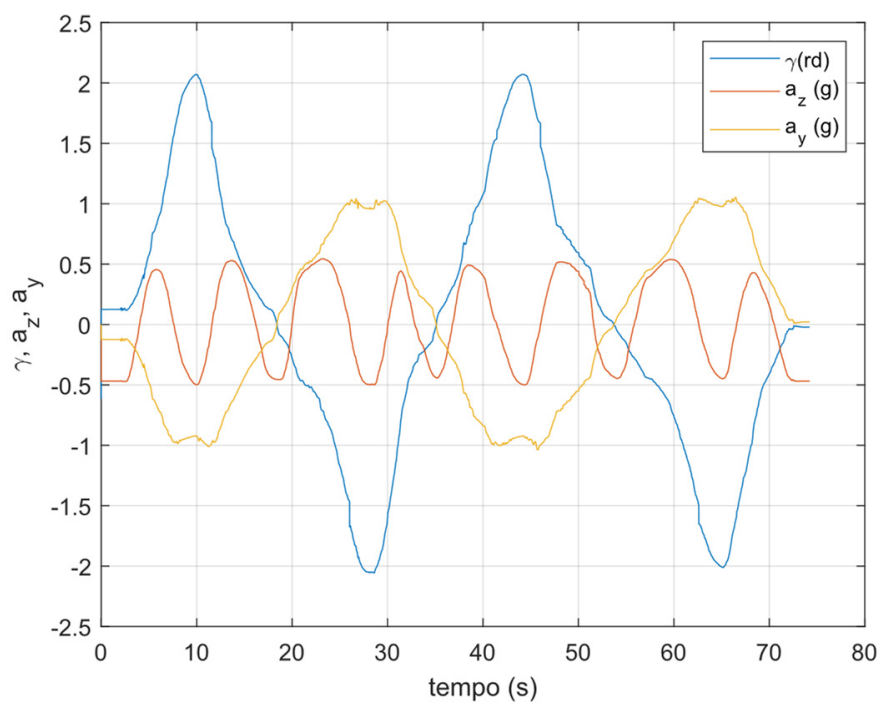

Figura 3-2 - Aceleração $a_{z}, a_{y}$ e o ângulo $\gamma$ medidos pelo acelerômetro sem o motorredutor [Fonte: Autoria própria]

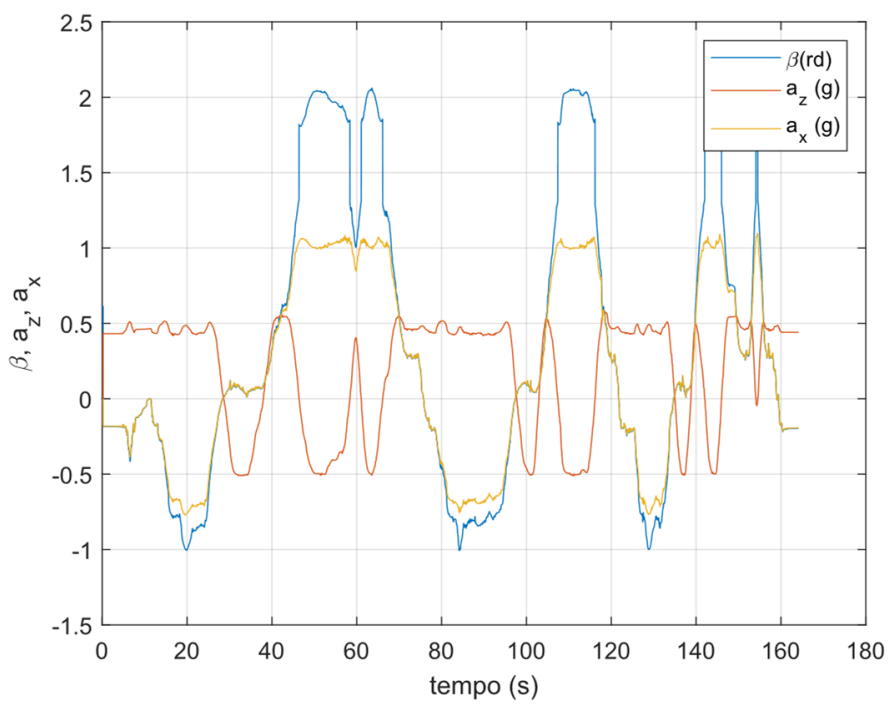

Figura 3-3 - Aceleração $a_{z}, a_{x}$ e o ângulo $\beta$ medidos pelo acelerômetro com o motorredutor [Fonte: Autoria própria]

Mediante uma análise conjunta dos ângulos $\beta$ e $\gamma$, a Figura 3-5 indica um losango de 1 radiano como zona de segurança para atuação da junta cardânica ativa. Mas, para que o ângulo de junta máximo possa ser garantido em toda a área de trabalho, deverá ser analisada a menor distância da zona de segurança com relação ao centro da junta. Sendo assim, o ângulo de junta máximo, que atende a toda a área de trabalho, pode ser calculado como: $1 \mathrm{rad} / \sqrt{2} \cong 0,707 \mathrm{rad} \cong 40^{\circ}$. Nos casos apresentados a seguir, o ângulo de junta máximo limitou-se a $\pi / 6 \mathrm{rad}=30^{\circ}$. Para um entendimento mais lúdico da área de atuação, na 
Figura 3-6, é apresentada a zona limite sem e com os motorredutores plotados no workspace esférico do atuador.

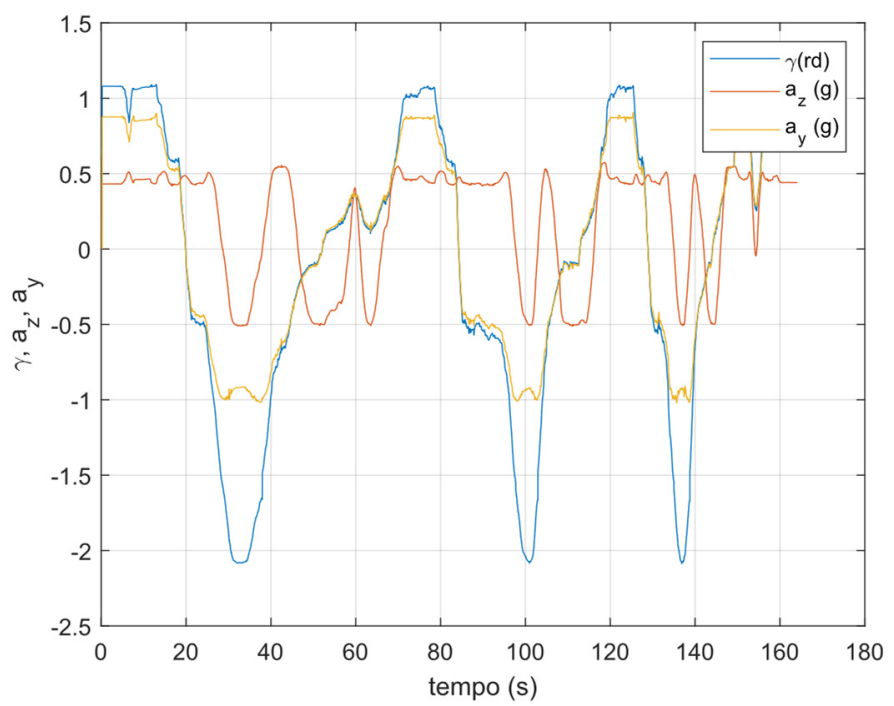

Figura 3-4 - Aceleração $a_{z}, a_{y}$ e o ângulo $\gamma$ medidos pelo acelerômetro com o motorredutor

[Fonte: Autoria própria]

Conforme o estudo de Oliveira et al. (2019), os valores apresentados dos ângulos de $\beta$ e $\gamma$, calculados pelo IMU, podem ser confirmados pela odometria dos motorredutores por apresentarem uma medida mais confiável, que poderá ser utilizada na proteção da programação de baixo nível (programação do microcontrolador), impedindo, assim, o contato das partes móveis da junta cardânica ativa (OLIVEIRA e WEBER, 2019).

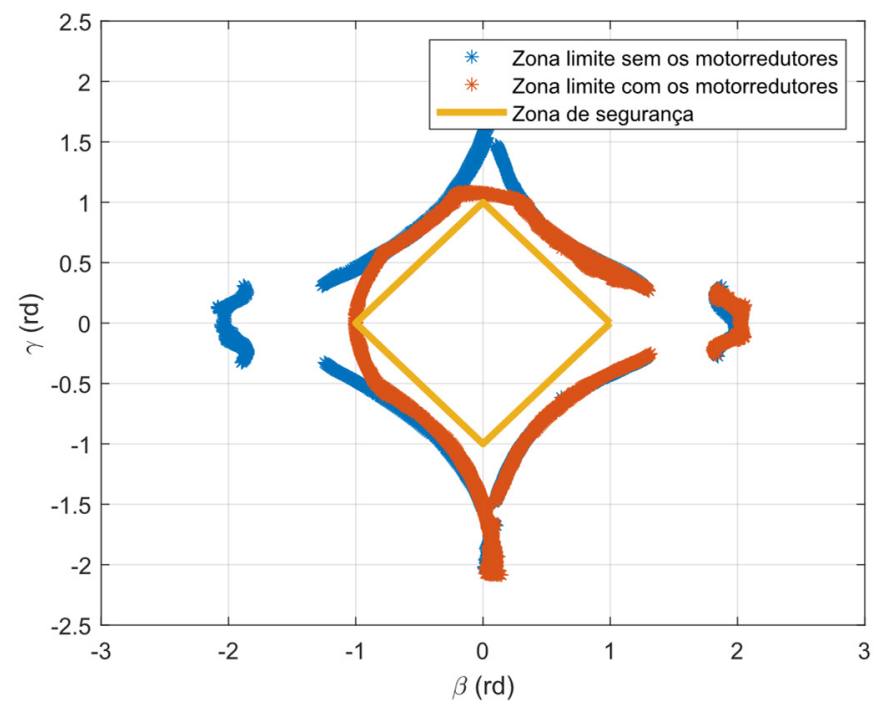

Figura 3-5 - Zona limite de atuação da junta cardânica ativa em função de $\beta$ e $\gamma$ [Fonte: Autoria própria] 


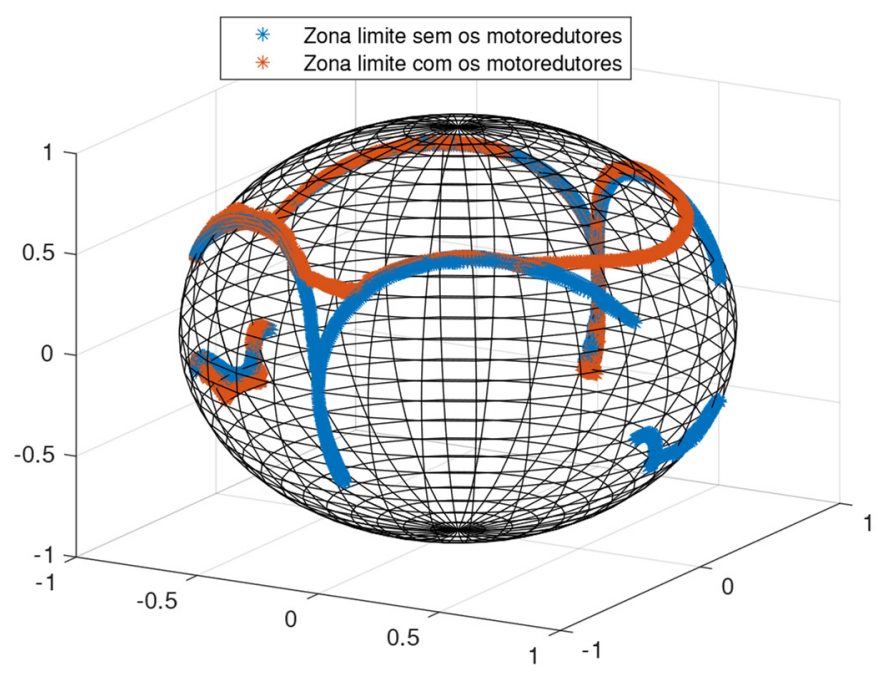

Figura 3-6 - Limites da área de trabalho workspace da junta cardânica ativa. [Fonte: Autoria própria]

\subsection{Análise dos resultados numéricos e experimental}

Para o cálculo dos momentos de inércia principal teórico, a modelagem feita no CAD Autodesk Inventor - permitiu obter os valores necessários para o preenchimento das matrizes de inércia apresentada na equação (2.22) usando os valores da eq. (3.2).

$$
\begin{array}{lll}
I_{1 x}=11.185 \mathrm{~kg} \cdot \mathrm{mm}^{2} & I_{2 x}=119 \mathrm{~kg} \cdot \mathrm{mm}^{2} & I_{3 x}=11.080 \mathrm{~kg} \cdot \mathrm{mm}^{2} \\
I_{1 y}=51.041 \mathrm{~kg} \cdot \mathrm{mm}^{2} & I_{2 y}=117 \mathrm{~kg} \cdot \mathrm{mm}^{2} & I_{3 y}=24.081 \mathrm{~kg} \cdot \mathrm{mm}^{2} \\
I_{1 z}=40.715 \mathrm{~kg} \cdot \mathrm{mm}^{2} & I_{2 z}=117 \mathrm{~kg} \cdot \mathrm{mm}^{2} & I_{3 z}=34.408 \mathrm{~kg} \cdot \mathrm{mm}^{2}
\end{array}
$$

De forma similar foi possível obter as massas dos corpos rígidos, $m_{1}$ para o corpo $1, m_{2}$ para o corpo 2 e $m_{3}$ para o corpo 3. Na Figura 2-4, a distância entre o ponto $\mathrm{O}$ e o centro de gravidade do corpo 3 é dada por $h_{2}$, onde os valores estão indicados na eq. (3.3).

$$
\begin{aligned}
& m_{1}=3,529 \mathrm{~kg} \quad m_{2}=0,217 \mathrm{~kg} \quad m_{3}=3,292 \mathrm{~kg} \\
& h_{2}=60 \mathrm{~mm}
\end{aligned}
$$

Várias simulações experimentais foram realizadas e registradas em arquivos e vídeos para futuros trabalhos ou verificações, conforme pode ser visto nos QRCODES da Figura 3-7. No entanto optou-se em discutir apenas um cenário de cada um dos casos, sendo suficiente para a explanação da dinâmica da junta cardânica ativa. 


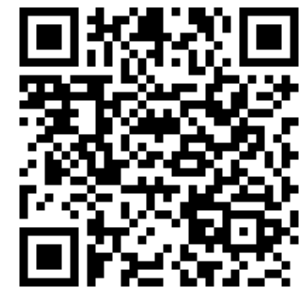

Arquivos Experimentais

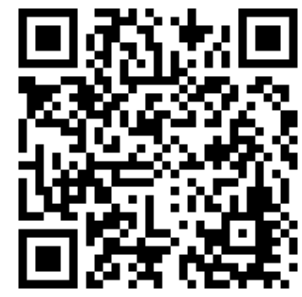

Playlist Caso 3

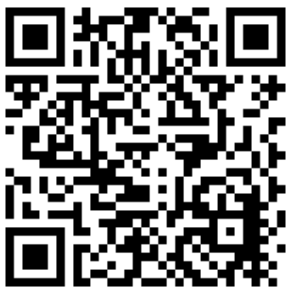

Playlist Caso 1

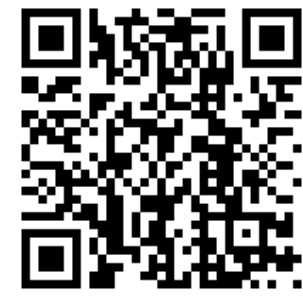

Playlist Caso 4

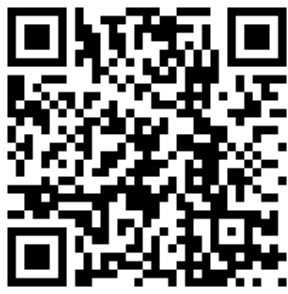

Playlist Caso 2

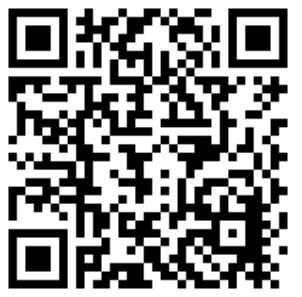

Playlist Caso 1 e 2 desbalanceado

Figura 3-7 - QRCODES dos arquivos e das listas de vídeos da realização do experimento [Fonte: Autoria própria]

\subsubsection{Caso 1 - Cinemática e Dinâmica}

Para os valores numéricos e experimentais registrados no subcapítulo 2.4 .1 foi selecionado o ângulo de junta de $\phi=\pi / 6 \mathrm{rad}$ e a velocidade angular do corpo $1 \mathrm{de} \dot{\alpha}=0,2 \mathrm{rad} / \mathrm{s}$. Resolvendo a equação (2.82) é possível obter os valores analíticos do vetor de estado $[\alpha, \beta, \gamma, \dot{\alpha}, \dot{\beta}, \dot{\gamma}]$ que serão utilizados como entrada no MATLAB para o comando dos motores de passo do experimento e como entrada analítica inicial para o cálculo da cinemática e da dinâmica para o caso 1, conforme pode ser observado na Figura 3-8.

Na Figura 3-9 é possível analisar a cinemática dos corpos rígidos, que foi calculada utilizando as equações (2.14), (2.15) e (2.16) para obter as velocidades angulares dos corpos rígidos 1, 2 e 3 com relação ao SR F para o caso 1.

Com a cinemática dos corpos rígidos calculada analiticamente e confirmada pela odometria dos motores foi utilizado a eq. (2.47) para obter os momentos de reações e os torques dos motorredutores nos SRs respectivos sem a folga, conforme pode ser observado na Figura 
3-10. O torque do motorredutor do grau de liberdade $\alpha$ para as condições iniciais do caso 1 será zero.

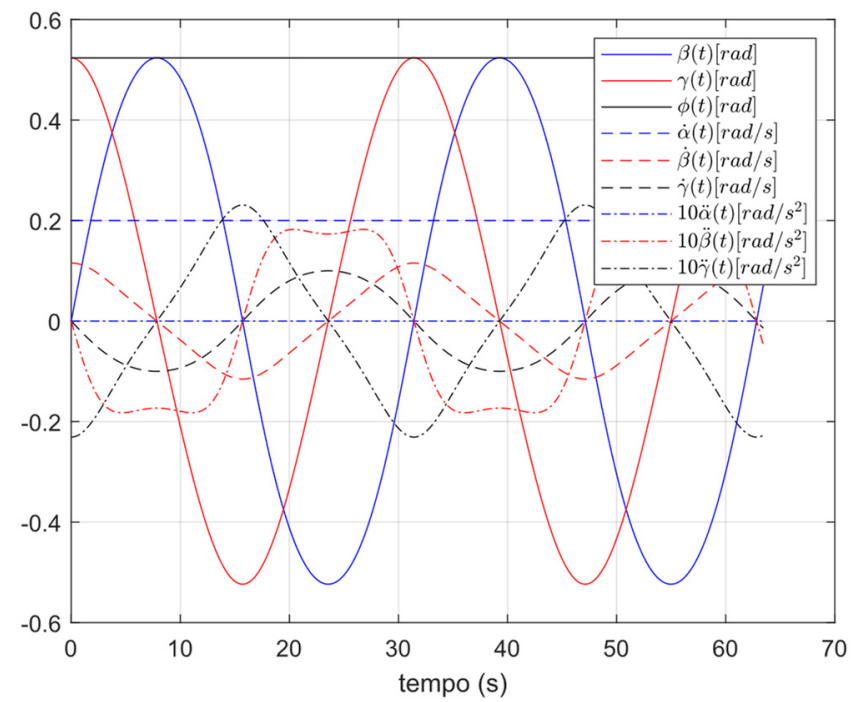

Figura 3-8 - Valores dos vetores de estado: ângulos cardânicos ( $\beta, \gamma)$, ângulo da junta $(\phi)$, velocidades angulares $(\dot{\alpha}, \dot{\beta}, \dot{\gamma})$, e acelerações angulares $(\ddot{\alpha}, \ddot{\beta}, \ddot{\gamma})$ para o Caso 1 $\operatorname{com} \phi=\pi / 6 \mathrm{rad}$ e $\dot{\alpha}=0,2 \mathrm{rad} / \mathrm{s}$ [Fonte: Autoria própria]

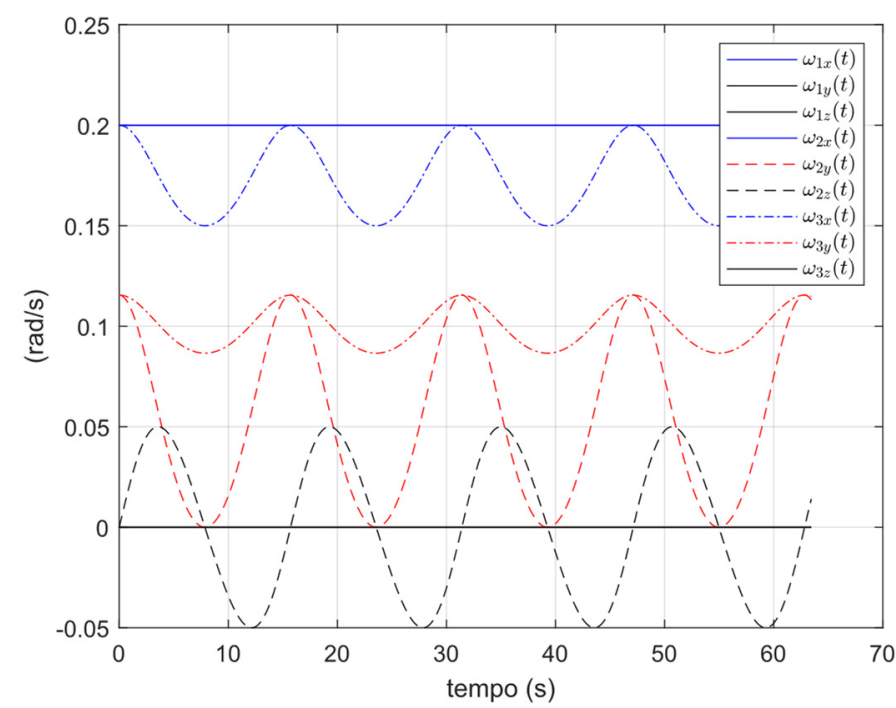

Figura 3-9 - Cinemática dos corpos rígidos no SR F para o Caso 1 para $\phi=\pi / 6 \mathrm{rad}$ e $\dot{\alpha}=0,2 \mathrm{rad} / \mathrm{s}$ [Fonte: Autoria própria]

Ao calcular numericamente o atrito, conforme modelado no subcapítulo 2.2.3, foi possível constatar que, ao utilizar os tipos de atrito considerados na equação (2.64), o momento de atrito devido às vedações contribui para a maior parcela do atrito, uma vez que os momentos de atrito rolantes, deslizantes e de perdas estão em função das velocidades envolvidas, das forças radiais e axiais que são extremamente baixas para os rolamentos 
especificados. Assim, a pequena variação periódica das funções de momento de atrito dos rolamentos, como se observa na Figura 3-11, permite a simplificação para um atrito constante $T a_{01} \cong 0,295 \mathrm{Nm}$ na direção de atuação do torque $T_{01}$, e $T a_{12} \cong T a_{23} \cong 0,037 \mathrm{Nm}$ para as direções de atuação dos torques $T_{12}$ e $T_{23}$, respectivamente. Comparando a grandeza dos torques $T_{12}$ e $T_{23}$ da Figura 3-10, o momento de atrito dos rolamentos equivale a $3,7 \%$ do torque máximo em condições ideias para que o movimento imposto pelo vetor de estado aconteça.

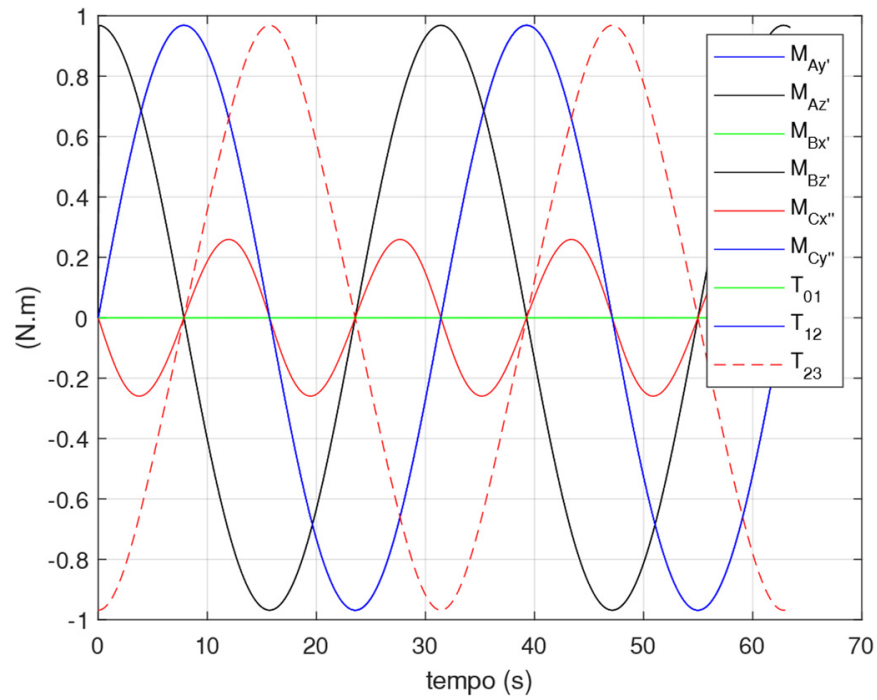

Figura 3-10 - Momentos de Reação e Torque dos motorredutores para o Caso 1 para $\phi=\pi / 6 \mathrm{rad}$ e $\dot{\alpha}=0,2 \mathrm{rad} / \mathrm{s}$ [Fonte: Autoria própria]

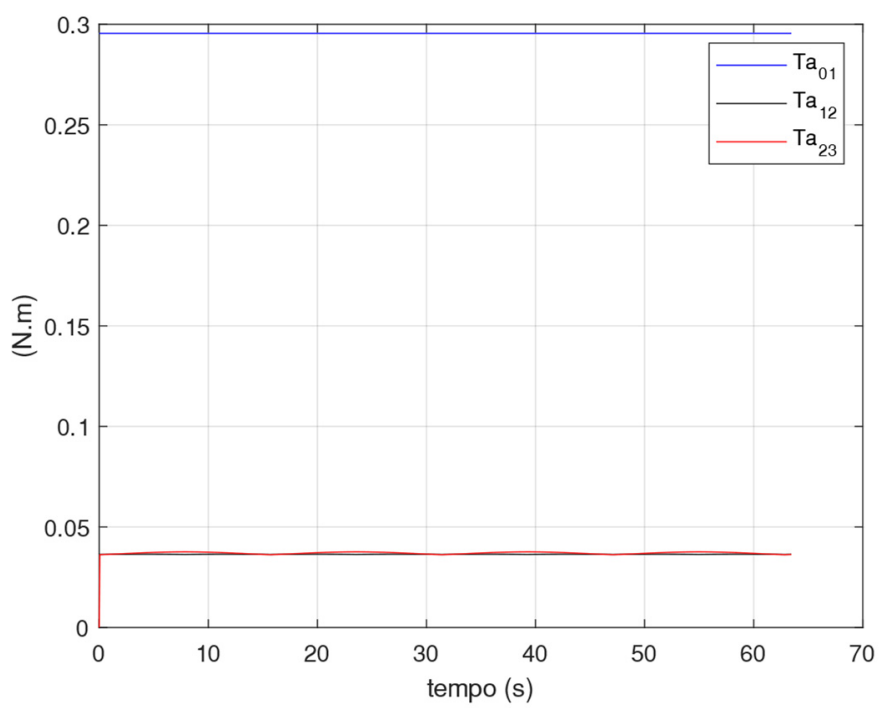

Figura 3-11 - Torque de atrito dos rolamentos para o Caso 1 para $\phi=\pi / 6 \mathrm{rad}$ e $\dot{\alpha}=0,2 \mathrm{rad} / \mathrm{s}$ [Fonte: Autoria própria] 
Para validar os resultados numéricos com os experimentais foi de extrema importância a inclusão da modelagem da fenomenologia da folga, tendo como leituras: o IMU e as células de carga na base da bancada experimental. Pelo lado experimental, ao utilizar as acelerações advindas do IMU, foram calculados os ângulos $\beta$ e $\gamma$ utilizando a eq. (3.1), aplicado o filtro de Kalman e plotado em conjunto com os resultados numéricos de $\beta$ e $\gamma$ extraídos do vetor de estado apresentado na Figura 3-8, e modificados discretamente para a inclusão da fenomenologia da folga. Para tal, as condições para que a folga aconteça obedeceram às equações (2.72) e (2.76), e, durante o processo da folga, os ângulos $\beta \mathrm{e}$ $\gamma$ seguiram as equações (2.73) e (2.77). Em seguida, foi necessário o cálculo do torque de impacto conforme as equações (2.75) e (2.79). Considerando que o torque de impacto atue num intervalo de tempo $\Delta t$, o impulso pôde ser calculado como $T_{I} \Delta t$, gerando uma vibração para o grau de liberdade em questão. O modelo de Kelvin, mostrado no Capítulo 2.2.4, foi utilizado para compreender a vibração apontada pelos acelerômetros do IMU, que, por consequência, reflete de forma abstrata no cálculo dos ângulos $\beta$ e $\gamma$. Isso porque, durante a vibração, as amplitudes dos ângulos calculadas pela equação (3.1), que depende da relação das acelerações, não corresponderam aos ângulos físicos reais do grau de liberdade. Entretanto serviram para compreender o fenômeno de vibração que ocorre com o grau de liberdade. Seguem algumas premissas e estimativas que foram adotadas baseadas em experimentação para o cálculo do fenômeno da folga e da vibração:

- A folga máxima $\delta_{\text {Max }}$ foi estimada em $\pi / 180 \mathrm{rad}=1^{0}$;

- O coeficiente de restituição estimado em $e_{r}=0,95$;

- A rigidez do impacto para os graus de Liberdade $k_{k}=70 \mathrm{Nm} / \mathrm{rad}$;

- Solução analítica do modelo de Kelvin para o impacto:

- Vibração do grau de Liberdade $\beta$

- $\delta_{1}^{(2)}(t)=\frac{T_{I}^{(2)} \Delta t}{\left(I_{2 y}+I_{3 y}\right) \omega_{d}^{(2)}} \cdot e^{-\xi \omega_{0}^{(2)} t} \cdot \sin \left(\omega_{d}^{(2)} t\right)$, onde: - $\omega_{d}^{(2)}=\omega_{0}^{(2)} \sqrt{1-\xi^{2}}$ e $\omega_{0}^{(2)}=\sqrt{k_{k} /\left(I_{2 y}+I_{3 y}\right)}$

- Vibração do grau de Liberdade $\gamma$

- $\delta_{1}^{(3)}(t)=\frac{T_{I}^{(3)} \Delta t}{I_{3 z} \omega_{d}^{(3)}} \cdot e^{-\xi \omega_{0}^{(3)} t} \cdot \sin \left(\omega_{d}^{(3)} t\right)$, onde:

- $\quad \omega_{d}^{(3)}=\omega_{0}^{(3)} \sqrt{1-\xi^{2}}$ e $\omega_{0}^{(3)}=\sqrt{k_{k} / I_{3 z}}$

Para o conhecimento do valor do torque de impacto é necessário resolver as equações (2.75) e (2.79). Dessa forma, o torque de impacto máximo do grau de liberdade $\beta$ é igual a 
$T_{\mathrm{I}}^{(2)}=\left[\begin{array}{llllll}0.355 & 0.3 & 0.299 & 0.301 & 0.301\end{array}\right]^{\mathrm{T}} \mathrm{Nm}$ e do grau de liberdade $\gamma$ é igual a $T_{\mathrm{I}}^{(3)}=\left[\begin{array}{llll}0.21 & 0.211 & 0.213 & 0.215\end{array}\right]^{\mathrm{T}} \mathrm{Nm}$.

Um fenômeno importante a observar na Figura 3-12 é a vibração que ocorre no grau de liberdade acoplado, quando o outro grau de liberdade se encontra no instante do impacto. Por serem corpos deformáveis, mesmo com pequenas velocidades, a vibração gerada na estrutura no momento do impacto é algo perceptível pelo IMU. Como os ângulos $\beta$ e $\gamma$ são acoplados pelo ângulo de junta, conforme a equação $\phi=\arccos \left(c_{\beta} c_{\gamma}\right)$, considerando que o ângulo de junta $\phi(t)$ terá o seu valor idêntico ao calculado antes do fenômeno da folga/impacto/vibração, assim pode-se calcular o valor do grau de liberdade oposto ao impacto por esta relação.

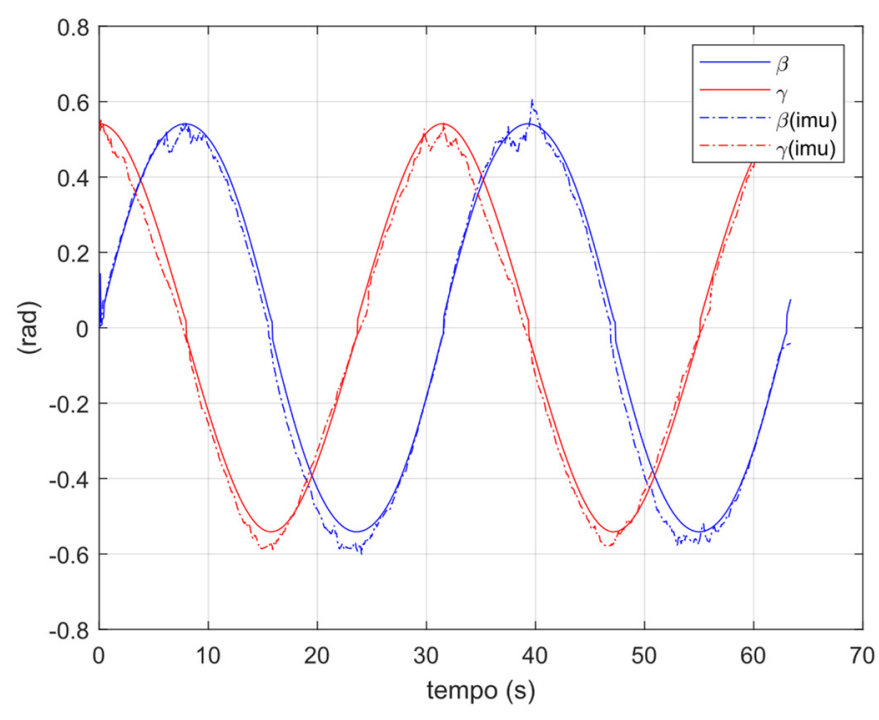

Figura 3-12 - Cálculo analítico com a identificação da folga e a leitura experimental dos ângulos pelo IMU para o Caso 1 [Fonte: Autoria própria]

Outra comparação experimental pode ser feita com a leitura das velocidades angulares do IMU posicionado na ponta do atuador com a velocidade angular do corpo 3. Para isso, é importante observar que o IMU está embarcado no corpo 3, portanto, é necessário escrever a velocidade angular do corpo 3 no SR S.

$$
{ }_{\mathrm{F}}^{\mathrm{S}} \boldsymbol{\omega}_{\mathrm{S}}={ }_{\mathrm{F}}^{\mathrm{S}} \boldsymbol{\omega}_{\mathrm{Q}}+{ }_{\mathrm{Q}}^{\mathrm{S}} \boldsymbol{\omega}_{\mathrm{R}}+{ }_{\mathrm{R}}^{\mathrm{S}} \boldsymbol{\omega}_{\mathrm{S}}=\mathrm{S} \mathbf{T} \mathrm{Q}\left[\begin{array}{c}
\dot{\alpha} \\
0 \\
0
\end{array}\right]+{ }^{\mathrm{S}} \mathbf{T}^{\mathrm{R}}\left[\begin{array}{c}
0 \\
\dot{\beta} \\
0
\end{array}\right]+\left[\begin{array}{c}
0 \\
0 \\
\dot{\gamma}
\end{array}\right]=\left[\begin{array}{c}
\omega_{3 x} \\
\omega_{3 y} \\
\omega_{3 z}
\end{array}\right]=\left[\begin{array}{c}
\dot{\beta} s_{\gamma}+\dot{\alpha} c_{\beta} c_{\gamma} \\
\dot{\beta} c_{\gamma}-\dot{\alpha} c_{\beta} s_{\gamma} \\
\dot{\gamma}+\dot{\alpha} s_{\beta}
\end{array}\right]
$$


Resolvendo a equação (3.4), para tanto, utilizando os valores de $\beta$ e $\gamma$ com a inclusão do modelo da folga, é possível observar na Figura 3-13 as instabilidades geradas pelo fenômeno da folga devido ao impacto na velocidade angular do corpo 3 .

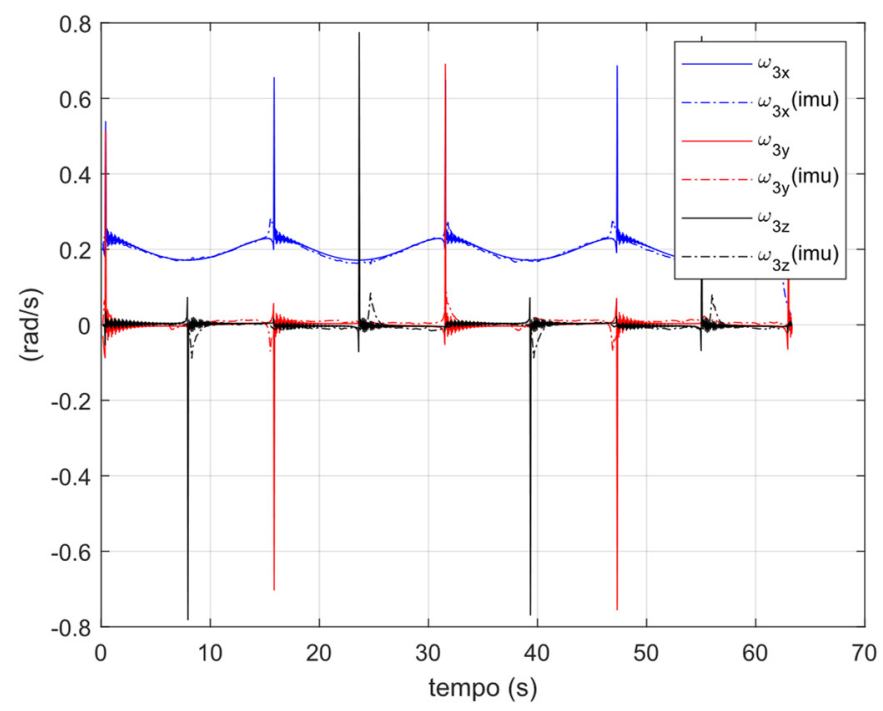

Figura 3-13 - Cálculo analítico com a identificação da folga e a leitura experimental da velocidade angular do corpo 3 no SR S do caso 1 [Fonte: Autoria própria]

Para a comparação do momento de reação no ponto A, torna-se necessário transformá-lo do SR Q, conforme indicado na Figura 3-10, para o SR F, sendo que as células de cargas encontram-se neste SR. Para tal, utiliza-se a equação (3.5) para obter as componentes das forças correspondentes aos binários.

$$
\begin{aligned}
& { }^{\mathrm{F}} \mathbf{M}_{A}={ }^{\mathrm{F}} \mathbf{T Q Q} \mathrm{Q} \mathbf{M}_{A} \\
& \mathbf{F}_{A}=\frac{{ }^{\mathrm{F}} \mathbf{M}_{A}}{r_{b}}
\end{aligned}
$$

Sendo $r_{b}=119 \mathrm{~mm}$.

A taxa de amostragem das células de carga é no máximo de $100 \mathrm{~ms}$ e, portanto, não permite captar o fenômeno da folga adequadamente. No entanto, ao observar o valor numérico constante $F_{2 x}-F_{4 x}=8,144 \mathrm{~N}$ na Figura 3-14, o sensor indica uma variação periódica máxima de $\pm 1 \mathrm{~N}$. Este erro máximo, de aproximadamente $12,2 \%$, ocorre devido ao desbalanceamento dos corpos rígidos envolvidos, neste caso, a matriz de inércia não é uma matriz diagonal, acarretando o aparecimento de produtos de inércia, mesmo com a utilização de contrapesos para contrabalancear os motorredutores. 


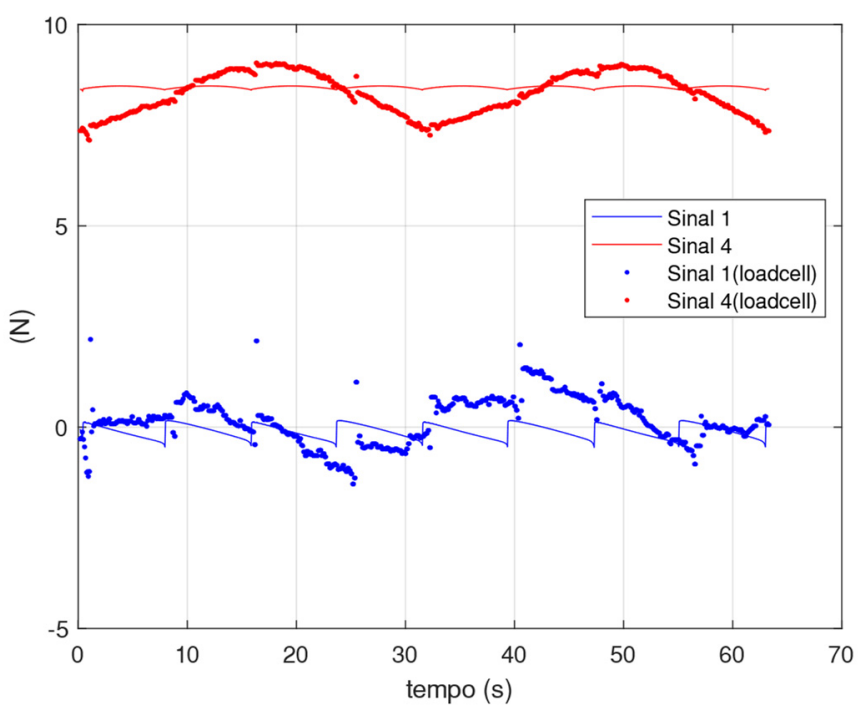

Figura 3-14 - Cálculo analítico com a identificação da folga e a leitura experimental das forças $F_{3 x}-F_{1 x}$ (Sinal 1) e $F_{2 x}-F_{4 x}$ (Sinal 4) do caso 1 no SR F [Fonte: Autoria própria]

\subsubsection{Caso 2 - Cinemática e Dinâmica}

Para os valores numéricos e experimentais registrados no subcapítulo 2.4 .2 foi selecionado o ângulo de junta de $\phi=\pi / 6 \mathrm{rad}$ e a velocidade angular do ângulo do plano de junta de $\dot{\theta}=0,2 \mathrm{rad} / \mathrm{s}$. Resolvendo a eq. (2.86) é possível obter os valores analíticos do vetor de estado $[\alpha, \beta, \gamma, \dot{\alpha}, \dot{\beta}, \dot{\gamma}]$ que serão utilizados como comando dos motores de passo do experimento e como entrada analítica inicial para o cálculo da cinemática e da dinâmica para o caso 2. Os valores de $\beta, \gamma$ e suas derivadas temporais são similares ao apresentado na Figura 3-8, sendo que não há valores $\alpha$, uma que vez que $\alpha(t)=0$ e corpo rígido 1 encontra-se parado. De forma similar, o valor do torque de impacto pode ser calculado resolvendo as equações (2.75) e (2.79), assim o grau de liberdade $\beta$ é igual a $T_{\mathrm{I}}^{(2)}=\left[\begin{array}{lll}0.158 & 0.143\end{array}\right]^{\mathrm{T}} \mathrm{Nm}$ e do grau de liberdade $\gamma$ é igual a $T_{\mathrm{I}}^{(3)}=\left[\begin{array}{lll}0.555 & 0.708\end{array}\right]^{\mathrm{T}} \mathrm{Nm}$. As cinemáticas dos corpos rígidos 2 e 3 são bem distintas em relação ao caso 1. Similar ao caso 1, na Figura 3-15 é possível analisar a cinemática dos corpos rígidos, que foi calculada utilizando as equações (2.15) e (2.16) para obter as velocidades angulares dos corpos rígidos 2 e 3 com relação ao SR F para o caso 2 . 


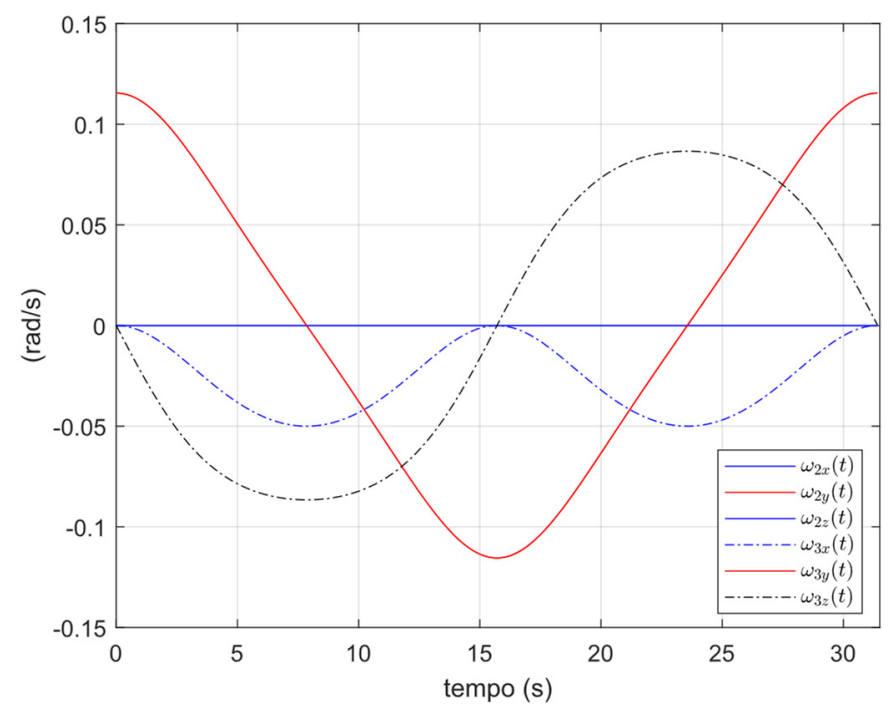

Figura 3-15 - Cinemática dos corpos rígidos no SR F para o Caso 2 para $\phi=\pi / 6 \mathrm{rad}$ e $\dot{\theta}=0,2 \mathrm{rad} / \mathrm{s}$ [Fonte: Autoria própria]

Após o cálculo da cinemática dos corpos rígidos, foi utilizado o sistema de equações em (2.47) para obter os momentos de reações e os torques dos motorredutores nos SRs respectivos sem a folga. Para o caso 2, os momentos de reações e os torques são idênticos aos do caso 1 apresentado na Figura 3-10. Entretanto, como o grau de liberdade $\alpha$ encontra-se parado, o SR F é igual ao SR Q, resultando nas reações exibidas na Figura 3-16. O erro apresentado entre o modelo numérico e o experimento, ocorreu pelo mesmo motivo apresentado no caso 1. De forma similar ao cálculo do atrito do caso 1, o caso 2 possui o atrito de rolamento igual à $T a_{12} \cong T a_{23} \cong 0,037 \mathrm{Nm}$, por possuir o vetor de estado idêntico para $\beta$ e $\gamma$. A única diferença é a ausência do atrito no grau de liberdade $\alpha$, portanto $T a_{01}=0$.

Realizando a comparação da velocidade angular do corpo 3 com o IMU, que se encontra embarcado no SR S, foi possível observar o comportamento coerente do movimento e as suas instabilidades no momento do impacto da folga, conforme Figura 3-17. 


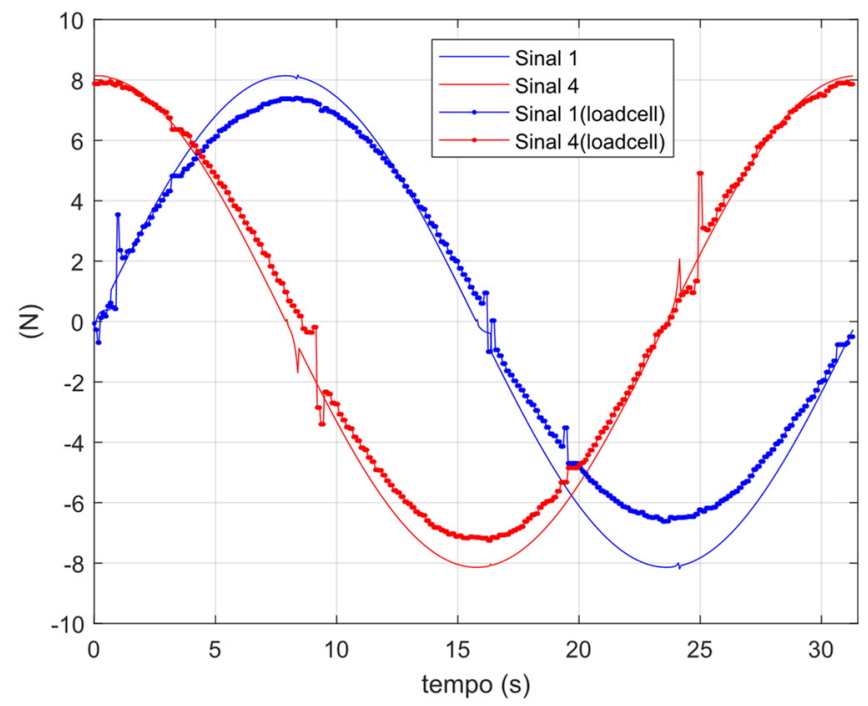

Figura 3-16 - Cálculo analítico com a identificação da folga e a leitura experimental das forças $F_{3 x}-F_{1 x}$ (Sinal 1) e $F_{2 x}-F_{4 x}$ (Sinal 4) do caso 2 no SR F [Fonte: Autoria própria]

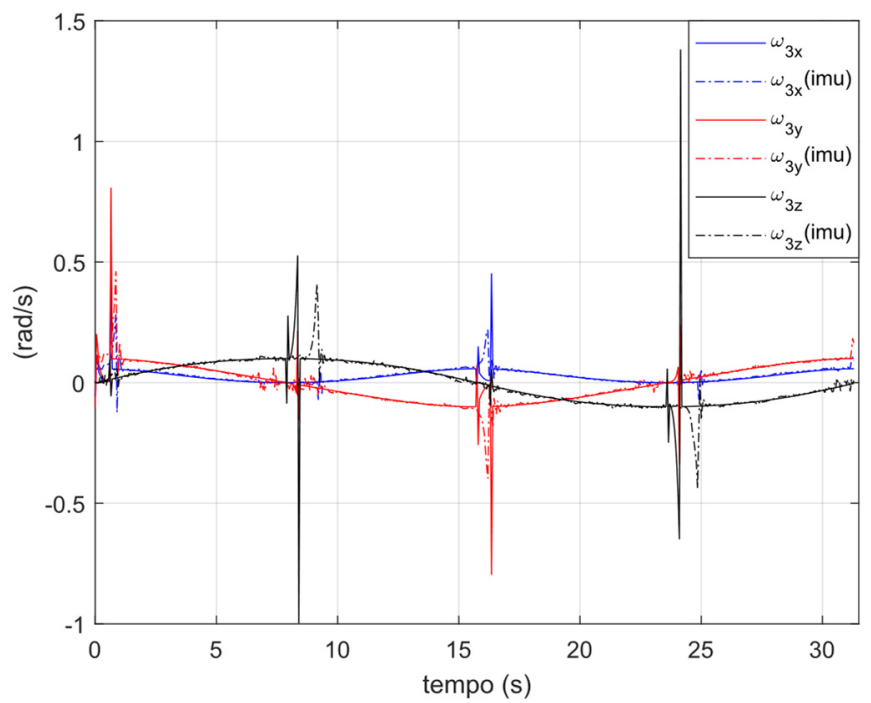

Figura 3-17 - Cálculo analítico com a identificação da folga e a leitura experimental da velocidade angular do corpo 3 no SR S do caso 2 [Fonte: Autoria própria]

\subsubsection{Caso 3 - Cinemática e Dinâmica}

Este caso 3 é a superposição da ideia dos movimentos dos casos 1 e 2, pois se deseja que o ângulo do plano de junta complete uma volta, enquanto o ângulo de spin realize cinco voltas. A superposição desses movimentos não é linear, tornando-se necessária a utilização das deduções cinemáticas e dinâmicas propostas no Capítulo 2.2. Para os valores numéricos e experimentais registrados no subcapítulo 2.4 .3 foi selecionado o ângulo de junta de 
$\phi=\pi / 6 \mathrm{rad}$ e a velocidade angular do ângulo do plano de junta de $\dot{\theta}=0,2 \mathrm{rad} / \mathrm{s}$ com o spin de $\dot{\psi}=1,0 \mathrm{rad} / \mathrm{s}$. Resolvendo as equações (2.87) e (2.88) é possível obter os valores analíticos do vetor de estado $[\alpha, \beta, \gamma, \dot{\alpha}, \dot{\beta}, \dot{\gamma}]$.

Na Figura 3-18 observa-se a comparação entre $\alpha$ dado pela eq. (2.87) e o ângulo do plano de junta $\theta$, além da pequena perturbação gerada em $\alpha$ necessária para garantir o spin de saída $\dot{\psi}$ constante.

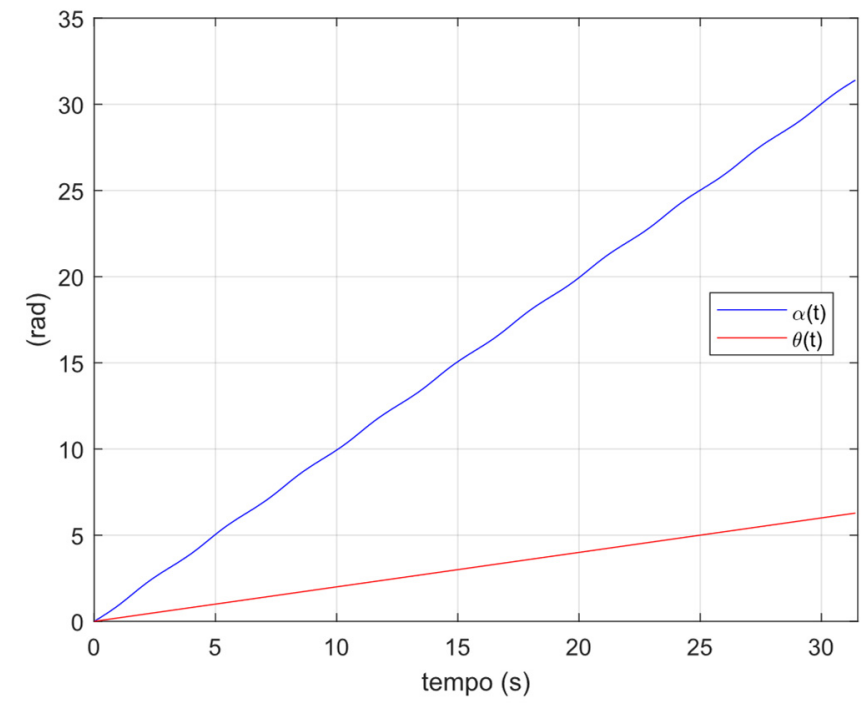

Figura 3-18 - Comparação entre $\alpha$ e $\theta$ para o Caso 3 para $\phi=\pi / 6 \mathrm{rad}, \dot{\theta}=0,2 \mathrm{rad} / \mathrm{s}$ e $\dot{\psi}=1,0 \mathrm{rad} / \mathrm{s}$ [Fonte: Autoria própria]

Por causa da relação $\psi=5 \theta$, os ângulos $\beta$ e $\gamma$ calculados na eq. (2.88) realizaram quatro ciclos dentro do período do ângulo $\theta$. Assim, as velocidades angulares dos motorredutores foram bem superiores às dos casos 1 e 2, como pode ser visto na Figura 3-19. Obviamente, esse aumento de velocidade se reflete nas velocidades angulares dos corpos rígidos, também, observado na Figura 3-20.

De forma similar aos casos anteriores, após o cálculo da cinemática, foi possível utilizar a eq. (2.47) para obter os momentos de reações e os torques dos motorredutores nos SRs respectivos sem a folga, conforme poder ser observado na Figura 3-21. 


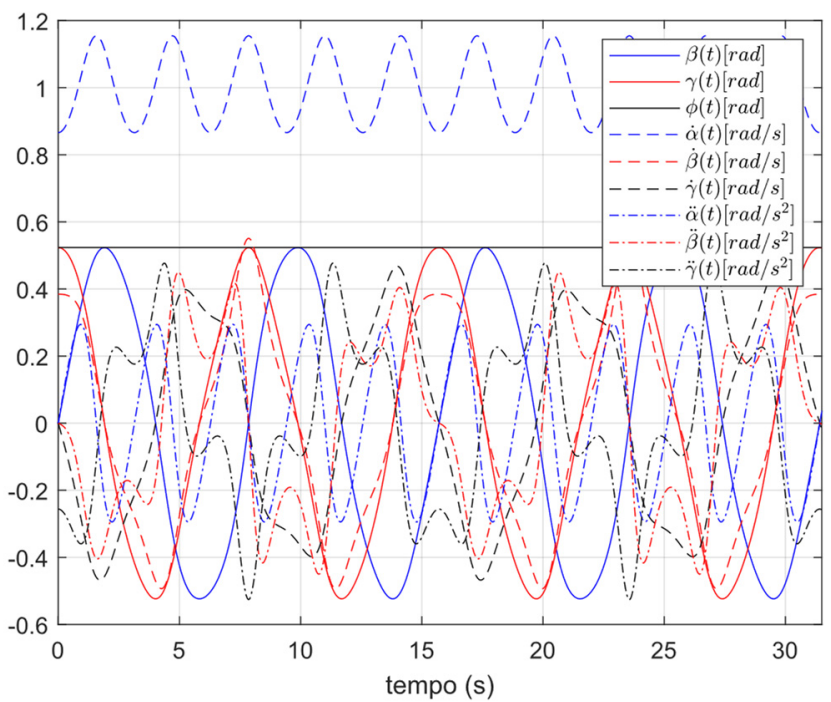

Figura 3-19 - Valores dos vetores de estado: : ângulos cardânicos ( $\beta, \gamma)$, ângulo da junta $(\phi)$, velocidades angulares $(\dot{\alpha}, \dot{\beta}, \dot{\gamma})$, e acelerações angulares $(\ddot{\alpha}, \ddot{\beta}, \ddot{\gamma})$ para o Caso 3 $\operatorname{com} \phi=\pi / 6 \mathrm{rad}, \dot{\theta}=0,2 \mathrm{rad} / \mathrm{s}$ e $\dot{\psi}=1,0 \mathrm{rad} / \mathrm{s}$ [Fonte: Autoria própria]

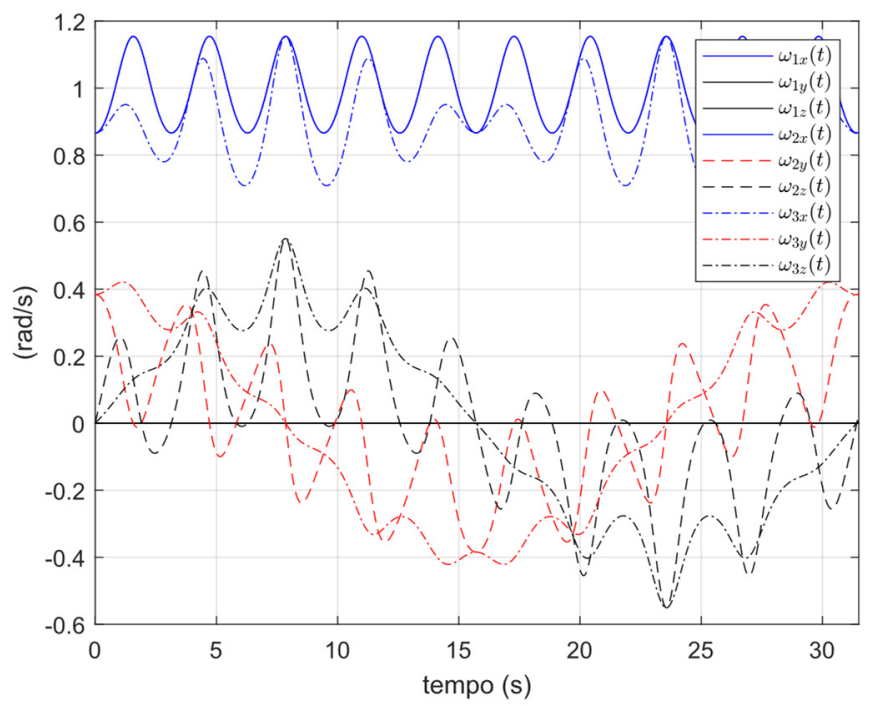

Figura 3-20 - Cinemática dos corpos rígidos no SR F para o Caso 3 para $\phi=\pi / 6 \mathrm{rad}$, $\dot{\theta}=0,2 \mathrm{rad} / \mathrm{s}$ e $\dot{\psi}=1,0 \mathrm{rad} / \mathrm{s}$ [Fonte: Autoria própria]

Para o conhecimento do valor máximo do torque de impacto foi necessário resolver as equações (2.75) e (2.79). Dessa forma, o torque de impacto do grau de liberdade $\beta$ é igual

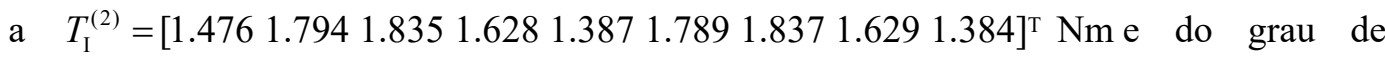

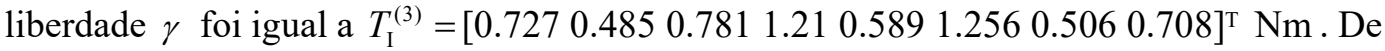
forma similar aos casos 1 e 2, com os torques de atrito calculados conforme a equação (2.64), os atritos podem ser considerados constantes, como na Figura 3-22. Essa 
simplificação permite escrever, $T a_{01} \cong 0,297 \mathrm{Nm}$ na direção de atuação do torque $T_{01}$, e $T a_{12} \cong T a_{23} \cong 0,037 \mathrm{Nm}$ para as direções de atuação dos torques $T_{12}$ e $T_{23}$, respectivamente.

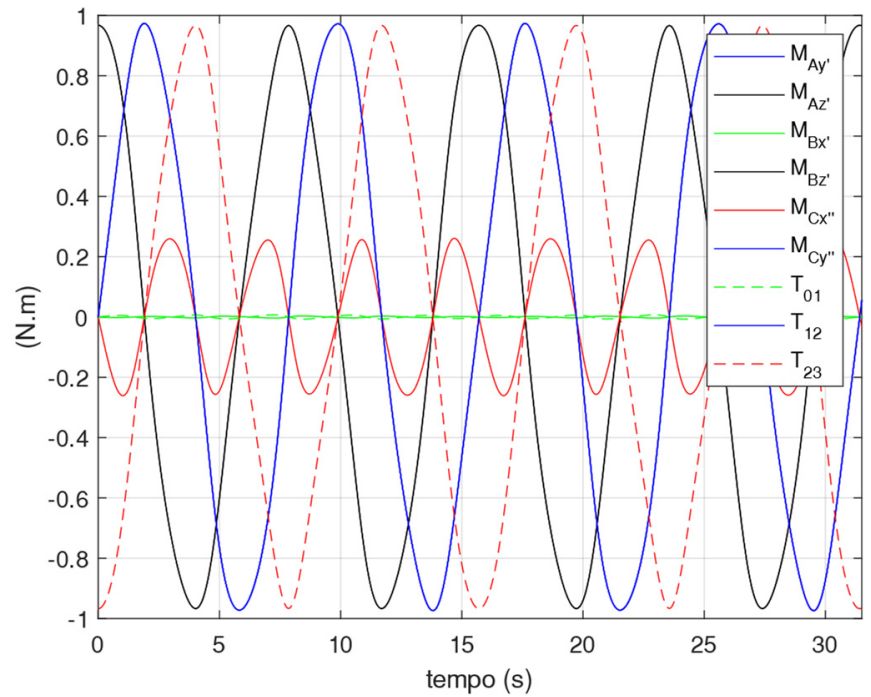

Figura 3-21 - Momentos de Reação e Torque dos motorredutores para o Caso 3 para $\phi=\pi / 6 \mathrm{rad}, \dot{\theta}=0,2 \mathrm{rad} / \mathrm{s}$ e $\dot{\psi}=1,0 \mathrm{rad} / \mathrm{s}$ [Fonte: Autoria própria]

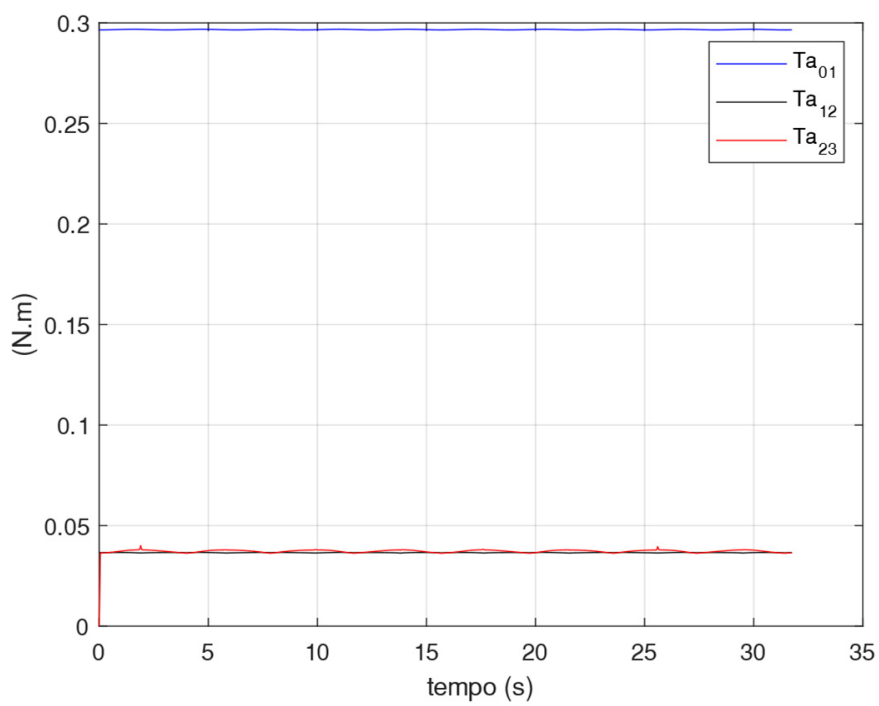

Figura 3-22 - Torque de atrito dos rolamentos para o Caso 3 para $\phi=\pi / 6 \mathrm{rad}, \dot{\theta}=0,2 \mathrm{rad} / \mathrm{s}$ e $\dot{\psi}=1,0 \mathrm{rad} / \mathrm{s}$ [Fonte: Autoria própria]

Ao utilizar as mesmas premissas para a fenomenologia da folga/impacto/vibração que foram usadas para os casos 1 e 2, foi possível observar o impacto e a vibração que ocorre 
nos graus de liberdade $\beta$ e $\gamma$, conforme a Figura 3-23. Devido à diminuição do período das funções de $\beta$ e $\gamma$, a vibração gerada pelo impacto não é amortecida antes da vibração que ocorre pelo impacto do grau de liberdade oposto. Entretanto a vibração consegue ser totalmente amortecida antes do fechamento do ciclo do período, impedindo o efeito de amplificação dos toques de impacto, que normalmente ocorre para os casos de altas velocidades e com grandes folgas.

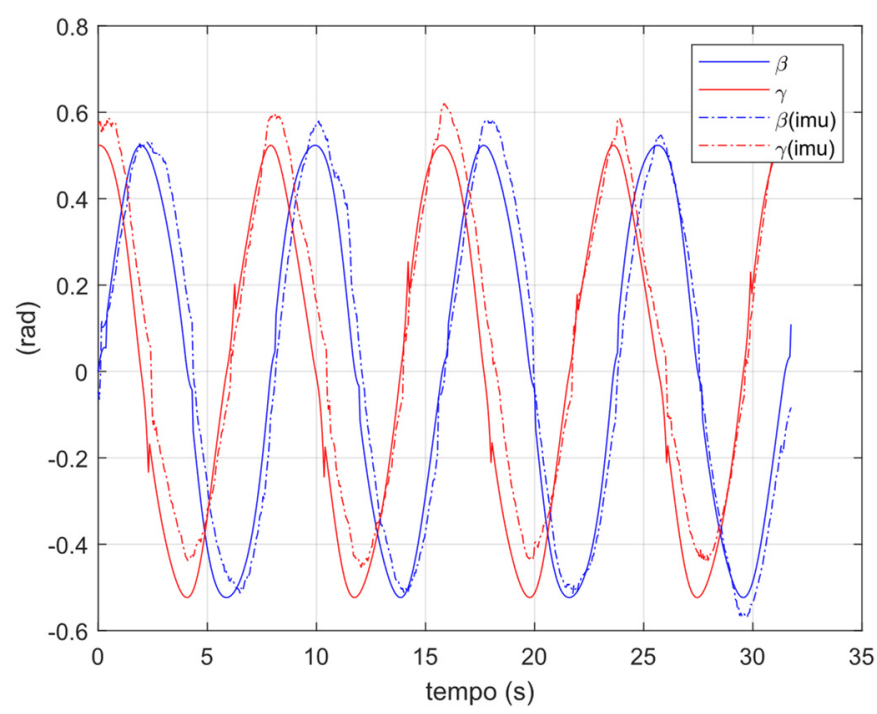

Figura 3-23 - Cálculo analítico com a identificação da folga e a leitura experimental dos ângulos pelo IMU para o Caso 3 [Fonte: Autoria própria]

Novamente comparando a velocidade angular do corpo 3 com o IMU, que se encontra embarcado no SR S, foi possível observar o comportamento coerente do movimento e as suas instabilidades no momento do impacto da folga conforme Figura 3-24.

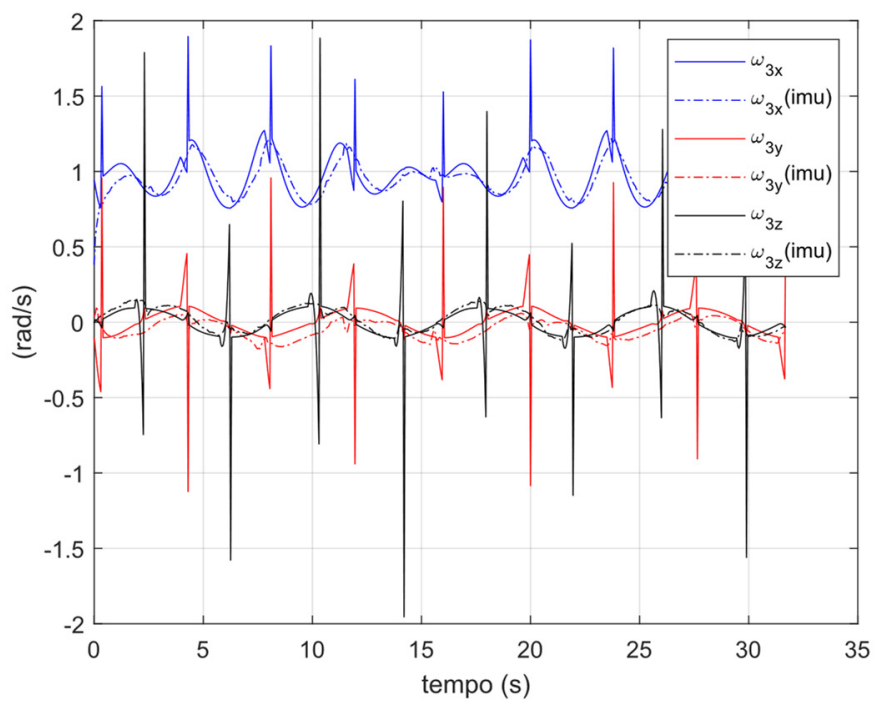


Figura 3-24 - Cálculo analítico com a identificação da folga e a leitura experimental da velocidade angular do corpo 3 no SR S do caso 3 [Fonte: Autoria própria]

Fazendo a transformação do momento de reação $\mathrm{Q} \mathbf{M}_{A}$ do SR Q para o SR F, conforme equação (3.5), as forças $F_{3 x}-F_{1 x}$ (Sinal 1) e $F_{2 x}-F_{4 x}$ (Sinal 4) são exibidas na Figura 3-25. $\mathrm{O}$ erro apresentado entre o modelo numérico e o experimento ocorre pelo mesmo motivo apresentado nos casos 1 e 2 .

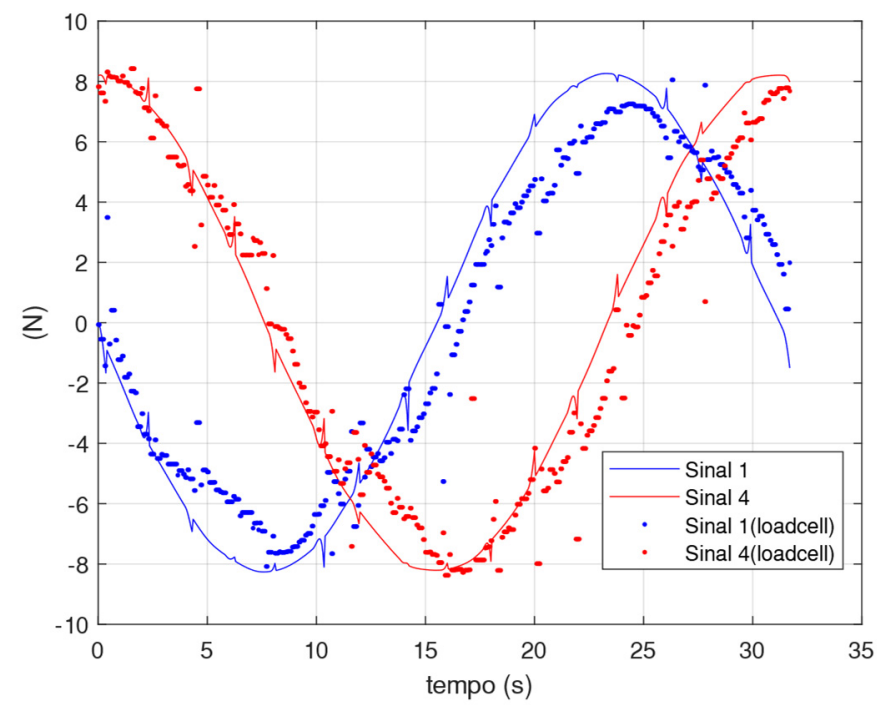

Figura 3-25 - Cálculo analítico com a identificação da folga e a leitura experimental das forças $F_{3 x}-F_{1 x}$ (Sinal 1) e $F_{2 x}-F_{4 x}$ (Sinal 4) do caso 3 no SR F [Fonte: Autoria própria]

\subsubsection{Caso 4 - Cinemática e Dinâmica}

Como descrito no capítulo 2.4.4, o caso 4 introduz uma novidade ao utilizar rotações cônicas para realizar o caminho mais econômico do atuador, isto é, a menor distância dentro do workspace esférico, também conhecido como distância do great-circle ou distância ortodrômica. Para o desenvolvimento numérico e experimental deste caso, foram consideradas as seguintes condições iniciais dos ângulos: para o ponto P1, o ângulo do plano de junta $\theta_{1}=0$ e ângulo de junta $\phi_{1}=\pi / 6$, e para o ponto P2, o ângulo do plano de junta $\theta_{2}=\pi / 2$ e ângulo de junta $\phi_{2}=\pi / 12$. Durante este trajeto foram definidas duas voltas de spin $\dot{\psi}=2 \dot{\Theta}$, que é escrito em função do ângulo do vetor de Euler $\Theta$. É possível obter ${ }^{R_{1}} \mathbf{T}^{R_{2}}$ através da equação (2.93) e extrair o novo vetor de Euler $\mathbf{p}$ e o ângulo $\Theta$ através da eq. (2.96) e confirmado pela eq. (2.97), resultando nos valores da eq. (3.6): 


$$
\begin{aligned}
& \mathrm{R}_{1} \mathbf{T}^{\mathrm{R}_{2}}=\left[\begin{array}{ccc}
0.837 & 0.5 & -0.224 \\
-0.483 & 0.866 & 0.129 \\
0.259 & 0 & 0.966
\end{array}\right] \\
& \mathbf{p}=\left[\begin{array}{lll}
(-0.1173439931) & (-0.4379337443) & (-0.8913161184)
\end{array}\right]^{\mathrm{T}} \\
& \Theta=33.464 \mathrm{o}
\end{aligned}
$$

Resolvendo a equação (2.102) para as condições iniciais informadas e utilizando o a equação (2.103) foi possível obter os ângulos cardânicos, conforme Figura 3-26, em função do ângulo do vetor de Euler $\Theta$.

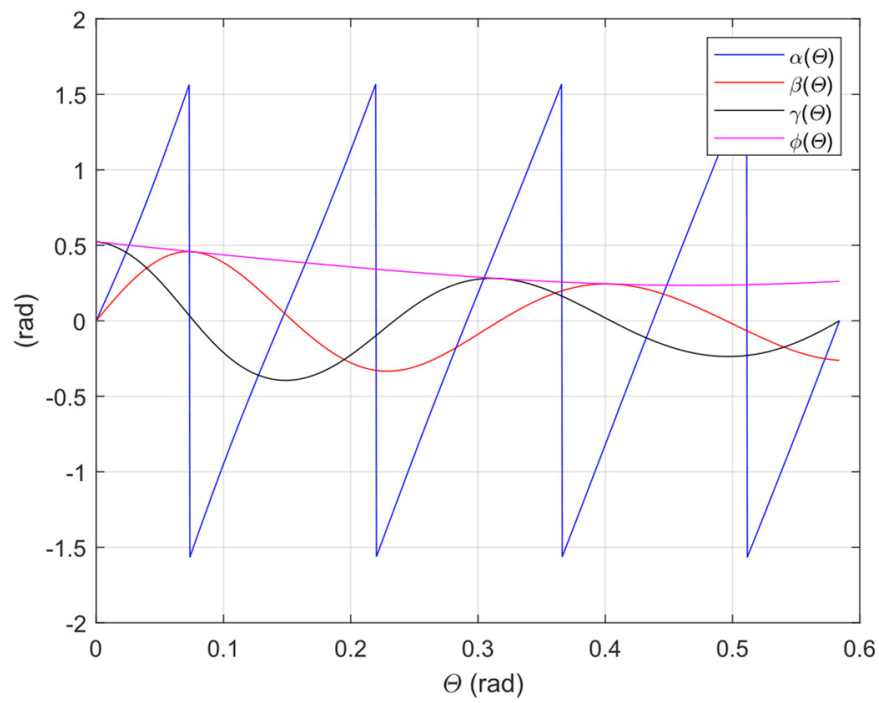

Figura 3-26 - Ângulos cardânicos $(\alpha, \beta, \gamma)$ e o ângulo da junta $(\phi)$ em função do ângulo do vetor de Euler $(\Theta)$ para o caso 4 [Fonte: Autoria própria]

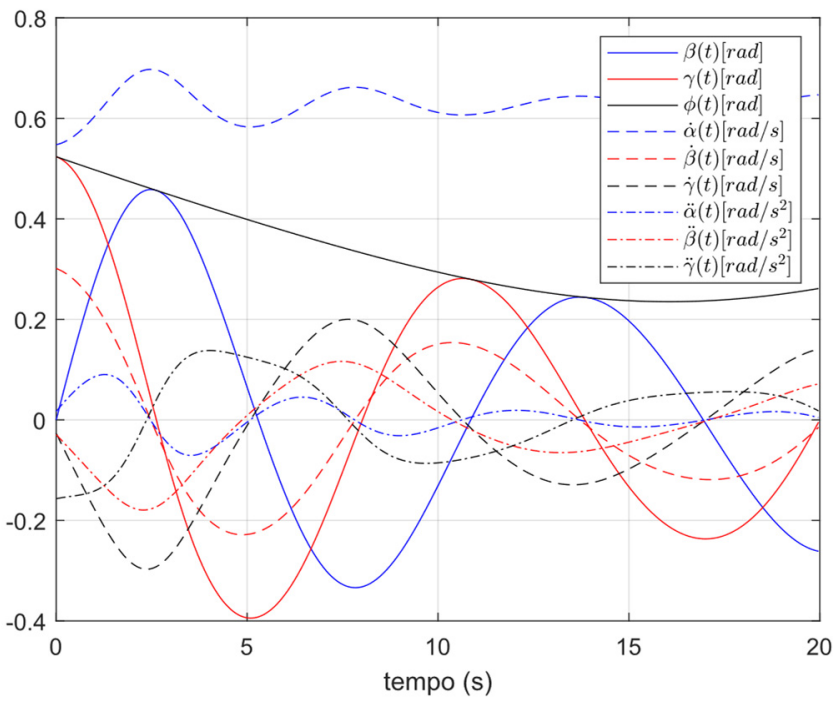

Figura 3-27 - Valores dos vetores de estado: ângulos cardânicos ( $\beta, \gamma)$, ângulo da junta $(\phi)$, velocidades angulares $(\dot{\alpha}, \dot{\beta}, \dot{\gamma})$, e acelerações angulares $(\ddot{\alpha}, \ddot{\beta}, \ddot{\gamma})$ para o caso 4 [Fonte: Autoria própria] 
Ao considerar o tempo total de 20 segundos para o movimento do ponto $\mathrm{P} 1$ ao ponto $\mathrm{P} 2$, pôde-se definir uma função $\Theta(t)$ linear para a obtenção dos vetores de estados conforme Figura 3-27.

Na Figura 3-28 é possível analisar a cinemática dos corpos rígidos, que foi calculada utilizando as equações (2.14), (2.15) e (2.16) para obter as velocidades angulares dos corpos rígidos 1, 2 e 3 com relação ao SR F para o caso 4.

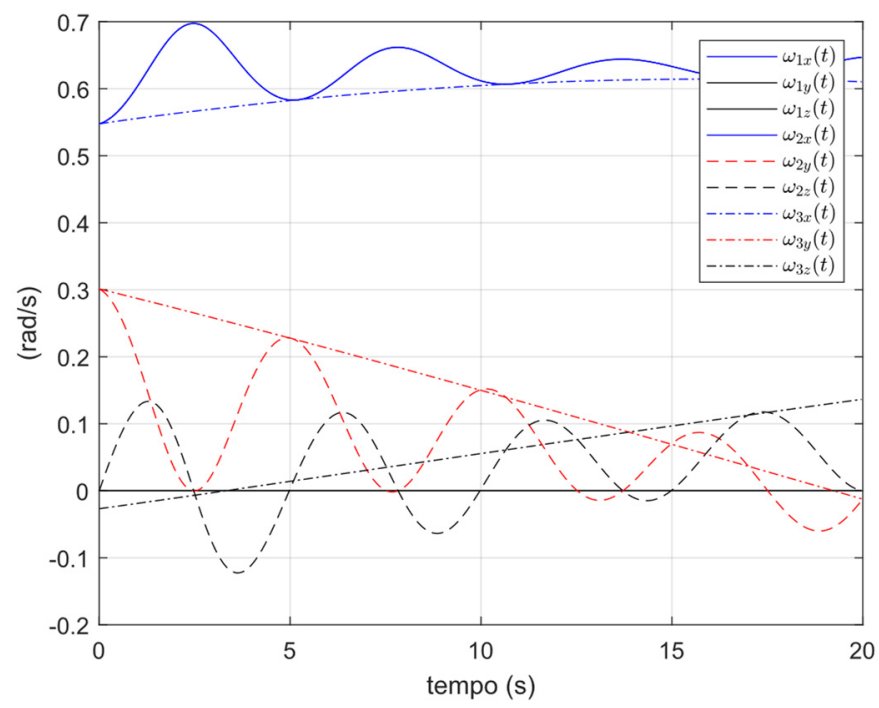

Figura 3-28 - Cinemática dos corpos rígidos no SR F para o caso 4 [Fonte: Autoria própria]

De forma similar aos casos anteriores, após o cálculo da cinemática, foi possível utilizar a eq. (2.47) para obter os momentos de reações e os torques dos motorredutores nos SRs respectivos sem a folga, conforme pode ser observado na Figura 3-29.

Similar aos casos anteriores, para o conhecimento do valor máximo do torque de impacto, foi necessário resolver as equações (2.75) e (2.79), resultando no torque de impacto do grau de liberdade $\beta$ é igual a $T_{\mathrm{I}}^{(2)}=\left[\begin{array}{llll}0.936 & 0.865 & 0.885 & 0.893\end{array}\right]^{\mathrm{T}}$ Nm e do grau de liberdade $\gamma$ é igual a $T_{\mathrm{I}}^{(3)}=\left[\begin{array}{lll}0.621 & 0.526 & 0.477\end{array}\right]^{\mathrm{T}} \mathrm{Nm}$. Com os torques de atrito calculados conforme a equação (2.64), os atritos puderam ser considerados constantes, similares aos casos anteriores. Essa simplificação permite escrever, $T_{01 \_a t r i t o} \cong 0,297 \mathrm{Nm}$ na direção de atuação do torque $T_{01}$, e $T_{12 \text { atrito }} \cong T_{23 \text { atrito }} \cong 0,037 \mathrm{Nm}$ para as direções de atuação dos torques $T_{12}$ e $T_{23}$, respectivamente. Na Figura 3-30 é possível observar o cálculo analítico com a 
identificação da folga comparado com medida experimental filtrada dos ângulos provenientes do IMU.

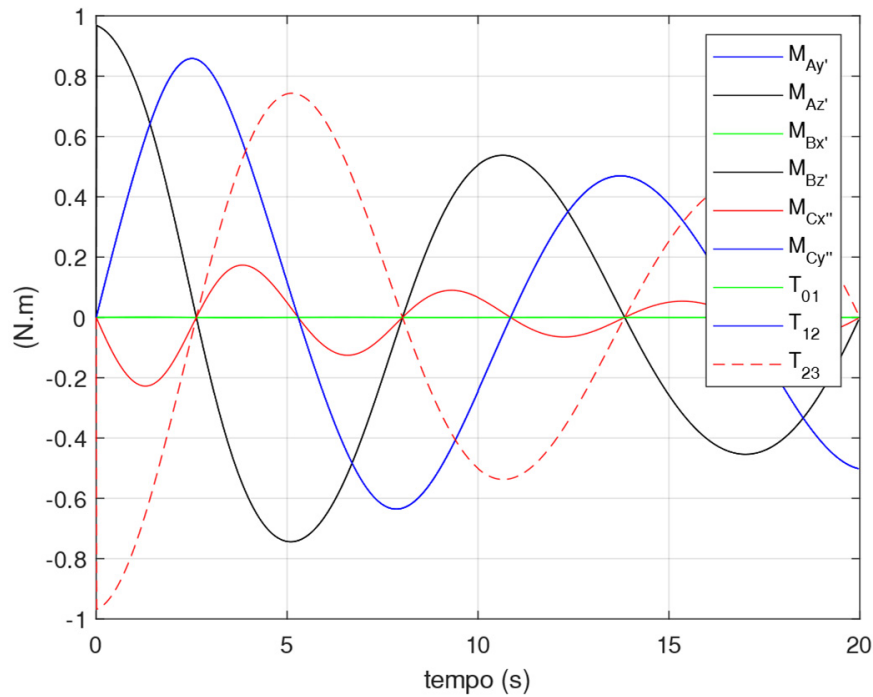

Figura 3-29 - Momentos de Reação e Torque dos motorredutores para o caso 4 [Fonte: Autoria própria]

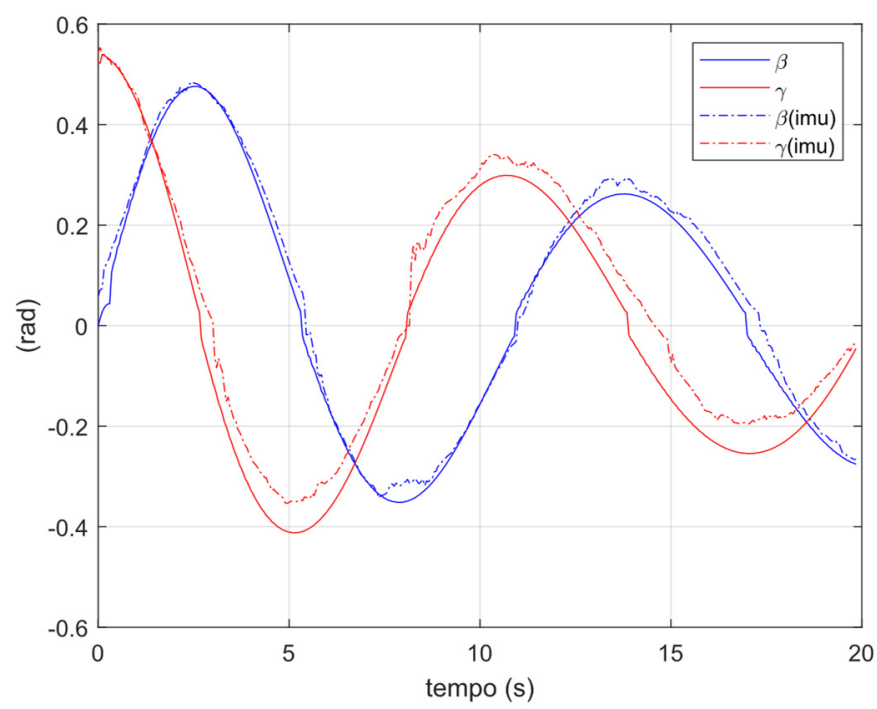

Figura 3-30 - Cálculo analítico com a identificação da folga e a leitura experimental dos ângulos pelo IMU para o caso 4 [Fonte: Autoria própria]

Ao comparar a velocidade angular do corpo 3 com o IMU, que se encontra embarcado no SR S, foi possível observar o comportamento coerente do movimento e as suas instabilidades no momento do impacto da folga, conforme Figura 3-31. 


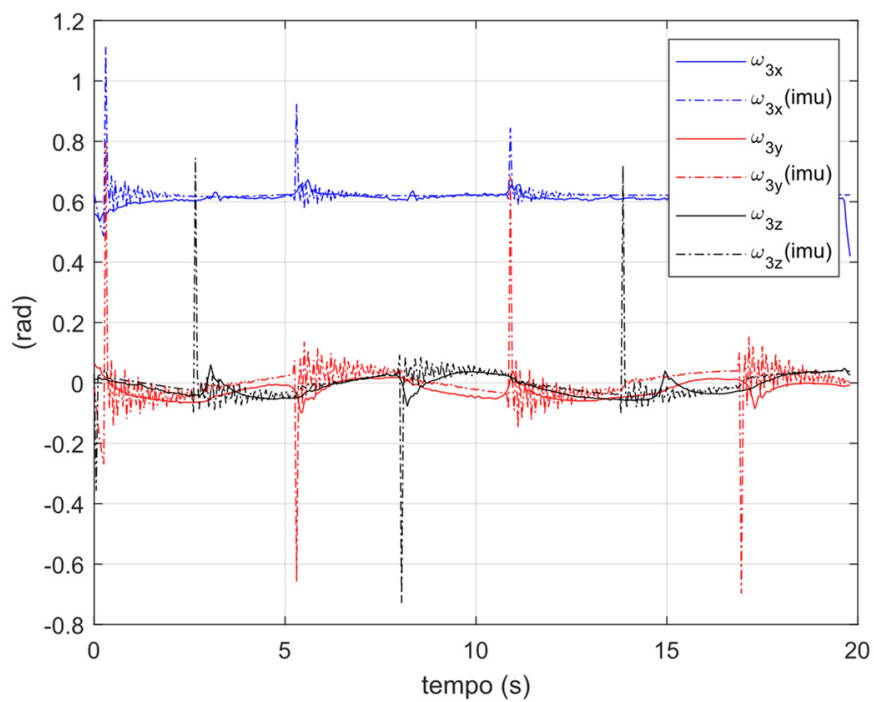

Figura 3-31 - Cálculo analítico com a identificação da folga e a leitura experimental da velocidade angular do corpo 3 no SR S do caso 4 [Fonte: Autoria própria]

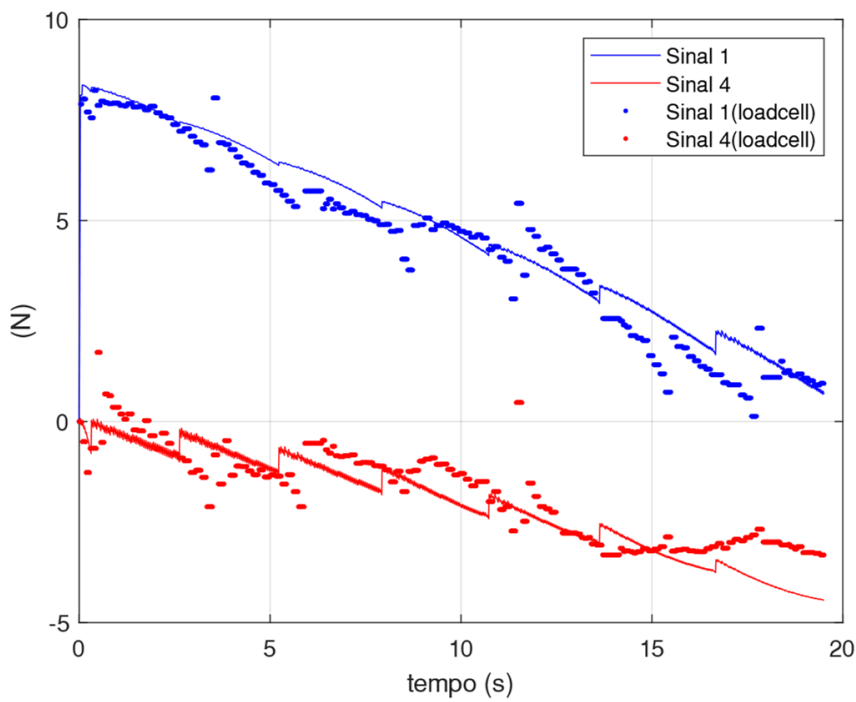

Figura 3-32 - Cálculo analítico com a identificação da folga e a leitura experimental das forças $F_{3 x}-F_{1 x}$ (Sinal 1) e $F_{2 x}-F_{4 x}$ (Sinal 4) do caso 4 no SR F [Fonte: Autoria própria]

Na Figura 3-32, a solução analítica com a identificação da folga tende a ser similar ao resultado experimental do IMU, inclusive, coincidindo os pontos de ocorrência das folgas. 


\subsection{Análise do redutor planetário}

Um dos desafios deste trabalho foi a seleção correta de um redutor viável que pudesse atender aos critérios do projeto, como torque e velocidade. Buscando trabalhar de forma compacta e embarcada na junta, redutores tradicionais, como de eixos paralelos, trariam prejuízos à geometria junta. Assim, a escolha de um redutor planetário alinhado ao eixo da cruzeta foi a opção deste trabalho, conforme Figura 3-33, mesmo conhecendo os desafios do porvir. Como a relação de um redutor planetário é fixa, diferentemente ao que ocorre, por exemplo, com os CVT "Continuously variable transmission", ao escolher um redutor de alta relação como 1:720, é esperado que a velocidade do motor reduza em 720 vezes e o torque aumente em 720 vezes. Assim, o motor utilizado NEMA 17HS8401 que possui o torque de $0,52 \mathrm{Nm}$ e velocidade máxima de $1500 \mathrm{rpm}$ faria o eixo do redutor trabalhar teoricamente com o torque de $374,4 \mathrm{Nm}$ e com velocidade aproximadamente de $2 \mathrm{rpm}$, ou seja, extremamente lento. No entanto este torque teórico não é permitido pelas engrenagens do redutor planetário, conforme já foi comprovado experimentalmente e simulado, utilizando uma análise não linear por elementos finitos com o Autodesk Nastran, na Figura 3-34. Dessa forma, trabalhou-se com outras duas relações de transmissão 1:139 e 1:19, o que permitiu alcançar velocidades maiores e proteger as engrenagens, mas comprometendo o torque.
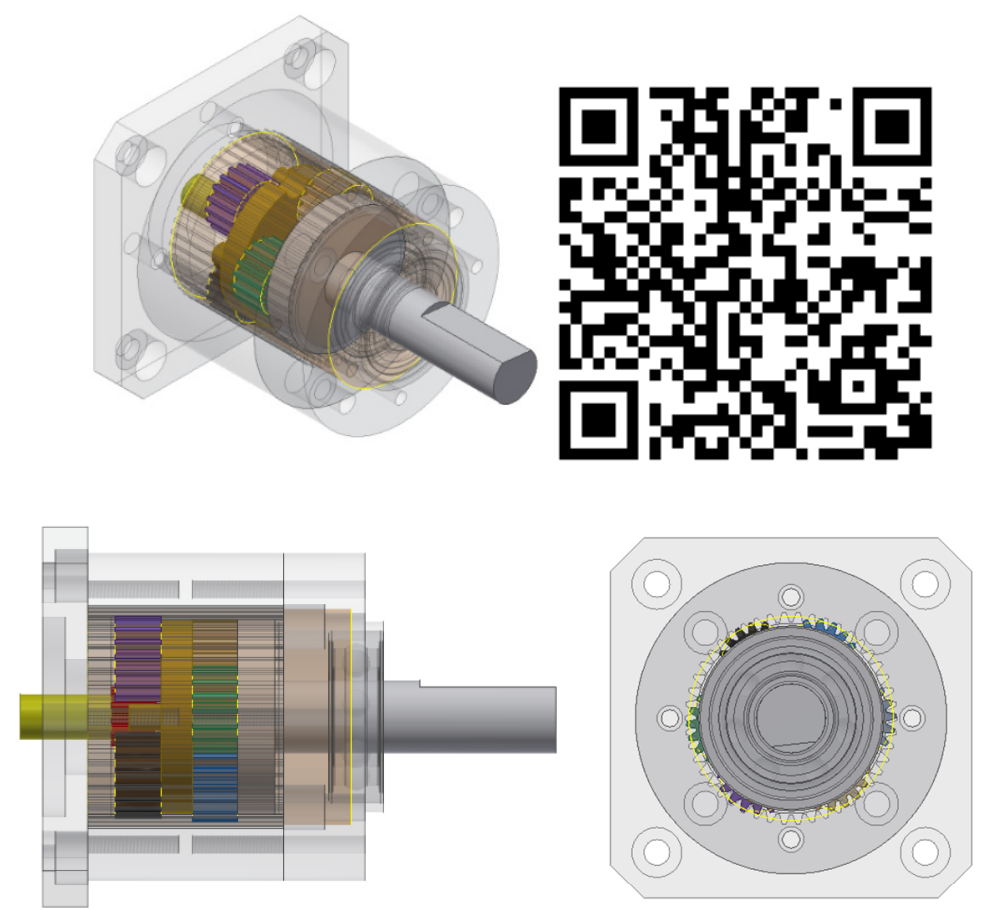

Figura 3-33 - Modelo BIM 3D do redutor planetário de dois estágios relação 1:139 construído no Autodesk Inventor e Dynamic Simulation e o QRCODE da simulação do redutor planetário de três estágios relação 1:720 [Fonte: Autoria própria] 


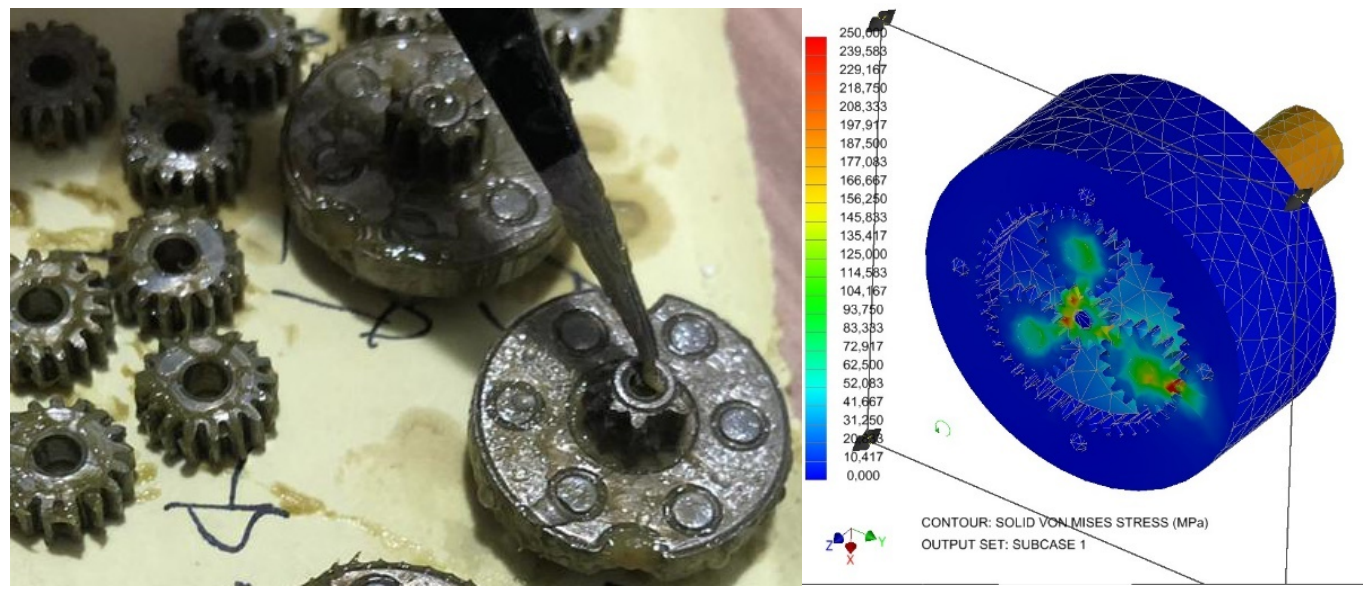

Figura 3-34 - Quebra do dente da engrenagem solar do último estágio do redutor planetário de relação de 1:720 (a esquerda) e simulação do último estágio (à direita) [Fonte: Autoria própria]

Uma das referências mundiais em acionamentos de alta precisão para a robótica é a empresa suíça Maxon, a qual, em seu catálogo, não possui redutores planetários de relação 1:720, apesar de seu alto custo. O redutor de relação máxima apresentado pela Maxon é o "Planetary Gearhead GP 81 A Ø81 mm, 20 - 120 Nm” com relação de 1:308. Dessa forma, após uma vasta pesquisa comercial, foi localizada uma empresa chinesa, Hanpose, que propôs um redutor planetário com a relação de 1:720 com o diâmetro externo de $36 \mathrm{~mm}$, que foi utilizado nesta tese por ser, até o momento, o redutor planetário com a maior relação de redução e com o menor diâmetro externo. Entretanto, conforme visto na Figura 3-34, esse redutor deverá ter o torque limitado para não comprometer as engrenagens do redutor. Uma das soluções possíveis é trabalhar com materiais avançados de alta resistência nos componentes do redutor para permitir, inclusive, ainda mais, a redução do redutor. Além disso, o uso de manufatura aditiva de alta precisão poderia ser uma das vertentes para o encapsulamento da solução.

Além da dificuldade na aplicação de redutores planetários comerciais, não foram encontradas soluções alternativas comerciais com relação ao peso/redução/potência necessários à junta cardânica ativa, como as engrenagens harmônicas ou de redutores planetários de rolamentos de engrenagens citado no subcapítulo 2.2.4. 


\section{Conclusão}

A obviedade relativa, após a apresentação dos resultados, é algo inerente às conclusões, que, por mais simples que estas sejam, seu conhecimento só é dado após a análise dos resultados. E isso significa que alguns questionamentos já podem ser respondidos adequadamente após diversos estudos e observações experimentais, como, por exemplo:

- Como projetar uma junta cardânica ativa de três graus de liberdade utilizando componentes comerciais existentes e de baixo custo?

- Por que foi escolhida a junta cardânica ao invés de outros tipos de junta: como homocinética, esférica ou outra com uma geometria particular?

- Qual tipo de acionamento utilizar para embarcar na junta? Elétrico, pneumático, hidráulico?

- Por que foram escolhidos motores de passo ao invés de motores DC?

- O que motivou a escolha dos sensoriamentos propostos? IMU e as células de carga?

- Quais seriam as limitações da junta com o propósito de transmitir o spin (rotação entre eixos) dentro de sua área de trabalho?

- Quais seriam as outras aplicações para a junta?

Além dessas perguntas iniciais, outras surgiram durante o caminho e que precisaram ser respondidas para vencer os percalços. Como, por exemplo:

- Qual será o tamanho da junta? Qual potência do motor deve ser utilizada? Qual a relação do redutor? Que tipo de redutor?

- Qual será o torque relativo aos atritos existentes no movimento? Será que é relevante?

- Qual é a relação entre a fenomenologia da folga e a cinemática/dinâmica?

- Por que foram propostos os casos 1,2,3 e 4?

- Quais são os componentes críticos no dimensionamento da junta ativa cardânica proposta?

E, por fim, outras perguntas servirão como base para futuros estudos. 


\subsection{Conclusão dos casos}

Conforme relatado, os casos apresentados nesta tese correspondem a uma pequena fração da bateria de testes realizada com a bancada experimental registrada pelos QRCODES da Figura 3-7, podendo, dessa forma, ser, a qualquer momento, verificados. Esses casos foram elaborados de forma a seguir uma ordem de complexidade no processo de movimentação da junta cardânica ativa e estão ligados à aplicação de possíveis equipamentos como manipuladores paralelos, manipuladores antropomórficos, misturadores, entre outras afinidades de equipamentos que podem ser desenvolvidos utilizando o conceito apresentado nesta tese.

A movimentação proposta no caso 1 é a função básica da junta cardânica e consiste na transmissão do movimento de spin entre os eixos. Para altas velocidades, as similaridades dos resultados, apresentadas no subcapítulo 3.2.1, podem ser consideradas, desde que o torque de impacto calculado não ultrapasse o torque máximo do motor de passo ou do limite de resistência do redutor planetário, e que a vibração, após o impacto, seja amortecida antes do impacto do grau de liberdade oposto. Pois, ao contrário, os torques de impactos amplificar-se-iam, aumentando a amplitude da vibração e do próximo torque de impacto até atingir o limite do torque da junta. Além disso, não foi escopo deste trabalho a análise experimental da vibração do impacto, pois seria necessária outra abordagem experimental, no entanto foi apresentada a solução analítica desta vibração.

Um aspecto interessante revelou-se nos resultados experimentais dos torques de impacto e cinemática inversa do caso 2 , que teve uma pequena modificação dos resultados esperados, mesmo tendo os ângulos $\beta$ e $\gamma$ analiticamente idênticos ao caso 1. Isso aconteceu devido à folga do grau de liberdade alpha, visto que o projeto não considerou o freio do eixo. Assim, os torques de impactos tenderam a ser maiores, fazendo com que a velocidade limite de operação da junta fosse menor do que a do caso 1. No entanto essa simulação da folga do grau de liberdade alpha não foi realizada. Mas essas observações estão registradas experimentalmente para futuros trabalhos que possam considerar essas folgas conjuntas $\alpha, \beta$ e $\alpha, \gamma$. 
No caso 3, a movimentação proposta permite uma aplicação mais abrangente para a junta cardânica ativa, por exemplo, atuar como misturador de eixos oblíquos. A sincronização do acionamento dos ângulos é essencial para garantir o correto posicionamento do efetuador do manipulador e impedir o acúmulo dos erros do movimento, que impreterivelmente poderá ser corrigido pela medida de outro sensor, por exemplo, um "encoder" fixado nos garfos da junta cardânica ativa. Ademais, ao correlacionar a velocidade angular do plano de junta $\dot{\theta}$ e o spin de saída $\dot{\psi}$ é possível calcular quantas voltas em torno do eixo de spin acontece com uma volta no plano de junta. Assim, ao aumentar o número de voltas, a velocidade angular dos ângulos cardânicos aumenta consideravelmente, fazendo com que o limite da junta possa ser atingido com muita facilidade. Por exemplo, para o redutor planetário com a menor redução, utilizado no experimento (1:19), a velocidade angular máxima foi de 78,947 rpm, e considerando 10 voltas de spin/plano de junta, não seria possível passar de 7,8947 rpm da velocidade angular do plano de junta $\dot{\theta}$. Mesmo ao tentar diminuir a relação da redução, isso não seria suficiente para atender à demanda de torque do manipulador, que, neste caso, trata-se apenas dos pesos próprios dos corpos 2 e 3 .

O caso 4, apresentado no subcapítulo 2.4.4 e 3.2.4, apresenta uma nova metodologia de movimentação do efetuador em sua área de trabalho, dessa forma, garantido que, através da rotação cônica, um arco de comprimento ortodrômico seja o menor caminho realizado pelo efetuador de um ponto $P_{1}$ para um ponto $P_{2}$. Com isso se torna possível generalizar o movimento do efetuador para qualquer caminho discreto. Como resultado da rotação cônica obtém-se a matriz de transformação e, a partir desta, são extraídos os parâmetros das rotações que, no caso deste trabalho, foram os ângulos cardânicos. Uma das vantagens deste método é a variação apenas do ângulo de Euler porque o vetor de Euler fica inalterado entre os pontos $P_{1}$ e $P_{2}$.

\subsection{Considerações finais}

A junta cardânica ativa proposta no subcapítulo 2.3.1 atingiu os objetivos do experimento ao utilizar diversos componentes comerciais e de custos relativamente baixos para sua manufatura. Comumente, as cruzetas de uma junta cardânica são fundidas, sendo esse processo de fabricação extremamente custoso, e construí-la mediante processo de manufatura subtrativa ou aditiva torna-se também custoso devido à sua geometria. Para 
viabilizar o experimento foi utilizada uma cruzeta comercial de aço fundido e os garfos foram construídos tripartidos de forma a permitir melhor manutenibilidade. No entanto a cruzeta e os garfos projetados foram claramente superdimensionados para os esforços esperados, por conseguinte, restando bem longe de fazer parte dos componentes críticos da junta cardânica ativa. Todavia, mesmo que seja trabalhado na redução do peso da cruzeta e dos garfos, ou diminuindo a sua espessura ou mudando o material, por exemplo, de aço para alumínio, a opção de manter o motorredutor nos eixos de atuação da cruzeta faz com que as dimensões da junta sejam limitadas às dimensões do motorredutor utilizado. E, ao retirar os motorredutores dos eixos de atuação da cruzeta por meio de outros elementos de máquinas como engrenagens, polias/correias dentadas, conforme proposto no trabalho de Zhao et al. (2013), por exemplo, iria contra o princípio da otimização de peso/volume dos componentes embarcados.

De acordo com o exposto no subcapítulo 1.1, a junta cardânica foi uma das primeiras juntas a serem descobertas. E, conforme visto na equação (2.17), ela não transmite a velocidade angular do primeiro eixo de forma constante para o segundo eixo, diferentemente da junta homocinética (CVJ - Constant Velocity Joint), da junta esférica ou da junta de Thompson. No entanto optou-se por utilizar a junta cardânica em virtude da facilidade de seu controle interno, caracterizando o conceito da junta ativa. Normalmente, os tipos de juntas CVJ são controlados externamente, e a elaboração de um projeto que permita o seu controle interno torna-se extremamente complexo e um desafio que faz com que alguns autores mudem a abordagem do acionamento, como é o caso de Bai et al. (2018), ao criarem um motor esférico, por exemplo.

A principal desvantagem em embarcar os motorredutores nos eixos principais da cruzeta é o alto torque necessário para a operação da junta cardânica ativa. Acionamentos pneumáticos ou hidráulicos foram cogitados e, em seguida, descartados, pois embarcá-los na junta para seguir o princípio da junta ativa passa a ser uma tarefa impraticável. A utilização de motorredutores, conforme especificado na Figura 2-9, passou a ser uma solução interessante porque altas reduções, através de redutores planetários, conseguem atingir os torques necessários para o movimento. Entretanto, conforme visto no subcapítulo 3.3, os redutores planetários passam a ser o principal componente crítico a ser analisado. E conhecer os torques envolvidos nos motorredutores, como descrito no subcapítulo 3.2, incluindo a fenomenologia da folga e do atrito, passa a ser essencial. Durante a fase experimental da tese, foram testadas diversas relações de reduções planetárias (1:720, 
1:139 e 1:19) e, por consequência, os valores de velocidade e torque estão correlacionados. O motor utilizado foi o NEMA17 (17HS8401) com o torque máximo informado pelo fabricante de $0,52 \mathrm{~N} . \mathrm{m}$ e velocidade máxima de $1500 \mathrm{rpm} \cong 157 \mathrm{rad} / \mathrm{s}$. Utilizando os redutores citados, os torques máximos ficaram limitados aos seguintes valores: 374, 4 N.m , 72,28 N.m e 9,88 N.m; e as velocidades máximas respectivas: 0,21 rad/s , 4,02 rad/s e $8,26 \mathrm{rad} / \mathrm{s}$. Os resultados apresentados no subcapítulo 3.2 foram realizados com velocidades relativamente pequenas para obter, de forma adequada, a captura das informações devido à limitação das taxas de amostragem dos sensores. O experimento utilizou a menor relação de redução (1:19), e poder-se-ia aumentar significativamente a velocidade e os torques envolvidos. Entretanto a fenomenologia da folga impede este aumento por completo porque o torque de impacto pode aumentar significativamente se comparado ao torque necessário ao movimento.

Para focalizar o estudo da cinemática e dinâmica da junta cardânica ativa, optou-se por utilizar motor de passo ao invés de motores DC em razão da garantia de posicionamento que ele proporciona através de seus pulsos. Mesmo sendo comum a utilização do motor DC em malha fechada com o seu encoder, este controle poderia prejudicar a odometria dos motores e, por consequência, o posicionamento dos ângulos requeridos do vetor de estado do problema.

Neste trabalho, para a verificação da movimentação angular do corpo rígido 3, foi adotado o IMU no efetuador do manipulador, ao invés de utilizar outros recursos como visão computacional, ou encoders - medidores angulares diretamente fixados nos garfos da junta cardânica ativa. O IMU MPU-9250 escolhido foi programado com uma taxa de amostragem de $20 \mathrm{~ms}(50 \mathrm{~Hz})$, o que permitiu captar, com segurança, a dinâmica dos corpos rígidos, que se encontra, para o caso relatado neste trabalho, extremamente lenta. Dessa forma, permitiu, inclusive, captar a vibração devido ao impacto da folga que vibra numa frequência natural aproximada de $8,56 \mathrm{~Hz}$ para o grau de liberdade $\beta$, e $7,179 \mathrm{~Hz}$ para o grau de liberdade $\gamma$, obedecendo ao teorema da amostragem de Nyquist-Shannon. Inclusive, pode chegar a captar qualquer desbalanceamento que exista no motor ou redutor, pois o motor pode chegar a $1500 \mathrm{rpm}$, isto é, $25 \mathrm{~Hz}$. Entretanto, como existe 400 pulsos por volta do motor, a frequência do pulso pode chegar a incríveis $10 \mathrm{kHz}$. Fenômeno este que obviamente não é captado de modo adequado pelo IMU, por conseguinte, causando ruídos para a leitura, portanto, sendo necessário a utilização de filtros para garantir a 
qualidade do sinal. O filtro de Kalman utilizado funcionou para este caso como um filtro passa-baixo. Outro ponto a considerar foi que o redutor com relação de 1:19 apresentou uma vibração/ruído superior no acionamento, comparado ao redutor com relação 1:720 para os problemas apresentados com baixas velocidades, isso obviamente aconteceu em razão de a frequência de excitação trabalhar próximo à frequência natural dos componentes internos dos motorredutores. Mesmo não sendo o escopo deste trabalho, a análise das frequências naturais é de vital importância para entender os ruídos que possam atrapalhar os sinais lidos pelo IMU.

O objetivo de conhecer a cinemática e a dinâmica de uma junta cardânica ativa foi atingido, inclusive, identificando as folgas e calculando os atritos. Os resultados experimentais dos casos propostos restaram dentro das margens de erros esperadas para os aparatos experimentais que permitem conhecer as suas velocidades, acelerações, além das forças e dos momentos envolvidos. As limitações de velocidade, torque e o limite de resistência dos componentes críticos do acionamento, porém, precisam de mais estudos e desenvolvimentos para alavancar as possíveis aplicações propostas nesta tese. Uma proposta de trabalhos futuros seria a de utilizar redutores planetários de rolamentos de engrenagens (VRANISH, 2003) para eliminar as folgas e aumentar a capacidade de torque, manufaturado com materiais de alta resistência, utilizando impressora de metal 3D, conhecida como "Direct Metal Laser Sintering" (DMLS) ou "Select Laser Melting" (SLM), utilizando o titânio $\operatorname{TiAl}_{6} V_{4}$, que pode chegar a uma tensão última de $950 \mathrm{MPa}$, ou seja, quase quatro vezes mais resistente que o aço comum. Apesar do alto custo envolvido em produzir um componente não comercial, essas ações aumentariam as aplicações da junta de mais de um grau de liberdade para diversos equipamentos.

Para definir o tamanho ou a bitola da junta da cardânica ativa, o projeto escolheu, primeiramente, o componente crítico, isto é, uma vez definido um redutor planetário com a maior redução possível e com possibilidade de haver outras reduções para trabalhar com o mesmo diâmetro externo do anel, define-se a geometria de garfos, cruzetas e eixos envolvidos. Esse processo é exatamente ao contrário do que ocorre na seleção do equipamento, quando, muitas vezes, são definidos a velocidade e o torque máximo de trabalho para a seleção. No entanto essa inversão foi necessária porque se desejava conhecer, dentro dos limites comerciais atuais, quais seriam as restrições de uma junta cardânica ativa. Qualquer outra solução exigiria o desenvolvimento de novos componentes que elevariam extremamente o custo do experimento. 
Outra inovação apresentada neste trabalho foi a modelagem da fenomenologia da folga, que apresentou uma proposta mais assertiva ao incluir a dinâmica da junta cardânica ativa durante o processo de folga, melhorando, assim, assertividade da solução quando comparado com a solução proposta por Nordin et al. (2002). Todavia a folga não é desejável no sistema de junta e deverá ser, dentro do possível, minimizada ou eliminada.

O cálculo do atrito do rolamento descrito no subcapítulo 2.2.3 teve um alto custo computacional ao ser realizado como exposto no subcapítulo 3.2, mas, como há um superdimensionamento dos rolamentos envolvidos, o atrito da vedação foi predominante e pôde ser considerado constante e com valores bem inferiores aos momentos envolvidos. Como exemplo, no caso 1, os torques $T_{12}$ e $T_{23}$ da Figura 3-10, o momento de atrito dos rolamentos equivale a $3,7 \%$ do torque máximo do movimento.

Por fim, os resultados analíticos, numéricos e experimentais encontram-se satisfatórios para corroborar o avanço na dinâmica dos estudos de juntas ativas cardânicas, principalmente em futuros projetos de equipamentos. E, com a abertura dos códigos dos programas, arquivos experimentais, vídeos de gravação do experimento, espera-se contribuir para futuros trabalhos em juntas de mais de um grau de liberdade.

\subsection{Trabalhos futuros}

Vários direcionamentos podem ser sugeridos a partir do estudo desta tese. Como, por exemplo: Redução do projeto dimensional da junta cardânica ativa dos elementos superdimensionados; Redução da folga mudando a solução do redutor de velocidade, ou usando o redutor de engrenagem harmônico ou o redutor planetário de rolamentos de engrenagens; Malha de Controle para minimizar as desvantagens da folga com a inclusão de um encoder nos corpos rígidos que estão em movimento; Analisar com uma nova abordagem as vibrações dos componentes envolvidos e o seu impacto no funcionamento da junta cardânica, incluindo sua análise modal; Aumentar o número de juntas do manipulador e estudar como a fenomenologia da folga propagar-se-ia; Usar dois motores por eixo para frear e eliminar as folgas, etc. Alguns desses estudos podem ser realizados com as informações experimentais já coletadas que se encontram nesta tese, porém outros necessitariam de uma nova abordagem e, por consequência, de novo experimento. 


\section{Referências Bibliográficas}

AKPOLAT, et al. Dynamic Model and Simulation of one Active Joint Robotic Fish. NWSAENS Engineering Sciences (ISSN: 1308 7231), January 2017.

ARAI , ; TACHI,. Position control system of a two degree of freedom manipulator with a passive joint. IEEE Transactions on Industrial Electronics, Volume: 38 , Issue: 1, Feb 1991.

ARAUJO, et al. Machine Vision for Industrial Robotic Manipulator using Raspberry Pi. Conference: 2018 13th IEEE International Conference on Industry Applications (INDUSCON), 2018. 894-901.

ASPRAGATHOS, N. A.; KOUSTOUMPARDIS, P. N.; MOULIANITIS, V. C. Advances in Service and Industrial Robotics: Proceedings of the 27th International Conference on Robotics in Alpe-Adria Danube Region (RAAD 2018), Mechanisms and Machine Science 67. [S.1.]: Springer Nature Switzerland, 2018.

BAEK, J. H. Modeling on a Gimbal with Antenna and Investigation on the Influence of Backlash. JSME International Journal Series C Mechanical Systems, Machine Elements and Manufacturing, Volume 49 (2006) Issue 3, 2006. 804-813.

BAEK, J. H.; KWAK, Y. K.; KIM, S. H. Backlash Estimation of a Seeker Gimbal with Two-Stage Gear. International Journal of Advanced Manufacturing Technology, 21, 2003. 604-611.

BAI, K. et al. Design and Development of a Spherical Motor for Conformal Printing of Curved Electronics. IEEE Transactions on Industrial Electronics, Volume 65, Number 11, November 2018. 9190-9200.

BANG, Y.-B. et al. A Three-Degree-of-Freedom Anthropomorphic Oculomotor Simulator. International Journal of Control, Automation, and Systems, vol. 4, no. 2, April 2006. 227-235.

BELLMAN, R. D.; HOLGATE, M. A.; SUGAR, T. G. SPARKy 3: Design of an active robotic ankle prosthesis with two actuated degrees of freedom using regenerative kinetics. 2nd IEEE RAS \& EMBS International Conference on Biomedical Robotics and Biomechatronics, 19-22 October 2008. 
BHATTACHARYA, S. et al. Learning Active Spine Behaviors for Dynamic and Efficient Locomotion in Quadruped Robots. CoRR, Volume abs/1905.06077, 28 May 2019. Disponivel em: <http://arxiv.org/abs/1905.06077>.

BISCHOFF, et al. The KUKA-DLR Lightweight Robot Arm - a new reference platform for robotics research and manufacturing. ISR / ROBOTIK, 2010. 741-748.

CACCAVALE, ; SICILIANO, ; VILLANI,. The Tricept robot: dynamics and impedance control. IEEE/ASME Transactions on Mechatronics, Volume: 8, Issue: 2, June 2003.

CARBONE, ; CECCARELLI,. A Serial-parallel robotic architecture for surgical tasks. Robotica (2005) volume 23, 2005. 345-354.

CARBOne, G.; CECCARElli, M.; PISLA, D. New Trends in Medical and Service Robotics: Advances in Theory and Practice, Mechanisms and Machine Science, Volume 65. [S.1.]: Springer Nature Switzerland, 2019.

CARDANO, H. Opera Omnia, tome $\mathrm{X}$ opuscala miscellanea ex fragmentis et paralipomenis. In: De Armillarum instrumento. [S.1.]: Lugduni (Lyon), 1663. p. p. $488-489$.

CARDOZO, S. Numerical and experimental study of a two degrees of freedom electrohydraulic manipulator. [S.1.]: THESIS - PONTIFÍCIA UNIVERSIDADE CATÓLICA DO RIO DE JANEIRO - PUC-RIO, 2017.

CARDOZO, W. S.; WEBER, H. I. A compact formulation for constant velocity joint kinematics. Mechanism and Machine Theory, Volume 121, March 2018, Pages 1-14, 12 October 2017.

DENKENA, et al. Design, modeling and advanced control of the innovative parallel manipulator PaLiDA. Proceedings, IEEE/ASME International Conference on Advanced Intelligent Mechatronics, Monterey, California, USA, 24-28 July 2005.

DERBEL , N.; GHOMMAM, J.; ZHU,. New Developments and Advances in Robot Control, Studies in Systems, Decision and Control, Volume 175. [S.1.]: Springer Nature Singapore Pte Ltd, 2019.

FAULHABER. 6.5 billion kilometers to the workplace. Faulhaber, 2014. Disponivel em: $<$ https://www.faulhaber.com/en/markets/aerospace-aviation/comet-probe-rosettamission>. Acesso em: 2019. 
FELDHAUS, F. M. Die Technik der Vorzeit, der Geschichtlichen Zeit und der Naturvölker. In: (Engineering in prehistoric times, in historical times and by primitive man). [S.1.]: Leipzig:Engelmann, 1914. p. p. 678, 869-870.

FLORES, ; LANKARANI, H. M. Contact Force Models for Multibody Dynamics. [S.1.]: Springer International Publishing Switzerland, v. Volume 226, 2016.

FROEHLIC, ; REISER,. Design and implementation of a spherical joint for mobile manipulators. International Symposium on Robotics (ISR), ISBN 978-3-8007-4231-8, ISR 2016 Munich, Germany), 21-22 June 2016.

FROEHLIC, T. et al. Concept And Design Of A Spherical Joint Mechanism For Service Robots. Procedia Manufacturing, Volume 24, Pages 74-79, 2018.

GALLARDO-ALVARADO, J. et al. Kinematics of the 3(RPSP)-S Fully Spherical Parallel Manipulator by Means of Screw Theory. A special issue of Robotics (ISSN 2218-6581), 15 June 2018.

GERDES, ; KUMAR,. An Impact Model of Mechanical Backlash for Control System Analysis. Proceedings of 1995 American Control Conference - ACC'95, Seattle, WA, USA, 21-23 June 1995.

GHOSH, B. B.; SARKAR, B. K.; SAHA,. Realtime performance analysis of different combinations of fuzzy-PID and bias controllers for a two degree of freedom electrohydraulic parallel manipulator. Robotics and Computer-Integrated Manufacturing 34 (2015), 8 December 2014. 62-69.

GOSSELIN, C. M.; CARON, F. https://patents.google.com/patent/US5966991A - Two degree-of-freedom spherical orienting device, 1999.

GOTTLIEB, et al. Coordinating two degrees of freedom during human arm movement: load and speed invariance of relative joint torques. Journal of Neurophysiology 76(5), 3196-206, December 1996.

GROTJAHN, ; HEIMANN ,; ABDELLATIF,. Identification of Friction and Rigid-Body Dynamics of Parallel Kinematic Structures for Model-Based Control. Multibody System Dynamics 11, 2004. 273-294.

GRUZMAN,. Sistema de Acompanhamento de Alvos Montado em um Corpo em Movimento. Rio de Janeiro: THESIS - PONTIFÍCIA UNIVERSIDADE CATÓLICA DO RIO DE JANEIRO - PUC-RIO, 2011. 
HAM, R. V. et al. Maccepa, The Mechanically Adjustable Compliance And Controllable Equilibrium Position Actuator: A 3dof Joint With Two Independent Compliances. International Applied Mechanics, Vol. 43, No. 4, 2007.

HIRZINGER, et al. Torque-Controlled Lightweight Arms and Articulated Hands: Do We Reach Technological Limits Now? The International Journal of Robotics Research, Vol. 23, No. 4-5, April-May 2004. 331-340.

HONEYWELL. Honeywell Spherical Motor. Honeywell Aerospace, 2019. Disponivel em: $<$ https://aerospace.honeywell.com/en/sites/spherical-motor>.

HOURAN, M. A.; YANG, X.; CHEN, W. Free Angular-Positioning Wireless Power Transfer Using a Spherical Joint. A special issue of Energies (ISSN 1996-1073), 14 December 2018.

HUANG, et al. Mechanism design and kinematic analysis of a robotic manipulator driven by joints with two degrees of freedom (DOF). The International Journal of Robotics Research and Application, Volume 45, Issue 1, 25 September 2017. 34-43.

IKEDA, ; TAKANASHI,. https://patents.google.com/patent/US4683406 - Joint assembly movable like a human arm, 1985.

JAZAR, R. N. Theory of Applied Robotics: Kinematics, Dynamics, and Control (2nd Edition). [S.1.]: Springer Science+Business Media, 2010.

JIN, et al. Nonlinear Characteristic of Spherical Joints with Clearance. J. Aerosp. Technol. Manag. vol.7 no.2 São José dos Campos April/June 2015, 2015.

KELLY, ; SANTIBÁÑEZ, V.; LORÍA,. Control of Robot Manipulators in Joint Space, Advanced Textbooks in Control and Signal Processing (ISBN-10: 1852339942). [S.1.]: British Library Cataloguing in Publication Data - Springer Science+Business Media, 2005. KIM, B.-S.; PARK, J.-J.; SONG, J.-B. Double Actuator Unit with Planetary Gear Train for a Safe Manipulator. Proceedings 2007 IEEE International Conference on Robotics and Automation (ISSN: 1050-4729), 10-14 April 2007.

KIM, H.-S.; SONG, J.-B. Multi-DOF Counterbalance Mechanism for a Service Robot Arm. IEEE/ASME Transactions on Mechatronics, Volume 19, Number 6, December 2014.

KIMATA, K. et al. Numerical Analyses and Experiments on the Characteristics of BallType Constant-Velocity Joints. JSME International Journal Series C, Volume 47, Issue 2, 2005. 746-754. 
KOVA, M. C. et al. Configuration Lattices for Planar Contact Manipulation Under Uncertainty. https://arxiv.org/pdf/1605.00169v1.pdf, 30 April 2016.

KRUDE ,. https://patents.google.com/patent/US4012925A - Constant velocity torque transmitting joint, 1974.

KRUDE ,. US4156354A - Angularly flexible cardan shaft joint, 1977.

LEE, J. ; CHOI, M. J. Robust Inertial Measurement Unit-Based Attitude Determination Kalman Filter for Kinematically Constrained Links. Sensors, Volume 19 , Issue 4 , 10.3390/s19040768, 13 February 2019.

LEE, K. M.; SHAH,. Kinematic analysis of a three-degrees-of-freedom in-parallel actuated manipulator. IEEE Journal on Robotics and Automation Volume: 4, Issue: 3, Jun 1988.

LEGNANI, G.; FASSI, I. Kinematics Analysis of a Class of Spherical PKMs by Projective Angles. Special Issue Kinematics and Robot Design I, KaRD2018, Robotics, MDPI, 20 September 2018.

LENARCIC, J.; PARENTI-CASTELLI, V. Advances in Robot Kinematics 2018 Springer Proceedings in Advanced Robotics 8. [S.1.]: Springer International Publishing AG, 2018

LESSARD, et al. A Bio-Inspired Tensegrity Manipulator with Multi-DOF, Structurally Compliant Joints. https://arxiv.org/pdf/1604.08667v2.pdf, 1 September 2016.

LI, J. et al. Kinematics and performance analysis of a serial hip assistive mechanism. Advances in Mechanical Engineering, Volume 10(4), March 2018. 1-19.

LIU, B. et al. Design and Realize a Snake-Like Robot in Complex Environment. Journal of Robotics, Volume 2019, Article ID 1523493, 9 pages, 2019.

LONG, J.; SHUAI, L.; MIRZA, A. Kinematic control of redundant robot arms using neural networks. [S.1.]: IEEE Press Wiley - JohnWiley \& Sons Ltd, 2019.

MANFREDI, L.; CUSCHIERI, A. Design of a 2 DOFs Mini Hollow Joint Actuated with SMA Wires. Materials (Basel, Switzerland), ISSN: 1996-1944, Vol: 11, Issue: 10, 2018. MARQUES, et al. A Study on the Dynamics of A Study on the Dynamics of Spatial Mechanisms With Frictional Spherical Clearance Joints. Journal of Computational and Nonlinear Dynamics, 12(5):051013-051013-10, 4 May 2017.

MAXON. Maxon Corporation, 1961. Disponivel em: <https://www.maxonworld.com/>. Acesso em: 26 dez. 2019. 
MCGINNIS, R. S.; PERKINS, N. C. Inertial sensor based method for identifying spherical joint center of rotation. Journal of Biomechanics, Volume 46, Issue 14, 27 September 2013. 2546-2549.

MEKID ,. https://patents.google.com/patent/US8608398B2 - Spherical joint with internal brake, 2011.

MGHAMES, S. et al. A Spherical Active Joint for Humanoids and Humans. IEEE Robotics and Automation Letters, Volume. 4, Number 2, APRIL 2019. 838-845.

MILLER, L. A. et al. Control of a Six Degree-of-Freedom Prosthetic Arm after Targeted Muscle Reinnervation Surgery. Arch Phys Med Rehabil. 89(11), November 2008. 2057 2065.

MUSSER, C. W. Strain wave gearing. US2906143A, 1955. Disponivel em: $<$ https://patents.google.com/patent/US2906143A/en>.

MUTLU, et al. Effects of passive and active joint compliance in quadrupedal locomotion. Journal - Advanced Robotics- Volume 32, Issue 15: Special Issue on Adaptive Motion of Animals and Machines, 2018. 809-824.

NISHIDA, J. K. O Design Como Ferramenta De Inovação Para Desenvolvimento De Novas Tecnologias Na Área De Captura De Movimento Humano. [S.1.]: Dissertação de Mestrado - UFSC - Universidade Federal de Santa Catarina, 2017.

NORDIN, M.; GALIC, J.; GUTMAN, P.-O. New Models for Backlash and Gear Play. International Journal of Adaptative Control and Signal Processing, 11, 1997. 49-63.

NORDIN, M.; GUTMAN, P.-O. Controlling mechanical systems with backlash—a survey. Automatica 38 (2002) 1633 - 1649, 2002.

OLIVEIRA, J. C. F.; WEBER, H. I. Dynamics of Cardan Active Joints for Robotic Applications. 25th ABCM International Congress of Mechanical Engineering, Uberlândia, MG, Brazil, 20-25 October 2019.

OSUKA, ; NAKAMURA,. https://patents.google.com/patent/US6841964B2 - Parallel link manipulator and its control device, 2003.

OżÓG,. The modelling of two DOF joints controlled by elastic inner ties. ITM Web Conf. Volume 15. II International Conference of Computational Methods in Engineering Science (CMES'17), 2017.

PALPACELLI, M. et al. Design of a Lockable Spherical Joint for a Reconfigurable 3-URU Parallel Platform. Kinematics and Robot Design I, KaRD2018, August 2018. 
PATRÃO, S. M. C. Ferramenta de Teste e Validação para Algoritmos de Fusão Sensorial. Coimbra: Instituto Superior de Engenharia de Coimbra, 2015.

PISLA, et al. Kinematic modelling of a 5-DOF hybrid parallel robot for laparoscopic surger. Robotica, Volume 30, Cambridge University Press, 2012. 1095-1107.

PLITEA, et al. Innovative development of surgical parallel robots. 1st International Conference on Advancements of Medicine and Health Care through Technology, MediTech2007, 2007.

ROSHEIM, M. E. https://patents.google.com/patent/US5979264 - Robotic manipulator, 1999.

SCHOTT, C. Technica curiosa sive mirabilia artis, Pars II, Liber Nonus, Mirabilia Chronometrica, propositio XIX. [S.1.]: Nuremberg, 1664. p. p. 618, 664-665, 727 and Table VII, Fig. 32.

SEHERR-THOSS, ; SCHMELZ , F.; AUCKTOR, E. Universal Jointed Driveshafts for Transmitting. In: Universal Joints and Driveshafts - Analysis, Design, Applications (ISBN 3-540-41759-1). [S.1.]: Springer-Verlag Berlin Heidelberg, 2006. p. p1-79.

SHAH, ; SAHA, S. K.; DUTT, J. K. Denavit-hartenberg parameters of euler-angle-joints for order (n) recursive forward dynamics. Proceedings of the ASME 2009 International Design Engineering Technical Conferences \& Computers and Information in Engineering Conference, IDETC/CIE 2009, San Diego, California, USA., 2009.

SHAH, S. V.; SAHA, S. K.; DUTT, J. K. Denavit-Hartenberg Parameterization of Euler Angles. Journal of Computational and Nonlinear Dynamics, Vol. 7 / 021006-1, ASME, April 2012.

SHAMMAS, ; WOLF, ; CHOSE,. Three degrees-of-freedom joint for spatial hyperredundant robots. Mechanism and Machine Theory, Volume 41, Issue 2, February 2006. $170-190$

SKF. Bearing friction, power loss and starting torque - The SKF model for calculating the frictional moment. Bearing friction, power loss and starting torque, 2019. Disponivel em: $\quad<$ https://www.skf.com/group/products/bearings-units-housings/principles/bearingselection-process/operating-temperature-and-speed/friction-powerlossstartingtorque/index.html>. Acesso em: 11 dez. 2019. 
SREEDHAR, M. et al. Review on Bio-Mimitic Robotic Bird. International Journal of Trend in Scientific Research and Development (IJTSRD), Volume: 3, Issue: 3, MarApr 2019.

STAMENIĆ, et al. Influence of the Geometry Parameters of Cardan Joint Rolling Parts on the Load Distribution. FME Transactions Volume 40, 2012. 135 -143.

SZEWCZYK, R.; ZIELIŃSKI, C.; KALICZYŃSKA, M. Automation 2018: Advances in Automation, Robotics and Measurement Techniques - Springer - Advances in Intelligent Systems and Computing. [S.1.]: Springer International Publishing AG, 2018.

TIAN, et al. Dynamics of spatial flexible multibody systems with clearance and lubricated spherical joints. Computers and Structures 87, 2009. 913-929.

UM, et al. Two types of snake-like robots for complex environment exploration: Design, development, and experiment. Advances in Mechanical Engineering 2017, Vol. 9(9) 115, 20 June 2017.

VALENCIA C, A. J.; AVILÉS, Ó. F.; MAULEDOUX, M. F. Sliding Modes for a Manipulator Arm of 4 Degrees of Freedom. International Journal of Online Engineering (eISSN: 2626-8493). 2017, Vol. 13 Issue 10, 9p, 2017. 114-122.

VRANISH, J. M. Gear Bearings. US-PATENT-6,626,792, US-PATENT-APPL-SN799872, $\quad 30 \quad$ September $2003 . \quad$ Disponivel em: $<$ https://ntrs.nasa.gov/search.jsp?R=20080007052>.

WANG, L.-S.; PAO, Y.-H. Jourdain's variational equation and Appell's equation of motionn for nonholonomic dynamic systems. American Association of Physics Teachers, 26 July 2002. 72-82.

WANG, Z. et al. A Robot Calibration Method Based on Joint Angle Division and an Artificial Neural Network. Hindawi, Mathematical Problems in Engineering, Volume 2019, Article ID 9293484, 12 pages, 2019.

WATSON, ; PRUSTY , B. G.; OLSEN,. Conceptual design optimisation of a constantvelocity coupling. Mechanism and Machine Theory, Volume 68, October 2013. 18-34.

WEBER, H. I. Raciocinando Dinâmica de Rotação. Rio de Janeiro: KDP - Kindle Direct Publishing - Amazon - Independently published, v. 1, 2019.

$\mathrm{XU}$, et al. Study on coupling effect between the time-varying gear backlash and the different time-varying mesh parameters on the gear system. Journal of Vibroengineering, Issue 8, Vol. 19, 2017. 5874-5891. 
YESHMUKHAMETOV, A.; KOGANEZAWA, K.; YAMAMOTO, Y. Design and Kinematics of Cable-Driven Continuum Robot Arm with Universal Joint Backbone. Proceedings of the 2018 IEEE International Conference on Robotics and Biomimetics, 12-15 December 2018. 2444-2449.

YOSHIKAWA,. Dynamic Hybrid Position/Force Control of Robot ManipulatorsDescription of Hand Constraints and Calculation of Joint Driving Force. IEEE Journal of Robotics and Automation, Vol. RA-3, No. 5, 1987.

YUAN, Q. et al. Uncertainty-Based IMU Orientation Tracking Algorithm for Dynamic Motions. IEEE/ASME Transactions on Mechatronics, Volume 24, Number 2, April 2019. 872-882.

ZAFER, Y. Dynamic Modeling of High Precision Servo System with Gear. [S.1.]: A thesis submitted to the graduate school of natural and applied sciences of middle east technical university, 2013.

ZENG, ; ZHANG,. Internal model control of inductive magnetic suspension spherical active joints based on fuzzy neural network inverse system. Advances in Mechanical Engineering 2015, Vol. 7(11) 1-11, 23 November 2015.

ZHANG, ; WEI,. Mechatronics and Robotics Engineering for Advanced and Intelligent Manufacturing - Springer - Lecture Notes in Mechanical Engineering. [S.1.]: Springer International Publishing Switzerland, 2017.

ZHANG, F. et al. Electromagnetic Driving Modal and Control of Magnetic Levitation Spherical Active Joint. 3rd Annual International Conference on Mechanics and Mechanical Engineering (MME 2016), Advances in Engineering Research (AER), volume 105, 2016.

ZHAO, D. H.; LIU, Y.; LI, H. N. Modified Hertz-damp model for based-isolated strucutural pounding simulation under near-fault earthquakes. Journal of Vibroengineering, Vol. 19 Issue 3, 2017.

ZHAO, et al. Development of a cardan mechanism for the asteroid lander. International Journal on Smart Sensing and Intelligent Systems, Volume 6, Number 3, 5 June 2013. 1283-1297.

ZOLLO, et al. Identification of Dynamic Parameters for Robots with Elastic Joints. Hindawi Publishing Corporation - Advances in Mechanical Engineering, 7 October 2014. 


\section{Apêndice I}

O momento do atrito rolante pode ser calculado como:

$M_{r r}=\phi_{i s h} \phi_{r s} G_{r r}(v n)^{0,6}$

Sendo as constantes e variáveis da equação (4.1) definidas da seguinte forma:

- $\quad v$, viscosidade operacional real do óleo ou do óleo base da graxa. $\left[\mathrm{mm}^{2} / \mathrm{s}\right]$;

- $n$, velocidade de rotação. [rpm];

- $\quad \phi_{i s h}=\frac{1}{1+1,84 \cdot 10^{-9}\left(n d_{m}\right)^{1,28} V^{0,64}}$, fator de redução de cisalhamento devido à temperatura, onde: $d_{m}=0.5(d+D)$ é o diâmetro médio do rolamento, sendo $d$ o diâmetro interno e $D$ o diâmetro externo do mesmo.

- $\phi_{r s}=\frac{1}{e^{K_{r s} v n(d+D) \sqrt{\frac{K_{z}}{2(D-d)}}}}$ é o fator de redução de reposição cinemática, onde:

○ $K_{r s}$ é a constante de reposição: $=3 \times 10^{-8}$ banho de óleo em baixo nível e lubrificação por jato de óleo ou $=6 \times 10^{-8}$ lubrificação com graxa e óleo-ar.

○ $K_{z}$ é a constante geométrica: $=3,1$ para o rolamento rígido de esferas e $=6,2$ para rolamentos de rolos cilíndricos.

- $G_{r r}=R_{1} d_{m}^{1,96}\left(F_{r}+\frac{R_{2}}{\sin \left(24,6\left(F_{a} / C_{0}\right)^{0,24}\right)} F_{a}\right)$, variáveis dependentes da geometria e da carga para a variável de atrito do rolamento rígido de esferas, ou $G_{r r}=R_{1} d_{m}^{2,41} F_{r}^{0,31}$ para rolamento de rolos cilíndricos que será considerado no caso do rolamento agulha utilizado na cruzeta do experimento, sendo: $F_{r}$ e $F_{a}$, as forças radiais e axiais no rolamento, respectivamente; $R_{1}$ e $R_{2}$ constantes geométricas para o momento de atrito de rolamento e $C_{0}$ a classificação de carga estática básica que depende cada rolamento:

- Rolamento do motor SKF 625-2Z:

- $R_{1}=3,9 \cdot 10^{-7}, R_{2}=1,7$ e $C_{0}=0,38 k N$;

- Rolamento do redutor SKF W619/8-2Z:

- $R_{1}=4,3 \cdot 10^{-7}, R_{2}=1,7$ e $C_{0}=0,45 \mathrm{kN}$;

○ Rolamento do corpo 1 SFK 6205-2Z:

- $R_{1}=3,9.10^{-7}, R_{2}=1,7$ e $C_{0}=7,8 \mathrm{kN}$;

- Rolamento de agulha SKF RNA 4901:

- $R_{1}=1,63 \cdot 10^{-6}$ e $C_{0}=12,2 k N$;

O momento de atrito deslizante pode ser calculado como:

$M_{s l}=G_{s l} \mu_{s l}$

Sendo as constantes e variáveis da equação (4.2) definidas da seguinte forma: 
- $G_{s l}=S_{1} d_{m}^{-0,145}\left(F_{r}^{5}+\frac{S_{2} d_{m}^{1,5}}{\sin \left(24,6\left(F_{a} / C_{0}\right)^{0,24}\right)} F_{a}^{4}\right)^{1 / 3}$, variáveis dependentes da geometria e da carga para a variável de atrito de deslizamento rígido de esferas, ou para rolamento de rolos cilíndricos $G_{s l}=S_{1} d_{m}^{0,9} F_{a}+S_{2} d_{m} F_{r}$, sendo:

- Rolamento do motor SKF 625-2Z:

- $S_{1}=3,23 \cdot 10^{-3}$ e $S_{2}=36,5$;

○ Rolamento do redutor SKF W619/8-2Z:

- $S_{1}=4,75.10^{-3}$ e $S_{2}=3,6$;

○ Rolamento do corpo 1 SFK 6205-2Z:

- $S_{1}=3,23.10^{-3}$ e $S_{2}=36,5$;

- Rolamento de agulha SKF RNA 4901:

- $S_{1}=0,16$ e $S_{2}=0,0015$;

- $\mu_{s l}=\phi_{b l} \mu_{b l}+\left(1-\phi_{b l}\right) \mu_{E H L}$, é o coeficiente de atrito deslizante devido ao efeito da lubrificação, onde

○ $\quad \phi_{b l}$ - Coeficiente de ponderação para o atrito deslizando que pode ser calculado como: $\phi_{b l}=\frac{1}{e^{2,6.10^{-8}(n v)^{1,4} d_{m}}}$;

○ $\quad \mu_{b l}$ - Constante que depende do movimento, $\mu_{b l}=0,15 \rightarrow n=0$ e $\mu_{b l}=0,12 \rightarrow n>0$;

- $\mu_{E H L}$ - Condições do coeficiente de atrito deslizante em filme lubrificante completo, sendo $\mu_{E H L}=0,04$ para lubrificações com óleos sintéticos e $\mu_{E H L}=0,02$ para rolamentos cilíndricos.

$\mathrm{O}$ momento de atrito das vedações existe apenas nos rolamentos rígidos de esferas SKF 625-2Z, SKF W619/8-2Z e SFK 6205-2Z, podendo ser calculado como:

$$
M_{\text {seal }}=K_{S 1} d_{S}^{\beta}+K_{S 2}
$$

Sendo os expoentes e constante da equação (4.3) definidos conforme o modelo do rolamento rígido de esferas para a vedação do tipo RS1 SKF, resultando em $K_{S 1}=0,023$, $\beta=2,25, K_{S 2}=2$, e $d_{S}$ igual ao diâmetro externo da vedação que é definido para cada rolamento como:

- $\quad \operatorname{SKF} 625-2 Z\left(d_{S}=d_{2}=13,22 \mathrm{~mm}\right)$;

- $\quad \operatorname{SKF} W 619 / 8-2 Z\left(d_{S}=d_{2}=16,66 \mathrm{~mm}\right)$;

- $\quad$ SFK 6205-2Z: $\left(d_{S}=d_{2}=46,21 \mathrm{~mm}\right)$.

O momento de atrito de perdas pode ser calculado para o rolamento rígido de esferas como:

$M_{\text {drag }}=0,4 V_{M} K_{\text {ball }} d_{m}^{5} n^{2}+1,093 \cdot 10^{-7} R_{S} d_{m}^{3} n^{2}\left(\frac{n d_{m}^{2} f_{t}}{v}\right)^{-1,379}$

E para o rolamento de rolos rígidos: 
$M_{\text {drag }}=4 V_{M} K_{\text {roll }} C_{W} B d_{m}^{4} n^{2}+1,093.10^{-7} R_{S} d_{m}^{3} n^{2}\left(\frac{n d_{m}^{2} f_{t}}{v}\right)^{-1,379}$

Sendo que as constantes relacionadas aos elementos rolantes nas equações (4.4) e (4.5) podem ser calculadas da seguinte forma:

- $\quad V_{M}$ - Fator de perda de arrasto ver gráfico $H / d_{m}$ em (SKF, 2019) - Diagram 4;

- Para os rolamentos rígidos de esferas blindados SKF 625-2Z, SKF W619/8-2Z e SFK 6205-2Z, onde normalmente utilizam graxa sólida na totalidade dos vazios dos rolamentos, será considerado: $H / d_{m}=1$ portanto $V_{M}=0,0010$.

- Para os rolamentos de rolos rígidos do tipo agulha SKF RNA 4901 será considerado um filme mínimo de graxa/óleo do diâmetro dos rolos, portanto: $H / d_{m}=1,8 / 16=0,1125$ e $V_{M}=0,00012$.

- $\quad B$ - Largura do rolamento [mm];

- $\quad H$ - Nível do óleo em [mm];

- $K_{\text {ball }}=\frac{i_{r w} K_{Z}(d+D)}{D-d} \cdot 10^{-12}$ - Constante geométrica;

- $K_{\text {roll }}=\frac{K_{L} K_{Z}(d+D)}{D-d} \cdot 10^{-12}$ - Constante geométrica;

- $i_{r w}$ - Número de linhas de esferas do rolamento;

- $K_{Z}$ - Constante geométrica para rolamento de esfera rígido $K_{Z}=3,1$ e para rolamento de rolos $K_{Z}=6,2$;

- $K_{L}$ - Constante geométrica para rolamento de rolos $K_{L}=0,7$;

- $l_{D}=5 \frac{K_{L} D}{d_{m}}$ - Constante geométrica;

- $C_{W}=2,780.10^{-10} l_{D}^{3}-2,786.10^{-4} l_{D}^{2}+0,0195 l_{D}+0,6439$ - Constante geométrica;

- $t=2 \operatorname{acos}\left(\frac{0,6 d_{m}-H}{0,6 d_{m}}\right), \quad$ se $H \geq 1,2 d_{m} \rightarrow H=1,2 d_{m}$ - Constante geométrica;

- $f_{t}=\left\{\begin{array}{c}\sin (0,5 t), \text { se } 0 \leq t \leq \pi \\ 1, \text { se } \pi<t<2 \pi\end{array}\right.$ - Constante geométrica;

- $f_{A}=0,05 \cdot \frac{K_{Z}(D+d)}{D-d}-$ Constante geométrica;

- $\quad R_{S}=0,36 d_{m}^{2}(t-\sin (t)) f_{A}$ - Constante geométrica; 


\section{Apêndice II}

Na Figura 7-1 é possível observar o modelo unidimensional simplificado da rigidez torcional do grau de liberdade composta pela rigidez do eixo do redutor, rigidez das duas planetárias do motorredutor de redução de 1:19 e rigidez do eixo do motor.

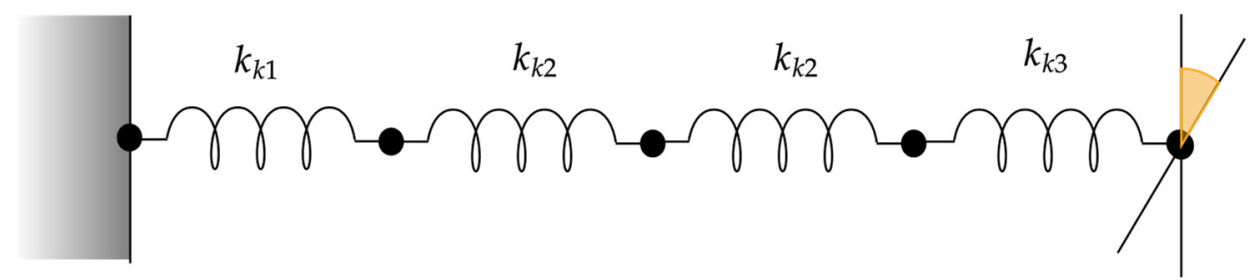

Figura 7-1 - Modelo linear unidimensional da rigidez torcional de um grau de liberdade

A rigidez do eixo do redutor $k_{k 1}$ pode ser calculada pela razão do torque aplicado com a deformação angular do eixo, resultando em:

- $\quad k_{k 1}=\frac{G J_{1}}{L_{1}} \cong 908 \mathrm{Nm} / \mathrm{rad}$, onde:

○ $G=70 \mathrm{GPa}$ - Módulo de cisalhamento;

○ $J_{1}=\left(\pi r_{1}^{4}\right) / 2$ - Momento de inércia geométrico polar, sendo: $r_{1}=4 \mathrm{~mm}$;

○ $L_{1}=31 \mathrm{~mm}$ - Comprimento do eixo.

Para calcular a rigidez de um estágio da planetária $k_{k 2}$, optou-se por realizar uma análise estática linear por elementos finitos para conhecer a rigidez torcional de cada engrenagem envolvida. Dessa forma, foi utilizado o software Autodesk Nastran, conforme Figura 7-2, para conhecer a deformação máxima $\Delta_{\text {Strain }}$ ao aplicar uma carga $P=125 \mathrm{kN}$, na linha de contato do dente de cada tipo de engrenagem do redutor planetário, permitindo calcular assim a rigidez torcional da seguinte forma:

- $\quad k=\left(\operatorname{Pr}^{2}\right) / \Delta_{\text {Strain }}$

○ $\quad r$ - Raio primitivo da engrenagem.

- Rigidez da engrenagem solar (corpo e dente) - $k_{k 2 a} \cong 1493 \mathrm{Nm} / \mathrm{rad}$

- Rigidez da engrenagem planetária (corpo e dente) - $k_{k 2 b} \cong 4005 \mathrm{Nm} / \mathrm{rad}$

- Rigidez da engrenagem do anel (corpo e dente) - $k_{k 2 c} \cong 63937 \mathrm{Nm} / \mathrm{rad}$ 
Conhecida a rigidez de cada engrenagem envolvida em um estágio da planetária, é possível escrever a rigidez equivalente de um estágio da redução planetária sendo:

- $k_{k 2}=3\left(\frac{1}{k_{k 2 a}}+\frac{2}{k_{k 2 b}}+\frac{1}{k_{k 2 c}}\right)^{-1} \cong 2532 \mathrm{Nm} / \mathrm{rad}$


OUTPUT SET: SUBCASE

CONTOUR: SOLID EFFECTIVE STRAIN-ELASTIC DEFORMED TOTAL: $($ MIN $=0$, MAX $=0,00188554)$ OUTPUT SET: SUBCASE 1

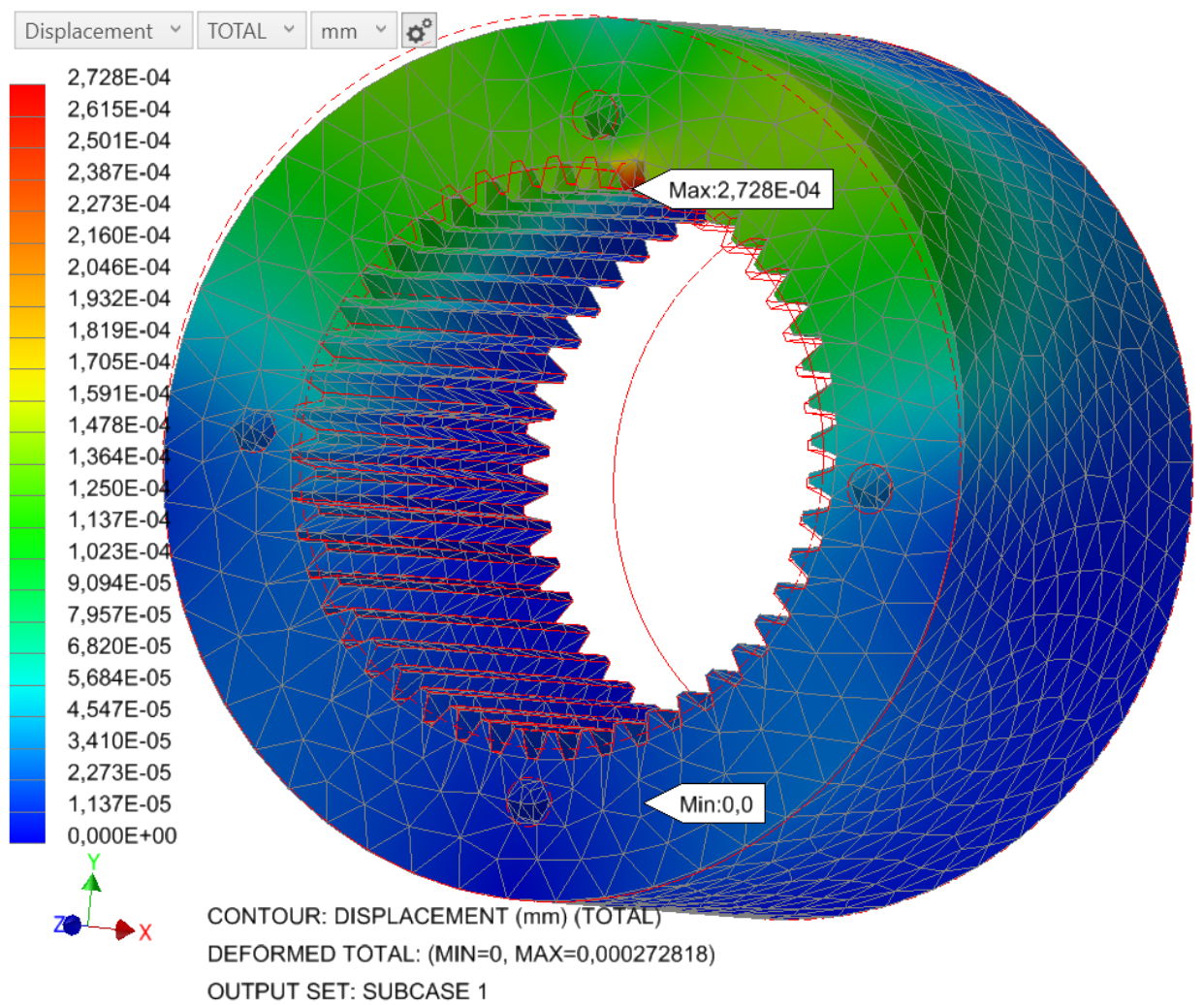

Figura 7-2 - Deformação máxima do modelo estático linear por elementos finitos das engrenagens do redutor para uma carga de $125 \mathrm{~N}$ na linha de contato do dente [Fonte: Autoria própria] 
A rigidez do eixo do motor $k_{k 3}$ pode ser calculada de forma semelhante à rigidez do redutor, logo:

- $\quad k_{k 3}=\frac{G J_{3}}{L_{3}} \cong 93 \mathrm{Nm} / \mathrm{rad}$, onde:

- $G=70 \mathrm{GPa}$ - Módulo de cisalhamento;

- $J_{3}=\left(\pi r_{3}^{4}\right) / 2$ - Momento de inércia geométrico polar, onde $r_{3}=2.5 \mathrm{~mm}$;

○ $L_{3}=53 \mathrm{~mm}$ - Comprimento do eixo.

Voltando a Figura 7-1, a rigidez equivalente do grau de liberdade $k_{k}$ é calculada conforme a expressão que segue:

- $k_{k}=\left(\frac{1}{k_{k 1}}+\frac{1}{k_{k 2}}+\frac{1}{k_{k 2}}+\frac{1}{k_{k 3}}\right)^{-1} \cong 70 \mathrm{Nm} / \mathrm{rad}$

É possível observar que o eixo do motor é responsável pela maior parte da parcela da flexibilidade do sistema, no entanto o modelo apresentado nesta tese é bem mais assertivo se comparado com o modelo de Nordin et al. (1997), que utiliza apenas o eixo do motor como rigidez do grau de liberdade. 